Miguel Angelo de Abreu de Sousa

Metodologias para desenvolvimento de Mapas Auto-organizáveis de Kohonen executados em FPGA 
Miguel Angelo de Abreu de Sousa

\section{Metodologias para desenvolvimento de Mapas Auto-organizáveis de Kohonen executados em FPGA}

Tese apresentada à Escola Politécnica da Universidade de São Paulo para obtenção do título de Doutor em Ciências, Programa de Engenharia Elétrica.

Área de Concentração: Engenharia de Sistemas Eletrônicos.

Orientador: Prof. Dr. Emílio Del Moral Hernandez, Livre Docente. 
Este exemplar foi revisado e corrigido em relação à versäo original, sob responsabilidade única do autor e com a anuência de seu orientador.

São Paulo de de

Assinatura do autor:

Assinatura do orientador:

Catalogação-na-publicação

Sousa, Miguel Angelo de Abreu de

Metodologias para desenvolvimento de Mapas Auto-organizáveis de Kohonen executados em FPGA / M. A. A. Sousa -- versão corr. -- Säo Paulo, 2018 .

$216 \mathrm{p}$.

Tese (Doutorado) - Escola Politécnica da Universidade de São Paulo. Departamento de Engenharia de Sistemas Eletrônicos.

1.Redes neurais 2. Circuitos FPGA 3. Reconhecimento de padrões 4.Processamento de imagens 5.Telecomunicações I.Universidade de São Paulo. Escola Politécnica. Departamento de Engenharia de Sistemas Eletrönicos II.t. 
Aos meus amores, Greice, Arthur e Catarina. 


\section{AGRADECIMENTOS}

Ao meu professor e orientador, Emilio Del Moral Hernandez, pelos ensinamentos sobre os mais diversos assuntos da Academia, da Pesquisa e da Política. Obrigado pela paciência.

Aos colegas do Grupo Icone, em especial, àqueles com os quais mais convivi, Julio Saldaña, Elia Matsumoto, Mark Ferreira e Fernando Itano, por todos os debates e apoios mútuos em nossas reuniões.

Ao colega Ricardo Pires, pelo constante interesse em desenvolver trabalhos de pesquisa. Agradeço também pelas muitas conversas, ao longo destes anos, no Mate.

Ao Instituto Federal de São Paulo, por ter criado as condições de trabalho necessárias para a realização do doutorado.

Aos meus pais, Alcides e Carmem, por todas as orações e por todo o esforço que fizeram em suas vidas para a solidificação da minha estrutura de base. É sobre esta estrutura que procuro construir minha existência. À minha irmã, Marta Estela, por todo interesse demonstrado e pelas boas vibrações que continuamente me manda.

Aos meus amados filhos, Arthur e Catarina, pela energia contagiante que vocês espalham pelo lar, pela paciência que tiveram durante a realização deste trabalho e também pela curiosidade que tiveram com ele. (Obrigado por me ajudarem com as "bolinhas").

À minha esposa Greice, que impulsionou minha dedicação à pesquisa, por todos os ensinamentos que me dá sobre Educação. Agradeço o amor e carinho durante estes anos. Obrigado por compartilhar comigo essa grande aventura que chamamos de Vida. 
A educação é a arma mais poderosa que temos para mudar o mundo.

(Nelson Mandela).

A educação não transforma o mundo. Educação muda pessoas.

Pessoas transformam o mundo.

(Paulo Freire) 


\section{RESUMO}

Dentro do cenário de projeto de circuitos elétricos orientados para o processamento de redes neurais artificiais, este trabalho se concentra no estudo da implementação de Mapas Auto-organizáveis (SOM, do inglês, Self-Organizing Maps) em chips FPGA. A pesquisa aqui realizada busca, fundamentalmente, responder à seguinte pergunta: como devem ser projetadas as arquiteturas computacionais de cada etapa de processamento do SOM para serem adequadamente executadas em FPGA?

De forma mais detalhada, o trabalho investiga as possibilidades que diferentes circuitos de computação do SOM oferecem em relação à velocidade de processamento, ao consumo de recursos do FPGA e à consistência com o formalismo teórico que fundamenta esse modelo de rede neural. Tal objetivo de pesquisa é motivado por possibilitar o desenvolvimento de sistemas de processamento neural que exibam as características positivas típicas de implementações diretas em hardware, como o processamento embarcado e a aceleração computacional ${ }^{1}$.

\section{CONTRIBUIÇÕES PRINCIPAIS}

No decorrer da investigação de tais questões, o presente trabalho gerou contribuições com diferentes graus de impacto. A contribuição mais essencial do ponto de vista de estruturação do restante da pesquisa é a fundamentação teórica das propriedades de computação do SOM em hardware. Tal fundamentação é importante pois permitiu a construção dos alicerces necessários para o estudo das diferentes arquiteturas de circuitos exploradas neste trabalho, de forma que estas permanecessem consistentes com as premissas teóricas que certificam o modelo de computação neural estudado.

Outra contribuição avaliada como de grande impacto, e que se consolida como um objeto gerado pela pesquisa, é a proposta de um circuito processador para SOM em FPGA que possui o estado-da-arte em velocidade de computação, medido em CUPS (Connections Updated Per Second). Tal processador permite atingir 52,67 GCUPS, durante a fase de treinamento do SOM, um ganho de aproximadamente $100 \%$

\footnotetext{
${ }^{1}$ Os destaques em negrito realizados no texto indicam trechos da escrita que sintetizam a ideia apresentada no entorno.
} 
em relação aos trabalhos publicados na literatura. A aceleração possibilitada pela exploração de processamentos paralelos em FPGA, desenvolvida neste trabalho, é de três a quatro ordens de grandeza em relação a execuções em software do SOM com a mesma configuração.

A última contribuição considerada como de grande impacto é a caracterização da execução do SOM em FPGA. Tal avaliação se faz necessária porque os processos de computação dos modelos neurais em hardware, embora semelhantes, não são necessariamente idênticos aos mesmos processos executados em software. Desta forma, a contribuição deste ponto de pesquisa pode ser entendida como a análise do impacto das mudanças implementadas na computação do SOM em FPGA em relação à execução tradicional do algoritmo, feita pela avaliação dos resultados produzidos pela rede neural por medidas de erros topográficos e de quantização.

Este trabalho também gerou contribuições consideradas como de médio impacto, que podem ser divididas em dois grupos: aplicações práticas e aportes teóricos. A primeira contribuição de origem prática é a investigação de trabalhos publicados na literatura envolvendo SOM cujas aplicações podem ser viabilizadas por implementações em hardware. Os trabalhos localizados nesse levantamento foram organizados em diferentes categorias, conforme a área de pesquisa - como, por exemplo, Indústria, Robótica e Medicina - e, em geral, eles utilizam o SOM em aplicações que possuem requisitos de velocidade computacional ou embarque do processamento, portanto, a continuidade de seus desenvolvimentos é beneficiada pela execução direta em hardware. As outras duas contribuições de médio impacto de origem prática são as aplicações que serviram como plataforma de teste dos circuitos desenvolvidos para a implementação do SOM.

A primeira aplicação pertence à área de telecomunicações e objetiva a identificação de símbolos transmitidos por 16-QAM ou 64-QAM. Estas duas técnicas de modulação são empregadas em diversas aplicações com requisitos de mobilidade - como telefonia celular, TV digital em dispositivos portáteis e $\mathrm{Wi}-\mathrm{Fi}$ - e o SOM é utilizado para identificar sinais QAM recepcionados com ruídos e distorções. Esta aplicação gerou a publicação de um artigo na revista da Springer, Neural Computing and Applications: Sousa; Pires e Del-Moral-Hernandez (2017).

A segunda aplicação pertence à área de processamento de imagem e visa reconhecer ações humanas capturadas por câmeras de vídeo. $O$ processamento 
autônomo de imagens executado por chips FPGA junto às câmeras de vídeo pode ser empregado em diferentes utilizações, como, por exemplo, sistemas de vigilância automática ou assistência remota em locais públicos. Esta segunda aplicação também é caracterizada por demandar arquiteturas computacionais de alto desempenho.

Todas as contribuições teóricas deste trabalho avaliadas como de médio impacto estão relacionadas ao estudo das características de arquiteturas de hardware para computação do modelo SOM. A primeira destas é a proposta de uma função de vizinhança do SOM baseada em FPGA. O objetivo de tal proposta é desenvolver uma expressão computacional para ser executada no chip que constitua uma alternativa eficiente tanto à função gaussiana, tradicionalmente empregada no processo de treinamento do SOM, quanto à função retangular, utilizada de forma rudimentar nas primeiras pesquisas publicadas sobre a implementação do SOM em FPGA.

A segunda destas contribuições é a descrição detalhada dos componentes básicos e dos blocos computacionais utilizados nas diferentes etapas de execução do SOM em FPGA. A apresentação dos detalhes da arquitetura de processamento, incluindo seus circuitos internos e a função computada por cada um de seus blocos, permite que trabalhos futuros utilizem os desenvolvimentos realizados nesta pesquisa. Esta descrição detalhada e funcional foi aceita para publicação no IEEE World Congress on Computational Intelligence (WCCI 2018): Sousa et al. (2018).

A terceira contribuição teórica de médio impacto é a elaboração de um modelo distribuído de execução do SOM em FPGA sem o uso de uma unidade central de controle. Tal modelo permite a execução das fases de aprendizado e operação da rede neural em hardware de forma distribuída, a qual alcança um comportamento global de auto-organização dos neurônios apenas pela troca local de dados entre elementos de processamento vizinhos. A descrição do modelo distribuído, em conjunto com sua caracterização, está publicada em um artigo no International Joint Conference on Neural Networks do IEEE (IJCNN 2017): Sousa e Del-Moral-Hernandez (2017a).

A última contribuição deste grupo de aporte teórico é a comparação entre diferentes modelos de execução do SOM em FPGA. A comparação tem a função de avaliar e contrastar três diferentes possibilidades de implementação do SOM: o modelo distribuído, o modelo centralizado e o modelo híbrido. Os testes realizados e os resultados obtidos estão publicados em um trabalho no International Symposium on Circuits and Systems do IEEE (ISCAS 2017): Sousa e Del-Moral-Hernandez (2017b). 
Finalmente, apresentam-se a seguir as contribuições avaliadas como de menor impacto, em comparação com as contribuições já descritas, ou ainda incipientes (e que possibilitam continuidades da pesquisa em trabalhos futuros), sendo relacionadas a seguir como contribuições complementares:

- Pesquisa de literatura científica sobre o estado-da-arte da área da Engenharia de Sistemas Neurais Artificiais.

- Identificação de grupos internacionais de pesquisa de execução do SOM em hardware, os quais foram reconhecidos por publicarem regularmente seus estudos sobre diferentes tipos de implementações e categorias de circuitos computacionais.

- Enumeração das justificativas e motivações mais frequentes na literatura para o processamento de sistemas neurais de computação em hardware.

- Comparação e contraste das características de microprocessadores, GPUs, FPGAs e ASICs (tais como, custo médio do componente, paralelismo computacional oferecido e consumo típico de energia) para contextualização do tipo de aplicações que a escolha pela pesquisa com o dispositivo FPGA possibilita.

- Levantamento das propriedades de computação do SOM em hardware mais frequentemente utilizadas nas pesquisas publicadas na literatura, tais como, quantidade de bits usados nos cálculos, tipo de representação de dados e arquitetura típica dos circuitos de execução das diferentes etapas de processamento do SOM.

- Comparação do consumo de área do FPGA e da velocidade de processamento entre a execução da função de vizinhança tradicional gaussiana e a função de vizinhança proposta neste trabalho (com resultados obtidos de aproximadamente 4 vezes menos área do chip e 5 vezes mais velocidade de operação).

- Caracterização do aumento dos recursos consumidos no chip e da velocidade de operação do sistema, em relação à implementação do SOM com diferentes complexidades (quantidade de estágios decrescentes do fator de aprendizado e da abertura da função de vizinhança) e comparação destas propriedades da arquitetura proposta em relação aos valores publicados na literatura. 
- Proposta de uma nova métrica para caracterização do erro topográfico na configuração final do SOM após o treinamento.

Palavras-chave: Mapas Auto-organizáveis; SOM; FPGA; Redes Neurais Artificiais; Arquitetura de Circuitos Elétricos. 


\begin{abstract}
In the context of design electrical circuits for processing artificial neural networks, this work focuses on the study of Self-Organizing Maps (SOM) executed on FPGA chips. The work attempts to answer the following question: how should the computational architecture be designed to efficiently implement in FPGA each one of the SOM processing steps?

More specifically, this thesis investigates the distinct possibilities that different SOM computing architectures offer, regarding the processing speed, the consumption of FPGA resources and the consistency to the theory that underlies this neural network model. The motivation of the present work is enabling the development of neural processing systems that exhibit the positive features typically associate to hardware implementations, such as, embedded processing and computational acceleration $^{2}$.
\end{abstract}

\title{
MAIN CONTRIBUITIONS
}

In the course of the investigation, the present work generated contributions with different degrees of impact. The most essential contribution from the point of view of structuring the research process is the theoretical basis of the hardware-oriented SOM properties. This is important because it allowed the construction of the foundations for the study of different circuit architectures, so that the developments remained consistent with the theory that underpins the neural computing model.

Another major contribution is the proposal of a processor circuit for implementing SOM in FPGA, which is the state-of-the-art in computational speed measured in CUPS (Connections Updated Per Second). This processor allows achieving 52.67 GCUPS, during the training phase of the SOM, which means a gain of $100 \%$, approximately, in relation to other published works. The acceleration enabled by the FPGA parallel processing developed in this work reaches three to four orders of magnitude compared with software implementations of the SOM with the same configuration.

\footnotetext{
${ }^{2}$ The highlights made in the text indicate pieces of writing that synthesize the idea presented.
} 
The last main contribution of the work is the characterization of the FPGA-based SOM. This evaluation is important because, although similar, the computing processes of neural models in hardware are not necessarily identical to the same processes implemented in software. Hence, this contribution can be described as the analysis of the impact of the implemented changes, regarding the FPGA-based SOM compared to traditional algorithms. The comparison was performed evaluating the measures of topographic and quantization errors for the outputs produced by both implementations.

This work also generated medium impact contributions, which can be divided into two groups: empirical and theoretical. The first empirical contribution is the survey of SOM applications which can be made possible by hardware implementations. The papers presented in this survey are classified according to their research area - such as Industry, Robotics and Medicine - and, in general, they use SOM in applications that require computational speed or embedded processing. Therefore, the continuity of their developments is benefited by direct hardware implementations of the neural network. The other two empirical contributions are the applications employed for testing the circuits developed.

The first application is related to the reception of telecommunications signals and aims to identify 16-QAM and 64-QAM symbols. These two modulation techniques are used in a variety of applications with mobility requirements, such as cell phones, digital TV on portable devices and Wi-Fi. The SOM is used to identify QAM distorted signals received with noise. This research work was published in the Springer Journal on Neural Computing and Applications: Sousa; Pires e Del-Moral-Hernandez (2017).

The second is an image processing application and it aims to recognize human actions captured by video cameras. Autonomous image processing performed by FPGA chips inside video cameras can be used in different scenarios, such as automatic surveillance systems or remote assistance in public areas. This second application is also characterized by demanding high performance from the computing architectures.

All the theoretical contributions with medium impact are related to the study of the properties of hardware circuits for implementing the SOM model. The first of these is the proposal of an FPGA-based neighborhood function. The aim of the proposal is to develop a computational function to be implemented on chip that enables an efficient 
alternative to both: the Gaussian function (traditionally employed in the SOM training process) and the rectangular function (used rudimentary in the first published works on hardware-based SOMs).

The second of those contributions is the detailed description of the basic components and blocks used to compute the different steps of the SOM algorithm in hardware. The description of the processing architecture includes its internal circuits and computed functions, allowing the future works to use the architecture proposed. This detailed and functional description was accepted for publication in the IEEE World Congress on Computational Intelligence (WCCI 2018): Sousa et al. (2018).

The development of an FPGA distributed implementation model for the SOM composes the third of those contributions. Such a model allows an execution of the neural network learning and operational phases without the use of a central control unit. The proposal achieves a global self-organizing behavior only by using local data exchanges among the neighboring processing elements. The description and characterization of the distributed model are published in a paper in the IEEE International Joint Conference on Neural Networks (IJCNN 2017): Sousa e Del-MoralHernandez (2017a).

The last contribution of this group is the comparison between different FPGA architectures for implementing the SOM. This comparison has the function of evaluating and contrasting three different SOM architectures: the distributed model, the centralized model and the hybrid model. The tests performed and the results obtained are published in an article in the IEEE International Symposium on Circuits and Systems (ISCAS 2017): Sousa e Del-Moral-Hernandez (2017b).

Finally, the contributions assessed as having a minor impact, compared to contributions already described, or still incipient (and which allow the continuity of the research in possible future works), are presented as complementary contributions:

- Research in the scientific literature on the state-of-the-art works in the field of Artificial Neural Systems Engineering.

- Identification of the international research groups on hardware-based SOM, which were recognized for regularly publishing their studies on different types of implementations and categories of computational circuits.

- Enumeration of the justifications and motivations often mentioned in works on hardware developments of neural computing systems. 
- Comparison and contrast of the characteristics of microprocessors, GPUs, FPGAs and ASICs (such as, average cost, parallelism and typical power consumption) to contextualize the type of applications enabled by the choice of FPGA as the target device.

- Survey of literature for the most commonly hardware properties used for computing the SOM, such as the number of bits used in the calculations, the type of data representation and the typical architectures of the FPGA circuits.

- Comparison of the FPGA resources consumption and processing speed between the execution of the traditional Gaussian neighborhood function and the proposed alternative neighborhood function (with obtained results of approximately 4 times less chip area and 5 times more computational speed).

- Characterization of the increase in chip resources consumptions and the decrease in system speeds, according to the implementations of the SOM with different complexities (such as, the number of stages in learning factor and the width of the neighborhood function). Comparison of these properties between the proposed architecture and the works published in the literature.

- Proposal of a new metric for the characterization of the topographic error in the final configuration of the SOM after the training phase.

Keywords: Self-Organizing Maps; SOM; FPGA; Artificial Neural Networks; Electrical Circuit Architecture. 


\section{LISTA DE ILUSTRAÇÕES}

Figura 1 - Publicações na literatura que podem ser viabilizados por uma execução direta do SOM em FPGA divididas nas diferentes áreas de aplicação.

Figura 2 - Curva da quantidade de pesquisas sobre FPGA nas publicações do IEEE por ano, entre 1989 e

2015. Fonte: Romoth; Porrmann e Rückert (2017).

Figura 3 - Diagrama dos blocos lógicos, potenciais conexões, Slices e portas de comunicação de entrada e saída do FPGA 51

Figura 4 - Diagrama dos Slices, LUTs e Flip-Flops que constituem parte do circuito eletrônico FPGA. O número de Slices/LUTs utilizados em uma implementação permite mensurar a quantidade de recursos consumidos no chip para síntese do sistema elaborado.

Figura 5 - Exemplificação do SOM, com quatro entradas e grade em arranjo bidimensional de 5x5 neurônios. Cada neurônio é descrito por seu respectivo vetor peso $\boldsymbol{w}_{\boldsymbol{j}}$ de mesma dimensão da entrada. Os vetores de entrada $\boldsymbol{x}_{\boldsymbol{i}}$, pertencentes ao espaço multidimensional $\mathbb{R} 3$, são amostrados pelos atributos $x^{1}, x^{2}$, $x^{3}$ e $x^{4}$ nas entradas da rede neural.

Figura 6 - Exemplos de tipos de arranjo da matriz de neurônios de saída do SOM em grades hexagonal (a) e quadrada (b). .58

Figura 7 - Exemplo de progressão do fator de aprendizagem $\alpha t$ alternativo, executado pela operação binária de deslocamento aritmético à direita e sem o uso de multiplicadores. .68

Figura 8 - Variação do coeficiente de abertura da função gaussiana (a) e da função de vizinhança $h c j$ proposta pela Equação 3.5 (b). O ponto central das funções corresponde à intensidade de ajuste de pesos do neurônio vencedor. O progressivo decaimento do valor das funções determina a intensidade de ajuste de pesos dos neurônios vizinhos ao vencedor (que diminui conforme a distância do ponto central). Em ambos os casos, uma curva mais aberta identifica situações de início de treinamento da rede, na qual acontece a ordenação principal dos neurônios; curvas mais fechadas correspondem ao final da fase de treino, quando ocorre o ajuste fino do vetor peso dos neurônios

Figura 9 - Conceituação do modelo distribuído do SOM: ilustração de 9 unidades de processamento identificadas como neurônios, as interconexões entre elas e o com o vetor de dados de entrada $\boldsymbol{x i}$...........80

Figura 10 - Os quatro blocos de computação básicos, internos a uma unidade de processamento (neurônio) do modelo distribuído. A ilustração enfatiza o bloco de cálculo de distância.

Figura 11 - Destaque para o bloco "menor de 5 distâncias" (interno a uma unidade neuronal) e suas conexões. O bloco recebe como entrada os sinais externos $d h, d i, d k$ e $d l$, com os valores de distância dos 4 neurônios vizinhos; e o valor interno $(d j)$ calculado pelo bloco anterior. O resultado da comparação, 
simbolizado por $c j$, é propagado tanto para o bloco de distância de vizinhança (interno), quanto para os neurônios circundantes.

Figura 12 - Bloco "distância de vizinhança” (interno a uma unidade neuronal) e suas conexões. Os sinais $n j, n h, n i, n k$ e $n l$, contêm, respectivamente, o valor de distância do neurônio ilustrado e os quatro valores de distância dos neurônios ao seu redor. O sinal $n j$ também é propagado internamente para o bloco de ajuste do vetor peso do neurônio.

Figura 13 - Exemplo de uma possível configuração de distância de vizinhança em torno do neurônio vencedor $c$. A figura ilustra apenas a primeira e segunda região de vizinhança. .84

Figura 14 - Barramento de comunicação entre dois neurônios do modelo distribuído. Os sinais transmitidos apenas localmente entre os blocos "menor de 5 distâncias" e "distância de vizinhança" permitem que a rede realize o processo de auto-organização global da rede.

Figura 15 - Unidade de processamento da rede (neurônio) com destaque para o bloco computacional interno "ajuste do vetor peso".

Figura 16 - Diagrama de blocos completo do modelo centralizado de processamento do SOM.

Figura 17 - Circuito interno do bloco de cálculo de distância de Manhattan.

Figura 18 - Arquitetura de torneio para busca progressiva do menor valor de distância pertencente ao modelo centralizado de execução do SOM.

Figura 19 - Representação dos componentes utilizados para o cálculo da distância entre o vetor de entrada $\boldsymbol{x} \boldsymbol{i}$ e os vetores peso $\boldsymbol{w} \boldsymbol{j}$ dos neurônios, e de suas interligações com os componentes que computam o menor entre dois valores, utilizados no circuito de busca da menor distância.

Figura 20 - Circuito interno do componente de comparação do bloco para busca da menor distância. ....90

Figura 21 - Circuito interno do componente de cálculo do bloco para ajuste dos vetores peso do SOM...91

Figura 22 - Modelo híbrido para execução do SOM em FPGA, no qual os cálculos das distâncias são efetuados em paralelo, a identificação do menor valor de distância é feita de forma semelhante ao modelo centralizado e a computação de distância na grade para o neurônio vencedor é realizada de maneira similar ao modelo distribuído.

Figura 23 - Gráfico da quantidade de LUTs ocupados no FPGA de acordo com a quantidade de neurônios para cada um dos modelos de execução do SOM, segundo os resultados de síntese fornecidos pela plataforma ISE (as linhas pontilhadas demarcam os ensaios realizados). 
Figura 24 - Gráfico da quantidade de Slices ocupados no FPGA de acordo com a quantidade de neurônios para cada um dos modelos de execução do SOM, segundo os resultados de síntese fornecidos pela plataforma ISE (as linhas pontilhadas demarcam os ensaios realizados).

Figura 25 - Gráfico da frequência máxima de operação do SOM em FPGA, de acordo com os experimentos efetuados com diferentes quantidades de neurônios, para cada um dos modelos de execução comparados. As linhas pontilhadas demarcam os ensaios realizados, segundo os resultados de síntese fornecidos pela plataforma ISE.

Figura 26 - Quatro momentos da progressão do aprendizado do SOM: neurônios marcados como pontos pretos interconectados e os dados $(\mathbb{R} 2)$ ilustrados em verde.

Figura 27 - Quatro momentos da progressão do aprendizado do SOM: neurônios marcados como pontos pretos interconectados e os dados $(\mathbb{R} 3)$ ilustrados em verde.

Figura 28 - Exemplo de constelação 64-QAM no plano IQ (“In-phase / Quadrature”) 106

Figura 29 - Exemplo de constelação 16-QAM para transmissão de quadbits (a). Ilustração de duas possíveis situações de recepção do sinal: constelação com ruído branco gaussiano de baixa intensidade (b) e com maior espalhamento dos símbolos por ruído branco gaussiano, associado à rotação da constelação por efeito Doppler e à deformação dos agrupamentos por condições não-lineares do canal (c). 106

Figura 30 - Três condições de distorção da constelação 16-QAM obtidas pelos canais reais de comunicação do repositório SPIB. Canal 8: maior espalhamento dos símbolos (a); canal 11: menor espalhamento e rotação leve à direita (b); e canal 7: rotação mais intensa à esquerda (c)

Figura 31 - Progressão da aprendizagem do SOM de acordo com a recepção de símbolos QAM por dois canais diferentes. Os pontos em verde (à esquerda) mostram um cenário de maior distorção que o cenário em vermelho (à direita). .108

Figura 32 - Progressão do processo de aprendizagem em hardware para identificação de sinais QAM após inicialização dos pesos, no quadro (a), com posição original da constelação sem distorção (círculos pretos para os vetores peso do SOM e os círculos azuis para os símbolos da constelação). Ilustração de seis momentos do treinamento, segundo o número de iterações: (a) 1; (b) 50; (c) 100; (d) 150; (e) 200; e (f) 400.

Figura 33 - Progressão do processo de treinamento do SOM em FPGA configurado com diferentes parâmetros: (a) $\alpha=0,125$ e $\beta=3$, (b) $\alpha=0,25$ e $\beta=2$, (c) $\alpha=0,5$ e $\beta=5$.

Figura 34 - Taxa de erro de bit em função da relação sinal/ruído da execução do SOM em FPGA para sete diferentes canais da base de dados SPIB. 
Figura 35 - Desempenho da implementação do SOM em hardware para reconhecimento de 64-QAM distorcido pelo canal 4 SPIB: bits corretamente identificados pela quantidade de símbolos recebidos (a) e repetição do experimento 35 vezes para cálculo da média e do desvio padrão (b).

Figura 36 - Desempenho da implementação do SOM em hardware para reconhecimento de 64-QAM distorcido pelo canal 9 SPIB: bits corretamente identificados pela quantidade de símbolos recebidos (a) e repetição do experimento 35 vezes para cálculo da média e do desvio padrão (b).

Figura 37 - Sinais 16-QAM dinâmicos compostos por (a) 10k símbolos e por (b) 1k símbolos. As cores menos intensas identificam o início da sequência transmissão, sujeita às condições de ruído do canal 4; as cores mais intensas identificam o final da sequência transmissão, sujeita às condições de ruído do canal 6; as cores de intensidade intermediária identificam a transição entre ambos os canais. 116

Figura 38 - Progressão do processo de treinamento do SOM executado em FPGA submetido a uma condição dinâmica de distorção das amostras de entrada: (a) rotação mais lenta, ocorrendo em 10k símbolos e (b) com uma rotação mais rápida, ocorrendo em 1k símbolos.

Figura 39 - Repetição dos experimentos anteriores 35 vezes para cálculo da média e do desvio padrão da taxa de acertos sob condições dinâmicas do sinal: 10k símbolos (a) e 10k símbolos (b).

Figura 40 - Taxa de erro de bit em função da relação sinal/ruído para a implementação do SOM em três cenários de migração 16-QAM entre canais SPIB diferentes.

Figura 41 - Diagrama de blocos do SOMprocessor: arquitetura de circuito para processamento de redes com grande volume de conexões neurais pela incorporação de componentes multiplexadores e registradores ao circuito básico de processamento do SOM.

Figura 42 - Detalhe do registradores de entrada (inteiramente ilustrado no diagrama de blocos do SOMprocessor da Figura 41)....

Figura 43 - Detalhe do bloco de Cálculo de $G$ diferenças e distâncias e suas entradas (inteiramente ilustrado no diagrama do SOMprocessor da Figura 41).

Figura 44 - Detalhe do bloco de busca pelo neurônio vencedor (inteiramente ilustrado no diagrama do SOMprocessor da Figura 41) 126

Figura 45 - Detalhe do bloco Cálculo de G ajustes de pesos (inteiramente ilustrado no diagrama do SOMprocessor da Figura 41)

Figura 46 - Progressão da fase de aprendizagem do SOMprocessor durante o $1^{\circ}$ experimento com dados controlados

Figura 47 - Progressão da fase de aprendizagem do SOMprocessor durante o $2^{\circ}$ experimento com dados controlados 
Figura 48 - Exemplos de imagens pertencentes aos vídeos do repositório público INRIA 4D IXMAS com ações humanas, utilizados no treinamento e teste do SOMprocessor.

Figura 49 - Dois quadros consecutivos selecionados da ação chutar (imagens esquerda e central) e a diferença resultante entre eles (imagem à direita).

Figura 50 - Sucessão de neurônios ativados na primeira camada SOM treinado para reconhecimento de ações, chamadas de trajetórias. O círculo com borda destacada contínua representa o primeiro neurônio da trajetória e o circulo com borda segmentada, o último (exceto na ação acenar, na qual um mesmo círculo com borda segmentada representa o primeiro e o último neurônio da trajetória).

Figura 51 - Neurônios ativados na segunda camada SOM para reconhecimento das ações (identificados por letras): A. olhar o relógio, B. cruzar os braços, C. coçar a cabeça, D. sentar, E. levantar, F. dar uma volta, G. andar, H. acenar, I. socar, J. chutar, K. apontar, L. pegar e M. arremessar.

Figura 52 - Decréscimo do erro de quantização em função do processo de aprendizagem do SOM para as implementações da mesma rede em software e em hardware.

Figura 53 - Curva dos erros topográficos do SOM para as implementações em software e em hardware da mesma rede conforme progressão do processo de treinamento.

Figura 54 - Os quatro primeiros vizinhos ao neurônio vencedor $c$ considerados no cálculo da medida tradicional do erro topográfico. 151

Figura 55 - Ilustração das oito posições consideradas como possível segundo neurônio vencedor próximo a $c$ na proposta da medida de erro topográfico alternativo.

Figura 56 - Curva para as implementações do SOM em software e em hardware do erro topográfico alternativo em função da progressão do processo de treinamento.

Figura 57 - Relação direta entre a potência do chip e a quantidade de ajustes de pesos por segundo obtida na sequência de experimentos realizados.

Figura 58 - Taxa de ajuste de pesos ("Connection Updates Per Second") do SOMprocessor segundo a quantidade de níveis de $\alpha$ e $\beta$ usados durante o treinamento.

Figura 59 - Evolução da taxa de identificação correta de símbolos 16-QAM distorcidos pelo SOM executado em FPGA (a). Desempenho do algoritmo VQ (b) sob as mesmas condições de teste a que estava submetido o SOM. 206

Figura 60 - Configuração final do posicionamento dos vetores peso do SOM (a), identificados por círculos vermelhos, em relação aos símbolos 16-QAM, identificados por círculos azuis. Configuração final dos vetores do algoritmo VQ (b), identificados por círculos vermelhos, em relação aos mesmos símbolos QAM. .206 
Figura 61 - Repetição de 35 vezes dos experimentos de comparação do SOM (a) com o VQ (b) para cálculo da média da taxa de acertos (linha vermelha) e do desvio padrão (barras azuis).

Figura 62 - Resultado da primeira repetição do experimento para comparação dos erros de quantização entre o SOMprocessor e a implementação em software da mesma rede.

Figura 63 - Resultado da segunda repetição do experimento para comparação dos erros de quantização entre o SOMprocessor e a implementação em software da mesma rede.

Figura 64 - Resultado da terceira repetição do experimento para comparação dos erros de quantização entre o SOMprocessor e a implementação em software da mesma rede.

Figura 65 - Resultado da primeira repetição do experimento para comparação dos erros topográficos entre o SOMprocessor e a implementação em software da mesma rede. 211

Figura 66 - Resultado da segunda repetição do experimento para comparação dos erros topográficos entre o SOMprocessor e a implementação em software da mesma rede. .211

Figura 67 - Resultado da terceira repetição do experimento para comparação dos erros topográficos entre o SOMprocessor e a implementação em software da mesma rede. 


\section{LISTA DE TABELAS}

Tabela 1 - Resumo da comparação entre quatro tipos de circuitos eletrônicos frequentemente utilizados como plataforma de execução do SOM.

Tabela 2 - Exemplos de trabalhos publicados que utilizam SOM e que podem ser viabilizados pela execução direta em FPGA.

Tabela 3 - Algoritmo de treinamento sequencial do SOM.

Tabela 4 - Algoritmo de operação do SOM.

Tabela 5 - Comparação da área ocupada no chip e da velocidade de operação entre a curva gaussiana e a função de vizinhança alternativa proposta pela expressão (11), segundo os resultados de síntese fornecidos pela plataforma ISE.

Tabela 6 - Algoritmo de treinamento do SOM em hardware.

Tabela 7 - Algoritmo de operação do SOM em hardware. 76

Tabela 8 - Propriedades utilizadas na computação do SOM em FPGA.

Tabela 9 - Comparação da área ocupada no chip e da frequência de operação do sistema entre os três modelos propostos para execução do SOM em configuração de 3x3 neurônios, segundo os resultados de síntese fornecidos pela plataforma ISE. . .94

Tabela 10 - Comparação da área ocupada no chip e da frequência de operação do sistema entre os três modelos propostos para execução do SOM em configuração de 4x4 neurônios, segundo os resultados de síntese fornecidos pela plataforma ISE. .95

Tabela 11 - Comparação da área ocupada no chip e da frequência de operação do sistema entre os três modelos propostos para execução do SOM em configuração de 5x5 neurônios, segundo os resultados de síntese fornecidos pela plataforma ISE.

Tabela 12 - Comparação do processo de escrita de código VHDL entre os modelos distribuído, centralizado e híbrido para execução do SOM em FPGA.

Tabela 13 - Resumo das características dos quatro grandes processos executados pelo SOM segundo o modelo centralizado proposto para implementação em FPGA

Tabela 14 - Comparação da área ocupada no chip, potência e velocidade de operação do sistema entre os dois tipos de projeto para execução em FPGA do SOM com configuração de 4x4 neurônios, segundo os resultados de implementação fornecidos pela plataforma ISE. 
Tabela 15 - Dados da implementação em FPGA para arquitetura do SOM na identificação de sinais 64QAM.

Tabela 16 - Pseudocódigo da unidade de controle do diagrama de blocos do SOMprocessor (Figura 41) exemplificado para dois grupos de neurônios processados alternadamente.

Tabela 17 - Condições do experimento de teste do SOMprocessor no reconhecimento de vídeos.

Tabela 18 - Ações identificadas e taxas de reconhecimento correto do artigo original e do experimento realizado com o SOMprocessor

Tabela 19 - Principais diferenças entre as características computacionais da execução do SOM no artigo original e da implementação em FPGA.

Tabela 20 - Dados da implementação do SOMprocessor para 3 níveis de $\alpha$ e $\beta$ durante o treinamento.. 155

Tabela 21 - Dados da implementação para 4 e 5 níveis de $\alpha$ e $\beta$ durante o treinamento 156

Tabela 22 - Comparação entre publicações sobre execução de SOM em diferentes hardwares.

Tabela 23 - Tempos de treinamento para 1 vídeo (“Andreas") da base de dados INRIA 4D para implementações do SOM em software e em FPGA. 


\section{LISTA DE ABREVIATURAS E SIGLAS}

ASIC Application Specific Integrated Circuits

BMU Best Match Unit

bSOM binary SOM

CLA Carry Look-Ahead Adder

CUPS Connections Updated Per Second

DPLL Digital Phase Locked Loop

HDL Hardware Description Language

IEEE Instituto de Engenheiros Eletricistas e Eletrônicos

IJCNN International Joint Conference on Neural Networks

IoT Internet of Things

IQ In-phase / Quadrature

ISCAS International Symposium on Circuits and Systems

ISE Integrated Synthesis Environment

FPGA $\quad$ Field Programmable Gate Array

LUT Look Up Table

MLP Multilayer Perceptron

MSbit Most Significant bit

OFDM Orthogonal frequency-division multiplexing

PET Positron Emission Tomography

QAM Quadrature Amplitude Modulation

RAM Random Access Memory

SOM Self-Organizing Maps

SPIB Signal Processing Information Base

VHDL Very High Speed Integrated Circuit HDL

VHSIC Very High Speed Integrated Circuits

VQ Vector Quantization

W Watt

WCCI World Congress on Computational Intelligence

WNN Weightless Neural Network

16-QAM QAM com 16 símbolos

64-QAM QAM com 64 símbolos 


\section{LISTA DE SÍMBOLOS}

$\arg \min$

\section{BETA}

C

$c_{i}$

$C_{\text {clock }}$

$d$

$d_{h}, d_{i}, d_{j}, d_{k}$ e $d_{l}$

deltaPeso

distVizinhança

$\operatorname{dist}(\mathbf{a}, \mathbf{b})$

erroj

$F_{m}$

fatorAprendizado

$h_{c_{j}}(t)$

$i$

I

J

$J_{m}$

$l_{1}$

$l_{2}$

n
Argumento do mínimo

Valor de abertura da função de vizinhança $h_{c_{j}}$ no instante $t$ Índice do neurônio vencedor (BMU ou champion)

Índice do neurônio vencedor dentre os 5 neurônios vizinhos na execução do SOM em hardware pelo modelo de distribuição de informações sem controle central

Quantidade de ciclos de clock usados na atualização de todos os vetores peso da rede sistema de neurocomputação executado em hardware

Dimensão do espaço matricial $\left(\mathbb{Z}^{\boldsymbol{d}}\right)$ de saída do SOM

Valores de distância comunicados entre 5 neurônios vizinhos na execução do SOM em hardware pelo modelo de distribuição de informações sem controle central

Armazenamento temporário do valor resultante da operação: $\alpha(t) \cdot h_{c_{j}}(t) \cdot\left[\mathbf{x}_{\mathbf{i}}-\mathbf{w}_{\mathbf{j}}\right]$

Distância de vizinhança em relação ao neurônio vencedor

Medida de distância entre os vetores a e b

Vetor de diferenças $\left[\mathbf{x}_{\mathbf{i}}-\mathbf{w}_{\mathbf{j}}\right]$

Frequência máxima de clock do sistema de neurocomputação executado em hardware

Valor de $\alpha$ no instante $t$

Função de vizinhança do SOM

Distância de vizinhança na grade em relação ao neurônio vencedor

Quantidade de dados do conjunto de entrada do SOM

Quantidade de neurônios do SOM

Quantidade de neurônios do sistema de neurocomputação executado em hardware

Distância de Manhattan

Distância Euclidiana

Dimensão do espaço vetorial de entrada do SOM 


\begin{tabular}{|c|c|}
\hline$n_{h}, n_{i,}, n_{j}, n_{k}$ e $n_{l}$ & $\begin{array}{l}\text { Valores de indexação comunicados entre } 5 \text { neurônios vizinhos na } \\
\text { execução do SOM em hardware pelo modelo de distribuição de } \\
\text { informações sem controle central }\end{array}$ \\
\hline$N_{m}$ & $\begin{array}{l}\text { Dimensão dos vetores peso dos neurônios do sistema de } \\
\text { neurocomputação executado em hardware }\end{array}$ \\
\hline $\mathbb{R}^{n}$ & Espaço vetorial de dimensão $n$ de entrada do SOM \\
\hline sra & Operador de deslocamento aritmético à direita \\
\hline$t$ & Iteração da fase de treinamento do SOM \\
\hline$T$ & Número máximo de iterações da fase de treinamento do SOM \\
\hline temp & Armazenamento temporário do valor do produto $\alpha(t) \cdot\left[\mathbf{w}_{\mathbf{j}}-\mathbf{x}_{\mathbf{i}}\right]$ \\
\hline$V_{j}$ & Volume dentro do diagrama de Voronoi \\
\hline$V_{s}$ & $\begin{array}{l}\text { Velocidade de operação do sistema de neurocomputação } \\
\text { executado em hardware }\end{array}$ \\
\hline $\mathbf{w}_{\mathbf{j}}$ & Vetor de pesos do j-ésimo neurônio do SOM \\
\hline $\mathbf{x}_{\mathbf{i}}$ & i-ésimo vetor de entrada do SOM \\
\hline $\mathbb{Z}^{d}$ & Espaço matricial de dimensão $d$ de saída do SOM \\
\hline$\alpha$ & Fator de aprendizado do SOM \\
\hline$\beta$ & $\begin{array}{l}\text { Valor de abertura da função de vizinhança } h_{c_{j}} \text { proposta no } \\
\text { instante } t\end{array}$ \\
\hline
\end{tabular}




\section{SUMÁRIO}

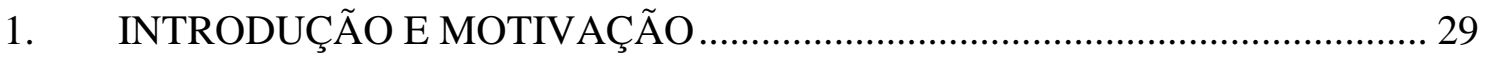

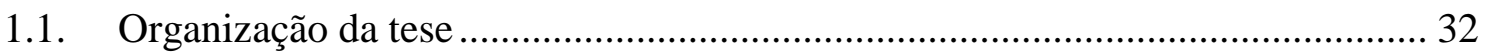

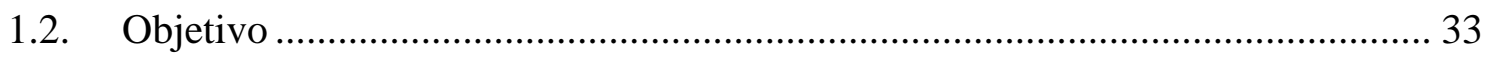

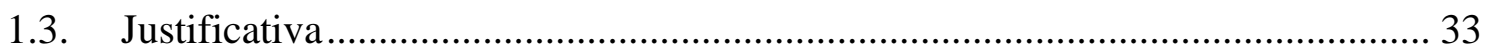

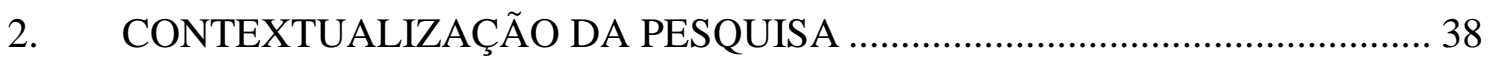

2.1. Comparação entre tipos de hardware …............................................................... 38

2.2. A importância do SOM - operações da rede sem interpretação humana do mapa... 43

2.3. Categorias de aplicações viabilizadas pela execução do SOM em FPGA .......... 46

3. PRINCÍPIOS CONCEITUAIS E FUNDAMENTAÇÃO TEÓRICA ................. 50

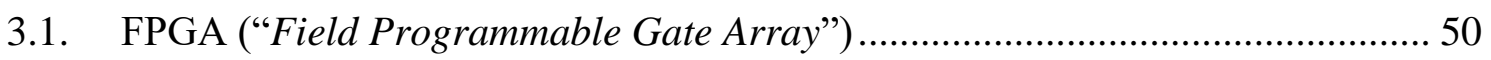

3.2. A linguagem de descrição de hardware VHDL ............................................... 52

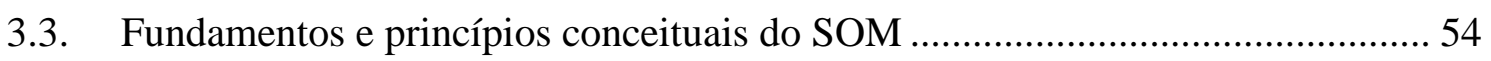

3.4. Definições matemática e algorítmica do SOM................................................... 57

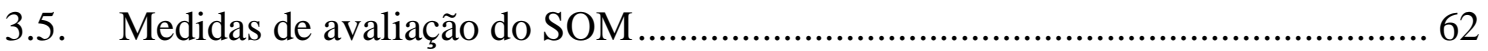

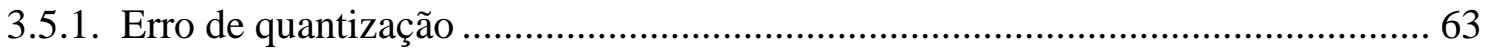

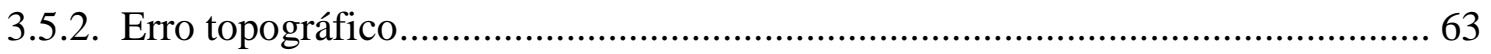

4. PROPRIEDADES DA COMPUTAÇÃO DO SOM EM HARDWARE - A METODOLOGIA EXISTENTE E AS PROPOSTAS ELABORADAS ...................... 65

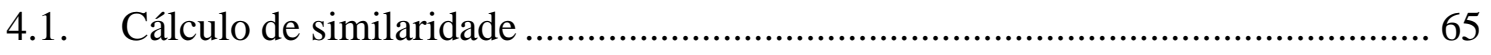

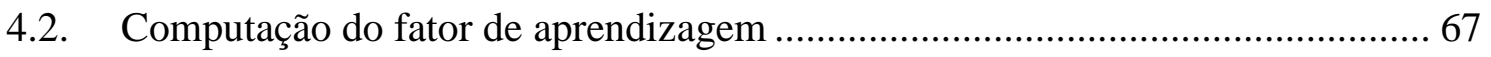

4.3. A função de vizinhança proposta e a aritmética binária utilizada ....................... 70

4.4. Os algoritmos de treinamento e operação do SOM em FPGA propostos e suas

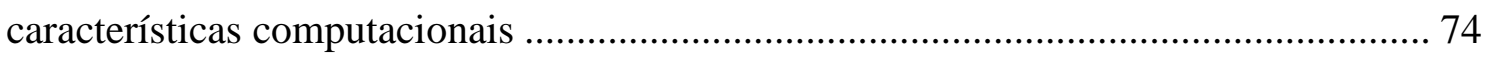

4.5. A quantidade de conexões neurais ajustadas por segundo como métrica de

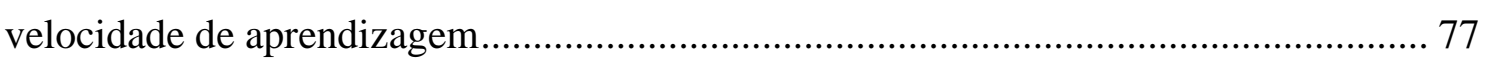


5. DESENVOLVIMENTO DA ARQUITETURA DE CIRCUITO E DOS

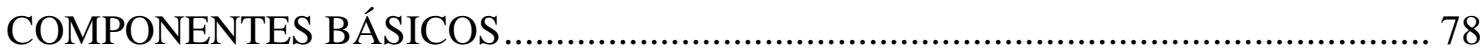

5.1. Possíveis modelos de execução do SOM em FPGA …........................................ 78

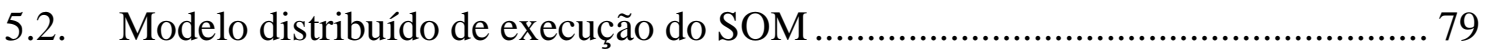

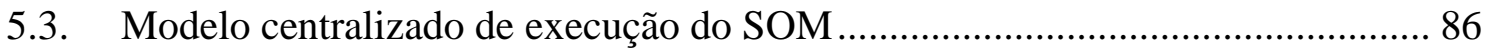

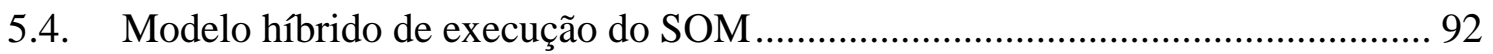

5.5. Comparação entre diferentes modelos de execução do SOM em FPGA ............ 93

5.6. Discussão sobre os resultados da comparação e a continuidade do desenvolvimento do sistema

5.7. Possíveis estruturas de descrição de hardware e teste com dados sintéticos .... 100

5.8. Aplicação da arquitetura de implementação do SOM em FPGA na área de telecomunicações - identificação de sinais QAM ...................................................... 104

5.9. Arquitetura SOM com aprendizado contínuo para identificação de sinais QAM não estacionários

6. DESENVOLVIMENTO DO PROCESSADOR SOM BASEADO EM FPGA EXPLORAÇÃO DE ESTRATÉGIAS COMPUTACIONAIS PARA POTENCIALIZAR O

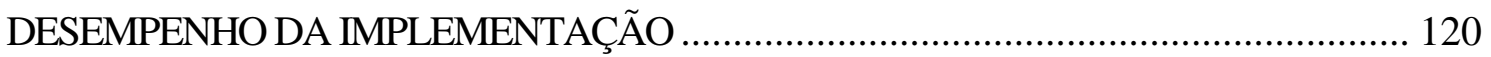

6.1. Teste do SOMprocessor com dados sintéticos controlados .............................. 132

6.2. Aplicação do SOMprocessor na identificação de vídeos de ações humanas .... 134

7. CARACTERIZAÇÃO DAS METODOLOGIAS PESQUISADAS E ANÁLISES

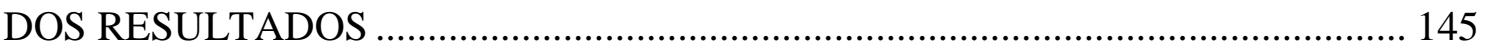

7.1. Avaliação da resolução do mapa produzido pelo SOMprocessor ...................... 147

7.2. Avaliação da estrutura de relação entre as posições mapeadas pelo SOMprocessor

7.3. Proposta de alteração da caracterização do mapa SOM pelo erro topográfico . 150

7.4. Avaliação da velocidade computacional e das propriedades de operação do SOMprocessor

8. CONCLUSÕES E TRABALHOS FUTUROS 162

8.1. Trabalhos futuros 164 
REFERÊNCIAS 166

Apêndice A - Modelo distribuído em VHDL 183

Apêndice B - Modelo centralizado em VHDL 190

Apêndice C - Modelo híbrido em VHDL 198

Apêndice D - Avaliação da relevância da estrutura do SOM no processo de identificação de sinais QAM 206

Apêndice E - Conjunto de experimentos para comparação entre as implementações do SOM em hardware e em software. 209

Apêndice $\mathrm{F}$ - Abstracts dos artigos publicados durante a realização desta pesquisa... 212 


\section{INTRODUÇÃO E MOTIVAÇÃO}

A área de pesquisa intitulada Engenharia de Sistemas Neurais (Neuroengineering) consiste no estudo, projeto e implementação de circuitos eletrônicos dedicados à execução de modelos neurais de computação (FURBER; TEMPLE, 2007). Uma das metas desta área de pesquisa é possibilitar uma forma de processamento mais eficiente das computações realizadas por diferentes tipos de redes neurais artificiais. De forma genérica, estes circuitos eletrônicos possuem arquiteturas que não seguem o modelo clássico de Von Neumann, pois são projetados para execuções computacionais típicas dos neurônios artificiais, os quais são caracterizados por um processamento massivamente paralelo (GOMES, 2017). A pesquisa em Engenharia de Sistemas Neurais tem gerado alguns trabalhos de grande escala, como por exemplo, o sistema SpiNNaker, desenvolvido em uma placa de circuito impresso que agrupa 48 chips para a execução de redes neurais, consiste em 868 núcleos simples e uma densa malha de interligação entre os núcleos. O sistema possui, como princípio, comunicação assíncrona de pequenos pacotes de dados, de forma a se alinhar com modelos pulsados de computação neural (RAST et al., 2011). Pode-se também citar o circuito eletrônico TrueNorth fabricado pela IBM como outro exemplo de trabalho produzido neste campo de estudo. O chip, chamado de "neuromórfico", pode executar diversas arquiteturas neurais, como "Restricted Boltzmann Machines" e "Support Vector Machines", em um amplo conjunto de elementos processadores simples, todos interligados entre si. Nota-se que este componente não é plástico, ou seja, o aprendizado da rede neural é feito em um software externo e, em sequência, os valores de parâmetros da rede devem ser fixados para execução no chip (MEROLLA et al., 2014).

O componente eletrônico digital FPGA (Field Programmable Gate Array) permite que suas funções lógicas internas sejam configuradas dinamicamente, inclusive durante sua atividade. O dispositivo possui, também, uma propriedade inerente de execução paralela de suas operações. Ambas as características - reprogramação simplificada e computação paralela - motivam a adoção do FPGA como uma plataforma para execução direta $^{3}$ de redes neurais artificiais, principalmente quando

\footnotetext{
${ }^{3}$ Neste trabalho, o termo execução direta esclarece que o circuito em questão não foi projetado como um processador de propósito geral para, desta forma, executar as computações requeridas pelo modelo neural, e sim que este circuito foi elaborado para efetuar de modo direto as computações requeridas pelo modelo de processamento neural.
} 
também se implementa a fase de aprendizado, na qual os parâmetros internos da rede são ajustados (OMONDI; RAJAPAKSE, 2006). A intensidade de tal motivação pode ser notada pelo trabalho de pesquisa de Romoth; Porrmann e Rückert (2017), o qual contabiliza que a implementação de redes neurais artificiais é o $7^{\circ}$ emprego mais frequente dentre as pesquisas com o uso de FPGAs nas publicações do IEEE (Instituto de Engenheiros Eletricistas e Eletrônicos) entre os anos de 2000 e 2015.

Um dos grandes interesses no desenvolvimento de chips "neuromórficos" é possibilitar que os modelos neurais de computação atendam aos requisitos específicos de uma ampla gama de aplicações (INDIVERI et al., 2011). A diminuição do tamanho físico e do consumo de energia dos dispositivos de processamento das redes neurais são exigências de aplicações embarcadas, tais como, a robótica móvel e os dispositivos inteligentes pessoais / portáteis. O aumento da velocidade de processamento das redes neurais também é um dos requisitos atendidos por circuitos "neuromórficos" construídos com arquiteturas massivamente paralelizadas. Algumas aplicações demandam um curto período de treinamento e operação para alcançar taxas de computação de dados que não são possíveis quando se utilizam processadores de propósito geral. Pode-se citar o processamento online de vídeo e a mineração de dados em tempo real como exemplos típicos de aplicações de sistemas neurais que exigem altas velocidades em seus tempos de resposta.

Mapas Auto-organizáveis (SOM, do inglês, Self-Organizing Maps), o modelo neural de computação estudado nesta pesquisa, possui capacidade de aprendizado nãosupervisionado. Isto significa que, em seu processo de treinamento, podem ser utilizados dados que não disponham de rótulos de classificação previamente atribuídos. De acordo com os estudos de Nakamura e Hasegawa (2017), Abraham; Falcon e Koeppen (2017), entre outros, a quantidade massiva de dados gerada tanto pelo surgimento das redes de sensores ubíquos, quanto pelo intenso crescimento dos sistemas de comunicações, reforça o interesse no desenvolvimento de pesquisas de sistemas computacionais de aprendizado não-supervisionado. Este interesse se deve ao fato de que tais dados são caracterizados por terem grande volume, variedade e velocidade, propriedades que dificultam processos prévios de atribuições de rótulos ou classificação.

Portanto, há um alinhamento de demandas que podem ser atendidas por circuitos eletrônicos que executem - com baixo consumo de energia, pequenas dimensões e alta velocidade de processamento - modelos computacionais de aprendizado não- 
supervisionado. Pode-se exemplificar a utilidade desses circuitos no processamento de grandes volumes de dados não estruturados (por exemplo, Big Data) e a computação de informações originadas em redes de sensores integrados e embarcados (IoT - Internet of Things ou, em português, Internet das Coisas). O interesse na investigação desse tema pode ser verificado em uma revisão da literatura científica, a qual aponta para o estabelecimento de alguns grupos de pesquisa de circuitos elétricos específicos para a execução das fases de treinamento e operação do SOM:

- O grupo da School of Computer Science, University of Lincoln, no Reino Unido, liderado pelo pesquisador Kofi Appiah, que desenvolveu uma versão puramente binária do SOM para ser executado em FPGA com o objetivo de processar informações visuais de câmeras de segurança (APPIAH et al., 2009; APPIAH et al., 2010; APPIAH et al., 2012).

- O grupo da University of Technology and Life Sciences, Polônia, liderado pela pesquisadora Marta Kolasa, que desde 2010 estuda a execução direta do SOM em diversos tipos de circuitos eletrônicos, como microprocessador, FPGA e ASIC (Application Specific Integrated Circuits). Recentemente, seus estudos têm se concentrado em desenvolvimento de ASICs para aplicações de implantes biomédicos e dispositivos instalados junto ao corpo utilizando o SOM (PRZEDWOJSKI et al., 2010; DŁUGOSZ et al., 2011; DŁUGOSZ; KOLASA; SZULC, 2011; KOLASA et al., 2012; KOLASA et al., 2017; KOLASA; TALAŚKA; DŁUGOSZ, 2017).

- O grupo da Faculty of Engineering Science, Kansai University, Japão, liderado pelo professor doutor Hiroomi Hikawa, que desenvolveu uma metodologia baseada em DPLL (Digital Phase Locked Loop) para execuções diretas de WTANNs (Winner-Take-All Neural Network) e SOM em FPGA. O foco do desenvolvimento do grupo é o processamento de imagens (HIKAWA， 2005; TERAHARA; OBA; HIKAWA, 2013; AZUMA; HIKAWA, 2014; HIKAWA; KAIDA, 2015; HIKAWA, 2015; HIKAWA; MAEDA, 2015; TAMAKI; HIKAWA, 2016; HIKAWA; TAMAKI; ITO, 2018).

- O grupo da Bielefeld University, Alemanha, liderado pelo pesquisador Jan Lachmair, que estuda o desenvolvimento de placas de circuito compostas por conjuntos de chips FPGAs para aceleração do processo de treinamento do 
SOM aplicado a operações de mineração de dados em grandes repositórios (LACHMAIR et al., 2012, LACHMAIR et al., 2013, LACHMAIR et al., 2017).

Em resumo, pode-se perceber que o estudo de uma arquitetura de circuito para execução direta de SOM em FPGA oferece uma alternativa de processamento que permite aliar as propriedades de flexibilidade, dinamismo e baixo custo de desenvolvimento - que execuções de redes neurais artificiais em software possuem - às características específicas de sistemas baseados em hardware ${ }^{4}$ - tais como, a redução do consumo de energia e dimensões físicas dos dispositivos computacionais e a diminuição do tempo de resposta, pela exploração do paralelismo de seus cálculos.

\subsection{ORGANIZAÇÃO DA TESE}

Para apresentar as metodologias investigadas e desenvolvidas nesta tese, a continuação do texto está dividida da seguinte forma: a seguir se especifica o objetivo do trabalho (seção 1.2) e as motivações que originaram o projeto de pesquisa (seção 1.3). O capítulo $\underline{2}$ apresenta a contextualização do estudo em relação ao dispositivo de hardware escolhido, ao modelo neural utilizado e às aplicações viabilizadas pela implementação do SOM em FPGA. Tendo concluído a parte introdutória do texto, o capítulo 3 descreve a fundamentação teórica na qual a tese está baseada e o capítulo 4 discute as propriedades específicas da computação do SOM em hardware existentes e as propostas elaboradas. Partindo destes dois capítulos estruturais, o capítulo 5 apresenta o desenvolvimento da arquitetura de circuito e dos componentes básicos para execução dos cálculos envolvidos na computação neural; e o capítulo 6 propõe a exploração de técnicas computacionais para aprimorar o desempenho da implementação em hardware. Os capítulos 5 e 6 relatam também a utilização do SOM executado em FPGA em duas aplicações distintas: processamento de sinais de telecomunicações e identificação de ações humanas capturadas por câmeras de vídeo. Finalmente, o capítulo 7 apresenta a caracterização do processador SOM desenvolvido, analisa os resultados obtidos e os compara com outros estudos publicados na literatura; e o capítulo 8 discute as conclusões da pesquisa e as possibilidades de continuações em trabalhos futuros.

\footnotetext{
${ }^{4}$ Este trabalho refere-se a execuções de redes neurais em software como a computação realizada, por exemplo, usando $\mathrm{C}++$, Matlab ou Python, em processadores de propósito geral e refere-se a execuções em hardware como a computação feita diretamente por diferentes arquiteturas de circuitos elétricos, típicos de implementações em chips como FPGA ou ASIC.
} 


\subsection{OBJETIVO}

O objetivo deste trabalho é pesquisar, desenvolver e experimentar metodologias para a execução direta das fases de aprendizado e operação dos Mapas Auto-organizáveis de Kohonen em FPGA.

A partir da premissa de que, embora semelhantes, os processos de computação dos modelos neurais em hardware não são necessariamente idênticos aos mesmos processos em software, esta pesquisa tem como objetivo específico investigar como deve ser projetada cada etapa da arquitetura de processamento de computação neural, de forma que o circuito elaborado seja adequado tanto ao formalismo teórico original e posteriores desenvolvimentos do modelo SOM, quanto aos aspectos positivos que são característicos de sistemas executados diretamente em hardware.

Portanto, esta pesquisa também visa, do ponto de vista de desenvolvimento de circuitos eletrônicos, obter um equilíbrio entre duas importantes características relacionadas ao projeto de sistemas computacionais: velocidade de processamento e consumo de recursos disponibilizados pelo componente eletrônico.

\subsection{JUSTIFICATIVA}

Mapas Auto-organizáveis (SOM, do inglês, "Self-Organizing Maps") podem ser classificados como uma arquitetura de rede neural artificial de aprendizado nãosupervisionado, tendo sido aplicados em áreas da Ciência e da Engenharia desempenhando diferentes funções. Entre elas, pode-se citar: método de abstração topológica em problemas de análise de informações (ALHONIEMI, 2000), algoritmo de computação em processos não-lineares (OJA et al., 2003), e técnica de compressão de dados (PALOMO; DOMINGUEZ, 2012). O SOM é um modelo de computação neural com intensa pesquisa e milhares de aplicações publicadas na literatura científica, conforme o levantamento de Pöllä, Honkela e Kohonen (2009). Ademais, a abrangência do formalismo do SOM continua sendo estudada, como, por exemplo, a pesquisa de Zhen, Cheng e Qiang (2010) sobre diferentes estratégias para incremento e decremento da quantidade de neurônios conforme o avanço do processo de treinamento; o trabalho de pesquisa de Colombini, Abreu e Cerri (2017) que propõe seu uso em categorizações 
multi-rótulo (em inglês, "multi-label classification"); e a proposta Zhang, Chow, e Wu (2016) sobre agrupamentos de SOMs para compor mapas de várias camadas, cada uma orientada para um nível de abstração diferente das informações processadas.

Tradicionalmente, as aplicações que empregam SOM - assim como outros modelos neurais de computação - são realizadas em software utilizando linguagens de programação como C++ (KOHONEN; KANGAS; LAAKSONEN, 1992) e Matlab (VESANTO et al., 1999; BLOSSOM, 2005). É importante destacar os recursos de flexibilidade de parametrização e dinamismo de ensaios que tais ferramentas computacionais fornecem ao projetista do sistema, pois tais recursos são características comuns de projeto em aplicações que utilizam redes neurais artificiais.

No entanto, nas últimas duas décadas houve um crescimento no número de pesquisas que procuram estender as técnicas de computação neural na direção de execuções diretas em hardware, como pode ser constatado nos levantamentos feitos por Zhu e Sutton (2003), Omondi e Rajapakse (2006), Misra e Saha (2010) e Schuman et al., (2017). A intensificação das pesquisas sobre implementações de modelos neurais diretamente em hardware também pode ser notada nos desenvolvimentos industriais de larga escala de chips, chamados de "neuromórficos", como o sistema SpiNNaker (RAST et al., 2011), o TrueNorth produzido pela IBM (MEROLLA et al., 2014) e o Loihi, fabricado pela Intel (DAVIES et al., 2018).

O crescente interesse científico e comercial em execuções de redes neurais artificiais diretamente em hardware originou a linha de pesquisa identificada como Engenharia de Sistemas Neurais (Neuroengineering). Esta linha tem como objetivo estudar, projetar e implementar circuitos eletrônicos dedicados à execução de modelos neurais de computação (FURBER; TEMPLE, 2007) e suas arquiteturas de hardware, geralmente, não seguem o modelo clássico de processamento de Von Neumann, pois são projetadas para execuções computacionais massivamente paralelas (GOMES, 2017). Os estudos publicados na área de Engenharia de Sistemas Neurais têm seus desenvolvimentos motivados por três fatores principais, descritos a seguir:

- Aceleração da execução nos processos de computação neural: algumas redes neurais artificiais, quando aplicadas a grandes quantidades de dados, podem demorar horas ou até mesmo dias para concluir parte de seu processamento. Com objetivo de diminuir esse tempo, existem estudos que propõem uma execução alternativa de tais processos em hardware. Pode-se citar, por exemplo, 
o trabalho de Papadonikolakis e Bouganis (2012) sobre a aceleração da fase de classificação de "Support Vector Machines" em duas a três ordens de magnitude comparando-se execuções diretas em FPGA com execuções em CPU. Outro exemplo é o trabalho de Borgese et al. (2013) sobre a execução de "Cellular Neural Networks" para resolver equações diferenciais de sistemas físicos dinâmicos em FPGA, que obteve um tempo de processamento 10 vezes menor comparado com um processador de uso geral de quatro núcleos. Pode-se citar também a aceleração de aproximadamente 100 vezes que a implementação em FPGA possibilitou em relação ao treinamento em software para classificação de sinais de ECG (JEWAJINDA; CHONGSTITVATANA, 2010). Um último exemplo é o estudo de Kim et al. (2009) sobre o tempo de treinamento em hardware de grandes conjuntos de "Restricted Boltzmann Machines" em arquiteturas do tipo "Deep Learning", o qual atinge uma redução de 25 a 30 vezes quando comparado com o treinamento em software. Ressalta-se ainda, que o interesse na redução dos tempos de processamento das fases de aprendizado e operação das redes neurais - permitida por execuções em hardware - é intensificado em aplicação que demandem a computação de grandes volumes de dados não estruturados (como, por exemplo, "Big Data”).

- Atendimento aos requisitos das aplicações embarcadas: diversas áreas, tais como telecomunicações e robótica móvel, possuem aplicações com demanda de diminuição do tamanho físico e da energia consumida por seus dispositivos de processamento, originalmente simulados e testados em software. Os trabalhos sobre robótica móvel de Esmaeilzadeh et al. (2006), Brassai (2014) e Bora, Rao e Rajendran (2014) são exemplos de redes neurais artificiais operacionalizadas em circuitos eletrônicos com o objetivo de serem embarcadas em sistemas portáteis com significativas limitações de espaço físico e potência. No contexto de robótica, o trabalho de Rodriguez, Miramond e Granado (2015), inclusive, enfatiza a importância da inclusão de etapas de pré-processamento e pósprocessamento - aliadas à execução da rede neural - no chip FPGA. Além dos exemplos sobre plataformas robóticas, também é importante destacar o crescimento da demanda pela computação embarcada de dados originados em redes integradas de sensores embarcados do tipo IoT ("Internet of Things" ou, em português, Internet das Coisas). Aplicações industriais de IoT que utilizam 
modelos neurais implementados em hardware para atender aos requisitos de embarque podem ser vistos, por exemplo, nos trabalhos de Cao, Chang e Li (2008) sobre sistemas de controle de plantas de energia fotovoltaica em campo e de Mouzinho et al. (2005) sobre estimação da velocidade de motores de indução em grandes plantas industriais.

- Necessidade de restrições do tempo de processamento segundo a taxa de entrada de dados: há uma classe de aplicações que empregam computações neurais executadas em hardware com o objetivo de concluir processos em tempo-real de resposta (INDIVERI et al., 2011). Estes sistemas, em geral, operam imersos em seus ambientes de aplicação, anexados ao elemento sensor, obtendo informações de forma automática. Execuções das fases de treinamento e operação de redes neurais diretas em circuitos eletrônicos podem ser fundamentais para viabilizar, por exemplo, aplicações de extração de características, reconhecimento e classificação de imagens em câmeras de vídeo, realizadas de forma independente do usuário e diretamente em seus ambientes de funcionamento (APPIAH et al., 2010; SÉGUIN-GODIN; MAILHOT; ROUAT, 2015). Também são exemplos de processamento autônomo de imagens o estudo de McElroy e Howells (2010) sobre o reconhecimento de face em sistemas de segurança e a pesquisa de Appiah et al. (2012) sobre reconhecimento de pessoas por vídeo, computado diretamente em FPGA. Com requisitos semelhantes de execução das fases de aprendizado e operação segundo a taxa de entrada de dados, tem-se o trabalho de Terahara, Oba e Hikawa (2013) sobre o uso de SOMs para compressão de imagens - a cada aquisição de um novo quadro - sendo realizada por um dispositivo de hardware posicionado junto à câmera. Por fim, pode-se ilustrar a motivações por necessidades de tempo-real de resposta, citando-se o conjunto de pesquisas realizadas pela equipe de Torres-Huitzil, as quais utilizam o mesmo componente eletrônico para executar dois modelos de computação neural para o processamento de sensores e atuadores de um robô móvel. Um dos modelos é específico para identificação visual de objetos em movimento e outro, para controle do dispositivo de locomoção do dispositivo robótico. Ambos executam as fases de aprendizado, ajuste de comportamento e operação durante o 
deslocamento do robô (TORRES-HUITZIL; GIRAU e CASTELLANOSSÁNCHEZ, 2005; BARRON-ZAMBRANO; TORRES-HUITZIL, 2013).

Nesta seção, apresentaram-se as justificativas frequentemente encontradas em publicações da literatura sobre Engenharia de Sistemas Neurais. Além de tais motivações, as quais são comuns à investigação da execução direta de diversos tipos de redes neurais em circuitos elétricos, também há motivações estritamente relacionadas com o modelo neural de computação pesquisado (SOM) e o dispositivo de hardware escolhido (FPGA). As características de ambos, quando associadas, possibilitam a realização de uma coleção de pesquisas publicadas na literatura de diversas áreas de aplicação, as quais já tiveram sua simulação e experimentação realizadas com sucesso em software. O capítulo 2 a seguir, sobre a contextualização desta pesquisa, apresenta uma relação de trabalhos cujas demandas podem ser atendidas pelo alinhamento das propriedades dos dispositivos de hardware - baixo consumo de energia, pequenas dimensões e alta velocidade de processamento - com os princípios fundamentais do SOM - modelo de computação neural de aprendizado não-supervisionado. 


\section{CONTEXTUALIZAÇÃO DA PESQUISA}

Diversas propriedades importantes são viabilizadas quando os modelos de computação neural são executados diretamente em circuitos elétricos - principalmente aquelas associadas à velocidade de processamento e aos requisitos de diminuição do espaço e energia utilizados - conforme discutido na seção 1.3 sobre as justificativas para esta pesquisa. O capítulo anterior apresentou diversos aspectos compartilhados como motivação por um grande conjunto de estudos da área de Engenharia de Sistemas Neurais, que estão relacionados a diferentes tipos de redes neurais e a diferentes dispositivos de hardware. No entanto, além disso, há também um grupo de propriedades específicas que são características das opções de investigação feitas no presente trabalho: o SOM e o FPGA. As próximas seções, sobre a contextualização desta pesquisa, apresentam as particularidades do chip FPGA contrastadas com outros circuitos eletrônicos (seção 2.1) e as propriedades associadas à execução do SOM como algoritmo de aprendizado não-supervisionado (seção 2.2). Tendo discutido tais especificidades, descreve-se ao final do capítulo, um levantamento de aplicações do SOM publicadas na literatura que possuem a viabilização da continuidade de seu desenvolvimento (ou o atendimento de requisitos de implementação) pela execução direta da rede em FPGA. Este levantamento foi realizado para ilustrar a relevância do estudo realizado e ele elenca conjuntos de publicações pertencentes a diferentes áreas de pesquisa (seção 2.3).

\subsection{COMPARAÇÃO ENTRE TIPOS DE HARDWARE}

Esta seção tem por objetivo realizar uma comparação entre quatro tipos de circuitos eletrônicos candidatos à plataforma de execução de arquiteturas neurais de computação, pelo contraste de suas principais propriedades. Os hardwares comparados são microprocessadores, FPGAs, ASICs ${ }^{5}$ ("Application Specific Integrated Circuits") e GPUs ("Graphics Processing Units"), pois são as tecnologias mais usadas para execução direta de redes neurais artificiais (HAMMERSTRON, 2003 e INDIVERI et al., 2011). A Tabela 1 apresenta, de forma simplificada, esta comparação a fím de

\footnotetext{
${ }^{5}$ Horta (2013), assim como outros autores, consideram FPGA como pertencente à categoria dos dispositivos ASICs. Neste trabalho, rotulou-se como ASIC o componente eletrônico cujo projeto do circuito é fabricado sob encomenda e não pode ser alterado no ambiente de execução.
} 
contextualizar a adequação das caraterísticas que a opção por algum dos dispositivos possibilita.

Tabela 1 - Resumo da comparação entre quatro tipos de circuitos eletrônicos frequentemente utilizados como plataforma de execução do SOM.

\begin{tabular}{|c|c|c|c|c|}
\hline & Microprocessador & GPU & FPGA & ASIC \\
\hline Tipos de processamento & $\begin{array}{c}\text { Analógico ou } \\
\text { Digital }\end{array}$ & $\begin{array}{c}\text { Analógico ou } \\
\text { Digital }\end{array}$ & $\begin{array}{c}\text { Principalmente } \\
\text { Digital }\end{array}$ & $\begin{array}{c}\text { Principalmente } \\
\text { Analógico }\end{array}$ \\
\hline $\begin{array}{l}\text { Consumo típico } \\
\text { de energia }\end{array}$ & $\begin{array}{c}\text { Médio } \\
(\sim 400 \mathrm{~mW} \text { a } \\
\sim 5000 \mathrm{~mW})\end{array}$ & $\begin{array}{c}\text { Alto } \\
(\sim 40 \mathrm{~W} \text { a } \\
\sim 300 \mathrm{~W})\end{array}$ & $\begin{array}{c}\text { Baixo } \\
(\sim 10 \mathrm{~mW} \mathrm{a} \\
\sim 5000 \mathrm{~mW})\end{array}$ & $\begin{array}{c}\text { Mínimo } \\
\text { (ordem de } \\
\mu \mathrm{W} \text { ) }\end{array}$ \\
\hline $\begin{array}{l}\text { Flexibilidade de } \\
\text { modificações }\end{array}$ & Alta & Alta & Alta & Baixa \\
\hline $\begin{array}{l}\text { Paralelismo de } \\
\text { computação }\end{array}$ & Baixo & Alto & Alto & Alto \\
\hline $\begin{array}{l}\text { Custo médio do } \\
\text { componente }\end{array}$ & $\begin{array}{c}\text { Médio } \\
\text { (típico } \sim \$ 20 \mathrm{a} \\
\sim \$ 1 \mathrm{~K} \text { ) }\end{array}$ & $\begin{array}{c}\text { Alto } \\
\text { (típico } \sim \$ 200 \\
a \sim \$ 3 \mathrm{k} \text { ) }\end{array}$ & $\begin{array}{c}\text { Baixo } \\
\text { (típico } \sim \$ 30 \mathrm{a} \\
\sim \$ 100)\end{array}$ & $\begin{array}{c}\text { Alto } \\
\text { (ordem de } \\
\$ 1 \mathrm{M} \text { ) }\end{array}$ \\
\hline $\begin{array}{l}\text { Tempo característico } \\
\text { de projeto }\end{array}$ & Baixo & Baixo & Médio & Alto \\
\hline $\begin{array}{l}\text { Facilidade de conexão } \\
\text { com diferentes processos }\end{array}$ & Alta & Alta & Médio & Baixa \\
\hline
\end{tabular}

A seguir, expõe-se com mais detalhes as propriedades descritas na Tabela 1, em conjunto com a argumentação para a categorização atribuída em cada uma das propriedades.

- Tipo de processamento (analógico ou digital): Embora haja projetos digitais de ASICs e FPGAs analógicos, a maioria dos desenvolvimentos de arquiteturas neurais em hardware envolvem projetos analógicos de ASICs e FPGAs digitais. Computações analógicas permitem a realização de cálculos complexos, como multiplicações, divisões e tangentes hiperbólicas - operações comuns às redes neurais artificiais - utilizando uma quantidade de transistores bem menor do que as computações digitais, portanto, ocupando menor área do componente utilizado e consumindo menos energia. Computações digitais, não restrito a execuções de redes neurais mas abrangendo toda a área de DSP (“Digital Signal 
Processor", em inglês), permitem uma maior robustez em relação a condições externas como temperatura e faixa de tensões de alimentação (STRANNEBY; WALKER, 2004).

- Consumo típico de energia: As computações analógicas, como o caso geral de ASICs, permitem um consumo de potência bem menor do que as computações digitais. Este baixo consumo pode ser fundamental para viabilizar algumas aplicações, tais como, processamentos biológicos por dispositivos implantáveis no corpo executando redes neurais artificiais (HSIEH; TANG, 2013), principalmente, no crânio, em operações de interface cérebro-computador (KARKARE; GIBSON; MARKOVIĆ, 2013). FPGAs têm valores de consumo de energia variáveis de acordo com a configuração de processamento utilizada, porém, superior aos valores típicos de ASICs, inviabilizando aplicações implantáveis. O desenvolvimento de FPGAs com consumo ultrabaixo de energia (menor que 10mW) ainda está em seu início (BELHADJ et al., 2009. e HUDA; ANDERSON, 2015). Entretanto, o consumo de energia típico de sistemas baseados em FPGA possibilita atender às aplicações com requisitos de mobilidade, como, por exemplo, dispositivos médicos portáteis e processamento de redes de sensores posicionados junto ao corpo (BASTERRETXEA; ECHANOBE; DEL CAMPO, 2014). Permite atender também às aplicações com requisitos de embarque computacional, como satélites artificiais e plataformas robóticas (BAKO, 2009). GPUs possuem um consumo de potência que inviabiliza o atendimento às aplicações com restrições de energia (PAUWELS et al., 2012 e YASUKAWA et al., 2016). Lachmair et al. (2017) realizou um estudo detalhado sobre o consumo de energia em implementações de um tipo específico de SOM - o CSOM, ou "conscience SOM" - em aplicações de mineração de dados, comparando FPGA, GPU e Microprocessador. O FPGA superou os outros em eficiência energética, a qual foi mensurada no trabalho pela quantidade de conexões neurais processadas por segundo, por Watt (CPS/W). Tal característica de maior eficiência energética do FPGA em relação à GPU é confirmada por outros estudos de computações neurais embarcadas, como, por exemplo, o trabalho de Dundar et al. (2017).

- Flexibilidade de modificações: Microprocessadores, GPUs e FPGAs permitem que seu projeto seja facilmente reprogramado no dispositivo físico, fato que possibilita ao projetista do sistema a alteração das propriedades da arquitetura 
neural executada, inclusive durante a operação do dispositivo em questão. Nos dispositivos FPGAs, tal característica de reprogramação durante o tempo de execução é chamada de Reconfiguração Parcial Dinâmica (ZHANG; NG, 2000). Projetos com ASIC têm propriedades com menor flexibilidade de mudanças após a fabricação do dispositivo, pois, em geral, alterações no sistema implicam em novos projetos físicos. Por este motivo, os sistemas de computação neural em ASIC têm maior tendência de possuir a fase de treinamento executada de forma "off-line", ou seja, fora do chip (PARTZSCH; SCHÜFFNY, 2011).

- Paralelismo de computação: Microprocessadores têm um acelerado crescimento em sua capacidade de processamento e velocidade do clock de operação, fatores que os permitem realizar uma simulação do paralelismo dos cálculos propostos pelos modelos neurais de computação. No entanto, muitas redes neurais possuem alta conectividade entre seus neurônios e requerem que o estado de todos os neurônios seja acessado a cada iteração de funcionamento, o que demanda uma grande largura de banda no acesso à memória e tende a limitar a velocidade de execução de computações neurais em microprocessadores (HAMMERSTRON, 2003). A naturalidade do processamento paralelo em FPGAs e ASICs e a possibilidade da utilização de registradores internos ou o uso de múltiplas conexões para o acesso à memória tornam estes dispositivos uma escolha habitual em projetos com demandas de tempo-real de resposta ou aceleração da velocidade de execução em sistemas para embarque de redes neurais (TORRES-HUITZIL; GIRAU; CASTELLANOS-SÁNCHEZ, 2005). Assim, como FPGAs e ASICS, GPUs também possuem arquitetura computacional paralela. No entanto, a quantidade de memória de seus núcleos computacionais, assim como a taxa de transferência de dados entre núcleos, é restrita (ASANO; MARUYAMA; YAMAGUCHI, 2009, ORCHARD et al., 2013 e TAKASU et al., 2014).

- Custo médio do componente: ASICs têm, tipicamente, um alto custo de desenvolvimento para a fabricação de poucas unidades e tal custo tende a diminuir em profusão para produções em larga escala. GPUs têm custo fixo relativamente alto, independente da escala de produção. Microprocessadores e FPGAs têm custos bem variáveis, porém mesmo os FPGAs de menor custo permitem obter altas taxas de velocidade de processamento pelo paralelismo de suas operações quando aplicados a projetos específicos, como no caso de 
sistemas executando redes neurais artificiais (por exemplo, SOUSA et al., 2014). Microprocessadores projetados para execuções de computações neurais - com processamento massivamente paralelo e grande largura de banda para acesso à memória - como o "Silicon Graphics" da NASA Ames Research Center (SHAN et al., 2002) e ASICs que executam sistemas "neuromórficos", como o TrueNorth da IBM (MEROLLA et al., 2014) e o Loihi da Intel (DAVIES et al., 2018), têm um alto valor de investimento, o qual pode inviabilizar um conjunto de aplicações e pesquisas acadêmicas tipicamente de baixo custo e menor escala.

- Tempo característico de projeto: Em geral, o tempo consumido para concepção, teste e efetuação de circuitos eletrônicos realizados em ASICs é bem maior do que os realizados em Microprocessadores, GPUs e FPGAs. Pois, sendo concebido para uma aplicação em específico, e tendo restrições a mudanças após a fabricação do dispositivo, é natural que o período de projeto e teste do ASIC seja maior (OMONDI; RAJAPAKSE, 2006). GPUs e microprocessadores são dispositivos programáveis por software e possibilitam ao projetista fácil acesso a execução final. FPGAs possuem períodos de concepção e teste de projeto semelhante aos ASICs, porém requerem tempos menores para prototipagem pois não há necessidade de fabricação exclusiva do dispositivo, somente a configuração do circuito elaborado em chips padronizados comercialmente.

- Facilidade de conexão com diferentes processos: Após o processo de fabricação, ASICs não permitem modificações no circuito integrado fabricado para conexão com diferentes processos de pré-processamento e pósprocessamento. GPUs e Microprocessadores permitem incluir novas etapas ao algoritmo que computam por mudanças na programação do dispositivo; e FPGAs requerem alteração do projeto de circuito antes da reprogramação do chip. Considerando que os recursos disponibilizados pelos dispositivos reprogramáveis - FPGAs, GPUs e Microprocessadores - permitam a expansão (como, por exemplo, memória) tal possibilidade permite ao projetista adicionar as possíveis fases de pré-processamento e pós-processamento ao mesmo componente que executa a rede neural. Um exemplo de um sistema completo em FPGA é o trabalho de Hikawa e Kaida (2015), o qual utiliza computação neural para reconhecimento de imagens adicionado aos processamentos para extração das características e para geração de saída em VGA, no mesmo chip. Outro exemplo são os trabalhos complementares em robótica móvel de Torres-Huitzil, 
Girau e Castellanos-Sánchez (2005) e Barron-Zambrano e Torres-Huitzil (2013), os quais utilizam o mesmo componente FPGA para execução de redes neurais aplicadas aos sistemas de processamento de imagens e controle de deslocamento. Além disso, segundo a pesquisa de catalogação realizada por Romoth; Porrmann e Rückert (2017), um dos motivos mais citados pelos quais os projetistas optaram pelo FPGA é a quantidade de pinos de entrada e saída para conexão com os demais circuitos ou dispositivos.

Destaca-se que as características discutidas acima não esgotam totalmente a comparação entre os componentes e que cada uma das particularidades não foi exaustivamente analisada. Além disso, nota-se que há grande sobreposição entre as características contrastadas, como, por exemplo, o tempo característico de projeto, a flexibilidade de modificações e a simplicidade de conexão com processos periféricos. Mesmo assim, pode-se situar a escolha pelo FPGA para ser o dispositivo de execução do SOM, como alinhada com os processos típicos de projetos que envolvem arquiteturas neurais, tais como: processamento massivamente paralelo e dinamismo de modificações na configuração das redes - variação de tamanho, dimensão e precisão - de acordo com os requerimentos da aplicação do sistema. Quanto às aplicações viabilizadas pelo SOM executado em FPGA, como detalhado nas duas próximas seções deste capítulo, destacam-se aquelas que estejam associadas a baixos custos de implementação, que sejam embarcadas (desde que não requeiram um consumo mínimo de energia, como as implantações biológicas) ou que requisitem tempos-reais de resposta.

\subsection{A IMPORTÂNCIA DO SOM - OPERAÇÕES DA REDE SEM INTERPRETAÇÃO HUMANA DO MAPA}

Nas últimas duas décadas houve um crescimento no número de trabalhos envolvendo pesquisas sobre execuções de técnicas de computação neural diretamente em circuitos elétricos, como indicam os levantamentos científicos realizados por Zhu e Sutton (2003), Misra e Saha (2010) e Schuman et al., (2017). Muitas destas pesquisas envolvem redes Perceptron de Múltiplas Camadas, ou MLP (do inglês, "Multilayer Perceptron"), arquiteturas neurais cujo treinamento normalmente é realizado de forma 
supervisionada pelo algoritmo "Error Backpropagation". Porém, quase todos os trabalhos publicados executam no chip apenas a fase de operação da rede neural, e não a sua fase de treinamento, como, por exemplo: Zhu; Milne e Gunther (1999), Lin et al. (2010), Sousa e Torres (2013), Tu et al. (2015). Há poucas publicações que relatam a execução da fase de treinamento do MLP diretamente em hardware, como o trabalho de Rezvani et al. (2012). Existe também um conjunto de estudos que investiga a execução de diversificados modelos supervisionados de computação neural em circuitos eletrônicos, tais como, Redes Auto-Associativas de Hopfield (MANSOUR et al., 2011; SOUSA et al., 2014), Redes Neurais Sem-Peso (LORRENTZ; HOWELLS; MCDONALD-MAIER, 2009), "Support Vector Machines" (PAPADONIKOLAKIS; BOUGANIS, 2012) e, mais recentemente, "Deep Neural Networks" (LO, 2010; HAILESELLASIE; HASAN, 2017).

Em nossa pesquisa, pôde-se perceber que, em muitos desses desenvolvimentos, os dados de rótulo para treinamento das redes neurais artificiais de aprendizado supervisionado devem ser acessados ou processados previamente por um computador e, posteriormente, transferidos para o chip, como, por exemplo, na pesquisa de Kim et al. (2009). Este fato permite o uso de execuções em hardware para diminuição do tempo de treinamento, porém restringe utilizações embarcadas com aprendizado executado diretamente pelo componente eletrônico. Percebeu-se, também, uma demanda por sistemas que recebam informações e possam realizar processamentos de forma autônoma e/ou em tempo-real, isto é, sem a possibilidade da geração de rótulos de classificação para cada dado de entrada recebido (MOLINA-CABELLO et al., 2017; RABBA et al., 2017; THURNHOFER-HEMSI et al., 2017). Além das tradicionais investigações em software, a demanda por estes sistemas autônomos também inclui pesquisas utilizando chips como plataforma de execução (POIKONEN; LAIHO, 2017; SCHÄFFER et al., 2017). Tal percepção direcionou a pesquisa para o desenvolvimento de uma metodologia de execução direta de algoritmos de treinamento nãosupervisionado em hardware.

Conforme apresentado na seção 1.3, o modelo de computação neural nãosupervisionado do SOM possui acentuado interesse de pesquisa, com um grande conjunto de aplicações publicadas na literatura científica (PÖLLÄ; HONKELA; KOHONEN, 2009), formalismo teórico constatado (FORT; PAGÈS, 1995 e FORT; LETREMY; COTTRELL, 2005) e continuidade atual de investigação e de desenvolvimento (COLOMBINI; ABREU; CERRI, 2017 e ABADI et al., 2018). Além 
disso, a pesquisa feita neste trabalho evidenciou um grande número de publicações nas quais o SOM é utilizado de forma autônoma, ou seja, sua operação não requer a interpretação humana do mapa produzido. Como será apresentado em detalhes na seção 3.4, sobre os fundamentos do SOM, o uso deste modelo neural permite que dados multidimensionais sejam projetados em um espaço matricial de saída, geralmente com duas dimensões (HAYKIN, 2007). Por este motivo, o SOM é largamente utilizado em aplicações de mineração de dados como método de verificação topológica e análise de informações, com sua saída visualizada em uma tela de computador (como os trabalhos de Alhoniemi (2000) e Kitani, Del-Moral-Hernandez e Silva (2013), por exemplo). Contudo, uma pesquisa na literatura científica sobre aplicações do SOM permite notar um conjunto de trabalhos que utilizam a rede neural - de diversas formas sem que seja necessária uma interpretação direta do mapa gerado, propiciando, assim, que se possa executar o modelo neural de maneira independente de um computador. A existência dessa propriedade de processamento autônomo do SOM estimula que se investiguem diferentes arquiteturas computacionais para sua implementação, principalmente explorando o paralelismo dos cálculos de seus algoritmos de treinamento e operação. Alguns dos trabalhos encontrados na pesquisa realizada estão apresentados na seção 2.3 .

$\mathrm{O}$ interesse pela elaboração de arquiteturas computacionais diferentes dos processadores de uso geral para execução específica do modelo SOM pode ser notada também pela existência de grupos de pesquisa que divulgam regularmente suas produções sobre o assunto (os quais foram enumerados no capítulo 1) e investigações individuais ou esporádicas sobre o tema publicadas na literatura da área. Para exemplificar este interesse na pesquisa de arquiteturas de circuitos elétricos para implementação do SOM, pode-se citar os trabalhos ${ }^{6}$ de Tamukoh et al. (2004), Peña, Vanegas e Valencia (2006), Lachmair et al. (2013), Hikawa e Maeda (2015), Abadi et al. (2016), Huang et al. (2017), Kolasa et al. (2017).

Contudo, a maioria dos trabalhos da literatura pesquisada carece de clareza no embasamento teórico das escolhas feitas na elaboração do hardware, de detalhes de implementação dos circuitos elétricos utilizados e de experimentações de caracterização dos sistemas propostos. No presente trabalho, portanto, procurouse fundamentar de forma criteriosa estes três aspectos essenciais para se

\footnotetext{
${ }^{6}$ As comparações e contrastes entre a metodologia desenvolvida nesta pesquisa com os resultados publicados nos trabalhos relacionados, entre outros, será feita no capítulo 7 e resumidas pela Tabela 22.
} 
compreender os processos de execução direta das fases de treinamento e operação do SOM em FPGA.

\subsection{CATEGORIAS DE APLICAÇÕES VIABILIZADAS PELA EXECUÇÃO DO SOM EM FPGA}

Esta seção apresenta o levantamento realizado de trabalhos publicados na literatura envolvendo SOM cuja aplicação pode se beneficiar de implementações em hardware para continuidade de seus desenvolvimentos ou para que possam, efetivamente, ser empregados em seus campos de atuação. Como discutido anteriormente na seção 2.2, os exemplos apresentados exploram o SOM em operações autônomas de processamento e não requerem uma interpretação humana do mapa gerado. Os trabalhos localizados nesse levantamento foram reunidos em diferentes categorias, conforme a área de pesquisa e, em geral, utilizam o modelo neural em aplicações com requisitos de velocidade de processamento ou embarque computacional, evidenciando mais uma vez a utilidade de execução da rede neural em FPGA. A Figura 1 mostra alguns desses exemplos de aplicações divididos por cores associadas aos respectivos campos de atuação; e a Tabela 2 - complementar a esta figura - apresenta detalhes do mesmo levantamento, com as referências bibliográficas dos trabalhos enumerados e a relação completa de aplicações pesquisadas em cada uma das áreas de investigação.

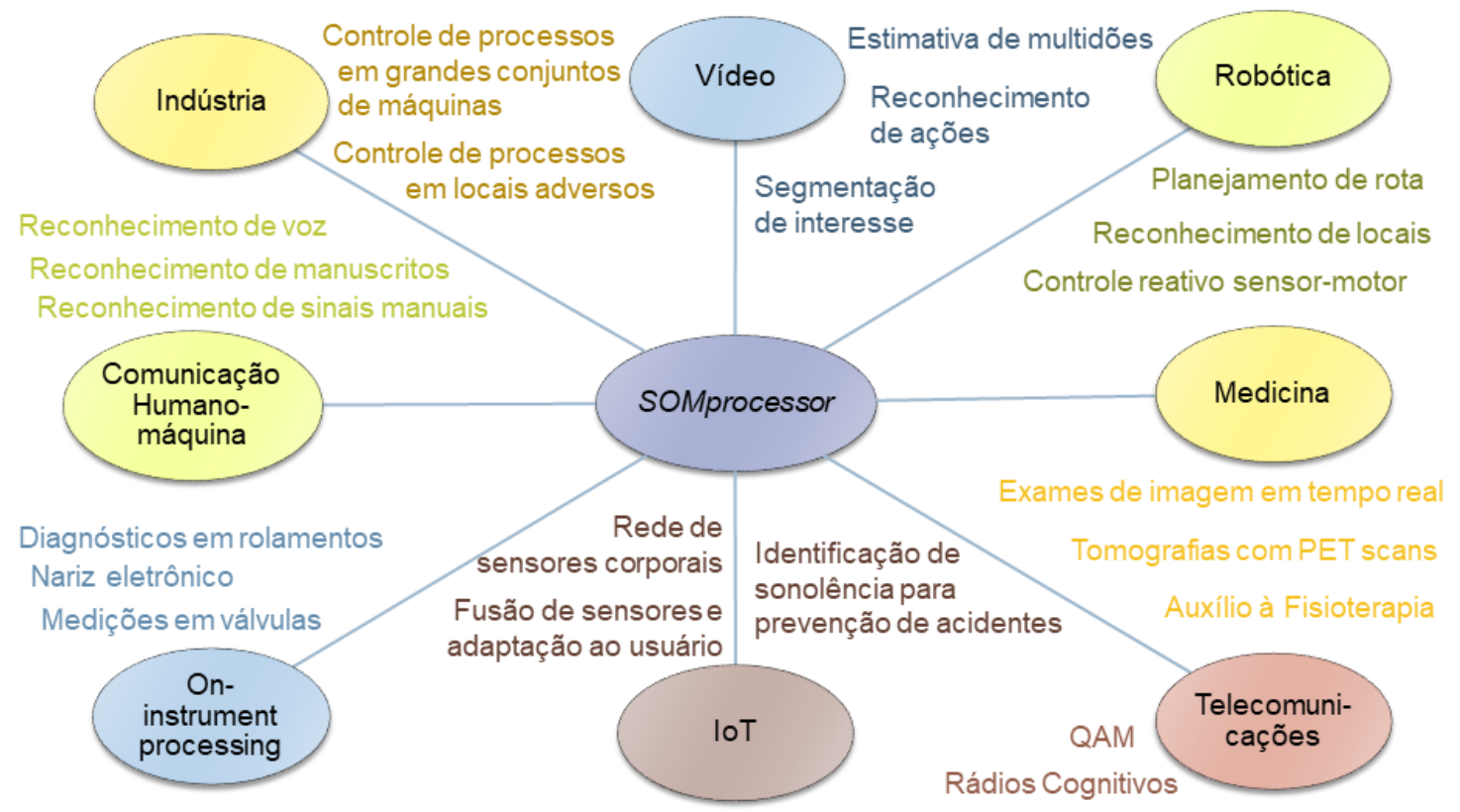

Figura 1 - Publicações na literatura que podem ser viabilizados por uma execução direta do SOM em FPGA divididas nas diferentes áreas de aplicação. 
Tabela 2 - Exemplos de trabalhos publicados que utilizam SOM e que podem ser viabilizados pela execução direta em FPGA.

\begin{tabular}{|c|c|c|}
\hline Área & Aplicação & Publicação \\
\hline \multirow{4}{*}{ 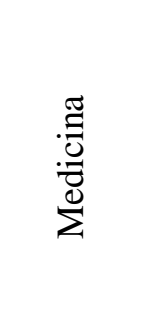 } & Exames de imagem em tempo real & (DE; ZHANG; GUO, 2016) \\
\hline & $\begin{array}{l}\text { Tomografias com detectores PET } \\
\text { ("Positron Emission Tomography") }\end{array}$ & (WANG et al., 2015) \\
\hline & Previsores portáteis de surtos epiléticos & (AZEVEDO; BOOS; AZEVEDO, 2015) \\
\hline & Auxílio à Fisioterapia & $(\mathrm{SU}, 2015)$ \\
\hline \multirow[b]{2}{*}{ 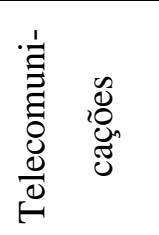 } & "Rádios Cognitivos & (CAI et al., 2010) \\
\hline & Identificação de sinais QAM & $\begin{array}{c}\text { (HIROSE; NAGASHIMA, 2003) e } \\
\text { (SOUSA; PIRES; DEL-MORAL- } \\
\text { HERNANDEZ, 2017) }\end{array}$ \\
\hline \multirow{3}{*}{ 흥 } & Rede de sensores corporais & $\begin{array}{l}\text { (THIEMJARUS; LO; YANG, 2006) } \\
\text { (THE }\end{array}$ \\
\hline & Fusão de sensores/adaptação ao usuário & (NAJJAR; REIGNIER, 2013) \\
\hline & $\begin{array}{l}\text { Identificação de sonolência e prevenção } \\
\text { de acidentes automobilísticos }\end{array}$ & (NOORI; MIKAEILI, 2015) \\
\hline \multirow{3}{*}{ 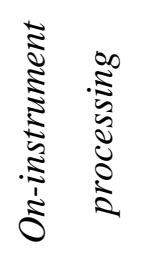 } & Diagnósticos em rolamentos & (HE; ZHOU, 2009) \\
\hline & Nariz Eletrônico & (GHOSH et al., 2015) \\
\hline & $\begin{array}{l}\text { Medições e previsão de falhas em } \\
\text { válvulas }\end{array}$ & (GONÇALVES et al., 2010) \\
\hline \multirow{3}{*}{ 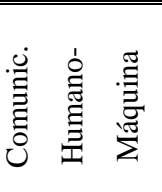 } & Reconhecimento de voz & (LAPIDOT; GUTERMAN; COHEN, 2002) \\
\hline & Reconhecimento de manuscritos & (BEHI; AROUS; ELLOUZE, 2012) \\
\hline & Reconhecimento de sinais manuais & (KUREMOTO et al., 2016) \\
\hline \multirow{2}{*}{ 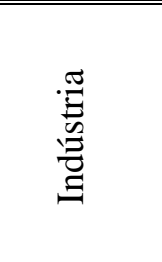 } & $\begin{array}{l}\text { Controle de processos em grandes } \\
\text { conjuntos de máquinas }\end{array}$ & (FREY, 2012) \\
\hline & $\begin{array}{l}\text { Controle de processos em locais } \\
\text { adversos }\end{array}$ & $\begin{array}{l}\text { (XIAOJIAN et al., 2014) e } \\
\text { (KUMAR et al., 2016) }\end{array}$ \\
\hline \multirow{3}{*}{$\frac{8}{i}$} & Segmentação da área de interesse & (DELIBASIS; GOUDAS; MAGLOGIANIS, 2016) \\
\hline & Reconhecimento de ações & (BUONAMENTE; DINDO; JOHNSSON, 2016) \\
\hline & Estimativa de multidões & (SALEH; SUANDI; IBRAHIM, 2015) \\
\hline \multirow{4}{*}{ 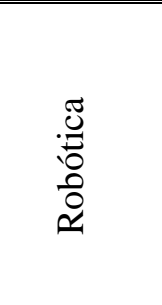 } & Reconhecimento de locais & (GUILLAUME et al., 2011) \\
\hline & Planejamento de rota & $\begin{array}{l}\text { (BRASSAI; IANTOVICS; } \\
\text { ENĂCHESCU, 2012) }\end{array}$ \\
\hline & Controle de robôs dotados de pernas & (ARAUJO; SANTANA, 2015) \\
\hline & Interpretação de imagens por robôs & (CHURAMANI et al., 2017) \\
\hline
\end{tabular}


Nota-se na Tabela 2 que a maioria dos trabalhos foi publicada na última década em congressos sobre redes neurais artificiais ou sobre a área de estudo da aplicação específica. Estes fatos mostram uma tendência de originalidade no conjunto de ideias de emprego da rede neural. Por exemplo, na área de Medicina, os trabalhos de Wang et al. (2015) e De, Zhang e Guo (2016) propõem o uso do SOM para segmentação de imagens médicas concomitantemente com a realização do exame, e para a computação em tempo real de detectores PET, usados em tomografias, com o processamento do DOI (do inglês, "depth-of-interaction" ou, em português, profundidade de interação). Em tais aplicações, a complexidade computacional exigida para processamento das imagens em tempo real é alta, e pode ser acelerado por uma paralelização massiva permitida pelo FPGA (WANG et al., 2016). Outro exemplo da relevância da implementação do SOM em FPGA é a área de IoT, a qual frequentemente utiliza métodos para realizar fusão de dados sensoriais em campo. A necessidade da integração de informações de diferentes sensores diretamente no ambiente é requerida em aplicações desta área em diversos ambientes, tais como, residenciais (NAJJAR; REIGNIER, 2013), automobilísticos (NOORI; MIKAEILI, 2015) e pessoais (THIEMJARUS; LO; YANG, 2006). Uma última classe de exemplos da importância de uma execução da rede neural em FPGA para permitir uma implementação efetiva das aplicações é a Robótica. Diversas tarefas associadas ao controle de robôs são solucionadas por simulações de modelos neurais em software e demandam por execuções diretas em hardware para continuidade do trabalho de pesquisa. Pode-se citar, como exemplo do uso do SOM na área de robótica, o trabalho de Brassai, Iantovics e Enăchescu (2012) sobre o planejamento de trajetórias de navegação de robôs móveis; a pesquisa de Guillaume et al. (2011) sobre categorização autônoma de ambientes para localização e deslocamento; e o estudo de Schillaci, Hafner e Lara (2014) sobre coordenação de informações visuais para movimento de braços robóticos. Ressalta-se, inclusive, que a maioria dos desenvolvimentos em software para aplicações de robótica requerem que ambas as fases da rede neural - aprendizado e operação - sejam realizadas autonomamente durante os deslocamentos pelo ambiente. Este processo, que demanda grande capacidade computacional, deve ser executado por dispositivos computacionais que atendam às restrições de espaço e energia tipicamente associadas às plataformas robóticas.

Após a descrição feita neste capítulo sobre os conceitos gerais dos objetos de pesquisa do trabalho - o SOM e o FPGA - o capítulo 3 a seguir apresenta a fundamentação teórica de ambos, de forma a possibilitar que, no capítulo 4, sejam 
discutidas as propriedades dos circuitos elétricos usados na computação dos algoritmos de treinamento e operação do SOM. A partir desse estudo, serão realizadas duas implementações práticas das metodologias desenvolvidas no trabalho, as quais pertencem (ainda com referência à Tabela 2) às áreas de telecomunicações e processamento de vídeo: a última seção do capítulo 5 apresenta o uso do SOM executado em FPGA para identificação de sinais QAM e a última seção do capítulo 6 descreve seu emprego no processamento de vídeos para reconhecimento de ações humanas. 


\section{PRINCÍPIOS CONCEITUAIS E FUNDAMENTAÇÃO TEÓRICA}

Este capítulo apresenta os dois aspectos teóricos nos quais o restante do texto está fundamentado: o FPGA, um circuito eletrônico digital configurável, e o SOM, a rede neural artificial de aprendizado não-supervisionado proposta por Teuvo Kohonen.

\subsection{FPGA ("FIELD PROGRAMMABLE GATE ARRAY")}

FPGA é um acrônimo em inglês para "Field Programmable Gate Array" e é traduzido para o português como Arranjo de Portas Programável em Campo. A possibilidade que o FPGA oferece de alteração de suas operações lógicas internas e, portanto, de sua funcionalidade, realizada em campo pelo usuário após a fabricação do dispositivo como indica seu nome - é a característica mais relevante deste componente eletrônico (OLDFIELD; DORF 1994). O FPGA foi originalmente concebido como um componente intermediário entre os processadores e os Circuitos Integrados de Aplicação Específica (ASIC acrônimo em inglês para "Application Specific Integrated Circuits") e teve como primeira utilização a prototipagem de circuitos ASIC. Entretanto, atualmente, segundo a extensa catalogação realizada por Romoth; Porrmann e Rückert (2017), a prototipagem ocupa apenas a $11^{\mathrm{a}}$ posição na lista de aplicações dos dispositivos FPGA, enquanto a execução de modelos neurocomputacionais, por exemplo, é o sétimo emprego mais frequente do dispositivo. A Figura 2 mostra a quantidade de trabalhos sobre FPGA nas publicações no IEEE (Instituto de Engenheiros Eletricistas e Eletrônicos) listadas até o ano de 2015. A curva pode indicar que a fase de pico de pesquisas com o dispositivo já ocorreu e que sua utilização entrou em uma fase de maior estabilidade (ROMOTH; PORRMANN; RÜCKERT, 2017).

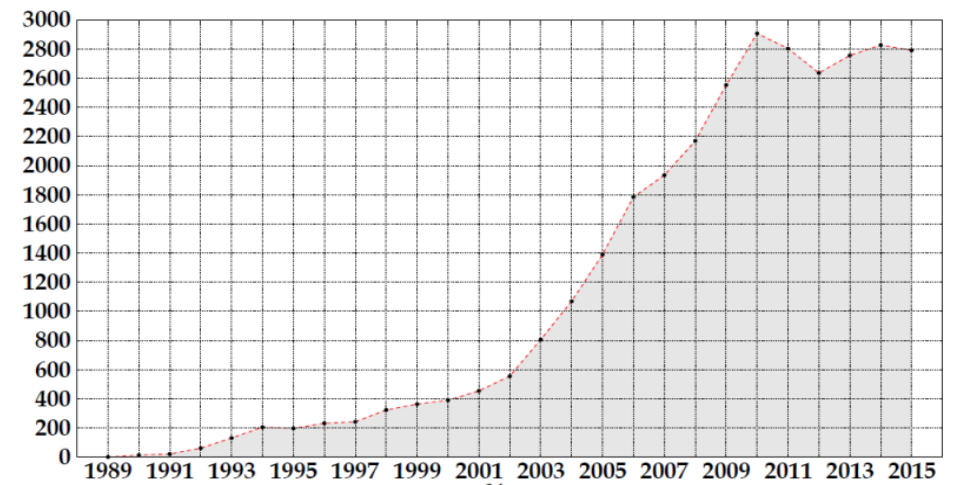

Figura 2 - Curva da quantidade de pesquisas sobre FPGA nas publicações do IEEE por ano, entre 1989 e 2015. Fonte: Romoth; Porrmann e Rückert (2017). 
O chip FPGA é composto por arranjos de blocos lógicos e potenciais conexões entre eles, além de portas de entrada e saída. Tantos os elementos lógicos como os elementos de roteamento podem ser configurados segundo a aplicação em que o componente será empregado sem que a área do circuito integrado seja alterada (HAUCK, 1998). A Figura 3 apresenta um diagrama de parte deste componente, composto por blocos lógicos, conexões e portas externas.

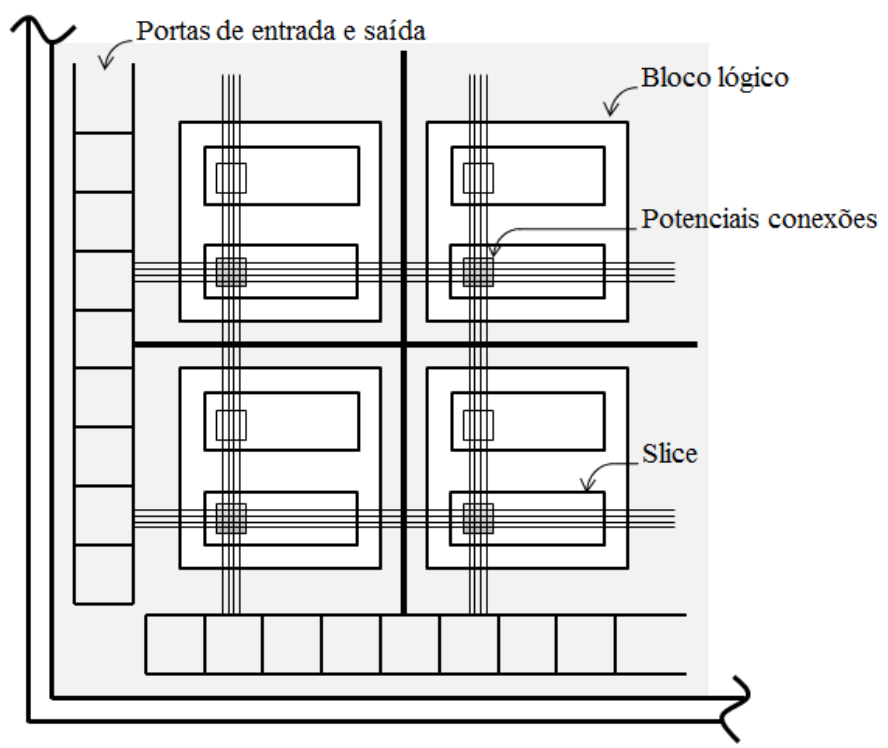

Figura 3 - Diagrama dos blocos lógicos, potenciais conexões, Slices e portas de comunicação de entrada e saída do FPGA.

A Figura 3 também ilustra os blocos lógicos do FPGA divididos em fatias, chamadas Slices. De acordo com as diferentes famílias de FPGA e seus fabricantes, há diversas configurações de Slices, os quais podem conter acréscimos de alguns elementos, como, por exemplo, blocos de memória RAM ou circuitos multiplicadores. Todos os Slices, entretanto, contêm Flip-Flops e LUTs (acrônimo em inglês para “Look Up Tables") de pequeno porte, responsáveis por permitir a configuração individual dos blocos lógicos e, portanto, da funcionalidade do circuito eletrônico inteiro (HORTA 2013). Pode-se mensurar a porção dos recursos utilizados por uma configuração do FPGA pela medida da quantidade de Slices e LUTs ocupados no chip. A Figura 4 apresenta um diagrama da composição padrão dos Slices, com LUTs e Flip-Flops.

De forma diferente dos processadores de uso geral, o FPGA permite explorar arquiteturas de computação diferentes da arquitetura clássica de Von Neumann, pois possibilita execução de tarefas de forma simultânea pela utilização de sua característica 
natural de processamento paralelo. Sua arquitetura interna, portanto, não está préestabelecida com nenhuma arquitetura de processamento fixa, como por exemplo, a unidade lógica e aritmética dos processadores. Aliado a esta possibilidade de configuração independente de seus recursos lógicos internos, outra característica frequentemente citada pelos pesquisadores como importante para o emprego do FPGA, é a quantidade de pinos do dispositivo e sua livre configuração como portas de entrada ou saída (ROMOTH; PORRMANN; RÜCKERT, 2017). Portanto, são comuns aplicações do FPGA nas quais a recepção de uma quantidade de dados originados por dispositivos externos ocorra de forma simultânea, o processamento interno esteja configurado para um paralelismo de seus cálculos, e a informação computada seja comunicada na saída do chip também de forma paralela.

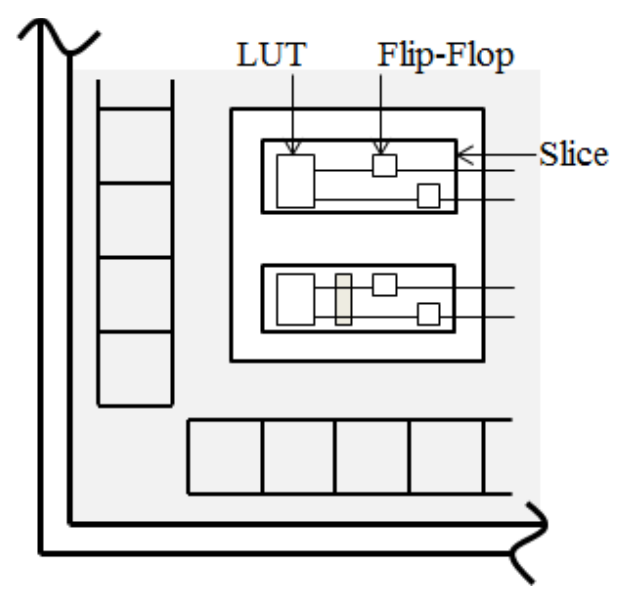

Figura 4 - Diagrama dos Slices, LUTs e Flip-Flops que constituem parte do circuito eletrônico FPGA. O número de Slices/LUTs utilizados em uma implementação permite mensurar a quantidade de recursos consumidos no chip para síntese do sistema elaborado.

Para realizar a configuração dos blocos lógicos e das conexões potenciais do FPGA, pode-se utilizar a linguagem de descrição de hardware VHDL. Alguns tópicos sobre esta linguagem serão discutidos a seguir.

\subsection{A LINGUAGEM DE DESCRIÇÃO DE HARDWARE VHDL}

VHDL é um acrônimo em inglês para "Very High Speed Integrated Circuit HDL", (HDL para Circuitos Integrados de Altíssima Velocidade) com a sigla em inglês HDL para "Hardware Description Language", ou Linguagem de Descrição de Hardware. Esta linguagem de programação permite descrever e projetar, em alto nível, desde 
componentes digitais básicos a sistemas completos e complexos. A linguagem VHDL surgiu a partir do projeto do governo americano chamado VHSIC (em inglês, "Very High Speed Integrated Circuits"), o qual recomendou a elaboração de uma linguagem padrão para a descrição da estrutura e funcionalidade de circuitos integrados. Posteriormente o Instituto de Engenheiros Eletricistas e Eletrônicos, IEEE, desenvolveu a linguagem e a apresentou em 1987 como IEEE Standard 1076, ou VHDL-87 (GONÇALVEZ; MARTINI, 2009).

A linguagem permite que se descreva um circuito eletrônico em diferentes níveis de abstração e que se altere a arquitetura projetada de forma similar a alteração de linhas de códigos de software. O projeto de hardware pode ser elaborado por uma descrição comportamental ou estrutural de sua arquitetura. A descrição comportamental estabelece a operação do circuito digital pela utilização de processos, de maneira semelhante aos comandos sequenciais de uma linguagem de programação em software. A descrição estrutural determina o funcionamento do circuito pela representação dos componentes internos e de suas interligações. Esta forma de representação estrutural é semelhante a um projeto esquemático de circuito eletrônico e permite a visualização dos elementos e interconexões do sistema, realçando a paralelização e concorrência existente na arquitetura elaborada (ASHENDEN, 2008).

As plataformas empregadas nesta pesquisa para a descrição em VHDL das arquiteturas de execução do SOM são as ferramentas de síntese, análise e configuração de projetos de circuitos digitais ISE, acrônimo em inglês para "Integrated Synthesis Environment" (ALUR et al., 2007) e Vivado Design Suite (CHURIWALA, 2016), ambas disponibilizadas pelo fabricante de FPGA Xilinx. A utilização do VHDL, além da descrição do circuito eletrônico, permite que se realizem testes de funcionamento da arquitetura elaborada. Tais testes são chamados pelas plataformas de "testbenches" (ou bancadas de teste) e permitem realizar experimentações com o sistema desenvolvido pela injeção simulada de sinais nas portas de entrada do sistema e verificação dos sinais gerados em sua saída. A ferramenta também possibilita que se obtenham relatórios com informações sobre as características e condições da arquitetura elaborada, como, por exemplo, a frequência máxima de operação do sistema e a área ocupada no chip pelos blocos lógicos em execução, característica esta mensurada pelo relatório sobre a quantidade de Slices e LUTs utilizados pelo circuito eletrônico mapeado no FPGA. 


\subsection{FUNDAMENTOS E PRINCÍPIOS CONCEITUAIS DO SOM}

Entre os anos de 1981 e 1982, o finlandês Teuvo Kohonen propôs o modelo matemático para processamento de dados multidimensionais, que ficou posteriormente conhecido como Mapas Auto-organizáveis, ou SOM, de Self-Organizing Maps (KOHONEN, 1982). A proposta do SOM por Kohonen tem fundamentos na técnica de quantização chamada Quantização Vetorial (VQ, do inglês, "Vector Quantization") e nos mapas cerebrais biológicos (KOHONEN, 2013).

VQ é uma técnica clássica de análise de dados, a qual inicia sua operação pela distribuição de um conjunto de vetores protótipos pelo espaço dimensional das informações a serem processadas. Os vetores protótipos têm mesma dimensão do espaço de entrada e, após um processo de treinamento, no qual tais protótipos são sucessivamente aproximados aos dados de entrada, permitem obter um modelo da função densidade de probabilidade da informação original (LINDE; BUZO; GRAY, 1980).

Mapas cerebrais naturais são conjuntos de neurônios próximos e conectados uns aos outros com função de processar e inter-relacionar os impulsos captados pelos órgãos sensoriais biológicos. Pode-se citar a região existente do córtex dos mamíferos responsável pelo processamento das informações visuais recebidas pelas células fotoreceptoras como um exemplo de mapa cerebral. Esta região, chamada de mapa retinotópico, processa os sinais multidimensionais captados pela retina e apresenta respostas dotadas de correlações topológicas, as quais emergem da especificidade local das conexões entre os neurônios. Em outras palavras, as ativações das células que compõem tal assembleia de neurônios formam um mosaico cuja amostragem segue um arranjo espacialmente ordenado segundo a relação existente nas informações da imagem captada (GOODHILL; XU, 2005).

Podem-se citar outros exemplos de tais assembleias de neurônios naturais como os mapas somatotópicos, os quais apresentam organizações topográficas entre as distintas regiões táteis do corpo; e, em conjunto com o mapa retinotópico, as colunas "ocular dominance", "orientation preference" e "direction of motion", as quais compõem o córtex visual, respectivamente com ativações para mapeamento do domínio lateral da visão, orientação da imagem formada e direção de movimento no campo visual (CHKLOVSKII; KOULAKOV, 2004). 
Assim como o VQ, SOM também distribui um conjunto de vetores protótipos pelo espaço dimensional das informações de entrada e realiza uma aproximação das posições destes vetores protótipos iniciais aos grupos de dados processados. Contudo, a possibilidade de manutenção de uma relação topológica entre os vetores que compõem o mapa que é um processo inspirado na fundamentação biológica, é o ponto de contraste entre o SOM e o VQ. O algoritmo completo de computação do SOM será matematicamente apresentado na seção 3.4.

Esta correspondência entre o SOM e os mapas cerebrais compõe também o embasamento pelo qual tal formalismo pode ser classificado como uma rede neural artificial. No entanto, a unidade básica de processamento do SOM, chamada de neurônio, é fundamentalmente diferente do neurônio artificial inicialmente proposto por McCulloch e Pitts (1943). Enquanto o neurônio artificial de McCulloch e Pitts busca realizar uma aproximação do comportamento de uma única célula do sistema neurológico pela soma ponderada das intensidades dos sinais de ativação admitidos em seu conjunto de entradas e pela subsequente produção de disparo ou inibição do neurônio segundo a aplicação de uma função não-linear sobre o valor desta soma, o neurônio do SOM é associado ao processamento realizado por um conjunto de neurônios naturais. Por este motivo, também é possível se referir ao neurônio do SOM como protótipo, unidade ou vetor peso.

Ainda sobre a nomenclatura, o SOM é denominado como mapa devido ao arranjo de interligação de seus neurônios, os quais, conectados apenas localmente geralmente em uma disposição bidimensional - formam uma configuração tipo grade ou treliça. Esta estrutura é posicionada, durante o processo de treinamento da rede, de forma a permitir uma identificação das relações topológicas entre os conjuntos multidimensionais dos dados de entradas (HAYKIN, 2007).

O processo de treinamento, inclusive, pode ser considerado como outro aspecto de similaridade entre o SOM e os mapas cerebrais biológicos. Assim como outras arquiteturas de computação neural, é na fase de aprendizagem que o SOM se torna específico para poder processar os dados do problema em que está sendo empregado. Da mesma forma, os mapas cerebrais também possuem um refinamento de seu comportamento de acordo com as experiências individuais vivenciadas, pois a formação inicial de tais assembleias de neurônios naturais tem determinação genética, porém o aprimoramento de sua estrutura e de sua escala de resposta depende dos estímulos particulares aos quais os órgãos sensoriais do indivíduo foram submetidos. Um exemplo 
de tal aprimoramento são as pesquisas que relatam que crianças nascidas em ambientes diferentes têm percepções semelhantes das tonalidades de cores, contudo, elas sofrem uma diferenciação na percepção com o passar dos anos, de acordo com o seu entorno particular. Em 2006, Roberson e seu grupo de pesquisa reportaram investigações comparativas sobre a percepção de cores por indígenas que vivem em pequenos povoados tribais isolados e por pessoas que vivem em centros urbanos da Inglaterra. Quando pequenas, tanto as crianças do povo Himba no norte da Namíbia e do povo Berinmo, de Papua-Nova Guiné, distinguem os tons de cores semelhantemente às crianças inglesas, entretanto, como os habitantes das tribos remotas estão expostos apenas a tons naturais, sem a estimulação de cores saturadas artificialmente, os adultos destas regiões diferenciam e classificam as cores de forma bem distinta dos adultos ingleses (ROBERSON et al., 2006).

Pode-se ainda ilustrar a especificidade de operação das células cerebrais com processo de transição que a percepção acústica sofre após o aprendizado da linguagem, deixando de exibir características genéricas para se tornar particularizada (KAWAI et al., 2007). Estudos reportam que as crianças são capazes de discernir uma grande variedade de sons e unidades fonéticas utilizadas por diversas línguas, inclusive pertencentes aos idiomas estrangeiros com os quais elas nunca tiveram contato e, à medida que o ocorre o processo de aquisição da linguagem presente em seu ambiente, tal capacidade genérica se converte em uma habilidade específica de identificar apenas os fonemas de sua própria língua. De maneira que, por exemplo, duas unidades fonéticas distintas, utilizadas em um idioma estrangeiro, podem ser diferenciadas por crianças, porém percebidas, ambas, como o mesmo fonema por um indivíduo falante de outra língua (KUHL; TSAO; LIU, 2003).

Capacidade semelhante tem a arquitetura do SOM de realizar agrupamentos dos dados de entrada pelo ajuste dos valores dos vetores que descrevem seus neurônios e, portanto, possibilitar que estes vetores representem conjuntos de informações semelhantes entre si. Nota-se também que, na fase de aprendizagem, o ajuste dos vetores de neurônios do SOM depende fundamentalmente das informações recebidas suas semelhanças, inter-relações e frequência de ocorrência - e não de rótulos de classificação previamente atribuídos. Por esta razão, o treinamento do SOM é chamado de não-supervisionado. Durante a fase de operação da rede, na qual não há mais ajustes nos valores dos vetores peso do SOM, os dados de entrada são mapeados em sua saída, de forma que se possa conhecer sua categorização em relação às demais informações 
previamente mapeadas. A formalização matemática dos processos de treinamento e operação do SOM será realizada a seguir.

\subsection{DEFINIÇÕES MATEMÁTICA E ALGORÍTMICA DO SOM}

SOM pode ser entendido como um método de projeção não-linear de um espaço vetorial multidimensional $\mathbb{R}^{n}$ de entrada para um espaço matricial $\mathbb{Z}^{d}$ de saída, geralmente com $d \in\{1,2,3\}$ (KOHONEN, 2013). A projeção realizada pelo SOM permite uma manutenção da ordem topográfica dos dados de entrada, assim como a visualização dessa ordenação em sua matriz de saída. A matriz de saída do SOM pode ser entendida como uma grade que possui, posicionado em cada nó, um neurônio. Conforme exposto na seção 3.3, os neurônios do SOM também podem ser denominados protótipos ou unidades. A cada neurônio está associado um vetor peso $\boldsymbol{w}_{\boldsymbol{j}}$ de mesma dimensão $n$ do espaço vetorial de entrada e com $j=1,2, \ldots, J$, sendo $J$ a quantidade de neurônios da rede. A camada de entrada do SOM admite vetores $\boldsymbol{x}_{\boldsymbol{i}}$, de dimensão $n$, com $i=1,2, \ldots$, $I$, sendo $I$ a quantidade de dados do conjunto de entrada. A Figura 5 ilustra um exemplo de $\operatorname{SOM} \operatorname{com} J=25$, configurado em uma matriz $5 \times 5(d=2)$ e $\operatorname{com} n=4$.

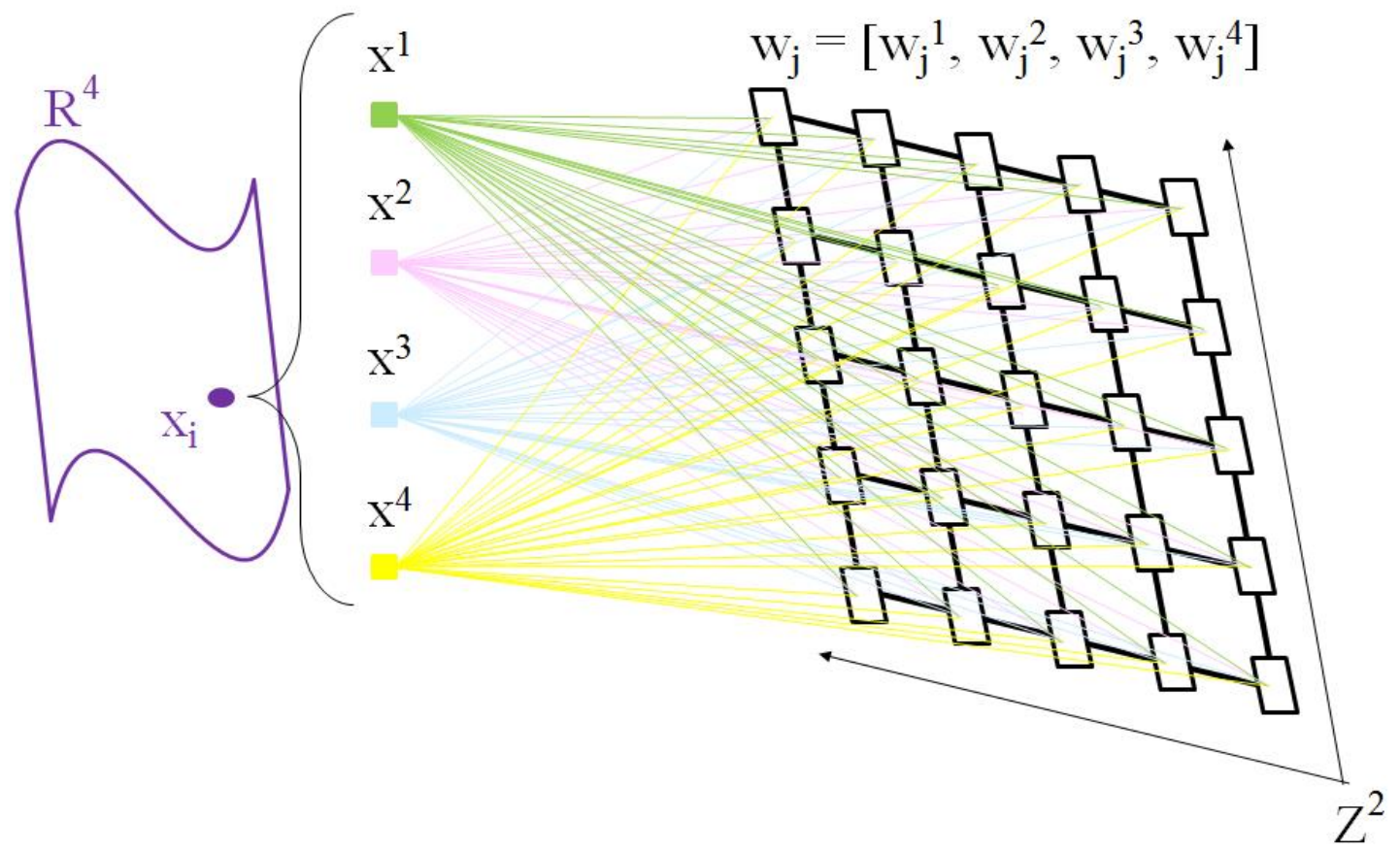

Figura 5 - Exemplificação do SOM, com quatro entradas e grade em arranjo bidimensional de $5 \times 5$ neurônios. Cada neurônio é descrito por seu respectivo vetor peso $\boldsymbol{w}_{j}$ de mesma dimensão da entrada. Os vetores de entrada $\boldsymbol{x}_{i}$, pertencentes ao espaço multidimensional $\mathbb{R}^{3}$, são amostrados pelos atributos $x^{1}, x^{2}, x^{3}$ e $x^{4}$ nas entradas da rede neural. 
O arranjo da grade de neurônios pode ter diferentes formatos, e escolhas típicas para o formato de tal arranjo são quadrado e hexagonal. A Figura 6 ilustra ambos os tipos de arranjos de grade do SOM.

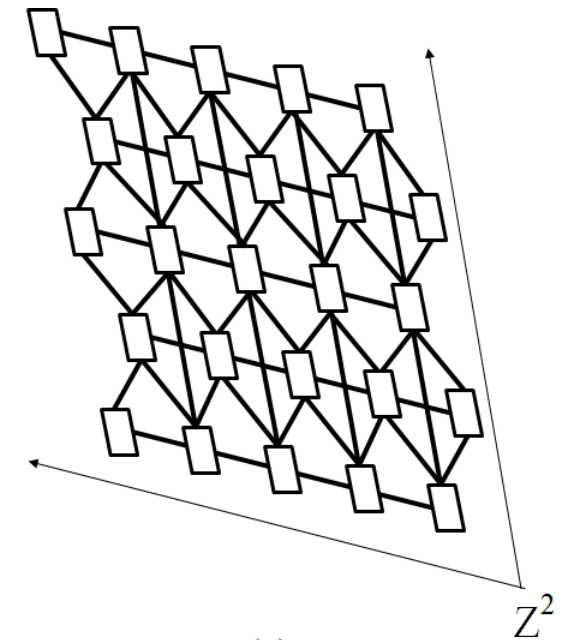

(a)

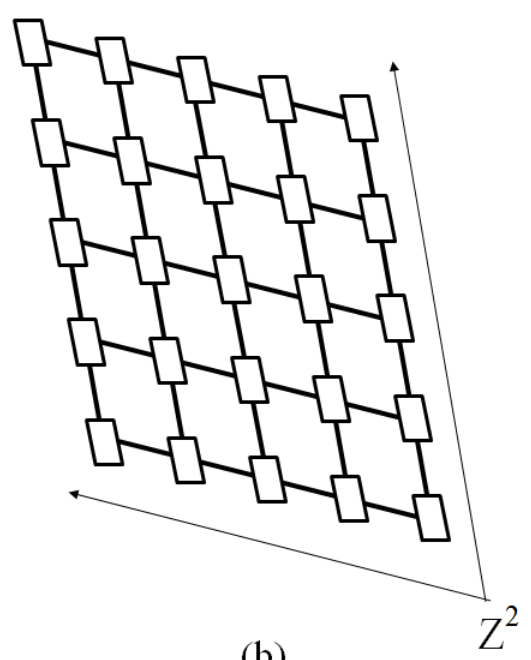

(b)

Figura 6 - Exemplos de tipos de arranjo da matriz de neurônios de saída do SOM em grades hexagonal (a) e quadrada (b).

O início de ambos os processos do SOM - treinamento e operação - envolvem a procura do neurônio de vetor peso $\boldsymbol{w}_{\boldsymbol{j}}$ de maior similaridade com o vetor de entrada $\boldsymbol{x}_{\boldsymbol{i}}$. A cada iteração de processamento do SOM, este neurônio de maior similaridade é chamado de neurônio vencedor (nomeado também pela sigla em inglês BMU para "best match unit") e é simbolizado por $c$. Durante a fase de treinamento, o neurônio vencedor $c$ terá seu vetor peso ajustado em conjunto com os vetores peso dos neurônios que estão em sua região de vizinhança matricial, ou seja, neurônios que estejam próximos, na grade, ao neurônio vencedor $c$. A fim de se determinar o neurônio de vetor peso $\boldsymbol{w}_{\boldsymbol{j}}$ de maior similaridade com o vetor de entrada $\boldsymbol{x}_{\boldsymbol{i}}$, utiliza-se uma medida de distância vetorial (simbolizada por dist) entre ambos os vetores. Assim, tem-se a expressão (1) a seguir para definição do neurônio vencedor:

$$
c=\arg \min _{j} \operatorname{dist}\left(\mathbf{w}_{\mathbf{j}}, \mathbf{x}_{\mathbf{i}}\right)
$$

Embora o SOM seja comumente computado com o emprego da distância Euclidiana a fim de se encontrar o neurônio de maior similaridade com a amostra de entrada, outras medidas de distância podem ser escolhidas. Em suas formulações do SOM, Teuvo Kohonen não restringe o uso de outras medidas de distância pois, como 
consta, por exemplo, em seu trabalho original: “...não é sempre necessário que a norma seja Euclidiana ${ }^{7} . "($ KONONEN, 1982, p. 61).

O controle da intensidade no ajuste dos vetores peso dos neurônios durante a progressão do processo de treinamento do SOM é feito pelo fator de aprendizagem $\alpha \in(0,1]$. A função $\alpha(t)$ é definida como escalar monótona decrescente (KOHONEN, 2014). Um exemplo de função utilizada para o fator de aprendizagem está descrita na expressão (2):

$$
\alpha(t)=\alpha_{i}(t)\left(\frac{\alpha_{f}}{\alpha_{i}}\right)^{\frac{t}{T}}
$$

com $T$ simbolizando o número de iterações totais do processo de treinamento do SOM e $t$, o valor atual da iteração. Os valores inicial $\left(\alpha_{i}\right)$ e final $\left(\alpha_{f}\right)$ do fator de aprendizagem, assim como a função utilizada, estão relacionados com o problema ao qual o SOM está aplicado. Valores possíveis para estes fatores são, por exemplo, $\alpha_{i}=0,1$ e $\alpha_{f}=0,01$, respectivamente.

Por fim, a moderação da amplitude de ajuste dos pesos nos neurônios vizinhos na grade ao neurônio vencedor $c$, é dada pela função de vizinhança $h_{c_{j}}(t)$. Tal função desempenha um papel fundamental na auto-organização alcançada pelo SOM (KOHONEN, 2013). Em 1995, Fort e Pagès demonstraram uma prova de convergência quase certa ${ }^{8}$ a um estado final após o processo de auto-organização do SOM para uma classe geral de funções de vizinhança que seja simétrica, decrescente, centrada no neurônio vencedor e inversamente proporcional à distância entre o neurônio vencedor e os demais neurônios no arranjo de saída da rede (FORT; PAGÈS, 1995). Uma função típica utilizada para determinara moderação de amplitude no ajuste de pesos dos neurônios é a função gaussiana, descrita pela expressão (3):

$$
h_{c_{j}}=\mathrm{e}^{\left(\frac{-(\operatorname{dist}(c, j))^{2}}{2 \sigma^{2}(t)}\right)}
$$

com $\operatorname{dist}(c, j)$ representando a distância na grade entre o neurônio vencedor $c$ e o neurônio $j$ a ser ajustado. A função $\sigma(t)$ determina a abertura da função de vizinhança e,

\footnotetext{
${ }^{7}$ Traduzido do inglês: “...it is not always necessary that the norm be Euclidean.” (KONONEN, 1982, p. 61).

${ }^{8}$ A prova de convergência quase certa é obtida se, quando o número de elementos de uma sequência (ou iterações) tende ao infinito, a probabilidade de convergência de tal sequência tender a 1.
} 
Segundo Kohonen (2014), o modelo matemático desta função não é crucial. O importante é que este valor seja maior no começo da fase de treinamento, de forma a facilitar o início do processo de auto-organização, e menor ao final da aprendizagem, para permitir um ajuste fino dos vetores peso do SOM. Desta forma, $\sigma(t)$ indica quantos neurônios vizinhos ao neurônio vencedor $c$ terão seu vetor peso ajustado com maior intensidade. A expressão (4) contém uma possível função para descrever esta abertura da função de vizinhança:

$$
\sigma(t)=\sigma_{i}(t)\left(\frac{\sigma_{f}}{\sigma_{i}}\right)^{\frac{t}{T}}
$$

com valores inicial e final possíveis como $\sigma_{i}=7,0$ e $\sigma_{f}=1,0, T$ identificando o número de iterações totais da fase de aprendizagem do SOM e $t$, o valor atual da iteração. Todos estes parâmetros são dependentes da aplicação e devem ser ajustados pelo projetista da rede neural.

Desta forma, o ajuste dos vetores peso $\boldsymbol{w}_{\boldsymbol{j}}$ dos neurônios do SOM durante o processo de treinamento é representado, em notação algorítmica, pela expressão (5).

$$
\boldsymbol{w}_{\boldsymbol{j}}(t+1)=\boldsymbol{w}_{\boldsymbol{j}}(t)+\alpha(t) \cdot h_{c_{j}}(t) \cdot\left[\mathbf{x}_{\mathbf{i}}-\mathbf{w}_{\mathbf{j}}\right]
$$

O processo de aprendizagem do SOM pode ser realizado pelo algoritmo de treinamento sequencial ${ }^{9}$, apresentado na Tabela 3 , em que há ajustes nos vetores peso $\boldsymbol{w}_{\boldsymbol{j}}$ a cada admissão de um vetor de entrada $\boldsymbol{x}_{\boldsymbol{i}}$ pela rede neural. O processo de treinamento sequencial pode ser particionado em duas fases: organização inicial dos neurônios e refinamento do mapa. Para diferenciar as duas fases, se alteram o valor do fator de aprendizagem e da abertura da função de vizinhança. A primeira fase, que possui maiores valores de $\alpha(t)$ e de abertura de $h_{c_{j}}(t)$, permite um processo de ordenação dos neurônios de forma a particionar o espaço multidimensional $\mathbb{R}^{\boldsymbol{n}}$ de entrada em $J$ células do Diagrama de Voronoi $V_{j}$, tais que $V_{j} \supset\left\{\mathbf{x}_{\mathbf{i}} \mid \operatorname{dist}\left(\mathbf{w}_{\mathbf{j}}, \mathbf{x}_{\mathbf{i}}\right)<\right.$

\footnotetext{
${ }^{9}$ A fase de aprendizagem do SOM também pode ser executada pelo algoritmo de treinamento por batelada, que apresenta algumas vantagens em relação ao algoritmo de treinamento sequencial: a convergência é atingida mais rapidamente; não requer fator de aprendizagem $\alpha(t)$ e possui resultados determinísticos, os quais podem ser reproduzidos se os valores aleatórios iniciais de $\boldsymbol{w}_{\boldsymbol{j}}$ forem conhecidos. Entretanto, possui, também, algumas desvantagens: possui forte dependência da inicialização dos valores de $\boldsymbol{w}_{\boldsymbol{j}}$ e, por este motivo, pode produzir mapas menos organizados (FORT; LETREMY; COTTRELL, 2005).
} 
$\left.\operatorname{dist}\left(\mathbf{w}_{\mathbf{k}}, \mathbf{x}_{\mathbf{i}}\right) \forall j \neq k\right\}$ (VESANTO et al., 1999). A segunda fase possui menores valores de $\alpha(t)$ e de abertura de $h_{c_{j}}(t)$, de forma que ocorra apenas o processo de sintonia fina de $\boldsymbol{w}_{j}$ e $V_{j}$.

Tabela 3 - Algoritmo de treinamento sequencial do SOM.

I. Configuração inicial do SOM:

a. Definição da dimensão $n$ do espaço de entrada e da dimensão $d$ do espaço de saída SOM;

b. Definição da quantidade $J$ de neurônios da rede, do formato da grade do mapa (quantidade de neurônios por linha e coluna, por exemplo) e do formato da grade de vizinhança (retangular ou hexagonal, por exemplo);

c. Determinação dos valores do fator de aprendizagem inicial $\left(\alpha_{i}\right)$ e final $\left(\alpha_{f}\right)$ e dos valores inicial $\left(\sigma_{i}\right)$ e final $\left(\sigma_{f}\right)$ da abertura da função de vizinhança.

d. Inicialização aleatória de cada vetor peso $\boldsymbol{w}_{\boldsymbol{j}}$ e inicialização de $t=0$;

e. Definição do número de iterações do processo de treinamento $T$, tal que $T>I$ (com I indicando a quantidade de dados do conjunto de treinamento);

II. Repetir:

a. Repetir:

i. Admissão aleatória de um vetor de entrada $\boldsymbol{x}_{\boldsymbol{i}}$ pela rede;

ii. Cálculo das distâncias $\operatorname{dist}\left(\mathbf{w}_{\mathbf{j}}, \mathbf{x}_{\mathbf{i}}\right)$ para todo $j \operatorname{com} 1 \leq j \leq J$;

iii. Determinação do neurônio vencedor $c=\arg \min _{j} \operatorname{dist}\left(\mathbf{w}_{\mathbf{j}}, \mathbf{x}_{\mathbf{i}}\right)$;

iv. Ajuste dos vetores peso do neurônio vencedor $c$ e dos neurônios pertencentes à região de vizinhança do neurônio vencedor $c$ :

$$
\boldsymbol{w}_{\boldsymbol{j}}(t+1)=\boldsymbol{w}_{\boldsymbol{j}}(t)+\alpha(t) \cdot h_{c_{j}}(t) \cdot\left[\mathbf{x}_{\mathbf{i}}-\mathbf{w}_{\mathbf{j}}\right] ;
$$

até que o conjunto de $I$ amostras seja todo admitido pela rede.

b. Incremento de $t$

até que $t=T$.

Após a conclusão da fase de treinamento do SOM, estado no qual os vetores peso $\boldsymbol{w}_{\boldsymbol{j}}$ atingem um estado final de ajuste, a rede neural pode ser utilizada para categorizar vetores de entrada $\boldsymbol{x}_{\boldsymbol{i}}$ não empregados durante seu aprendizado. Nesta fase de operação, em geral, as novas informações apresentadas à rede são mapeadas como 
pertencentes a um grupo identificado na fase de treinamento, conforme o algoritmo de operação apresentado pela Tabela 4. Tradicionalmente, o SOM tem sido utilizado para permitir a visualização em duas dimensões de vetores multidimensionais (KOHONEN, 2013), entretanto, existem diversas aplicações publicadas na literatura que utilizam esta rede neural de maneiras diferentes, incluindo sistemas de processamento autônomo sem interpretação humana do mapa gerado pelo SOM, conforme discutido em detalhes na seção 2.3.

Tabela 4 - Algoritmo de operação do SOM.

I. Configuração do SOM: definir os vetores peso $\mathrm{w}_{\mathrm{j}}$ com os valores obtidos ao final da fase de treinamento.

II. Repetir:
a. Admissão do um vetor de entrada $\mathbf{x}_{\mathbf{i}}$ pela rede;
b. Cálculo das distâncias $\operatorname{dist}\left(\mathbf{w}_{\mathbf{j}}, \mathbf{x}_{\mathbf{i}}\right)$ para todo $j \operatorname{com} 1 \leq j \leq J$;
c. Determinação do neurônio vencedor $c=\arg \min _{j} \operatorname{dist}\left(\mathbf{w}_{\mathbf{j}}, \mathbf{x}_{\mathbf{i}}\right)$;
d. Apresentar à saída o índice $j$ do neurônio vencedor $c$ ou a categoria representada por $c$.

até que o conjunto de $I$ amostras seja todo admitido pela rede.

\subsection{MEDIDAS DE AVALIAÇÃO DO SOM}

Assim como outros modelos neurais de computação, o SOM possui uma fase de treinamento na qual o pesquisador deve fazer suposições sobre seus parâmetros de configuração (HAYKIN, 2007). Estes parâmetros influenciam na organização dos neurônios da rede durante o processo de aprendizagem e, portanto, podem gerar versões finais diferentes do mapa. Desta forma, levanta-se o questionamento de quão bem o mapa produzido representa o conjunto de dados. Para responder esta pergunta, diversos pesquisadores propuseram métricas de avaliação do mapeamento obtido pelo SOM (KIVILUOTO, 1996; PÖLZLBAUER, 2004). Dentre as métricas mais utilizadas estão o erro de quantização e o erro topográfico, que serão apresentados nas seções $3.5 .1 \mathrm{e}$ 3.5.2. O erro de quantização será utilizado em uma das caracterizações finais da 
arquitetura de circuito desenvolvida como métrica para avaliar a resolução do mapa produzido pela implementação do SOM em hardware (seção 7.1). Em outra caracterização do sistema proposto, o erro topográfico será utilizado como métrica para avaliar a estrutura de relação entre as posições mapeadas pela execução direta do SOM em FPGA (seção 7.2).

\subsubsection{ERRO DE QUANTIZAÇÃO}

Como discutido na seção 3.3, uma das utilizações mais frequentes do SOM é como método de quantização vetorial, a qual pode ser definida - genericamente - como a tarefa de achar um subconjunto menor que represente um conjunto maior. Particularmente para o SOM, este processo ocorre com a representação dos vetores de entrada pelos seus vetores pesos. O erro de quantização $\left(Q_{\text {err }}\right)$ está tradicionalmente relacionado a todas as formas de quantificação vetorial e algoritmos de agrupamento (PÖLZLBAUER, 2004). Para o SOM, esta métrica avalia o ajuste do mapa ao conjunto de dados, feito pelo seu processo de treinamento e é calculado pela Equação (6):

$$
Q_{e r r}=\frac{1}{I} \sum_{i=1}^{I} \sqrt{\left(\boldsymbol{x}_{\boldsymbol{i}}-\boldsymbol{w}_{\boldsymbol{c}, \boldsymbol{i}}\right)^{2}}
$$

com $\boldsymbol{x}_{\boldsymbol{i}}$ representando o vetor de entrada e $\boldsymbol{w}_{\boldsymbol{c}, \boldsymbol{i}}$ o vetor peso do neurônio vencedor quando a entrada $\boldsymbol{x}_{\boldsymbol{i}}$ é apresentada à rede (BMU). Ou seja, somam-se os valores da distância Euclidiana entre o vetor de entrada e seu BMU para todo o conjunto de $I$ entradas de treinamento.

\subsubsection{ERRO TOPOGRÁFICO}

Além da capacidade de quantização mencionada na seção anterior, outra das principais características do SOM é a identificação das relações topológicas entre os conjuntos multidimensionais dos dados de entradas (conforme discutido na seção 3.3). Desta forma, com o objetivo de determinar o quão contínuo é o mapeamento do espaço de entrada para a grade do mapa, Kimmo Kiviluoto propôs em 1996 a métrica de erro 
topográfico (KIVILUOTO, 1996). O erro topográfico $T_{\text {err }}$ utiliza as amostras de entradas empregadas no processo de treinamento para quantificar preservação das correlações entre os dados e o mapa produzido, podendo ser calculado pela Equação (7).

$$
T_{\text {err }}=1-\frac{1}{I} \sum_{i=1}^{I} \lambda\left(\boldsymbol{x}_{\boldsymbol{i}}\right)
$$

na qual, para todo o conjunto de $I$ entradas de treinamento, tem-se:

$\lambda\left(\boldsymbol{x}_{i}\right)=1$, caso os dois neurônios mais semelhantes ao vetor de entrada $\mathbf{x}_{\mathbf{i}}$ sejam vizinhos imediatos no mapa.

$\lambda\left(\boldsymbol{x}_{\boldsymbol{i}}\right)=0$, caso contrário.

O erro topográfico pode ser usado, portanto, para verificar a qualidade da preservação da topologia dos dados de entrada no mapa produzido pelo SOM. 


\section{PROPRIEDADES DA COMPUTAÇÃO DO SOM EM HARDWARE - A METODOLOGIA EXISTENTE E AS PROPOSTAS ELABORADAS}

Diversos trabalhos têm sido publicados na literatura sobre circuitos elétricos para a execução de SOM em hardware como, por exemplo, Ramirez-Agundis, Gadea-Girones e Colom-Palero (2008); Hikawa e Maeda (2015); Kolasa, Talaśka e Długosz (2017) e Abadi et al. (2018). Todos os trabalhos apresentam algumas modificações no algoritmo de computação neural, em relação às execuções tradicionais em software, com o propósito de torná-lo adequado para uma implementação direta e eficiente no chip. Porém, constatou-se que tais modificações são frequentemente apresentadas na literatura sem que haja referência às premissas teóricas que fundamenta o modelo neural. Desta forma, o presente capítulo discute as propriedades específicas da computação do SOM executada diretamente em hardware com o intuito de construir o embasamento teórico da arquitetura de circuito empregada neste trabalho. Todas as modificações apresentadas são, portanto, consistentes com as proposições iniciais do SOM (KOHONEN, 1982) e seus desenvolvimentos subsequentes (KOHONEN, 2013 e KOHONEN, 2014). O capítulo apresenta, também, a proposta de uma função de vizinhança do SOM baseada em FPGA a ser utilizada no processo de aprendizagem da rede neural. O objetivo desta proposta é desenvolver uma expressão computacional para ser executada em hardware que constitua uma alternativa eficiente às funções tradicionalmente empregadas em software.

\subsection{CÁLCULO DE SIMILARIDADE}

Como descrito na seção 3.4, o primeiro processo computacional dos algoritmos de treinamento e operação do SOM é o cálculo de distância entre o vetor de entrada e o vetor peso de cada neurônio da rede, para determinação do neurônio de maior similaridade. Tradicionalmente em execuções em software, emprega-se a distância Euclidiana neste processo (HAYKIN, 2007; XIAOJIAN et al., 2014; KOHONEN, 2014). Porém, em execuções do SOM diretamente em hardware, a distância de Manhattan é a opção mais frequente (por exemplo, RÜPING; RÜCKERT; GOSER, 1993; HIKAWA, 2005; DŁUGOSZ et al., 2011). Esta opção é normalmente justificada 
pela economia de recursos do chip que sua computação permite, pois não utiliza exponenciação ou radiciação (PEÑA; VANEGAS; VALENCIA, 2006). Há duas únicas exceções ao emprego da distância de Manhattan encontradas na literatura. A primeira é a arquitetura batizada de bSOM (do inglês, “binary SOM”) desenvolvida pelo grupo da Universidade de Lincoln, no Reino Unido, o qual optou por utilizar a distância de Hamming no cálculo de proximidade pois opera com um sistema aplicado ao processamento de histogramas puramente binários, e não representações digitais de números decimais, (APPIAH et al., 2012). A segunda exceção à utilização da distância de Manhattan é o projeto de treinamento do SOM em placas com agrupamentos de diversos FPGAs desenvolvido pelo grupo de pesquisa liderado por Jan Lachmair para uma replicação exata do comportamento da rede em software (LACHMAIR et al., 2012, LACHMAIR et al., 2013) ${ }^{10}$.

No presente trabalho optou-se pelo emprego da distância de Manhattan em todas as computações de similaridade entre os valores de entrada de $\boldsymbol{x}_{\boldsymbol{i}}$ e os vetores $w_{j}$. A escolha por esta métrica é amparada pelos trabalhos de Aggarwal et al. (2001) e Kriegel et al. (2009) sobre fundamentos matemáticos em processos de agrupamento de dados ("clustering"). Tais trabalhos afirmam que a distância de Manhattan faz uma melhor avaliação da importância de pequenas distâncias em espaços dimensionais $\boldsymbol{N}$ elevados por possuir um menor valor de $\boldsymbol{p}$ na distância Minkowski em relação à distância Euclidiana. A distância de Minkowski $\left(d_{m}\right)$ está descrita na Equação (8):

$$
d_{m}=\left(\sum_{n=1}^{N}\left|x_{i}^{n}-w_{j}^{n}\right|^{p}\right)^{\frac{1}{p}}
$$

na qual as métricas $l_{1}$ (Manhattan) e $l_{2}$ (Euclidiana) têm valores de $p=1$ e $p=2$, respectivamente. Tais aprofundamentos teóricos sobre a escolha de métricas para tarefas de agrupamento de dados também são comprovados por resultados práticos na comparação de ambas as medidas de distâncias em processamentos de informações de

\footnotetext{
${ }^{10}$ Como o projeto deste grupo de pesquisa tem o objetivo apenas de aceleração da fase de aprendizagem do SOM, em comparação com execuções em CPU - e não de viabilizar aplicações com portabilidade foi realizada a escolha pela distância Euclidiana como métrica de similaridade. Esta opção implica em uma maior utilização dos recursos do FPGA e, como consequência, o sistema projetado utiliza conjuntos de chips interligados em uma placa de circuito impresso para o processamento do SOM.
} 
forma não supervisionada, realizados em CPU (KARKARE; GIBSON; MARKOVIĆ, 2013), os quais apontam para menores taxas de erro quando se emprega a distância de Manhattan.

Uma comparação de desempenho entre as distâncias de Manhattan e Euclidiana também foi realizada na pesquisa de Długosz et al. (2011). O trabalho executa um grande conjunto de simulações em software sobre o aprendizado do SOM e obtém resultados similares quando compara ambas as métricas (referenciadas como $l_{1}$ e $l_{2}$ ), com a seguinte conclusão: "As simulações do modelo em software mostram que a qualidade de aprendizagem é independente da medida de distância, e, portanto, a medida $l_{1}$ é preferida na nossa realização, uma vez que não exige operação de quadratura $^{11}$." (DŁUGOSZ et al., 2011, p. 2102).

Por fim, a opção pela utilização da distância de Manhattan não contradiz o desenvolvimento teórico do SOM, o qual especifica a necessidade apenas de alguma métrica consistente como a medida de similaridade, descrito por Teuvo Kohonen como: "Existem muitas versões do SOM, às quais se aplicação diferentes definições de similaridade $^{12}$." (KOHONEN, 2013, p. 54).

\subsection{COMPUTAÇÃO DO FATOR DE APRENDIZAGEM}

O fator de aprendizagem $\alpha$ - coeficiente de valor entre 0 (zero) e 1 (um) utilizado para regular a intensidade do ajuste dos pesos - deve ser uma função escalar monótona decrescente, conforme apresentado na seção 3.4. Em execuções do SOM em software geralmente se utilizam funções hiperbólicas ou exponenciais para execução de $\alpha(t)$ (HAYKIN, 2007), como, por exemplo, em Xiaojian et al. (2014). Entretanto, funções alternativas para computação do fator de aprendizagem também são possíveis, como, por exemplo, as funções compostas por segmentos lineares (em inglês, "piecewise linear function") utilizadas em experimentos reportados por Kohonen (2014). Com o objetivo de se diminuir o número de circuitos multiplicadores utilizados na execução do SOM, neste trabalho optou-se por utilizar o deslocamento aritmético à direita para execução do produto envolvendo o fator de aprendizagem. Desta forma

\footnotetext{
${ }^{11}$ Traduzido do inglês: "The software model simulations show that the learning quality is rather independent from the distance measure, and therefore the L1 measure is preferred in our realization, as it does not require squaring operation." (DŁUGOSZ et al., 2011, p. 2102).

${ }_{12}$ Traduzido do inglês: "There exist many versions of the SOM, which apply different definitions of similarity." (KONONEN, 2013, p. 54).
} 
a realização da multiplicação $\alpha(t) \cdot\left[\mathbf{w}_{\mathbf{j}}-\mathbf{x}_{\mathbf{i}}\right]$ existente na Equação (5) de ajuste de pesos do SOM é efetuada pela expressão (9) representada, em VHDL, a seguir:

$$
\text { temp <= erroj sra fatorAprendizado; }
$$

com o operador sra indicando deslocamento aritmético à direita (ou, em inglês, "shift right arithmetic"), erroj representando o vetor de diferenças $\left[\mathbf{x}_{\mathbf{i}}-\mathbf{w}_{\mathbf{j}}\right]$, fatorAprendizado (pertencente ao conjunto dos inteiros positivos) denotando o valor de $\alpha$ no instante $t$ (com $\alpha \in \mathbb{Z}_{+}$) e temp simbolizando o armazenamento temporário do valor resultante de multiplicação. A arquitetura desenvolvida também permite ao usuário determinar a taxa de decréscimo de $\alpha$ segundo o progresso da quantidade de épocas de treinamento, de forma que se obtenham patamares decrescentes dos valores de fator de aprendizagem conforme a progressão do treinamento. Esta estratégia contrasta com trabalhos que usam valores constantes durante toda a fase de treinamento na implementação em hardware, como, por exemplo, Huang et al. (2017). A Figura 7 ilustra um exemplo da função $\alpha(t)$ proposta com 5 patamares ${ }^{13}$.

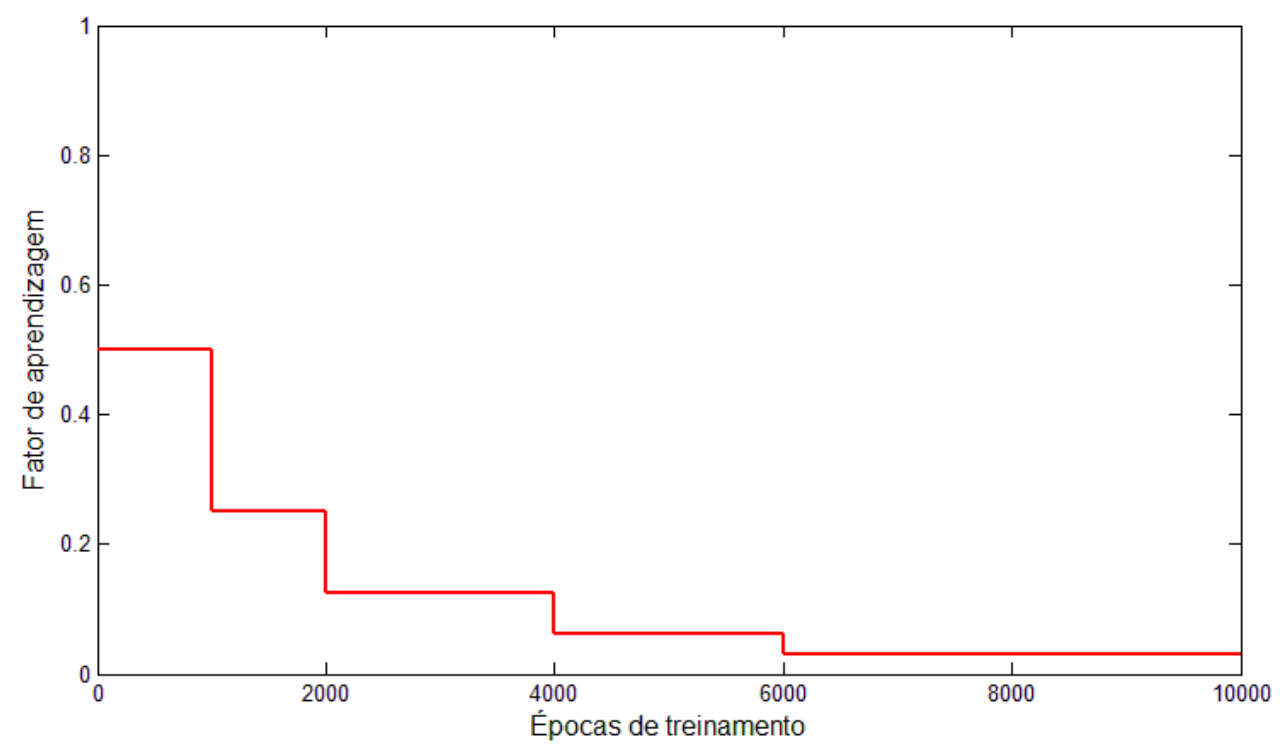

Figura 7 - Exemplo de progressão do fator de aprendizagem $\alpha(t)$ alternativo, executado pela operação binária de deslocamento aritmético à direita e sem o uso de multiplicadores.

A alternativa de deslocamento aritmético oferece menor complexidade computacional quando comparada a operação original de multiplicação por um

\footnotetext{
${ }^{13}$ Resultados de desempenho da implementação que emprega o $\alpha(t)$ apresentado na Figura 7 estão reportados nas seções 7.1 e 7.4 .
} 
coeficiente variável, favorecendo a velocidade de processamento e a economia de recursos do chip. Por outro lado, restringe os valores do fator de aprendizagem a potências negativas de base dois $(1 / 2,1 / 4, \ldots)$, com definição do expoente configurada pelo usuário - segundo as condições do problema em que a rede neural está sendo aplicada. Esta restrição não compromete o processo de aprendizagem do SOM, de acordo com Haykin (2007, p. 492), no capítulo dedicado a Mapas Auto-organizáveis, o qual afirma que a organização do SOM é robusta inclusive para valores não ótimos de fatores de aprendizagem.

A fundamentação teórica da robustez do SOM em relação a variações do parâmetro de aprendizagem é confirmada por trabalhos experimentais, como, por exemplo, (SMITH; NG, 2003), que obtêm mapeamentos de dados eficientes utilizando diferentes valores de $\alpha(t)$. A estrutura proposta nesta pesquisa, entretanto, suporta mudanças, caso necessário, se a aplicação da implementação do SOM requisitar valores diferentes de potências negativas de base dois, por exemplo, pela alteração do operador sra por uma operação de multiplicação, em detrimento da quantidade de recursos consumidos do chip. Ainda, como abordado na seção 8.1, futuras execuções do sistema baseadas em aprendizado contínuo (SILVA; SANDMANN; DEL-MORALHERNANDEZ, 2008; e RUMBELL; DENHAM; WENNEKERS, 2014) podem requisitar que o circuito eletrônico que executa o SOM esteja continuamente se ajustando às informações de entrada, com alternância no fator de aprendizagem. Desta forma, em tal persistência do processo de aprendizagem, não há uma segmentação definitiva do término da fase de aprendizado e início da fase de operação, e a rede, ao processar o dado de entrada e produzir uma resposta em sua saída (segundo o mapa já construído com as informações previamente recebidas), simultaneamente refina o mapa existente. Este modo de aprendizagem/operação do SOM pode ser obtido com uma definição dinâmica de $\alpha(t)$ para lidar com fluxos de dados com flutuações, ou "concept drift" (ZLIOBAITE et al., 2014), e beneficiar futuros sistemas de construção de mapas com o processo de aprendizado dinâmico (DAI; WANG; WANG, 2014). 


\subsection{A FUNÇÃO DE VIZINHANÇA PROPOSTA E A ARITMÉTICA BINÁRIA UTILIZADA}

A função de vizinhança $h_{c_{j}}(t)$ permite que o ajuste de pesos ocorra para o neurônio vencedor e, com intensidade diminuída, para os neurônios próximos ao vencedor. Conforme apresentado na seção 3.4, esta função deve ser simétrica, decrescente, centrada no neurônio vencedor e inversamente proporcional à distância entre o neurônio vencedor e os demais neurônios da matriz de saída do SOM. Em execuções em software, tipicamente se emprega a função gaussiana para execução de $h_{c_{j}}(t)$ (KOHONEN, 2014), como, por exemplo, em Zhai et al. (2014). Seguindo a mesma direção das duas seções anteriores (4.1 e 4.2) de obter um balanceamento entre a velocidade de processamento, dissipação de energia e o consumo dos recursos disponibilizados pelo chip, uma função alternativa à função gaussiana foi elaborada para a execução de $h_{c_{j}}(t)$. Tal modificação é relevante porque permite atender às metas de restrição no consumo de energia para o embarque em aplicações móveis e o escopo de aceleração do processamento em aplicações de tempo-real de resposta, como exposto no objetivo deste trabalho. Desta forma, a multiplicação de $\alpha(t)$. $\left[\mathbf{w}_{\mathbf{j}}-\mathbf{x}_{\mathbf{i}}\right]$ pela função de vizinhança $h_{c_{j}}(t)$ existente na Equação (5) de ajuste de pesos do SOM é realizada em hardware pela expressão (10) a seguir, descrita em VHDL:

$$
\text { deltaPeso <= temp sra }(\text { distVizinhança*BETA); }
$$

na qual o operador $\underline{\text { sra }}$ indica deslocamento aritmético à direita; temp simboliza o armazenamento temporário do valor $\alpha(t) \cdot\left[\mathbf{x}_{\mathbf{i}}-\mathbf{w}_{\mathbf{j}}\right]$, conforme computado pela Equação (9); distVizinhança indica o valor de distância na grade $\operatorname{dist}(c, j)$ entre o neurônio $j$ a ser atualizado e o neurônio vencedor $c$; BETA representa o valor de abertura da função de vizinhança $h_{c_{j}}$ no instante $t$ e deltaPeso simboliza o armazenamento temporário do valor resultante da operação $\alpha(t) \cdot h_{c_{j}}(t) .\left[\mathbf{x}_{\mathbf{i}}-\mathbf{w}_{\mathbf{j}}\right], \mathbf{o}$ qual será utilizado para ajustar o vetor peso $\boldsymbol{w}_{\boldsymbol{j}}$ do neurônio segundo a Equação (5).

A operação indicada pela Equação (10) executa a seguinte expressão matemática (11) como função de vizinhança $h_{c_{j}}(t)$ : 


$$
h_{c_{j}}(t)=2^{-(\operatorname{dist}(c, j) \cdot \beta(t))}
$$

com $\operatorname{dist}(c, j)$ representando a distância na grade entre o neurônio vencedor $c$ e o neurônio $j$ a ser ajustado; e $\beta$, pertencente ao conjunto dos inteiros positivos, o coeficiente de abertura da função no instante $t$ do processo de treinamento $\left(\beta \in \mathbb{Z}_{+}\right)$. Nota-se que, aqui, $\beta(t)$ tem função similar a $\sigma(t)$ da curva gaussiana, descrita na Equação (3).

É importante ressaltar que a expressão (11) tem um comportamento semelhante à função gaussiana e, quando comparada a esta, permite um menor custo de execução em hardware. A Figura 8 exemplifica ambas as funções com variação do coeficiente de abertura, de forma a ilustrar uma progressiva redução da intensidade de ajuste dos valores dos vetores peso dos neurônios vizinhos a $c$, fator essencial à auto-organização do SOM. Destaca-se também que esta função de vizinhança alternativa proposta é simétrica, decrescente, centrada no neurônio vencedor e inversamente proporcional à distância entre o neurônio vencedor e os demais neurônios no arranjo de saída da rede, ou seja, possui as características da classe geral de funções de vizinhança que obtiveram prova de convergência quase certa a um estado final após o processo de auto-organização do SOM (FORT; PAGÈS, 1995).

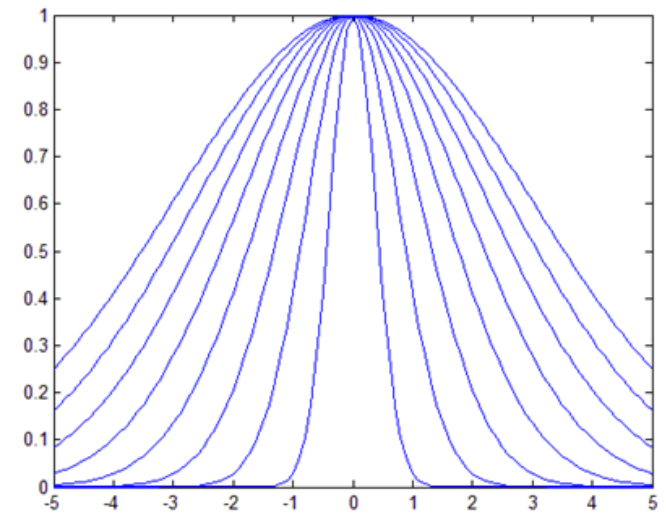

(a)

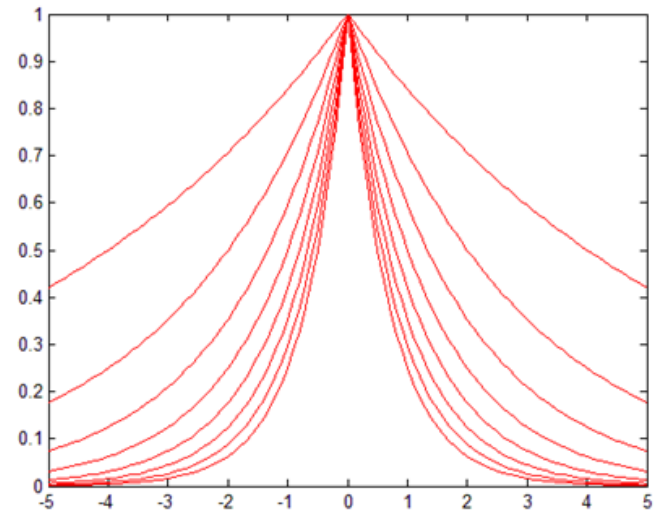

(b)

Figura 8 - Variação do coeficiente de abertura da função gaussiana (a) e da função de vizinhança $h_{c_{j}}$ proposta pela Equação 3.5 (b). O ponto central das funções corresponde à intensidade de ajuste de pesos do neurônio vencedor. O progressivo decaimento do valor das funções determina a intensidade de ajuste de pesos dos neurônios vizinhos ao vencedor (que diminui conforme a distância do ponto central). Em ambos os casos, uma curva mais aberta identifica situações de início de treinamento da rede, na qual acontece a ordenação principal dos neurônios; curvas mais fechadas correspondem ao final da fase de treino, quando ocorre o ajuste fino do vetor peso dos neurônios. 
Esta função alternativa contrasta com as funções de vizinhança empregadas em pesquisas iniciais de execução do SOM em hardware, como, por exemplo, a função retangular simples (HIKAWA, 2005 e DŁUGOSZ et al., 2011). Um comportamento semelhante ao da função apresentada é encontrado no trabalho de Hikawa e Maeda (2015). Porém, o circuito elétrico proposto pela publicação tem grande complexidade computacional e, portanto, atinge piores valores de velocidade de operação (conforme discutido em detalhes na seção 7.4 sobre a caracterização do sistema proposto). A arquitetura do circuito proposta possibilita a redução - restrita a valores binários - do coeficiente de abertura da função de vizinhança, $\beta(t)$, em taxa definida pelo usuário, a cada conjunto de iterações do processo de treinamento. $\mathrm{O}$ decaimento de $\beta(t)$ com a progressão da fase de aprendizagem ocorre, portanto, em patamares definidos pelo usuário de acordo com as características do problema ao qual o SOM está aplicado, de forma semelhante ao descrito anteriormente para $\alpha(t)$, o fator de aprendizagem (como ilustrado pela Figura 7). Ainda, da mesma forma que o fator de aprendizado, o projeto do circuito eletrônico que executa a função de vizinhança alternativa proposta prevê acesso a mecanismos para simples comutação entre coeficientes binários $\beta(t)$ de forma a permitir futuras execuções do SOM baseadas no aprendizado contínuo, na qual o SOM pode necessitar de novas ordenações para atender às mudanças que as informações processadas pelo sistema possam sofrer (conforme descrito na seção 8.1 sobre trabalhos futuros).

Assim como a maioria das pesquisas publicadas sobre a execução de diferentes arquiteturas de processamento neural em FPGA (por exemplo, ESMAEILZADEH et al., 2006; KURDTHONGMEE, 2011; ROSTRO-GONZALEZ et al., 2012), adotou-se neste trabalho operações aritméticas em ponto fixo. Esta opção tem como objetivo diminuir a complexidade dos cálculos efetuados quando comparado a operações em ponto flutuante. A diminuição da complexidade permite atingir um equilíbrio entre o consumo dos recursos disponibilizados pelo FPGA e sua velocidade de processamento/consumo de energia. Circuitos comerciais de computação neural, como o chip neuromórfico “SpiNNaker" (RAST et al., 2011), também adotam operações em ponto fixo e reportam que não há perda significativa de acurácia quando comparada a uma rede neural executada com operações em ponto flutuante (FURBER; TEMPLE, 2007). Concentrando-se nas especificidades do SOM executado em hardware, o estudo experimental de Jan Lachmair reporta que a redução da precisão com o uso de operações em ponto fixo ainda resulta em qualidade suficiente de mapeamento, 
mesmo para conjuntos de dados complexos e de alta dimensionalidade (LACHMAIR et al., 2017).

Em complemento à escolha feita neste trabalho por execução das operações em ponto fixo, o mapeamento dos vetores peso dos neurônios e dos vetores de entrada tem, como padrão, uma representação em complemento de dois (WEBER, 2012) por números binários de 16 bits. Tal opção de quantidade de bits também é comumente adotada por outros pesquisadores que estudam execuções de SOM e outras arquiteturas de redes neurais em hardware, como, por exemplo, nos trabalhos de Lo, (2010), Rostro-Gonzalez et al. (2012) e Brassai (2014). A escolha pela utilização de 16 bits se apoia em pesquisas realizadas com extensas simulações computacionais para determinação da influência da resolução de bits escolhida para representação de pesos para redes neurais aplicadas a problemas de benchmark (HOLT; BAKER, 1991; ZHU; SUTTON, 2003). A resolução de 16 bits usada para representação dos pesos também é normalmente escolhida por pesquisas que realizam prévias simulações computacionais para determinação da precisão necessária para a aplicação específica a qual o SOM está atendendo, como, por exemplo, Kim et al. (2009) e Prado et al. (2012). Entretanto, a descrição do circuito eletrônico, aqui desenvolvida, foi feita para que este parâmetro pudesse ser facilmente alterado pelo usuário, de forma possibilitar adequações às condições da aplicação em que o SOM estiver empregado.

Quanto ao emprego de operações em ponto fixo com resolução de 16 bits neste trabalho, nota-se também que o ajuste da quantidade de bits para a parte inteira e a resolução da parte decimal deve ser realizado segundo a dimensão do problema a ser mapeado. Como exemplo, realizou-se a síntese para FPGA da função de vizinhança proposta pela expressão (11) com 1 bit de sinal, 1 bit para representação da parte inteira e 14 bits para representação da parte decimal, ou seja, utilizou-se o formato Q1.14 com sinal (HUSSAIN; PARVIN, 2016). Para este processo de síntese, usou-se a ferramenta ISE da Xilinx (ALUR et al., 2007), a qual também gera relatórios com os resultados do processo de implementação em FPGA. O objetivo deste experimento é oferecer uma dimensão de escala quando a função proposta é comparada com a curva gaussiana, normalmente utilizada com função de vizinhança em execuções do SOM em software. Os dados obtidos estão descritos Tabela 5. 
Tabela 5 - Comparação da área ocupada no chip e da velocidade de operação entre a curva gaussiana e a função de vizinhança alternativa proposta pela expressão (11), segundo os resultados de síntese fornecidos pela plataforma ISE.

\begin{tabular}{|c|c|c|c|}
\hline \multicolumn{2}{|c|}{$\begin{array}{l}\text { Funções de vizinhança } \\
\text { executadas em FPGA }\end{array}$} & Função gaussiana & $\begin{array}{l}\text { Função alternativa } \\
\text { proposta (eq. (11)) }\end{array}$ \\
\hline Caracterização & & $\begin{array}{l}\text { Operações em ponto flutuante } \\
\text { com biblioteca FLOPOCO de } \\
\text { De Dinechin e Pasca (2011) }\end{array}$ & $\begin{array}{c}\text { Operações em ponto fixo e } \\
\text { dados no formato Q1.14 } \\
\text { com sinal }\end{array}$ \\
\hline Área ocupada & LUTs & 1036 & 258 \\
\hline do FPGA & Slices & 689 & 145 \\
\hline $\begin{array}{l}\text { Frequência de } \\
\text { operação }\end{array}$ & $\mathrm{MHz}$ & 88 & 450 \\
\hline
\end{tabular}

Pela Tabela 5 de comparação entre as execuções em FPGA das diferentes funções de vizinhança, pode-se perceber que a curva gaussiana consome entre 4 e 5 vezes mais recursos do chip e que sua velocidade de operação é aproximadamente 5 vezes mais lenta que a função proposta pela Equação (11).

A próxima seção apresenta o resumo e a formalização das propriedades computacionais já discutidas neste capítulo.

\subsection{OS ALGORITMOS DE TREINAMENTO E OPERAÇÃO DO SOM EM FPGA PROPOSTOS E SUAS CARACTERÍSTICAS COMPUTACIONAIS}

Com o objetivo de resumir as propriedades de execução do SOM em hardware apresentadas neste capítulo, a Tabela 6 contém o algoritmo de treinamento da rede e a Tabela 7 contém o seu algoritmo de operação. As propriedades computacionais dos algoritmos a serem implementados no FPGA, discutidas neste capítulo, estão resumidas pela Tabela 8 . 
Tabela 6 - Algoritmo de treinamento do SOM em hardware.

I. Configuração inicial do SOM:

a. Definição da dimensão $n$ do espaço vetorial de entrada e da dimensão $d$ do espaço matricial de saída SOM;

b. Definição da quantidade $J$ de neurônios da rede, do formato da grade do mapa (quantidade de neurônios por linha e coluna, por exemplo) e do formato da grade de vizinhança (retangular ou hexagonal, por exemplo);

c. Inicialização aleatória de cada vetor peso $\mathbf{w}_{\mathbf{j}}$ e inicialização de $t=0$;

d. Definição do número de iterações do processo de treinamento $T$, tal que $T>I$ (com $I$ indicando a quantidade de dados do conjunto de treinamento);

II. Repetir:

a. Repetir:

i. Admissão aleatória de um vetor de entrada $\mathbf{x}_{\mathbf{i}}$ pela rede;

ii. Cálculo da distância de Manhattan $d_{\text {manh }}$ para todo $j \operatorname{com} 1 \leq j \leq J$ :

$$
d_{m a n h}=\left(\sum_{n=1}^{N}\left|\boldsymbol{x}_{\boldsymbol{i}}^{\boldsymbol{n}}-\boldsymbol{w}_{\boldsymbol{j}}^{\boldsymbol{n}}\right|\right)
$$

iii. Determinação do neurônio vencedor $c=\arg \min _{j} d_{\operatorname{manh}}\left(\mathbf{w}_{\mathbf{j}}, \mathbf{x}_{\mathbf{i}}\right)$;

iv. Ajuste dos vetores peso do neurônio vencedor $c$ e dos neurônios pertencentes à região de vizinhança do neurônio vencedor $c$ :

$$
\begin{gathered}
\boldsymbol{w}_{\boldsymbol{j}}(t+1)=\boldsymbol{w}_{\boldsymbol{j}}(t)+\left[\mathbf{x}_{\mathbf{i}}-\mathbf{w}_{\mathbf{j}}\right] \underline{\boldsymbol{s r a}}\left(\alpha(t)+h_{c_{j}}(t)\right) ; \\
\operatorname{com} h_{c_{j}}(t)=2^{-(\operatorname{dist}(c, j) \cdot \beta(t))}, \quad \alpha \in \mathbb{Z}_{+} \text {e } \beta \in \mathbb{Z}_{+}
\end{gathered}
$$

até que o conjunto de $I$ amostras seja todo admitido pela rede.

b. Incremento de $t$

até que $t=T$. 
Tabela 7 - Algoritmo de operação do SOM em hardware.

a. Configuração do SOM: definir os vetores peso $\mathrm{w}_{\mathrm{j}}$ com os valores obtidos ao final da fase de treinamento.

b. Repetir:

c. Admissão do um vetor de entrada $\mathbf{x}_{\mathbf{i}}$ pela rede;

d. Cálculo da distância de Manhattan $d_{\text {manh }}$ para todo $j \operatorname{com} 1 \leq j \leq J$ :

$$
d_{m a n h}=\left(\sum_{n=1}^{N}\left|\boldsymbol{x}_{\boldsymbol{i}}^{\boldsymbol{n}}-\boldsymbol{w}_{\boldsymbol{j}}^{\boldsymbol{n}}\right|\right)
$$

e. Determinação do neurônio vencedor $c=\arg \min _{j} d_{\operatorname{manh}}\left(\mathbf{w}_{\mathbf{j}}, \mathbf{x}_{\mathbf{i}}\right)$;

f. Apresentar à saída o índice $j$ do neurônio vencedor $c$ ou a categoria representada por $c$.

até que o conjunto de $I$ amostras seja todo admitido pela rede.

Com direção alinhada pelo experimento inicial sobre a implementação de funções de vizinhança apresentado na seção 4.3, diferentes modelos de execução completa das fases de aprendizado e operação SOM em FPGA foram desenvolvidos, de modo que se suas características de funcionamento fossem obtidas experimentalmente. Em todos os modelos de execução - que serão discutidos na próxima seção - foram utilizadas as escolhas das propriedades de computação em hardware que esta seção fundamentou, as quais estão resumidas na Tabela 8 .

Tabela 8 - Propriedades utilizadas na computação do SOM em FPGA.

\section{Métrica de similaridade Distância de Manhattan}

Fator de aprendizagem Deslocamento aritmético binário para direita

$h_{c_{j}}(t)=2^{-(\operatorname{dist}(c, j) \cdot \beta(t))}$

Função de vizinhança $\quad \operatorname{com} \operatorname{dist}(c, j)$ para a distância na grade para o neurônio vencedor $c$; e $\beta(t)$ para abertura da função.

Aritmética binária Ponto fixo

Resolução de representação 16 bits em complemento de dois 


\subsection{A QUANTIDADE DE CONEXÕES NEURAIS AJUSTADAS POR SEGUNDO COMO MÉTRICA DE VELOCIDADE DE APRENDIZAGEM}

Para que seja possível referenciar a capacidade de processamento de sistemas neurais, utiliza-se a unidade de medida CUPS (em inglês, "Connection Updates Per Second") como métrica de velocidade. Tal unidade mensura a quantidade de ajustes que a rede neural artificial executa, por segundo, nos pesos de seus neurônios durante o seu processo de treinamento. A unidade de medida CUPS é considerada padrão nas pesquisas sobre a execução de redes neurais em hardware e é adotada como unidade de comparação em diversas publicações, como, por exemplo, nos trabalhos de Hikawa (2005), Lo (2010), Długosz et al. (2011), Abadi et al. (2016), Huang et al. (2017) e Lachmair et al. (2017). O cálculo da velocidade de operação do sistema, identificado aqui como $V_{s}$, pode ser obtido segundo a Equação (12).

$$
V_{s}[C U P S]=\frac{F_{m} \cdot J_{m} \cdot N_{m}}{C_{c l o c k}}
$$

com $F_{m}$ denotando a frequência máxima de clock do circuito e $J_{m}$, a quantidade de neurônios que possuem seu vetor peso, de dimensão $N_{m}$, ajustado por $C_{c l o c k}$ ciclos de trabalho.

O presente trabalho também emprega esta unidade de medida como uma das ferramentas de avaliação da execução do SOM. O capítulo 5 utiliza a métrica CUPS para uma das comparações realizadas entre os diferentes modelos propostos para implementação em FPGA. Por fim, no capítulo 7, a unidade de medida também é usada para caracterização do arquitetura de circuito proposta em relação a diversos trabalhos publicados na literatura. 


\section{DESENVOLVIMENTO DA ARQUITETURA DE CIRCUITO E DOS COMPONENTES BÁSICOS}

Após a realização da pesquisa, desenvolvimento e experimentação preliminar das propriedades de computação do SOM diretamente em hardware (capítulo 4), o presente capítulo discute a investigação realizada sobre os diferentes modelos de processamento que podem ser empregados para sua execução e apresenta detalhes dos componentes e circuitos básicos implementados em FPGA (seções 5.2, 5.3 e 5.4). O capítulo apresenta, também, o conjunto de experimentos utilizados para se coletar informações e caracterizar o comportamento dos modelos (seção 5.5) e, assim, direcionar a continuação da pesquisa (seção 5.6). Ao final do capítulo, após a opção por um dos circuitos eletrônicos elaborados (feita com base nos resultados dos experimentos), apresenta-se a primeira aplicação da arquitetura de circuito para execução do SOM. Nesta aplicação, a implementação desenvolvida é utilizada no processamento de sinais de telecomunicações sob duas diferentes demandas: dados com comportamento estático (seção 5.8) e com características dinâmicas (seção 5.9).

\subsection{POSSÍVEIS MODELOS DE EXECUÇÃO DO SOM EM FPGA}

Há diferentes modelos realizáveis em FPGA que permitem uma execução do SOM e que estão de acordo com a teoria que define este formalismo de computação neural.

O primeiro modelo desenvolvido nesta pesquisa opera pela difusão de informações entre blocos idênticos de processamento, chamados de neurônios, e não possui nenhum bloco central com função de realizar supervisão ou controle dos demais blocos. Tal modelo, identificado aqui como modelo distribuído, alcança um comportamento global de auto-organização dos neurônios apenas pela troca de dados local entre os blocos neurônios vizinhos. Cada bloco neurônio recebe unicamente o vetor de entrada $\boldsymbol{x}_{\boldsymbol{i}}$ e o sinal de clock, realiza internamente uma sequência de passos computacionais e se comunica com outros blocos idênticos imediatamente ao seu redor (do ponto de vista da grade de saída do SOM). O funcionamento global deste primeiro modelo distribuído, em conjunto com a sequência de passos computacionais internas dos neurônios, será detalhado na seção 5.2. 
O segundo modelo de execução do SOM desenvolvido nesta pesquisa possui um bloco central para controle dos sinais de operação da rede. O bloco central tem por função distribuir sinais de controle para os demais blocos computacionais que compõem o modelo. Este modelo, em contraponto ao modelo distribuído, é chamado de modelo centralizado. A seção 5.3 descreve a arquitetura do modelo centralizado e seu funcionamento.

Por fim, o último modelo desenvolvido para execução do SOM é chamado de modelo híbrido, e possui características dos outros dois modelos - centralizado e distribuído. O objetivo da criação deste modelo é possibilitar o estudo comparativo das características de centralização e de difusão dos dados processados. O modelo híbrido está detalhado na seção 5.4 .

As três arquiteturas de computação neural aqui descritas possuem as propriedades de computação do SOM em hardware descritas no capítulo 4. Além disso, todas as arquiteturas permitem a execução em chip do algoritmo de treinamento sequencial apresentado na Tabela 3. A escolha pelo treinamento sequencial, ao invés da opção pelo treinamento por batelada, foi feita porque permite uma maior orientação a aplicações futuras do sistema embarcado, as quais podem requisitar o processamento de fluxos de dados, de forma semelhante à aplicação preliminar, apresentada na seção 5.8. Além disso, a característica apontada por Fort; Letremy e Cottrell (2005) do algoritmo de treinamento por batelada sobre sua forte dependência da inicialização dos valores dos vetores peso do SOM - conforme a comparação apresentada na seção 3.4 - possui um maior alinhamento com ambientes de repetição de ensaios executados em software com múltiplas variações dos pesos iniciais da rede.

\subsection{MODELO DISTRIBUÍDO DE EXECUÇÃO DO SOM}

O conceito principal utilizado no desenvolvimento deste modelo de execução em hardware foi a elaboração de um processamento descentralizado para a computação do SOM. Desta forma, os cálculos envolvidos no algoritmo de treinamento da rede são feitos pela difusão de informação entre blocos de circuitos idênticos, interligados entre si, conforme ilustra a Figura 9. 


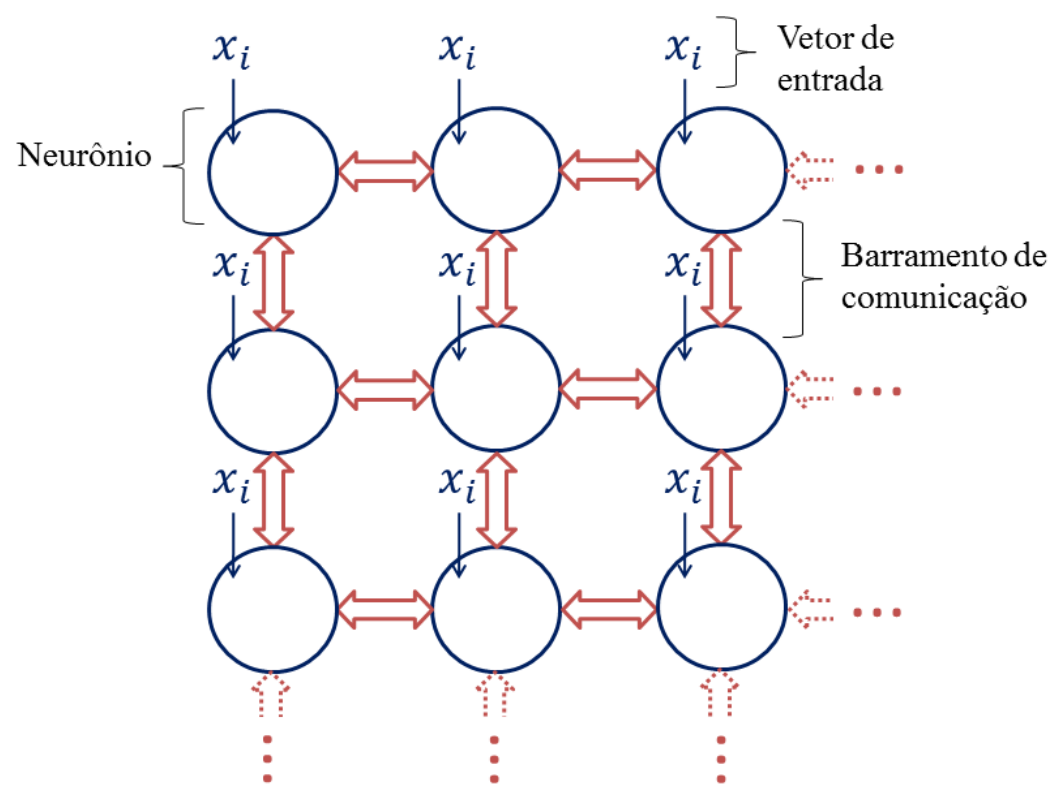

Figura 9 - Conceituação do modelo distribuído do SOM: ilustração de 9 unidades de processamento identificadas como neurônios, as interconexões entre elas e o com o vetor de dados de entrada $\boldsymbol{x}_{\boldsymbol{i}}$.

A motivação para se desenvolver este modelo distribuído de processamento está indicada em trabalhos de Długosz, Kolasa e Szulc (2011), Azuma e Hikawa (2014) e Rodriguez, Miramond e Granado (2015), que argumentam em favor de uma estrutura descentralizada de processamento do SOM em hardware. A principal justificativa para esta argumentação é evitar o retrabalho de projeto de uma unidade de controle de acordo com as alterações das configurações de rede, como, por exemplo, a quantidade total de neurônios do mapa ou o arranjo da grade de saída da rede.

A Figura 9 ilustra o conceito do modelo distribuído elaborado neste trabalho. Um neurônio (representado na figura por círculos azuis) é uma unidade macro de processamento compreendendo, internamente, um conjunto de blocos computacionais menores. Cada neurônio está conectado à entrada SOM (vetor de dados $\boldsymbol{x}_{\boldsymbol{i}}$ ) e aos quatro neurônios vizinhos imediatos. O barramento de comunicação que liga dois neurônios adjacentes é bidirecional (representado por setas duplas vermelhas). Nota-se que, além das unidades neuronais, não há outro bloco computacional na arquitetura proposta; nenhuma outra unidade para processar informações, gerenciar sinais de controle, reunir ou fornecer dados para os neurônios. Além do vetor de entrada $\left(\boldsymbol{x}_{\boldsymbol{i}}\right)$, o único sinal global distribuído para todos os neurônios é o clock do circuito.

Conforme ilustrado na Figura 10, cada unidade de processamento identificada como neurônio possui quatro blocos básicos de computação: "cálculo da distância", 
"menor de 5 distâncias", "distância de vizinhança" e "ajuste do vetor peso". A descrição desses blocos de computação, a função do barramento de comunicação e a forma como os neurônios do modelo de processamento distribuídos executam o algoritmo de aprendizado SOM no FPGA são discutidas a seguir.

Bloco de cálculo de distância: A Figura 10 representa os blocos computacionais dentro de um único neurônio, destacando o bloco de cálculo da distância. Este bloco calcula a distância de Manhattan $\left(d_{j}\right)$ entre o vetor de entrada $\left(\boldsymbol{x}_{\boldsymbol{i}}\right)$ e o vetor de peso correspondente ao neurônio representado $\left(\boldsymbol{w}_{\boldsymbol{j}}\right)$. A justificativa pela opção da distância de Manhattan como métrica de similaridade está detalhada na seção 4.1, e esta computação é realizada nas fases de aprendizagem e de operação da rede. Cada neurônio no sistema contém um bloco de cálculo de distância, que permite, portanto, que a computação de similaridade com o vetor de entrada seja executado simultaneamente em toda a rede. Também como discutido na seção 4.3 sobre as propriedades computacionais do SOM em hardware, cada componente do vetor de entrada $\left(\boldsymbol{x}_{\boldsymbol{i}}\right)$ e dos vetores peso $\left(\boldsymbol{w}_{\boldsymbol{j}}\right)$ são representados, internamente do FPGA, por 16 bits em complemento de dois e a aritmética é computada em ponto fixo. O valor da distância resultante $\left(d_{j}\right)$ é propagado dentro do neurônio para o bloco subsequente, chamado "menor de 5 distâncias", de forma a ativar seu funcionamento.

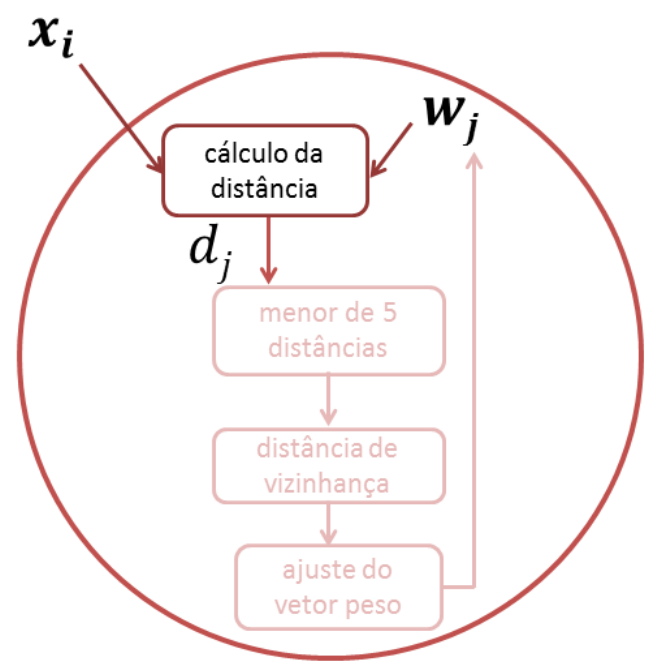

Figura 10 - Os quatro blocos de computação básicos, internos a uma unidade de processamento (neurônio) do modelo distribuído. A ilustração enfatiza o bloco de cálculo de distância.

Bloco menor de 5 distâncias: Conforme ilustrado na Figura 11, o segundo bloco computacional dentro de uma unidade de neurônio é identificado como o bloco "menor de 5 distâncias". Este bloco recebe, como entradas, o valor de distância $\left(d_{j}\right)$ calculado 
pelo bloco anterior e os resultados de distância calculados pelos neurônios vizinhos imediatos $\left(d_{h}, d_{i}, d_{k}\right.$ e $\left.d_{l}\right)$. O bloco compara estes cinco valores e propaga o menor dentre eles $\left(c_{j}\right)$. A propagação é feita tanto internamente, para o próximo bloco "distância de vizinhança", quanto externamente, para os quatro vizinhos imediatos do neurônio em questão. Desta forma, o valor $c_{j}$, computado por um neurônio, é usado como entrada para os blocos "menor de 5 distâncias" que compõem os neurônios circundantes. A propagação local do menor valor de distância entre neurônios vizinhos se difunde pelos barramentos de comunicação de toda a rede e permite que se encontre o menor valor global. Essa condição é alcançada quando todos os neurônios da rede convergem para o mesmo valor $c_{j}$, que é a mínima distância entre os vetores peso $\boldsymbol{w}_{\boldsymbol{j}} \mathrm{e}$ o vetor de entrada $\boldsymbol{x}_{\boldsymbol{i}}$. Portanto, pode-se verificar que o cálculo da Equação (1), apresentada na seção 3.4, é realizado por um processamento distribuído, pois o valor do vetor peso mais semelhante ao vetor de entrada é encontrado por um processo de difusão sem o uso de uma unidade central para reunir e comparar os valores de distância de todos os neurônios na rede. Tal processo é válido para as fases de treinamento e operação do SOM.

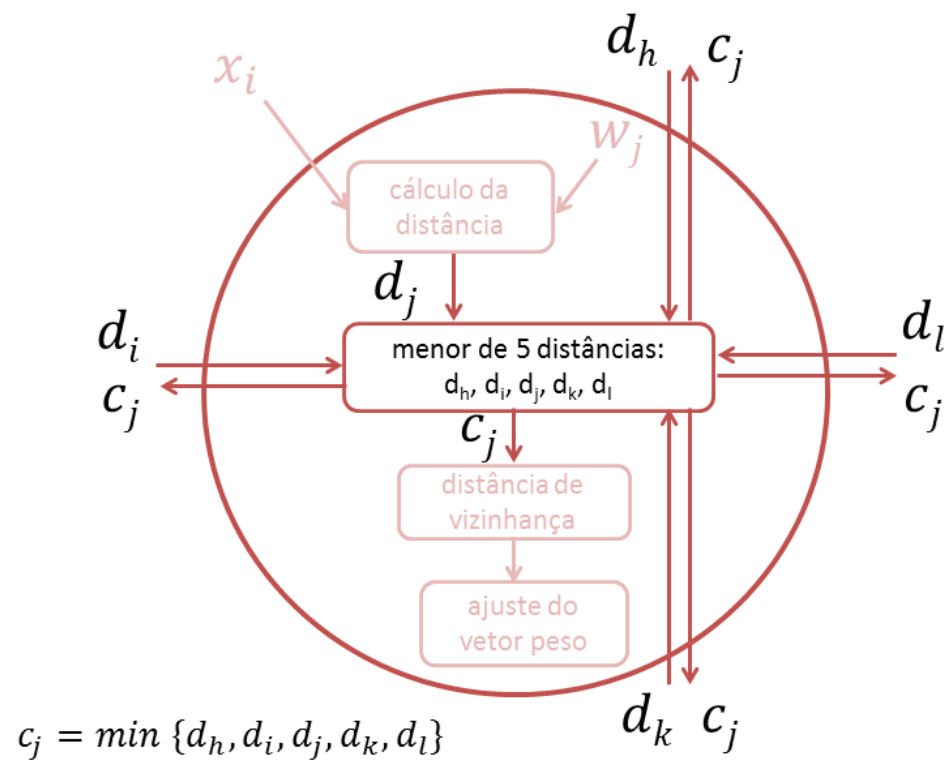

Figura 11 - Destaque para o bloco "menor de 5 distâncias" (interno a uma unidade neuronal) e suas conexões. O bloco recebe como entrada os sinais externos $d_{h}, d_{i}, d_{k}$ e $d_{l}$, com os valores de distância dos 4 neurônios vizinhos; e o valor interno $\left(d_{j}\right)$ calculado pelo bloco anterior. $\mathrm{O}$ resultado da comparação, simbolizado por $c_{j}$, é propagado tanto para o bloco de distância de vizinhança (interno), quanto para os neurônios circundantes. 
Bloco distância de vizinhança: A Figura 12 ilustra o bloco "distância de vizinhança" e seus sinais de entrada e de saída. O processamento realizado por todo o conjunto de tais blocos, interconectados pelo barramento de comunicação, é computar o valor distância - $\operatorname{dist}(c, j)$ - entre o neurônio vencedor $c$ e todos os outros neurônios, na grade de saída da rede. Estes valores são empregados apenas durante o processo de treinamento no cálculo da função de vizinhança $h_{c_{j}}(t)$. O neurônio vencedor, cujo vetor peso é o mais semelhante ao vetor de entrada, é identificado como distância ' 0 '. Este valor é incrementado em uma unidade conforme a distância na grade do neurônio para o neurônio vencedor. Desta forma, os quatro neurônios vizinhos imediatos do neurônio vencedor possuem distância '1', os seguintes, '2', e assim por diante. A Figura 13 ilustra uma possível configuração do processo de indexação de vizinhança em torno do neurônio $c$, ou seja, o neurônio que, neste instante do processo de treinamento, possui maior similaridade com a amostra admitida na entrada da rede neural. A Figura 13 apenas exemplifica dois níveis em torno de $c$.

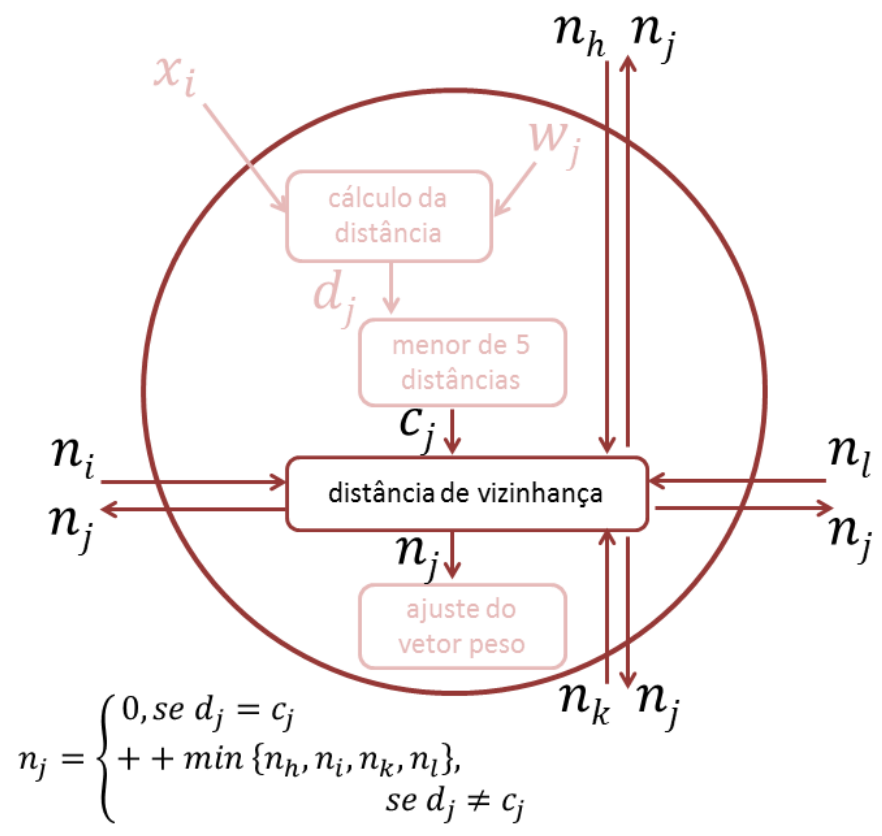

Figura 12 - Bloco "distância de vizinhança" (interno a uma unidade neuronal) e suas conexões. Os sinais $n_{j}, n_{h}, n_{i}, n_{k}$ e $n_{l}$, contêm, respectivamente, o valor de distância do neurônio ilustrado e os quatro valores de distância dos neurônios ao seu redor. O sinal $n_{j}$ também é propagado internamente para o bloco de ajuste do vetor peso do neurônio.

Similarmente ao processo de busca pelo neurônio vencedor, o modelo distribuído proposto também computa os valores de distância de vizinhança para todos os neurônios da rede sem o emprego de uma unidade de controle central. A alocação 
destes valores também é realizada por um processo de difusão, pela conexão local entre os blocos dos neurônios de forma semelhante ao bloco "menor de 5 distâncias" descrito anteriormente. A Figura 14 detalha o barramento de comunicação completo entre dois neurônios, com os sinais de conexão dos blocos "distância de vizinhança" e "menor de 5 distâncias".

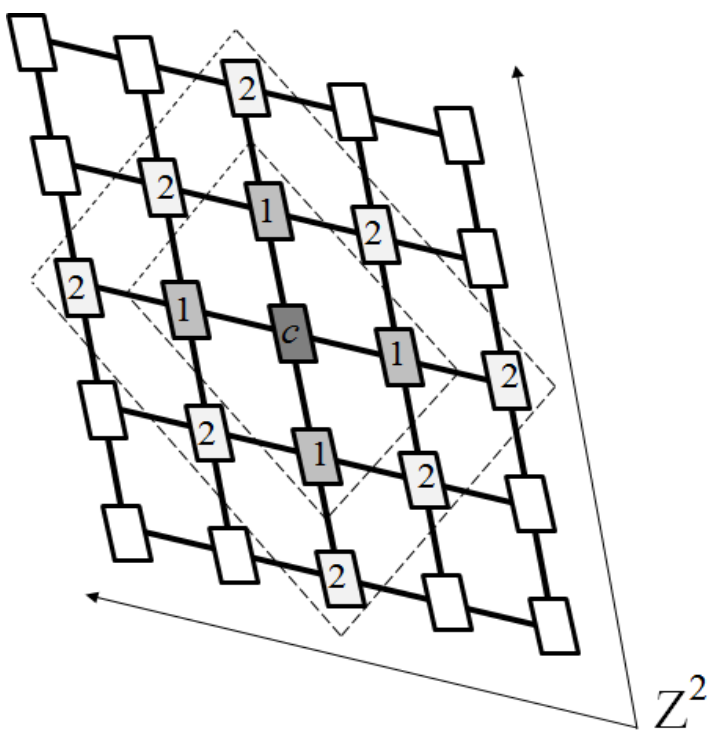

Figura 13 - Exemplo de uma possível configuração de distância de vizinhança em torno do neurônio vencedor $c$. A figura ilustra apenas a primeira e segunda região de vizinhança.

O bloco "distância de vizinhança" cujo valor de distância para entrada $\left(d_{j}\right)$ é igual ao valor de distância mínima em toda a rede $\left(c_{j}\right)$, define seu valor de saída no barramento de comunicação - distância de vizinhança $\left(n_{j}\right)$ - como ' 0 ', e desencadeia a propagação desse valor para os neurônios circundantes. Como entrada deste bloco computacional, cada neurônio recebe os quatro valores $\left(n_{h}, n_{i}, n_{k}\right.$ e $\left.n_{l}\right)$ de distância de vizinhança dos neurônios adjacentes e os compara para encontrar o menor, empregando, para tal, uma estrutura de hardware semelhante à usada no bloco anterior. Desta forma, para todos os neurônios, exceto o vencedor, o valor de distância de vizinhança $\left(n_{j}\right)$ é definido como o incremento unário do menor índice circundante. Logo, a computação realizada pelo bloco "distância de vizinhança”, pode ser descrito pela expressão (13):

$$
n_{j}=\left\{\begin{array}{l}
0, \text { se } d_{j}=c_{j} \\
++\min \left\{n_{h}, n_{i}, n_{k}, n_{l}\right\}, \text { se } \quad \neq c_{j}
\end{array}\right.
$$


com $n_{j}$ representando o valor de distância de vizinhança em relação ao neurônio vencedor - $\operatorname{dist}(c, j)$ - para o neurônio $j$ em questão. $\mathrm{O}$ índice $d_{j}$ denota o valor de distância entre o vetor peso do neurônio e o vetor de entrada, e $c_{j}$, o valor mínimo de distância para o vetor de entrada entre todos os vetores peso da rede. Os índices $n_{h}, n_{i}$, $n_{k}$ e $n_{l}$ representam os valores de distância de vizinhança dos quatro neurônios circundantes. Assim, o cálculo executado pelo bloco, associado às conexões locais aos neurônios vizinhos, permite a determinação das distâncias de vizinhança por um processo incremental difundido por toda a rede.

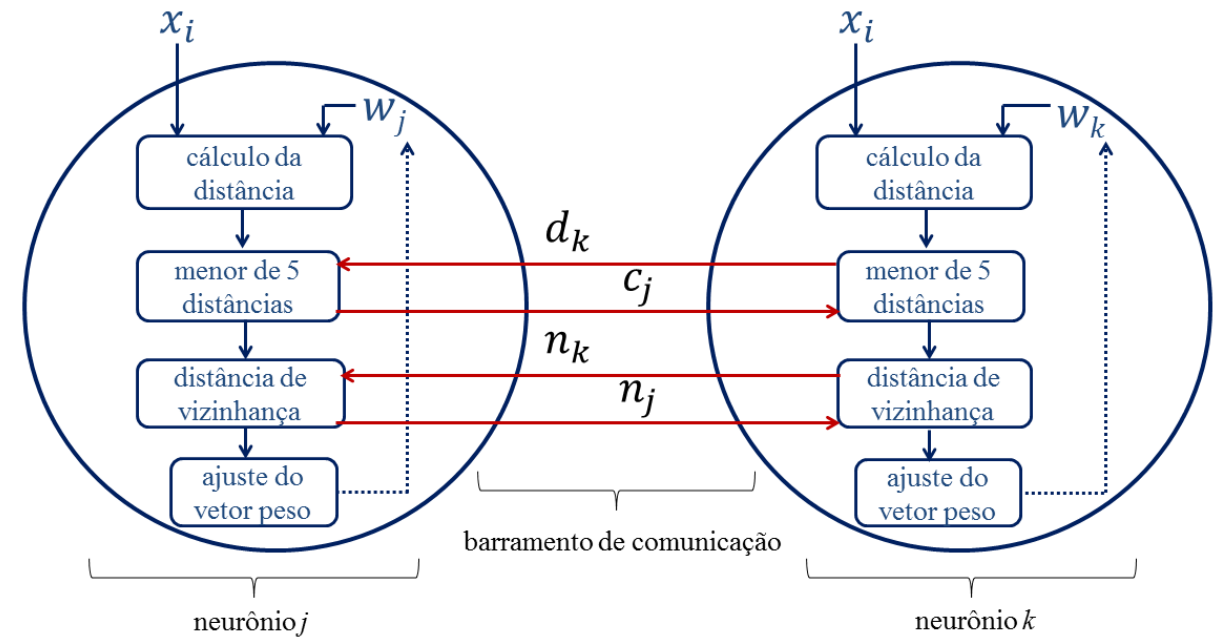

Figura 14 - Barramento de comunicação entre dois neurônios do modelo distribuído. Os sinais transmitidos apenas localmente entre os blocos "menor de 5 distâncias" e "distância de vizinhança" permitem que a rede realize o processo de auto-organização global da rede.

No caso excepcional em que há mais de um neurônio com valor de distância igual para o vetor de entrada e tal valor é o menor da rede inteira, há uma alocação de distância de vizinhança ' 0 ' para todos os neurônios vencedores. Novamente, os neurônios adjacentes aos vencedores recebem ' 1 ' como seus valores de vizinhança $\left(n_{j}\right)$. A identificação do menor índice de vizinhança inserido a partir de neurônios adjacentes permite uma justaposição correta de valores de índice por toda a rede.

Bloco de ajuste do vetor peso: A última etapa computacional realizada na fase de aprendizagem do SOM é a atualização dos pesos. A Figura 15 mostra o bloco responsável por atualizar o peso do neurônio $w_{j}$ de acordo com o sinal de entrada $n_{j}$ no modelo distribuído. Este sinal indica o valor distância de vizinhança $-\operatorname{dist}(c, j)-$ para o neurônio vencedor $c$, e é utilizado na execução da função de vizinhança $h_{c_{j}}(t)$. 
Conforme discutido na seção 4.3, a multiplicação pela função de vizinhança $h_{c_{j}}(t)$, na Equação (5) é executada por uma operação binária de deslocamento aritmético à direita. Portanto, o índice $n_{j}$ define, diretamente, quantas vezes a operação de deslocamento é executada internamente no bloco. Esta operação é realizada para cada uma das componentes do vetor peso do neurônio, de forma a permitir o ajuste de seu novo valor.

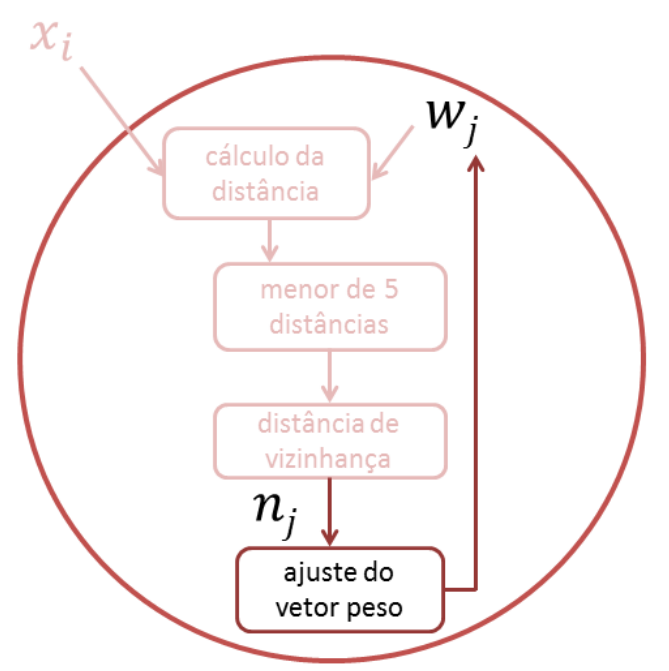

Figura 15 - Unidade de processamento da rede (neurônio) com destaque para o bloco computacional interno "ajuste do vetor peso".

O modelo distribuído para execução do SOM em FPGA, apresentado nessa seção, foi publicado no IJCNN 2017 - International Joint Conference on Neural Networks do IEEE (SOUSA; DEL-MORAL-HERNANDEZ, 2017a) e o Apêndice A contém o código VHDL para que o modelo distribuído possa ser sintetizado e implementado em FPGA por uma plataforma de projetos de circuitos digitais, como, por exemplo, o ISE (ALUR et al., 2007) ou o Vivado (CHURIWALA, 2016), da Xilinx.

\subsection{MODELO CENTRALIZADO DE EXECUÇÃO DO SOM}

O segundo modelo de execução desenvolvido é identificado como centralizado, em oposição ao modelo distribuído exposto na seção anterior 5.2. A Figura 16 contém o diagrama de blocos do modelo centralizado, com suas subdivisões ilustradas por cores: verde para os blocos de cálculo de distância, laranja para o circuito de busca pelo neurônio vencedor, rosa para o circuito de controle do processo de atualização dos pesos e azul para os blocos de ajuste do vetor peso dos neurônios. 


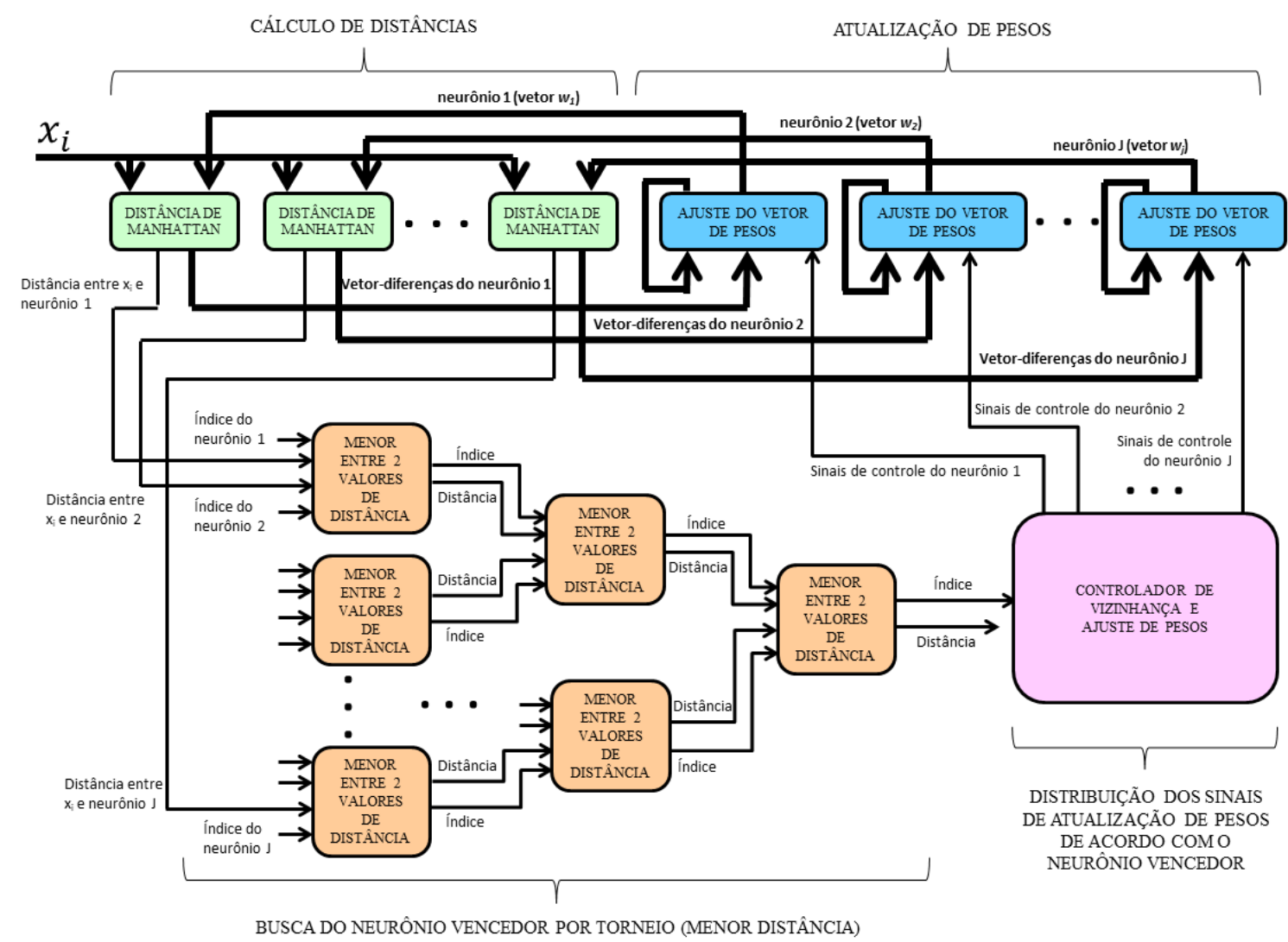

Figura 16 - Diagrama de blocos completo do modelo centralizado de processamento do SOM.

Conforme a Figura 16, o vetor de entrada $\boldsymbol{x}_{\boldsymbol{i}}$ é admitido na rede pelos blocos de computação de distância, que executam o cálculo de similaridade com os vetores peso $\boldsymbol{w}_{\boldsymbol{j}}$ dos neurônios. Estes blocos operam paralelamente, de forma a computar simultaneamente o valor de distância para toda a rede. Figura 17 contém o circuito interno de um destes blocos de cálculo de distância.

Além do paralelismo no cálculo de distância para todos os neurônios, pela Figura 17 pode-se perceber que o bloco computa também paralelamente as subtrações entre cada elemento do vetor de entrada e cada elemento do vetor peso. Em seguida, as operações de módulo e a soma de todos os valores são executadas. Desta forma, cada bloco apresenta, em sua saída, o valor de distância do neurônio - $\operatorname{dist}(c, j)$ - e o vetor de diferenças $\boldsymbol{d i} \boldsymbol{f}_{\boldsymbol{j}}$ que será utilizado como sinal do conjunto de entradas do bloco de ajuste de pesos. As opções pela distância de Manhattan e resolução padrão de representação de dados por 16 bits estão discutidas nas seções 4.1 e 4.3. A computação paralela dos blocos de cálculo de distância tem função de favorecer a velocidade de processamento do SOM, conforme o apresentado como objetivo deste trabalho. 


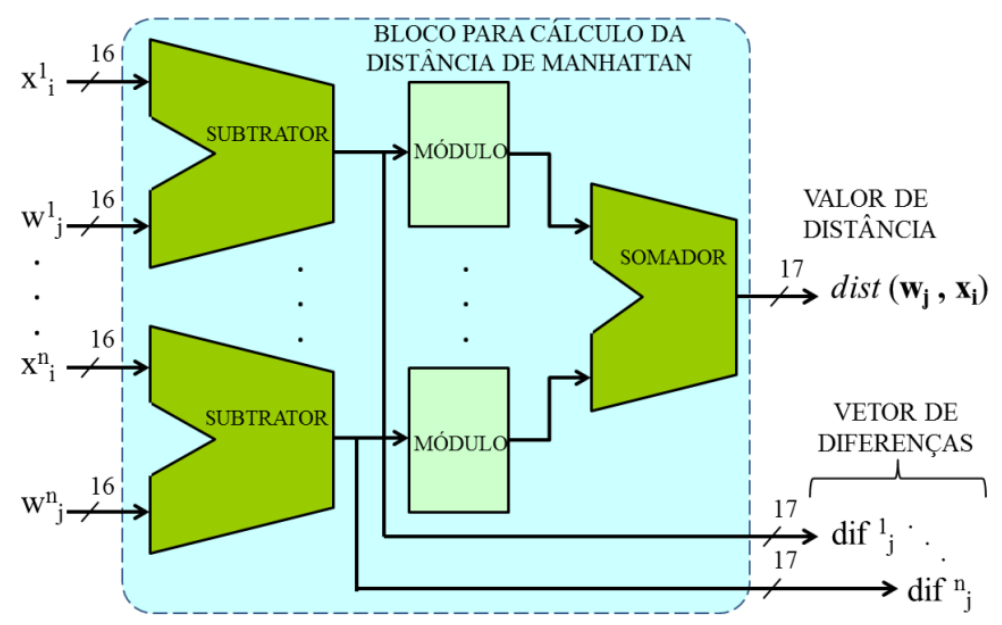

Figura 17 - Circuito interno do bloco de cálculo de distância de Manhattan.

A operação subsequente é realizada pelo circuito de busca do neurônio vencedor $c$, o qual é ilustrado em cor laranja na Figura 16. Este circuito é responsável por determinar o neurônio que possui o vetor de pesos mais similar ao vetor de entrada, e deve, para tanto, buscar pelo menor valor dentre todos os resultados de distância calculados pelo estágio anterior. No modelo centralizado, a arquitetura de processamento elaborada para esta busca é do tipo "torneio", de forma a eliminar, progressivamente, os maiores valores de distância por sucessivas comparações. A arquitetura é composta por blocos idênticos, agrupados em uma disposição do tipo "árvore”, que apresentam em sua saída o menor dos valores de suas entradas, conforme ilustrado de forma simplificada pela Figura 18.

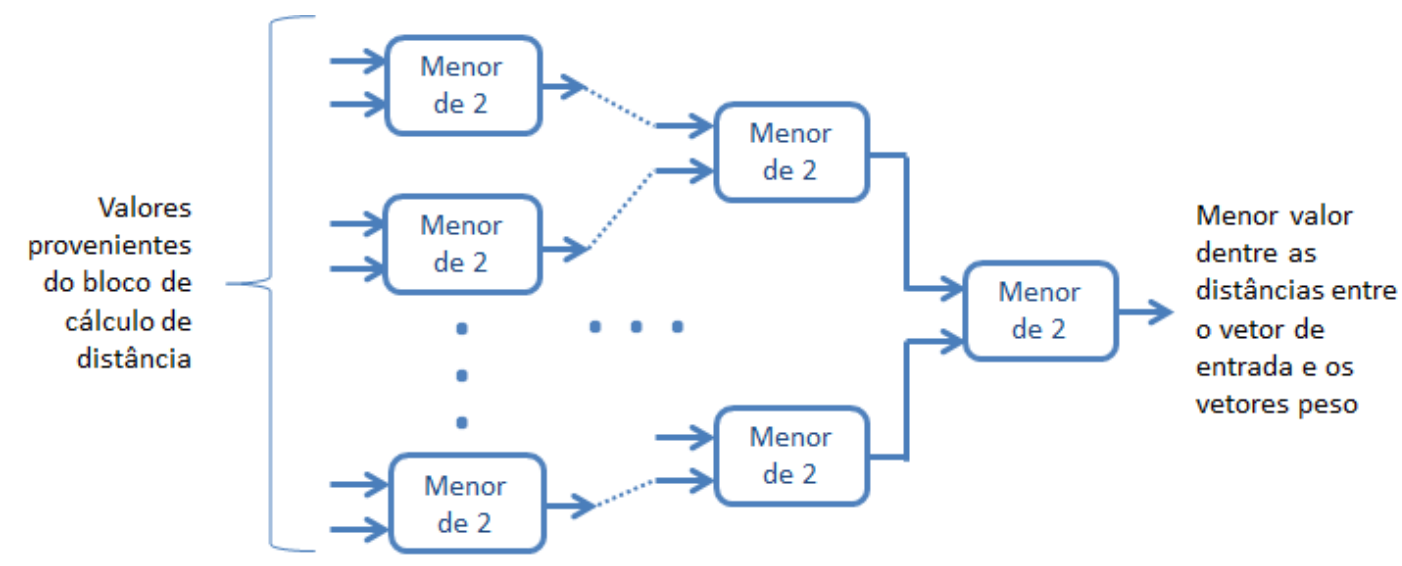

Figura 18 - Arquitetura de torneio para busca progressiva do menor valor de distância pertencente ao modelo centralizado de execução do SOM. 
Diversas pesquisas sobre a execução de SOM em hardware encontradas na literatura utilizam uma arquitetura do tipo árvore nesta procura pelo menor valor (por exemplo, Hikawa, 2005; Kurdthongmee, 2011; Appiah et al., 2012). O circuito de torneio empregado no modelo centralizado foi elaborado de forma a poder ser alterado para acomodar mudanças no SOM, como a quantidade de neurônios do mapa e a dimensão dos vetores peso. Nota-se que o circuito de torneio deve receber todos os valores de distância - que foram computados pelo estágio anterior - simultaneamente. A Figura 19, na sequência, ilustra de forma simplificada a conexão do primeiro e segundo estágios de computação do SOM do modelo centralizado.

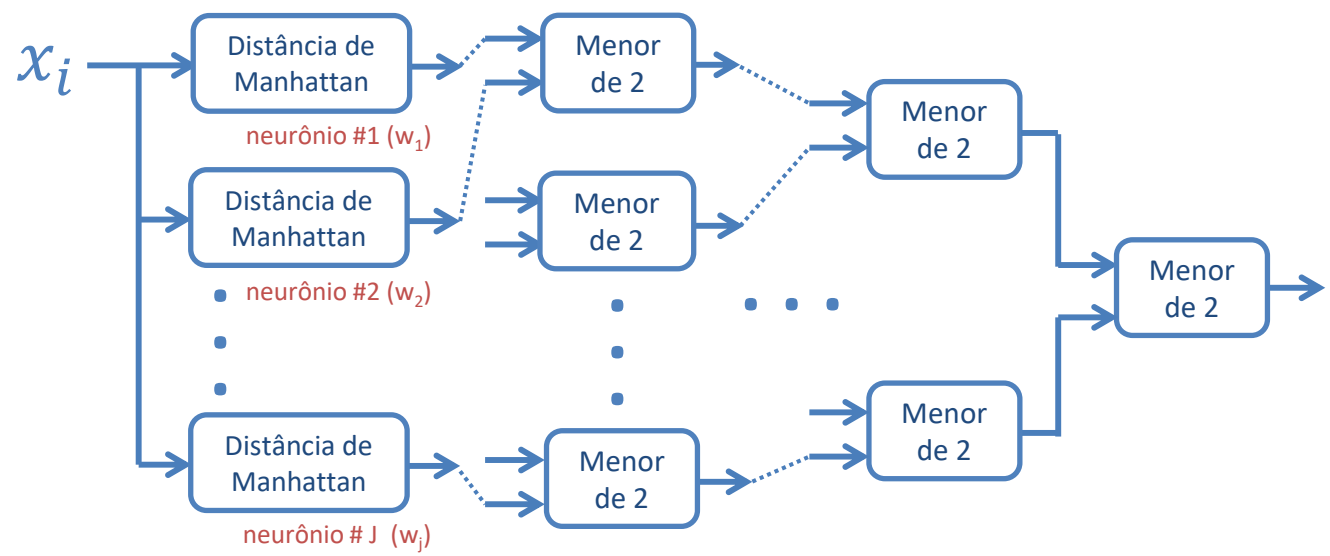

Figura 19 - Representação dos componentes utilizados para o cálculo da distância entre o vetor de entrada $\boldsymbol{x}_{\boldsymbol{i}}$ e os vetores peso $\boldsymbol{w}_{\boldsymbol{j}}$ dos neurônios, e de suas interligações com os componentes que computam o menor entre dois valores, utilizados no circuito de busca da menor distância.

A quantidade de blocos $\left(N_{\text {blocos }}\right)$ que compõem o circuito de torneio para busca progressiva do menor valor de distância varia de acordo com a quantidade de neurônios na rede $(J)$, segundo a expressão (14):

$$
N_{\text {blocos }}=\sum_{k=0}^{\left(\log _{2} J\right)-1} 2^{k}
$$

A Figura 20 ilustra o circuito interno do bloco componente de torneio para busca do menor valor de distância. Pode-se perceber na figura que este bloco recebe, como entrada, dois valores de distância em conjunto com os índices dos neurônios correspondentes (representados por um conjunto de 7 bits). Estes valores de distância são comparados entre si e o menor dos dois é propagado para a saída do bloco, juntamente com o índice do neurônio correspondente, pela seleção de dois componentes 
multiplexadores. Desta forma, a saída do último bloco da estrutura de árvore apresenta a computação da Equação (1) usada tanto na fase de treinamento, quanto na fase de operação do SOM, apresentada na seção 3.4.

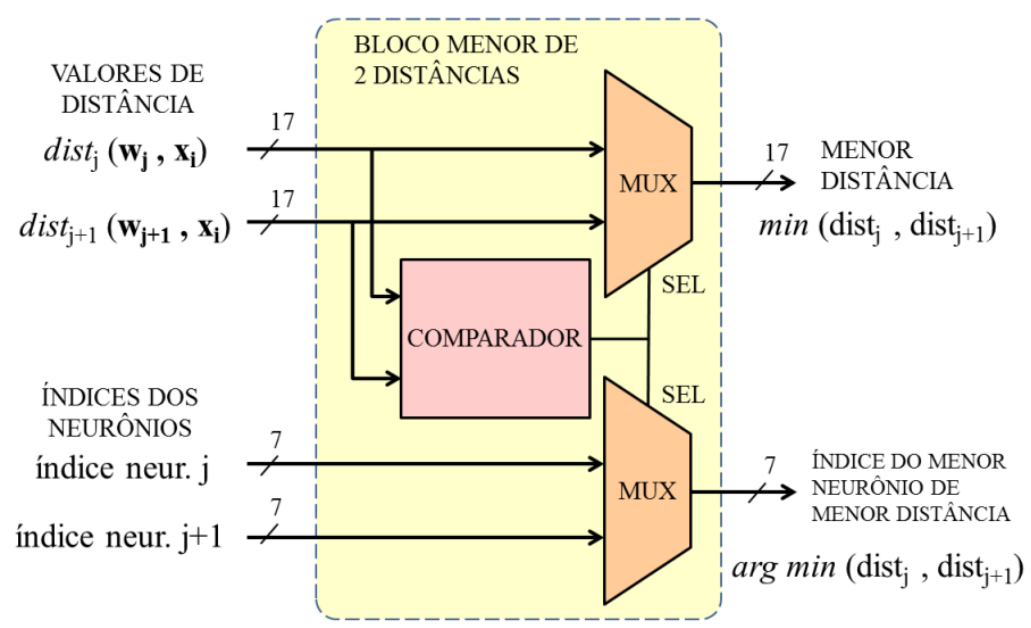

Figura 20 - Circuito interno do componente de comparação do bloco para busca da menor distância.

Colorido em rosa na Figura 16, a unidade de controle central é responsável pela distribuição dos sinais de fator de aprendizagem e função de vizinhança para os blocos de ajuste de peso. Este bloco de controle recebe, como sinal de entrada, o índice do neurônio vencedor, de forma a poder computar a distância de vizinhança de todos os neurônios da rede $-\operatorname{dist}(c, j)$. A unidade de controle central também tem a função de registrar a contagem das épocas de treinamento $(t)$ a fim de determinar o valor corrente de $\alpha(t)$ e $\beta(t)$, segundo as propriedades de computação do SOM discutidas no capítulo 4. Portanto, o bloco centraliza a geração de sinais globais comuns a todos os neurônios (como o valor corrente do fator de aprendizagem), e de sinais individuais, diferentes para cada bloco de ajuste de peso (como o valor de $h_{c_{j}}(t)$, dependente da distância, na grade de saída da rede, entre cada neurônio e o neurônio vencedor $c$ ). Destaca-se que a geração destes sinais permite diferenciar a fase de treinamento do SOM da fase de operação, na qual não há alterações nos vetores peso dos neurônios. É importante ressaltar também que a elaboração do circuito deste bloco de controle central permite alterar o arranjo de neurônios com o qual a rede será configurada. De acordo com a apresentação feita na seção 3.4 sobre as definições matemáticas do SOM, esta 
configuração pode ser feita tanto na dimensão $\boldsymbol{d}$ do espaço matricial $\mathbb{Z}^{\boldsymbol{d}}$ de saída ${ }^{14}$, quanto nos diferentes arranjos ${ }^{15}$ de grade de neurônios, e no formato da grade, por exemplo, com mapas planos, esféricos, cilíndricos ou toroidais (KOHONEN, 2014).

O conjunto final de circuitos para computação da fase de aprendizado do SOM é composto pelos blocos de ajuste do vetor peso dos neurônios, conforme ilustrado pela Figura 21. Este bloco tem a função de computar a Equação (5) para cada um dos neurônios da rede. Para tal, cada bloco recebe, como sinais de entrada, o valor atual do vetor peso do neurônio $\boldsymbol{w}_{\boldsymbol{j}}$, o vetor de diferenças $\boldsymbol{d i} \boldsymbol{f}_{\boldsymbol{j}}$ (computado pelo bloco de cálculo de distância correspondente), e o sinal de controle da unidade central, com os valores do fator de aprendizagem e da função de vizinhança. A conexão destes sinais pode ser vista no diagrama de blocos da Figura 16. Como discutido no capítulo 4, a multiplicação de cada componente do vetor de diferenças $\left(\boldsymbol{d i} \boldsymbol{f}_{\boldsymbol{j}}\right)$ por $\alpha(t)$ e $h_{c_{j}}(t)$ é realizada por uma operação binária de deslocamento aritmético à direita. Finalmente, cada componente do vetor $\boldsymbol{w}_{\boldsymbol{j}}$ é atualizado com o valor de deltaPeso da Equação (10), de forma a calcular o novo vetor peso. Assim como ocorre no bloco de cálculo de distância, é importante destacar que todos os componentes vetoriais de $\boldsymbol{w}_{\boldsymbol{j}}$ de todos os $J$ neurônios da rede são ajustados simultaneamente. Tal processamento paralelo tem função de favorecer a velocidade de computação do SOM, segundo o apresentado como objetivo deste trabalho.

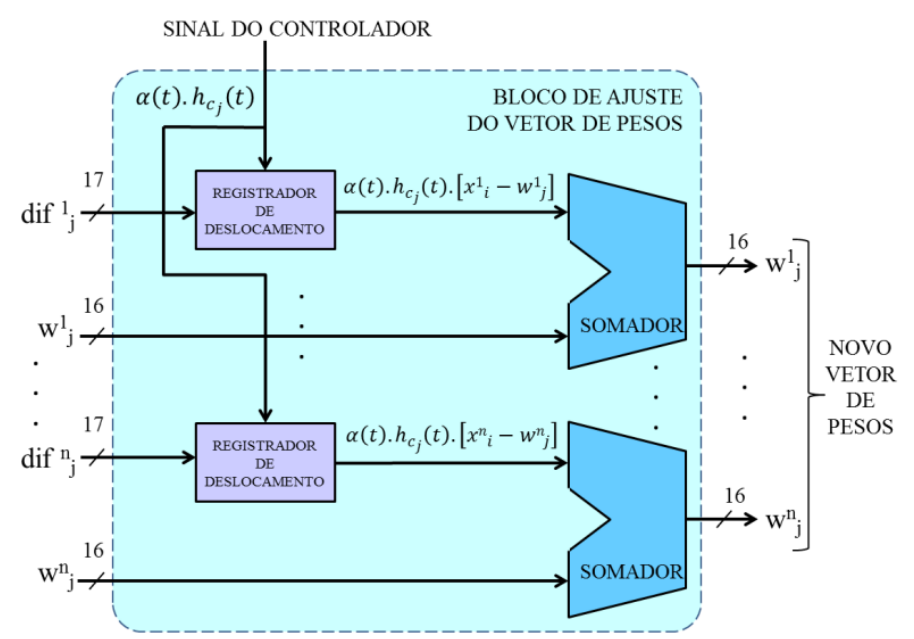

Figura 21 - Circuito interno do componente de cálculo do bloco para ajuste dos vetores peso do SOM.

\footnotetext{
${ }^{14}$ Normalmente o SOM é configurado com saída unidimensional, bidimensional ou tridimensional (HAYKIN, 2007).

${ }^{15}$ O SOM possui, geralmente, arranjos quadrados ou hexagonais, conforme ilustrado pela Figura 6 (KOHONEN, 2013).
} 
O código VHDL para execução do modelo centralizado apresentado nesta seção está descrito no Apêndice B e pode ser sintetizado pelas plataformas de descrição de hardware da Xilinx, ISE (ALUR et al., 2007) ou Vivado (CHURIWALA, 2016).

\subsection{MODELO HÍBRIDO DE EXECUÇÃO DO SOM}

Em complemento ao modelo distribuído, descrito na seção 5.2, e ao modelo centralizado, apresentado na seção 5.3, também se desenvolveu o modelo híbrido de execução do SOM. O modelo híbrido reúne parte das características da estrutura de difusão do modelo distribuído e parte das características da unidade de controle do modelo centralizado, a fim de se melhor compreender as propriedades dos modelos quando executados em FPGA. A Figura 22 ilustra este modelo híbrido.

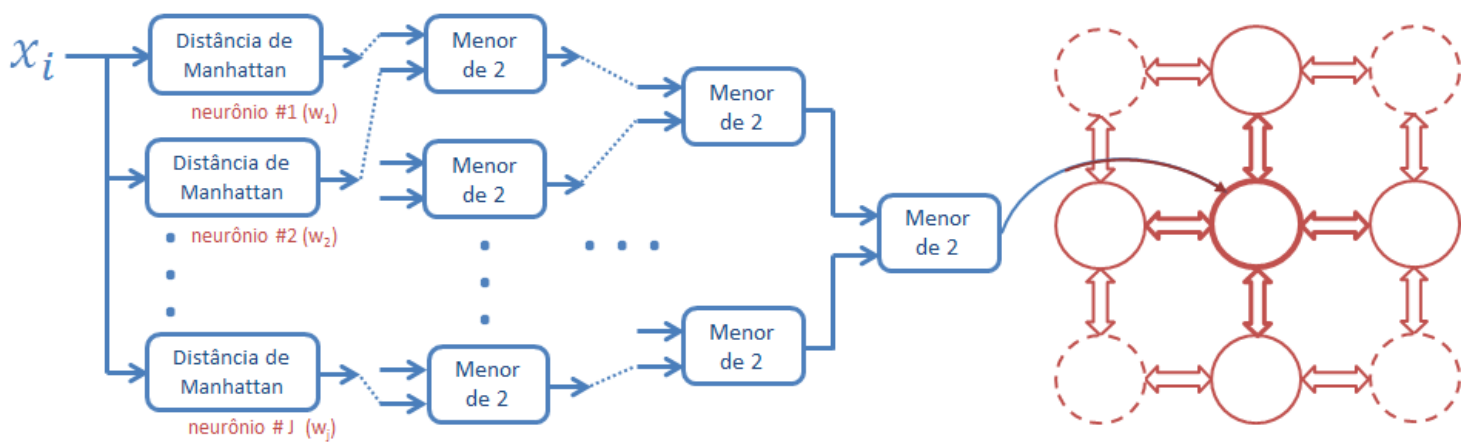

Figura 22 - Modelo híbrido para execução do SOM em FPGA, no qual os cálculos das distâncias são efetuados em paralelo, a identificação do menor valor de distância é feita de forma semelhante ao modelo centralizado e a computação de distância na grade para o neurônio vencedor é realizada de maneira similar ao modelo distribuído.

O modelo híbrido combina as arquiteturas centralizadas e distribuídas da seguinte forma: os blocos de cálculo de distância e os blocos de atualização de peso são mantidos executando o processamento em paralelo; o processo de busca do valor da distância mínima é executado pela estrutura do torneio, (conforme descrito na arquitetura centralizada); e a computação da distância entre cada neurônio e o neurônio vencedor é realizada pela propagação do índice de vizinhança (processo executado conforme descrito na arquitetura distribuída). No Apêndice $\mathrm{C}$ consta o código em VHDL da arquitetura de hardware elaborada para execução do modelo híbrido. 
A fim de se contrastar as características dos três modelos apresentados, a próxima seção contém a descrição dos experimentos e resultados obtidos com a síntese em FPGA, das três arquiteturas apresentadas.

\subsection{COMPARAÇÃO ENTRE DIFERENTES MODELOS DE EXECUÇÃO DO SOM EM FPGA}

As três seções anteriores descreveram modelos realizáveis em FPGA que permitem execuções do SOM. A seção 5.2 apresentou o modelo distribuído, no qual blocos idênticos de processamento, chamados de neurônios, trocam dados apenas localmente e alcançam um comportamento global de auto-organização sem o emprego de nenhuma unidade central de controle. A seção 5.3 descreveu o modelo centralizado, o qual emprega uma unidade de controle para agrupar os sinais gerados por blocos de processamento paralelo para o cálculo de distâncias, e para controlar a operação dos blocos de ajuste de peso, que também operam paralelamente. Por fim, a seção 5.4 apresentou o modelo híbrido de execução do SOM em FPGA, o qual reúne parte das características dos dois modelos anteriores. Com o objetivo de se comparar estes diferentes modelos, sintetizaram-se as três arquiteturas do SOM para execução em FPGA. Inicialmente, uma rede com 9 neurônios (mapa 3x3) foi elaborada usando os três modelos (distribuído, centralizado e híbrido). Os experimentos intencionaram investigar duas características importantes relacionadas ao desenvolvimento e aplicação de sistemas executados por circuitos eletrônicos - segundo o exposto na seção 1.2 - o objetivo da presente pesquisa: velocidade de processamento e consumo de recursos disponibilizados pelo componente eletrônico. A investigação sobre a velocidade de processamento é realizada pela comparação entre os valores de frequência máxima de operação do circuito e a investigação sobre o consumo de recursos disponibilizados pelo chip é realizada pela comparação entre as áreas ocupadas no componente eletrônico pelas arquiteturas em teste. A avaliação da área ocupada é feita contabilizando-se a quantidade de LUTs e Slices utilizados do dispositivo FPGA (conforme a descrição feita na seção 3.1). Os dados foram adquiridos nos relatórios fornecidos pela ferramenta de projetos de hardware ISE, descrita na seção 3.2, após a implementação das arquiteturas dos três modelos para o chip FPGA Spartan 3E-1200E da Xilinx. Todas as arquiteturas possuem entrada bidimensional $(n=2)$ representada por 16 bits em cada 
dimensão, além das demais propriedades da computação do SOM em hardware discutidas no capítulo 4. Os resultados na ocupação da área do chip e velocidade de operação do sistema para o SOM de 3x3 neurônios são mostrados na Tabela 9.

Tabela 9 - Comparação da área ocupada no chip e da frequência de operação do sistema entre os três modelos propostos para execução do SOM em configuração de 3x3 neurônios, segundo os resultados de síntese fornecidos pela plataforma ISE.

\begin{tabular}{|c|c|c|c|c|}
\hline \multicolumn{5}{|c|}{ Mapa 3x3 } \\
\hline & & $\begin{array}{c}\text { Modelo } \\
\text { Distribuído }\end{array}$ & $\begin{array}{c}\text { Modelo } \\
\text { Centralizado }\end{array}$ & $\begin{array}{l}\text { Modelo } \\
\text { Híbrido }\end{array}$ \\
\hline \multirow{2}{*}{ Área ocupada do FPGA } & LUTs & 1360 & 970 & 1100 \\
\hline & Slices & 720 & 500 & 570 \\
\hline Frequência de operação & $\mathrm{MHz}$ & 2,8 & 42,7 & 9,3 \\
\hline
\end{tabular}

Os experimentos foram repetidos mais duas vezes com aumento progressivo do tamanho da rede: 16 neurônios (mapas 4x4) e 25 neurônios (mapas 5x5). A Tabela 10 contém os resultados para os SOMs de 16 neurônios e a Tabela 11, para os SOMs de 25 neurônios, sob as mesmas condições de síntese dos primeiros experimentos (feitos com mapas 3x3). Os experimentos dos modelos elaborados para execução do SOM com mapas de $3 \times 3$ e de $4 \times 4$ neurônios têm por objetivo testar condições diferentes da arquitetura do bloco de "torneio" para busca do menor valor de distância (existente apenas nos modelos centralizado e híbrido). A arquitetura de circuito deste bloco possui uma quantidade de entradas que varia segunda a potência de dois $(2,4,8,16 \ldots)$, conforme apresentado na Figura 18. O primeiro teste (mapa 3x3), por possuir uma quantidade de nove neurônios, gera uma condição menos favorável de teste. Tal condição menos favorável ocorre porque esta quantidade de neurônios requer uma entrada a mais do que uma das configurações oferecidas pela estrutura do circuito (8 entradas), o que acarreta a necessidade de se utilizar uma estrutura de 16 entradas no circuito de torneio (das quais, 7 não recebem sinais de entrada). O segundo teste (mapa $4 \times 4)$, por utilizar exatamente 16 entradas da árvore de busca, constitui uma condição mais favorável ao teste da estrutura. Além dos experimentos com 9 e 16 neurônios, também realizou-se testes com 25 neurônios. O objetivo dos experimentos com mapas $5 \times 5$ é possibilitar uma observação da tendência nas sequências de resultados, em relação aos outros dois testes. 
Tabela 10 - Comparação da área ocupada no chip e da frequência de operação do sistema entre os três modelos propostos para execução do SOM em configuração de $4 \mathrm{x} 4$ neurônios, segundo os resultados de síntese fornecidos pela plataforma ISE.

\section{Mapa 4x4}

\begin{tabular}{llccc} 
& \multicolumn{1}{c}{$\begin{array}{c}\text { Modelo } \\
\text { Distribuído }\end{array}$} & $\begin{array}{c}\text { Modelo } \\
\text { Centralizado }\end{array}$ & $\begin{array}{c}\text { Modelo } \\
\text { Híbrido }\end{array}$ \\
\hline \multirow{2}{*}{ Área ocupada do FPGA } & LUTs & 3620 & 1630 & 1920 \\
\cline { 2 - 5 } & Slices & 1890 & 840 & 1000 \\
\hline Frequência de operação & $\mathrm{MHz}$ & 2,5 & 36,7 & 4,6 \\
\hline
\end{tabular}

Tabela 11 - Comparação da área ocupada no chip e da frequência de operação do sistema entre os três modelos propostos para execução do SOM em configuração de $5 \times 5$ neurônios, segundo os resultados de síntese fornecidos pela plataforma ISE.

\section{Mapa 5x5}

\begin{tabular}{llccc} 
& & $\begin{array}{c}\text { Modelo } \\
\text { Distribuído }\end{array}$ & $\begin{array}{c}\text { Modelo } \\
\text { Centralizado }\end{array}$ & $\begin{array}{c}\text { Modelo } \\
\text { Híbrido }\end{array}$ \\
\hline \multirow{2}{*}{ Área ocupada do FPGA } & LUTs & 5500 & 2530 & 2890 \\
\cline { 2 - 5 } & Slices & 2860 & 1310 & 1590 \\
\hline Frequência de operação & $\mathrm{MHz}$ & 1,6 & 31,4 & 3,4 \\
\hline
\end{tabular}

Com o objetivo de possibilitar outra visualização dos dados contidos nos experimentos, foram elaborados três gráficos com as informações contidas nas tabelas apresentadas. Os gráficos, porém, mostram os dados em uma situação comparativa, ou seja: a Figura 23 compara apenas a quantidade de LUTs para os três modelos (distribuído, centralizado e híbrido), configurados com três tamanhos de mapa (9, 16 e 25 neurônios); a Figura 24 compara o número de Slices empregados na síntese destas mesmas configurações no FPGA; e a Figura 25 compara as frequências de clock do SOM sintetizado no chip para as configurações descritas para possibilitar a verificação das velocidades de operação dos sistemas.

Como pode ser observado pelas informações sobre os recursos ocupados no FPGA obtidas nos experimentos, a quantidade de LUTs e Slices utilizados pelo modelo distribuído é bem maior que as outras duas alternativas - modelos centralizado e híbrido. Pode-se observar, também, que há a tendência de um maior consumo de recursos do chip conforme o incremento de neurônios na rede. Tal fato ocorre devido a 
maior quantidade de conexões (para a interligação das unidades de processamento) existentes no modelo distribuído, que exige o consumo de mais recursos do FPGA para ser sintetizada.

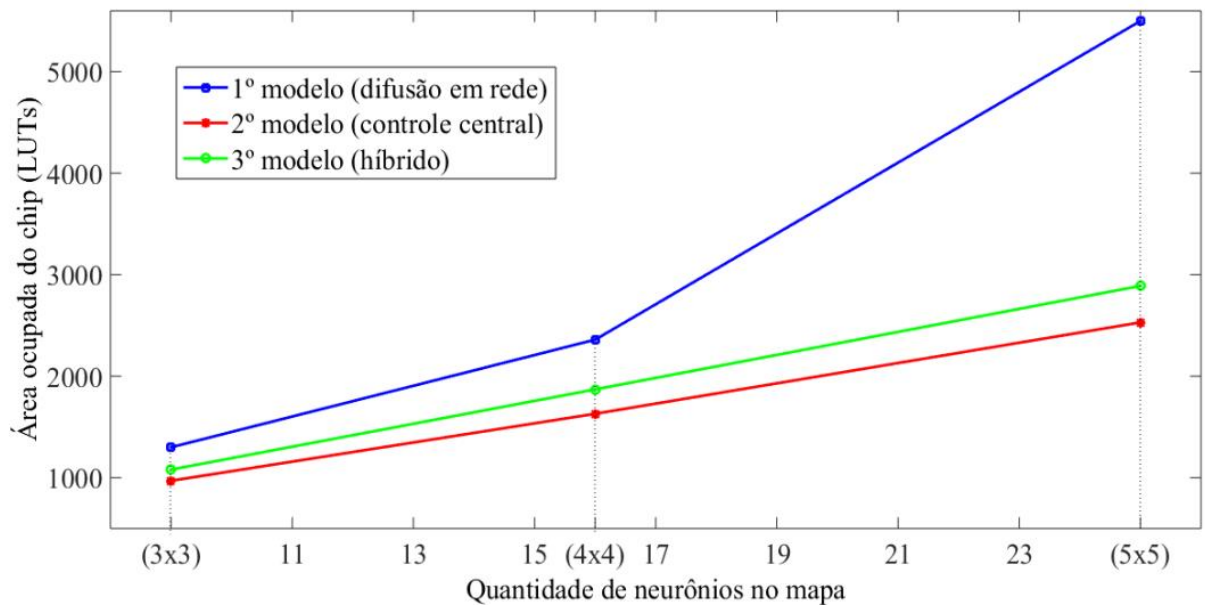

Figura 23 - Gráfico da quantidade de LUTs ocupados no FPGA de acordo com a quantidade de neurônios para cada um dos modelos de execução do SOM, segundo os resultados de síntese fornecidos pela plataforma ISE (as linhas pontilhadas demarcam os ensaios realizados).

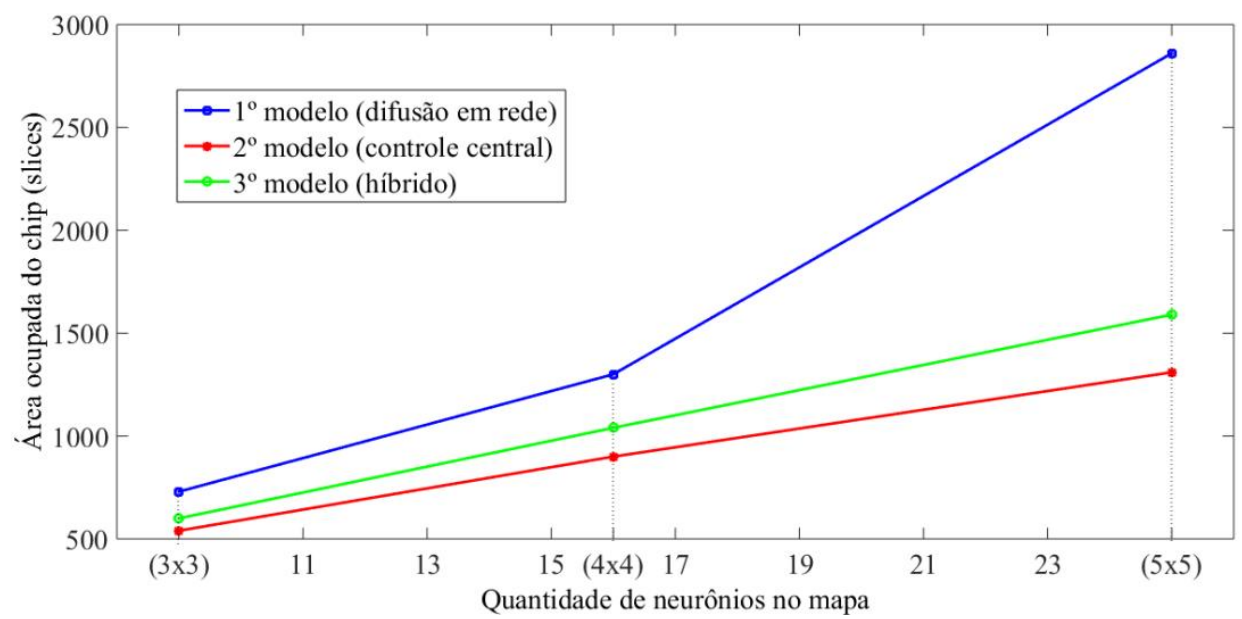

Figura 24 - Gráfico da quantidade de Slices ocupados no FPGA de acordo com a quantidade de neurônios para cada um dos modelos de execução do SOM, segundo os resultados de síntese fornecidos pela plataforma ISE (as linhas pontilhadas demarcam os ensaios realizados).

Os dados sobre a frequência de operação do chip obtidos nos experimentos podem ser associados à velocidade de operação da rede neural executada diretamente no FPGA. Os três modelos propostos neste trabalho realizam o conjunto completo de operações do SOM a cada pulso de clock. Isto é, todos os modelos operam os processos de cálculo de distância entre o vetor de entrada admitido e todos os vetores peso da rede, busca pelo neurônio de menor distância, cálculo de distância de vizinhança e atualização dos valores dos pesos dos neurônios em um único ciclo de trabalho. 


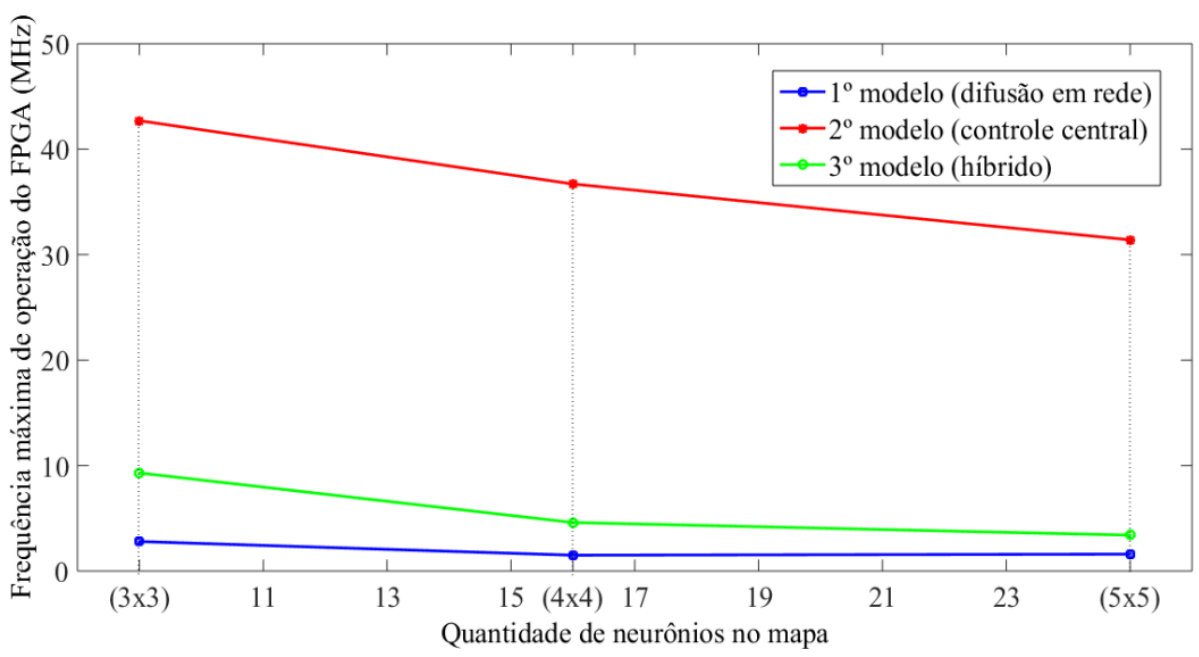

Figura 25 - Gráfico da frequência máxima de operação do SOM em FPGA, de acordo com os experimentos efetuados com diferentes quantidades de neurônios, para cada um dos modelos de execução comparados. As linhas pontilhadas demarcam os ensaios realizados, segundo os resultados de síntese fornecidos pela plataforma ISE.

Para se caracterizar a velocidade de operação da arquitetura centralizada pode-se utilizar a unidade de medida CUPS apresentada na seção 4.5. Esta métrica contabiliza a quantidade de conexões neurais atualizadas por segundo durante o processo de treinamento da rede e observa-se na Tabela 11 que o SOM com grade de $5 \times 5$ neurônios e dimensão $n=2$ possui frequência de operação de 31,4 MHz. Como todos os 25 neurônios são ajustados em paralelo pelo FPGA em um único ciclo de clock, o sistema desenvolvido atinge uma velocidade de 1570 MCUPS, conforme a Equação (12) da página 77. Sob as mesmas condições, os modelos distribuído e híbrido possuem velocidades de 80 MCUPS e 170 MCUPS, respectivamente. Tal diferença de velocidade de operação ocorre porque o processo de difusão de dados, que existe nos modelos distribuído e híbrido, consome um maior período de tempo para sua estabilização. Portanto, a frequência de operação destes modelos (como pode ser observado no gráfico da Figura 25) é menor em relação ao modelo centralizado. A arquitetura de circuito do modelo centralizado possui um fluxo mais direto de propagação dos dados processados pelos circuitos de busca do neurônio vencedor e de cálculo de distância de vizinhança; por este motivo, o modelo atinge maiores frequências de operação ${ }^{16}$.

Por fim, pode-se ainda realizar uma comparação entre os processos de síntese do código VHDL dos modelos propostos. Como abordado na seção 5.2, alguns trabalhos

\footnotetext{
${ }^{16}$ Comparações entre velocidades de operação do sistema deste trabalho e de outros trabalhos publicados na literatura serão feita na seção 7.4.
} 
recentes (como AZUMA; HIKAWA, 2014 e RODRIGUEZ; MIRAMOND; GRANADO, 2015), têm argumentado em favor de uma estrutura alternativa de busca do neurônio de menor distância da entrada e cálculo de distância de vizinhança, a fim de possibilitar a eliminação da fase de re-projeto e mudanças na arquitetura computacional quando o número total de neurônios da rede é alterado. Este fato motivou a elaboração do modelo distribuído de execução do SOM por difusão de informação sem controle central. Desta forma, uma importante característica da arquitetura do modelo distribuído proposto é que seu processo de descrição de código VHDL, quando comparado ao mesmo processo nos modelos centralizado e híbrido, permite uma redução no tempo de elaboração do circuito e depuração de código, conforme pode ser visualizado na Tabela 12.

Tabela 12 - Comparação do processo de escrita de código VHDL entre os modelos distribuído, centralizado e híbrido para execução do SOM em FPGA.

\begin{tabular}{|l|c|c|c|}
\hline & Distribuído & Centralizado & Híbrido \\
\hline $\begin{array}{l}\text { Linhas de comando de descrição } \\
\text { de hardware para adição de um } \\
\text { neurônio à uma rede existente }\end{array}$ & $\begin{array}{c}1 \text { adição } \\
7 \text { alterações }\end{array}$ & $\begin{array}{c}4 \text { adições } \\
7+\mathrm{N} \text { alterações } \\
(\mathrm{N}=\text { total neurônios) }\end{array}$ & $\begin{array}{c}4 \text { adições } \\
7+\mathrm{N} \text { alterações } \\
(\mathrm{N}=\text { total neurônios })\end{array}$ \\
\hline $\begin{array}{l}\text { Tempo comparativo de re-projeto } \\
\text { para alteração do circuito em } \\
\text { relação ao modelo distribuído }\end{array}$ & $1: 1$ & $\begin{array}{c}10: 1 \\
\text { (em média) }\end{array}$ & $\begin{array}{c}10: 1 \\
\text { (em média) }\end{array}$ \\
\hline
\end{tabular}

Como pode ser percebido pela Tabela 12, o processo de escrito de código VHDL é aproximadamente 10 vezes mais rápido para o modelo distribuído, quando comparado ao modelo centralizado. Este fato se deve à simplicidade de descrição da arquitetura que é possibilitada pelo modelo distribuído, pois alterações na estrutura da rede são feitas pela declaração da quantidade de neurônios do SOM e suas interligações (ilustrado pela Figura 9 da seção 5.2). O modelo de execução do SOM com controle central, em contraste, requer uma nova elaboração dos blocos de circuitos responsáveis pela busca do neurônio de maior semelhança com a entrada e controle do processo de ajuste de pesos, o que demanda maior complexidade na síntese de diferentes redes neurais no FPGA. Portanto, se a capacidade do FPGA disponível para execução do SOM for suficiente para a implementação do modelo distribuído, e a velocidade requerida pela aplicação da rede neural for atendida por esta arquitetura, a adoção do modelo distribuído é recomendada, devido à simplicidade de síntese de seu código VHDL. 
Em seguida, a seção 5.6 apresenta a análise dos dados obtidos na execução dos experimentos com os três modelos em FPGA, para que possa ser caracterizada a escolha que as três opções oferecem.

\subsection{DISCUSSÃO SOBRE OS RESULTADOS DA COMPARAÇÃO E A CONTINUIDADE DO DESENVOLVIMENTO DO SISTEMA}

Como pode ser observado pelas informações na Tabela 9, na Tabela 10 e na Tabela 11 sobre os recursos ocupados no FPGA, a quantidade de LUTs e Slices utilizados pelo modelo distribuído é bem maior que as outras duas alternativas -modelos centralizado e híbrido. Ademais, pode-se observar pelos gráficos da Figura 23 e da Figura 24 que a tendência de um maior consumo de recursos do chip pelo modelo de difusão é acentuada conforme o incremento de neurônios na rede. Por estes motivos, embora o modelo distribuído proposto possua simplicidade em sua estrutura de construção, optou-se por não o empregar na continuidade do presente trabalho.

Com relação à velocidade de processamento, a diferença entre o modelo centralizado (Figura 25), a qual permite que o SOM realize 1570 milhões de ajustes nos vetores peso de seus neurônios a cada segundo e o modelo híbrido, que efetua 170 milhões de ajustes sob as mesmas condições, conduziram a escolha do modelo de controle centralizado para seguir sendo experimentado e aperfeiçoado na sequência do desenvolvimento desta pesquisa sobre execuções do SOM em hardware.

A comparação dos resultados obtidos na implementação dos três modelos de execução do SOM em FPGA (apresentados nas seções 5.2, 5.3 e 5.4) e o contraste de suas características foram publicados no ISCAS 2017 - International Symposium on Circuits and Systems do IEEE (SOUSA; DEL-MORAL-HERNANDEZ, 2017b). O código em VHDL para descrição do modelo com controle centralizado - cujo desenvolvimento será continuado neste trabalho - pode ser encontrado no Apêndice B, possibilitando sua síntese e implementação em FPGA por uma plataforma de projetos de circuitos digitais, como, por exemplo, o ISE (ALUR et al., 2007) ou o Vivado (CHURIWALA, 2016), da Xilinx.

Tendo definido o modelo centralizado de execução no chip para a continuidade da pesquisa sobre implementação do SOM em FPGA, a próxima seção apresenta a 
primeira experimentação com este modelo. $\mathrm{O}$ objetivo dos testes é fundamentar o tipo de descrição em VHDL usada na elaboração da arquitetura de circuito utilizada. Em seguida, tal arquitetura tem seu comportamento verificado sob condições controladas, antes de um desenvolvimento do experimento sob condições reais (apresentado na seção $5.8)$.

\subsection{POSSÍVEIS ESTRUTURAS DE DESCRIÇÃO DE HARDWARE E TESTE COM DADOS SINTÉTICOS}

De forma a lidar com a maior complexidade de elaboração do modelo centralizado (conforme discutido na seção 5.5), elaborou-se um conjunto de experimentos para fundamentar a opção sobre o nível de descrição do VHDL (linguagem de descrição em hardware, apresentada na seção 3.2) adotado para a continuidade do desenvolvimento da pesquisa. Tais experimentos também têm como objetivo proporcionar o refinamento do processo de elaboração dos blocos computacionais detalhados na seção 5.3. Os blocos empregados no modelo com controle central, adotado de execução do SOM, estão resumidos pela Tabela 13, em conjunto com suas principais características (conforme discutido na seção 5.3).

Os experimentos consistiram em sintetizar o modelo centralizado, com auxílio da ferramenta ISE, utilizando dois tipos distintos de projeto de hardware: descrição em baixo nível e descrição de mais alto nível, do mesmo circuito eletrônico, segundo as possibilidades oferecidas pela linguagem VHDL. O primeiro tipo de projeto foi realizado de forma a refinar cada operação binária executada pelos blocos computacionais com o intuito de se obter um maior controle dos processos executados. Este refinamento utilizou, por exemplo, descrições de redes de somadores com vai-um antecipado CLA (acrônimo em inglês para "Carry Look-Ahead Adder") e circuitos comparadores de magnitude por rede iterativa com "MSbit-first" (WAKERLY, 2000). O segundo tipo de projeto foi executado descrevendo-se o circuito de forma comportamental no ambiente de projeto ISE, possibilitando que a ferramenta realizasse uma síntese do circuito em nível binário de maneira automática e permitindo uma descrição mais genérica do sistema. Tal descrição comportamental também teve o intuito de tornar o sistema mais flexível para futuras alterações na configuração da rede, conforme a aplicação na qual o SOM estiver sendo utilizado. Ambos os tipos de projeto 
executaram em FPGA um mapa de 4x4 neurônios, dimensão $n=2$, e os dados resultantes da síntese dos circuitos também foram obtidos com o uso da ferramenta ISE. Na Tabela 14 podem-se obter informações sobre os recursos consumidos no chip por cada tipo de projeto, a estimativa da potência consumida e a frequência de operação correspondente.

Tabela 13 - Resumo das características dos quatro grandes processos executados pelo SOM segundo o modelo centralizado proposto para implementação em FPGA.

\begin{tabular}{|c|c|}
\hline Processo & Propriedades \\
\hline Cálculo de distâncias & $\begin{array}{l}\text { A computação de distância entre o vetor de entrada e todos } \\
\text { os vetores peso da rede é realizada de forma paralela, o que } \\
\text { possibilita uma geração concomitante dos valores } \\
\text { necessários para a execução da próxima etapa. }\end{array}$ \\
\hline $\begin{array}{l}\text { Busca pelo neurônio } \\
\text { vencedor }\end{array}$ & $\begin{array}{l}\text { A procura pelo neurônio de maior semelhança com a } \\
\text { amostra de entrada é realizada por "torneio" para eliminação } \\
\text { progressiva dos maiores valores de distância. }\end{array}$ \\
\hline $\begin{array}{l}\text { Controle dos sinais } \\
\text { de ajuste de pesos }\end{array}$ & $\begin{array}{l}\text { Computação da distância de vizinhança dos neurônios da } \\
\text { rede segundo suas distância no mapa em relação ao neurônio } \\
\text { vencedor, e distribuição dos sinais do fator de aprendizagem } \\
\text { e função de vizinhança para os blocos de ajuste de peso, } \\
\text { conforme a progressão das épocas de treinamento. }\end{array}$ \\
\hline $\begin{array}{l}\text { Atualização dos } \\
\text { pesos }\end{array}$ & $\begin{array}{l}\text { Os ajustes dos pesos, com intensidades correspondentes aos } \\
\text { sinais recebidos da etapa anterior, são executados } \\
\text { paralelamente para cada componente vetorial de todos os } \\
\text { pesos dos neurônios da rede. }\end{array}$ \\
\hline
\end{tabular}

É possível perceber, pela Tabela 14, uma grande similaridade entre os dois tipos de projeto tanto na frequência de operação do sistema quanto na estimativa de consumo de energia e na área ocupada do circuito eletrônico. Esta semelhança nos dados obtidos para os três parâmetros medidos indicam que o processo de síntese do circuito descrito em alto nível, o qual é realizado de forma autônoma pela ferramenta de projeto ISE, gera um circuito eletrônico similar à arquitetura descrita em baixo nível. Portanto, na sequência da presente pesquisa, se utilizará uma descrição comportamental de alto nível em VHDL dos processos de execução do SOM em FPGA. Como exposto 
anteriormente, tal descrição comportamental do circuito também possibilita uma simplicidade de flexibilização do sistema, visando possíveis modificações futuras.

Tabela 14 - Comparação da área ocupada no chip, potência e velocidade de operação do sistema entre os dois tipos de projeto para execução em FPGA do SOM com configuração de $4 x 4$ neurônios, segundo os resultados de implementação fornecidos pela plataforma ISE.

\section{Mapa 4x4}

Projeto de baixo nível Projeto de alto nível

(descrição binária do circuito) (descrição comportamental circuito)

\begin{tabular}{lcc}
\hline Área ocupada & 1630 LUTs & 1540 LUTs \\
\cline { 2 - 3 } do FPGA & 840 Slices & 870 Slices \\
\hline $\begin{array}{l}\text { Frequência de } \\
\text { operação }\end{array}$ & $36,7 \mathrm{MHz}$ & $39,1 \mathrm{MHZ}$ \\
\hline Potência & $159 \mathrm{~mW}$ & $159 \mathrm{~mW}$ \\
\hline
\end{tabular}

Com a estrutura de descrição em VHDL definida, realizaram-se dois testes com o modelo centralizado na aprendizagem de dados gerados sinteticamente. O objetivo da elaboração de tais testes foi observar o comportamento da arquitetura de circuito durante seu processo de treinamento com um conjunto controlado de vetores de entrada. A geração dos dados controlados aplicados em ambos os experimentos se baseou nos testes realizados para verificação da arquitetura em FPGA para implementação do SOM proposta por Peña, Vanegas e Valencia (2006). Com base neste trabalho, os conjuntos de treinamento empregados foram compostos por 2000 amostras apresentadas à rede como um fluxo contínuo de dados (vetores bidimensionais foram utilizados no primeiro experimento e vetores tridimensionais, no segundo). O software Matlab foi usado para gerar os conjuntos de dados em formato binário e o simulador de hardware Xilinx ISim (PEDRONI, 2010) foi usado para verificar o comportamento da arquitetura proposta durante o processo de aprendizagem. A Figura 26 mostra quatro instantes do treinamento executado no primeiro experimento. 


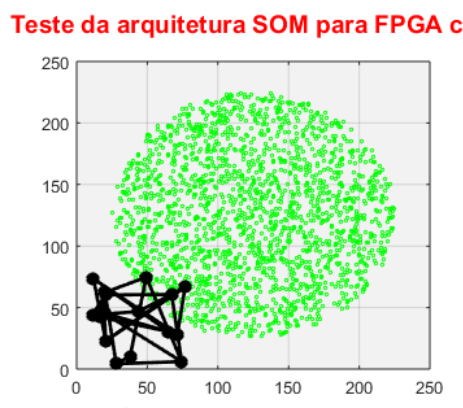

(a) após 1 amostra de treinamento

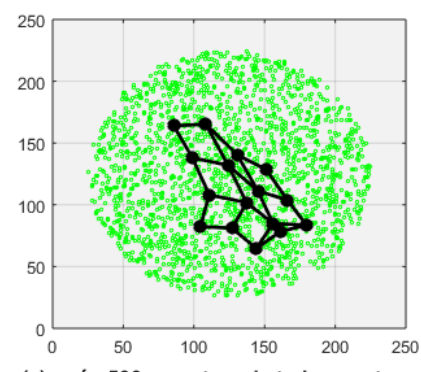

(c) após 500 amostras de treinamento

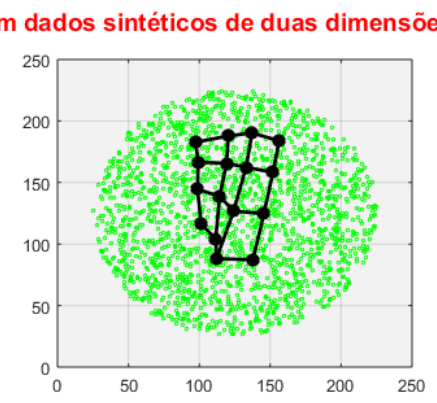

(b) após 100 amostras de treinamento

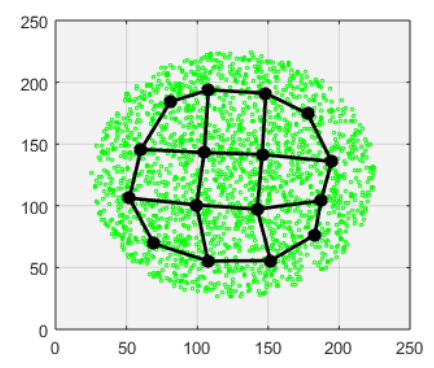

(d) após 2000 amostras de treinamento

Figura 26 - Quatro momentos da progressão do aprendizado do SOM: neurônios marcados como pontos pretos interconectados e os dados $\left(\mathbb{R}^{2}\right)$ ilustrados em verde.

Como pode ser observado na Figura 26(a), os vetores peso do SOM inicializados com valores aleatórios sofrem um processo de ordenação conforme ocorre o processamento das amostras de treinamento - quadros (b) e (c). Após 2000 exemplos (último quadro da figura), há uma distribuição adequada dos neurônios da rede pelo espaço de dados de entrada. A configuração de 16 neurônios do SOM (4x4) e a admissão dos vetores de entrada como fluxo de dados estão relacionadas com os requerimentos de uma das aplicações em telecomunicações do circuito desenvolvido, apresentada na seção 5.8 .

A Figura 27 ilustra o processo de aprendizagem do segundo experimento com dados controlados de três dimensões por uma rede de 25 neurônios. Da mesma forma que no primeiro experimento, se verifica uma ordenação dos vetores peso do SOM nos quadros (b) e (c) da Figura 27, após seu início com valores aleatórios - conforme mostra o quadro (a). O último quadro da figura mostra uma dispersão dos neurônios da rede pelo espaço de dados de entrada após 2000 amostras do processo de treinamento.

Tendo obtido resultados adequados no teste com um conjunto controlado de vetores de treinamento, a próxima seção apresenta o desempenho da arquitetura de circuito desenvolvida aplicada no processamento de sinais QAM. Por fim, na seção 5.9, submete-se a arquitetura a uma condição não estacionária dos sinais de entrada. 


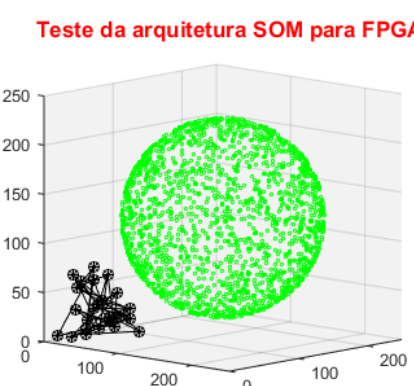

(a) após 1 amostra de treinamento

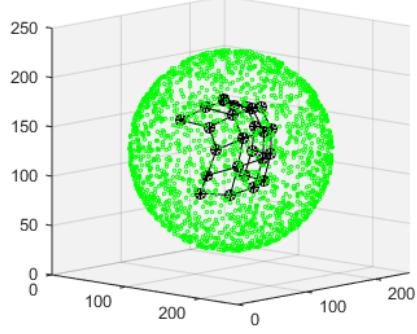

(c) após $\mathbf{5 0 0}$ amostras de treinamento

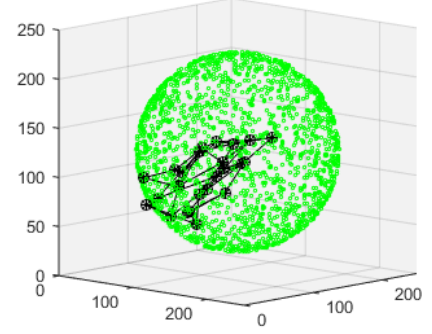

(b) após 100 amostras de treinamento

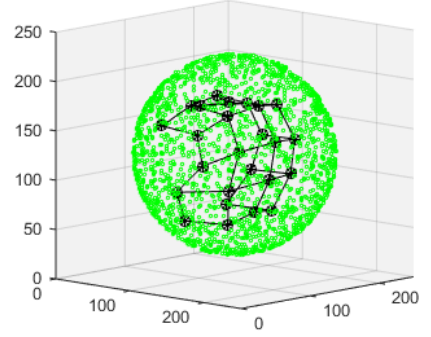

(d) após 2000 amostras de treinamento

Figura 27 - Quatro momentos da progressão do aprendizado do SOM: neurônios marcados como pontos pretos interconectados e os dados $\left(\mathbb{R}^{3}\right)$ ilustrados em verde.

\subsection{APLICAÇÃO DA ARQUITETURA DE IMPLEMENTAÇÃO DO SOM EM FPGA NA ÁREA DE TELECOMUNICAÇÕES - IDENTIFICAÇÃO DE SINAIS QAM}

Há diversos trabalhos na literatura relatando pesquisas sobre inteligência computacional aplicada a processos de telecomunicações, como as publicações de Loss et al. (2007), Rathkanthiwar, Dethe e Kulat (2011) e Craenen, Nandi e Ristaniemi (2013). Mais especificamente, há uma diversidade de trabalhos que utilizam SOM para melhorias do processo de multiplexação OFDM (acrônimo em inglês para "Orthogonal frequencydivision multiplexing”), por exemplo, Hirose e Nagashima (2003) e Rathkanthiwar et al. (2011). Uma aplicação frequente do SOM no aprimoramento dos processos OFDM é a identificação de sinais QAM (acrônimo em inglês para, "Quadrature Amplitude Modulation" ou, em português, modulação de amplitude em quadratura) distorcidos devido aos efeitos do canal de transmissão (WANG et al., 2004; SENEVIRATHNA; YAMASHITHA; LIN, 2005; JAVIDI; KHOSHBIN, 2013). Principalmente devido aos requisitos de velocidade computacional e portabilidade, a área de telecomunicações é a categoria de aplicação mais frequente de uso de FPGA nas pesquisas em publicações do 
IEEE entre os anos 2000 e 2015 (ROMOTH; PORRMANN; RÜCKERT, 2017). Alguns exemplos de aplicações que utilizam OFDM/QAM são as comunicações móveis via satélite, os sistema celular ou as redes metropolitanas sem fio (EKLUND et al., 2002), e sistemas desenvolvidos diretamente para FPGA auxiliam no processo de recuperação de informações destes sistemas (DICK; HARRIS, 2002; LIN; SHAO e ZHANG, 2010). Porém, não se encontrou na literatura publicações de trabalhos com execução direta do SOM em FPGA como alternativa de inteligência computacional ao processo de identificação de sinais QAM. Este fato motivou a escolha desta aplicação para testes práticos da arquitetura de circuito desenvolvida segundo o modelo centralizado, conforme discutido na seção 5.6.

Na modulação QAM, símbolos que representam uma sequência inteira de bits são transmitidos por duas portadoras com mesma frequência e defasagem de $90^{\circ}$ (PROAKIS, 2001). A resultante consiste na soma $S$ dos dois sinais, o sinal senoidal com amplitude $Q$ e o sinal cossenoidal com amplitude $I$. A Equação (15) mostra a composição da portadora de um sinal QAM:

$$
S(t)=Q \operatorname{sen}(\omega t)+I \cos (\omega t)
$$

com $\omega t$ representando a fase instantânea do sinal. Esta modulação pode ser graficamente ilustrada em um plano IQ (em inglês, "In-phase / Quadrature"), conhecido como constelação. A Figura 28 mostra um exemplo de constelação 64-QAM, a qual é composta por 64 símbolos, cada um representando uma sequência diferente de 6 bits a ser transmitida simultaneamente. É importante notar também, na figura, que é possível codificar os símbolos com base no código Gray, o que garante uma variação mínima de significado entre um símbolo e os símbolos adjacentes (apenas 1 bit).

A Figura 28 representa a constelação em sua forma original, ou seja, como produzida pelo sistema transmissor na modulação do sinal. Porém, ruídos por desvanecimento multi-caminho (em inglês, "multi-path fading"), condições não-lineares do canal de transmissão e pelo efeito Doppler - causado pelo deslocamento relativo entre o transmissor e o receptor - podem causar distorções na constelação original QAM. A Figura 29 ilustra algumas situações de ruído percebidas pelo receptor para um sinal 16-QAM (composto apenas por 16 símbolos, cada um representando uma sequência de 4 bits distinta). 


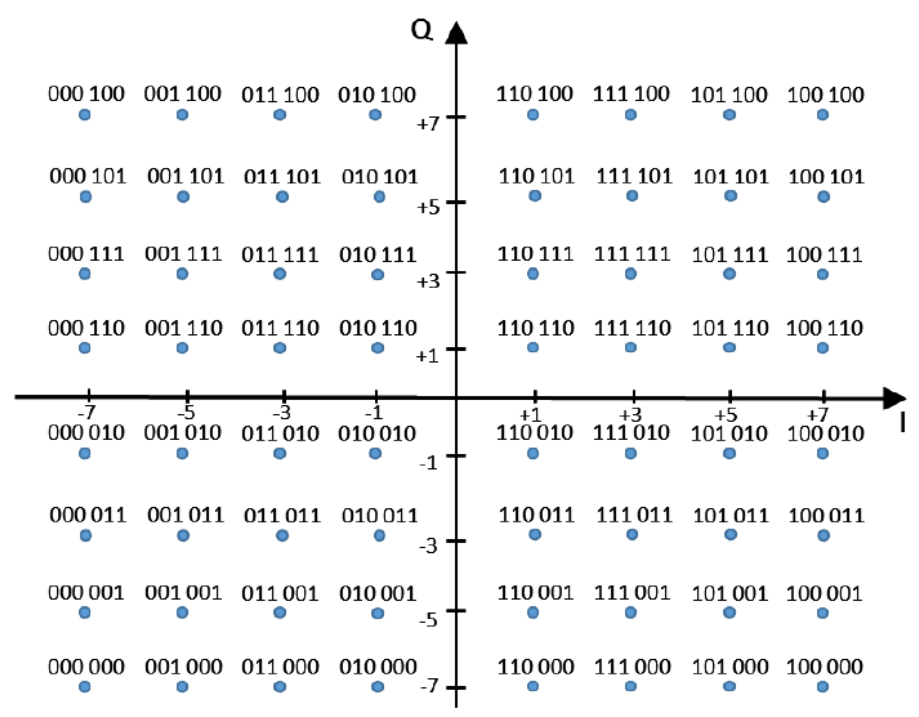

Figura 28 - Exemplo de constelação 64-QAM no plano IQ (“In-phase / Quadrature”).

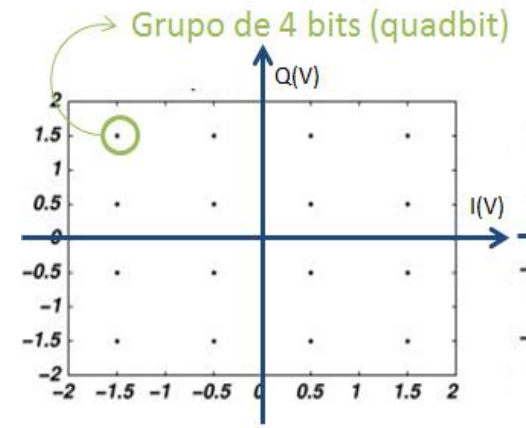

(a)

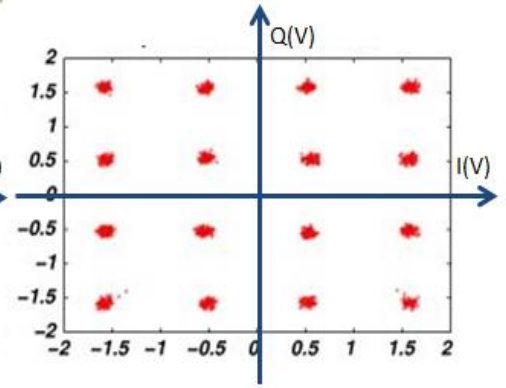

(b)

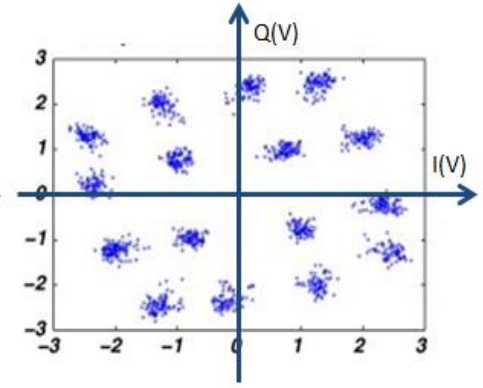

(c)

Figura 29 - Exemplo de constelação 16-QAM para transmissão de quadbits (a). Ilustração de duas possíveis situações de recepção do sinal: constelação com ruído branco gaussiano de baixa intensidade (b) e com maior espalhamento dos símbolos por ruído branco gaussiano, associado à rotação da constelação por efeito Doppler e à deformação dos agrupamentos por condições não-lineares do canal (c).

Como forma alternativa ao processo de equalização de sinais distorcidos existente no equipamento receptor - algumas pesquisas tem utilizado o SOM para reconhecimento dos símbolos QAM sem que seja necessário um conhecimento prévio das condições do canal de transmissão (HIROSE; NAGASHIMA, 2003; HAN, 2010 e JAVIDI; KHOSHBIN, 2013). Em tais trabalhos, o SOM é usado para identificar a qual agrupamento pertence cada símbolo recepcionados com ruído. O objetivo, neste tipo de aplicação, é evitar interferências entre os símbolos (ISI, em inglês "Intersymbol interference") e, portanto, erros na sequência dos bits recebidos. Portanto, a identificação de sinais QAM distorcidos pode ser entendida como um problema de 
“clustering” (agrupamento), pois a rede neural deve identificar cada símbolo de entrada como pertencente a algum dos grupos da constelação original. $\mathrm{O}$ reconhecimento de um sinal QAM recebido pelo SOM é feito pela avaliação da posição do símbolo, no plano IQ, em relação aos locais de posicionamento dos sinais recebidos anteriormente.

Para a elaboração dos ensaios com a arquitetura de circuito desenvolvida, utilizou-se uma base de dados com informações sobre 15 canais reais de transmissões. $\mathrm{O}$ repositório é chamado de $\mathrm{SPIB}^{17}$ e contém respostas de impulso de canais de rádio obtidos a partir de medições em sistemas reais. Cada canal de comunicação possui características distintas, permitindo que ocorram diferentes distorções com o sinal QAM transmitido por eles, fato que possibilita a realização de pesquisas com modelamento de condições reais de ruído, como, por exemplo, os estudos feitos por AGOSTINI et al. (2008) e ASHMAWY et al. (2009). A Figura 30 exemplifica distintos cenários de distorção obtidos por três canais diferentes da base de dados SPIB com a transmissão de sinais 16-QAM.

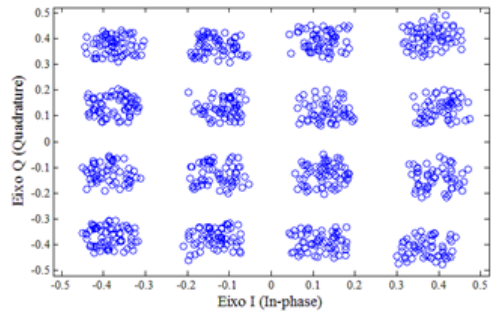

(a)

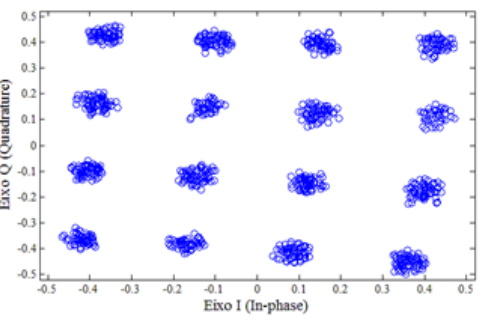

(b)

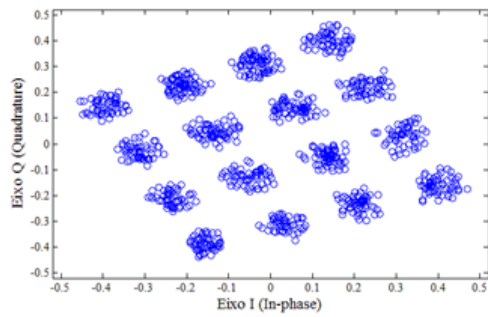

(c)

Figura 30 - Três condições de distorção da constelação 16-QAM obtidas pelos canais reais de comunicação do repositório SPIB. Canal 8: maior espalhamento dos símbolos (a); canal 11: menor espalhamento e rotação leve à direita (b); e canal 7: rotação mais intensa à esquerda (c).

A Figura 31 ilustra o uso da arquitetura do SOM de $8 \times 8$ neurônios para identificar constelações 64-QAM, com finalidade de se exemplificar esta aplicação da área de telecomunicações.

\footnotetext{
${ }^{17}$ SPIB (2013) Signal Processing Information Base. http://spib.linse.ufsc.br/index.html.
} 

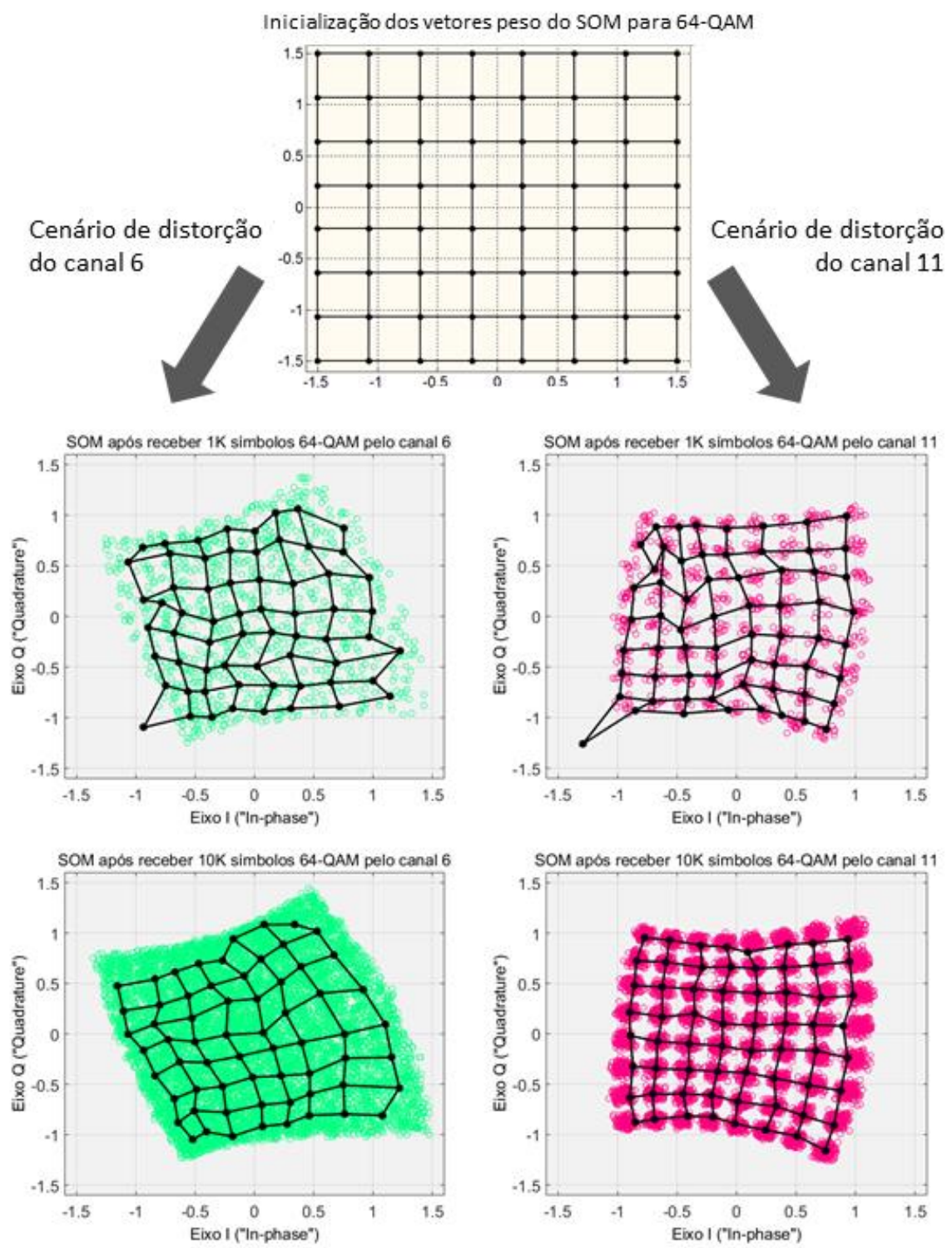

Figura 31 - Progressão da aprendizagem do SOM de acordo com a recepção de símbolos QAM por dois canais diferentes. Os pontos em verde (à esquerda) mostram um cenário de maior distorção que o cenário em vermelho (à direita).

Como pode ser visto no quadro superior da Figura 31, a grade de pontos pretos interligados representa a inicialização dos vetores peso do SOM. Seus valores não são aleatórios, e sim, acompanham o padrão de posicionamento padrão da constelação QAM original sem distorção, semelhante ao apresentado anteriormente na Figura 28. Uma sequência de símbolos QAM é, então, gerada aleatoriamente e distorcida de acordo com as características dos canais de comunicação da base de dados SPIB (os canais são numerados de 1 a 15). No exemplo da Figura 31 nota-se que o canal 6 dos quadros à esquerda (cujos símbolos estão ilustrados em verde) é mais dispersivo e possui maior rotação do que o canal 11 à direta (em vermelho). À medida que o fluxo de símbolos começa a ser apresentado à entrada da rede para seu treinamento, os neurônios 
do SOM sofrem atualização de seus valores para se adaptarem à constelação distorcida pelo ruído. Os quadros centrais da figura representam estados iniciais do processo de aprendizagem do SOM, para ambos os canais, quando apenas os primeiros 1000 símbolos foram recebidos e a disposição neural começa a ser ajustada. Os quadros inferiores da Figura 31 mostram um maior ajuste da rede aos dados recebidos, de forma que o emprego do SOM produz os agrupamentos dos símbolos em um dos 64 grupos possíveis e, o mapeamento de suas posições relativas, permite a identificação dos sinais QAM recebidos com ruído.

Os dois cenários na Figura 31 representam situações reais, ou seja, foram obtidas durante a realização dos experimentos de teste da arquitetura FPGA. Para a sequência de ensaios, houve dois conjuntos de experimentos: configuração da rede de $4 \times 4$ neurônios para identificação de sinais 16-QAM e configuração de 8x8 para sinais 64QAM. Ambos os conjuntos de teste foram executados conforme as seguintes etapas:

a. Produção em Matlab de sinais representando os símbolos QAM a serem transmitidos (de maneira semelhante ao ilustrado pela Figura 28), de forma aleatória e equiprovável.

b. Submissão dos sinais QAM aos efeitos de distorção dos canais da base de dados SPIB, por convolução, realizada também no Matlab.

c. Adição de ruído branco gaussiano e componentes não lineares aos sinais, após os efeitos de ruídos já existentes em cada canal.

d. Digitalização dos sinais de forma a compor vetores binários de duas dimensões - representando os sinais "In-phase" e "Quadrature" - com resolução de 16 bits por dimensão, para serem aplicados à entrada do SOM.

e. Execução do SOM, com os dados da etapa anterior, utilizando o software de testes ISim $^{18}$ da Xilinx (PEDRONI, 2010). A simulação foi realizada com a arquitetura apresentada na Figura 16 da seção 5.3 sintetizada para o chip FPGA Spartan 3E-1200E pela plataforma ISE da Xilinx (ALUR et al., 2007).

f. Utilização novamente do Matlab para visualização dos dados de saída gerados pelo processamento do FPGA, conforme a etapa anterior, e vierificação das informações obtidas no experimento, novamente usando-se o Matlab.

\footnotetext{
${ }^{18}$ Situação análoga aos ensaios realizados para a comparação entre os diferentes modelos de execução do SOM em FPGA apresentados anteriormente na seção 5.5.
} 
Os valores dos parâmetros de ensaios das etapas $b$ e $c$ acima foram escolhidos obedecendo aos mesmos critérios utilizados no estudo publicado por Loss et al. (2007): utilização dos canais de transmissão SPIB, adição de $35 \mathrm{~dB}$ de relação sinal/ruído na saída do canal e introdução de $5 \%$ de distorção na $2^{\mathrm{a}}$ e $3^{\mathrm{a}}$ harmônicas do sinal.

Para se realizar uma verificação preliminar, com o objetivo de se perceber se a estrutura de mapeamento que o SOM realiza sobre as amostras de entrada é relevante para o problema de identificação de símbolos 16-QAM, se realizou um grupo de testes que está apresentado no Apêndice D. Para alcançar esse objetivo, executou-se a mesma sequencia experimental utilizando o SOM e o método de quantização chamada Quantização Vetorial VQ. Considerou-se essa comparação importante porque o VQ (que foi mencionado na seção 3.3 como técnica precursora do SOM) é um método clássico de quantização vetorial, e a abordagem ao problema de identificação sinais QAM distorcidos é feita explorando-se a caraterística de agrupamento de dados do SOM. Como conclusão desta sequência experimental preliminar, percebeu-se que o processo de manutenção topológica que o SOM possui é essencial para a tarefa de identificação dos símbolos com ruído. A experimentação detalhada no Apêndice D mostrou que o processo de organização conjunta dos neurônios pelo modelo do SOM de ajuste de pesos por regiões de vizinhança é importante para capturar o fenômeno, pois as distorções presentes no canal de comunicação atingem coletivamente a constelação QAM.

Após as evidências de que as propriedades computacionais do SOM são importantes para identificar as distorções do sinal, concentrou-se no funcionamento da arquitetura FPGA proposta para execução da rede. A Figura 32 ilustra seis diferentes momentos da progressão do processo de treinamento do SOM, conforme a recepção dos símbolos 16-QAM. Na figura, os círculos pretos representam os vetores peso dos neurônios do SOM e os círculos azuis, os símbolos da constelação. É importante destacar que, como se realiza uma iteração de treinamento para cada símbolo QAM recebido, a progressão dos vetores peso na Figura 32 ocorre com a recepção/execução de: 1 símbolo/iteração (a), 50 símbolos/iterações (b), 100 símbolos/iterações (c), 150 símbolos/iterações (d), 200 símbolos/iterações (e) e 400 símbolos/iterações (f). A escolha da aplicação de identificação da constelação QAM como primeiro experimento da arquitetura para execução do SOM em FPGA também se deve à facilidade de acompanhamento da progressão do processo de treinamento da rede. Esta condição constitui um cenário favorável para testes e avaliações do hardware proposto de 
implementação do SOM. Como pode ser visto na Figura 33, o experimento permite observar os efeitos dos diferentes valores adotados para o fator $\alpha$ de aprendizagem computado em hardware por deslocamentos binários - e para o fator $\beta$ de abertura da função de vizinhança alternativa (segundo as propostas apresentadas na seção 4.2 e na seção 4.3 no capítulo sobre as propriedades da execução do SOM em FPGA). A Figura 33 mostra a porcentragem de identificação correta de símbolos QAM com a mesma condição do canal de comunicação para três diferentes conjuntos de parâmetros de execução do SOM em FPGA. Novamente, as condições desses ensaios foram as mesmas utilizadas na pesquisa Loss et al. (2007): $35 \mathrm{~dB}$ de relação sinal/ruído e $5 \%$ de distorção na $2^{\mathrm{a}}$ e $3^{\mathrm{a}}$ harmônicas do sinal 16-QAM transmitido pelo canal 7 do repositório SPIB.

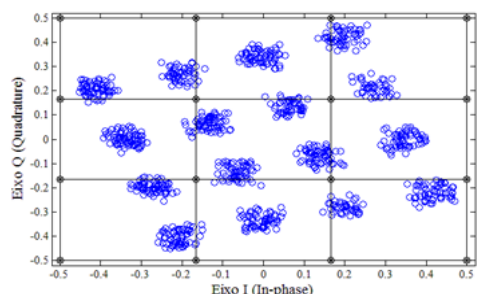

(a)

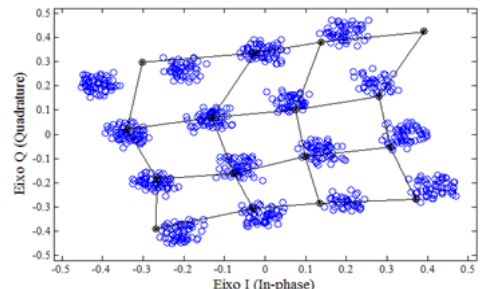

(c)

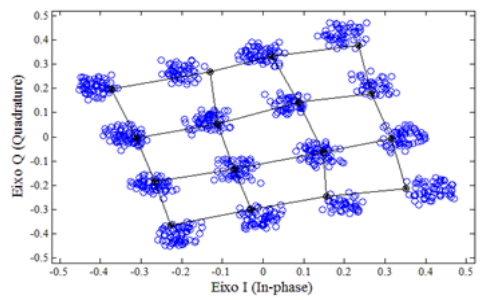

(e)

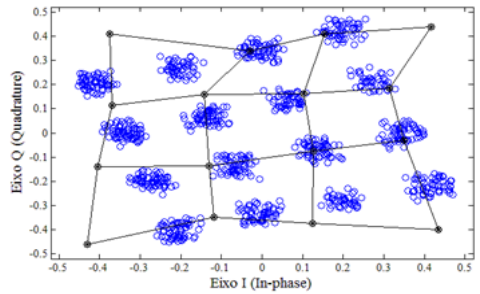

(b)

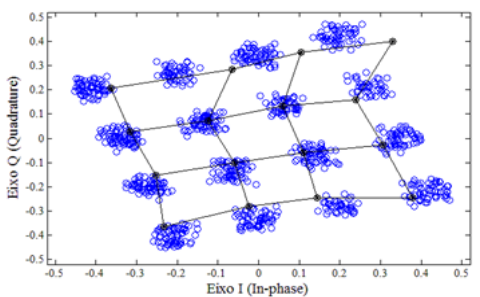

(d)

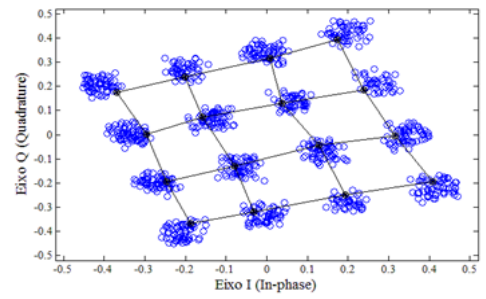

(f)

Figura 32 - Progressão do processo de aprendizagem em hardware para identificação de sinais QAM após inicialização dos pesos, no quadro (a), com posição original da constelação sem distorção (círculos pretos para os vetores peso do SOM e os círculos azuis para os símbolos da constelação). Ilustração de seis momentos do treinamento, segundo o número de iterações: (a) 1 ; (b) 50; (c) 100; (d) 150; (e) 200; e (f) 400.

Nota-se na Figura 33(a), com $\alpha=0,125$ e $\beta=3$, a ocorrência de uma estabilização satisfatória na taxa de identificação correta após a recepção de 
aproximadamente 250 símbolos da constelação 16-QAM distorcida. Na situação (b), com $\alpha=0,25$ e $\beta=2$, verifica-se que o mapeamento da constelação distorcida foi alcançado com maior rapidez, porém sem que ocorra uma estabilização satisfatória da taxa de identificação. Por fim, na situação (c), $\operatorname{com} \alpha=0,5$ e $\beta=5$, não se alcança a estabilização durante o processo de treinamento do SOM. Percebe-se que, da mesma forma feita nos ensaios em software com diferentes parâmetros neurais durante o desenvolvimento de aplicações, o comportamento do SOM em FPGA deve ser ajustado pela sintonia dos valores de configuração da rede.

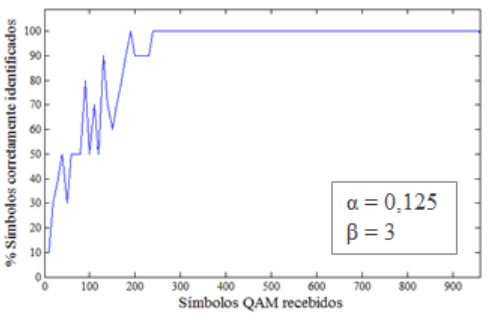

(a)

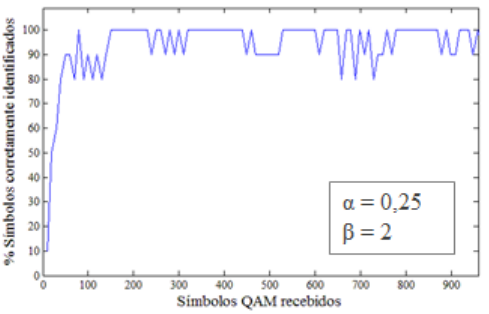

(b)

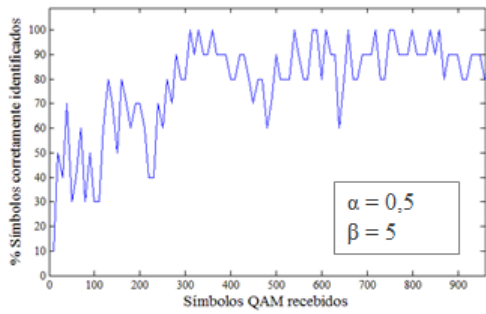

(c)

Figura 33 - Progressão do processo de treinamento do SOM em FPGA configurado com diferentes parâmetros: (a) $\alpha=0,125$ e $\beta=3$, (b) $\alpha=0,25$ e $\beta=2$, (c) $\alpha=0,5$ e $\beta=5$.

Tendo estabelecidos os parâmetros da rede, realizaram-se testes da arquitetura proposta com sete canais de comunicação para levantamento da taxa de erro de bit em uma função da relação sinal/ruído. Os canais SPIB selecionados foram escolhidos para abranger diferentes cenários de distorção. Para cada canal, realizou-se um experimento com 500 símbolos iniciais de treinamento da rede (sem considerá-los na medição da porcentagem de reconhecimento), em seguida apresentaram-se à arquitetura de circuito do SOM 10k símbolos para a medição da taxa de erro de bit com 5\% de distorção na $2^{\mathrm{a}}$ e $3^{\mathrm{a}}$ harmônicas do sinal. O experimento foi repetido mais 12 vezes para variação dos valores da relação sinal/ruído de 0 a $36 \mathrm{~dB}$, em degraus de $3 \mathrm{~dB}$. O resultado está apresentado na Figura 34.

$\mathrm{Na}$ Figura 34, a parada precoce das curvas parcelas para os canais 4, 8, 9, $10 \mathrm{e}$ 11 significa que o SOM identificou corretamente todos os símbolos QAM durante o aumento progressivo do valor da relação sinal/ruído. Os resultados das curvas plotadas na figura são melhores ou semelhantes ao desempenho de outros trabalhos, tais como Rathkanthiwar; Dethe e Kulat (2011), Javidi e Khoshbin (2013) e Muhammad, Tepe e Abdel-Raheem (2013), os quais utilizam softwares 
para testes de suas metodologias. A análise completa dos experimentos do SOM em FPGA para a identificação de sinais 16-QAM está publicada revista da Springer, Neural Computing and Applications (SOUSA; PIRES; DEL-MORAL-HERNANDEZ, 2017).

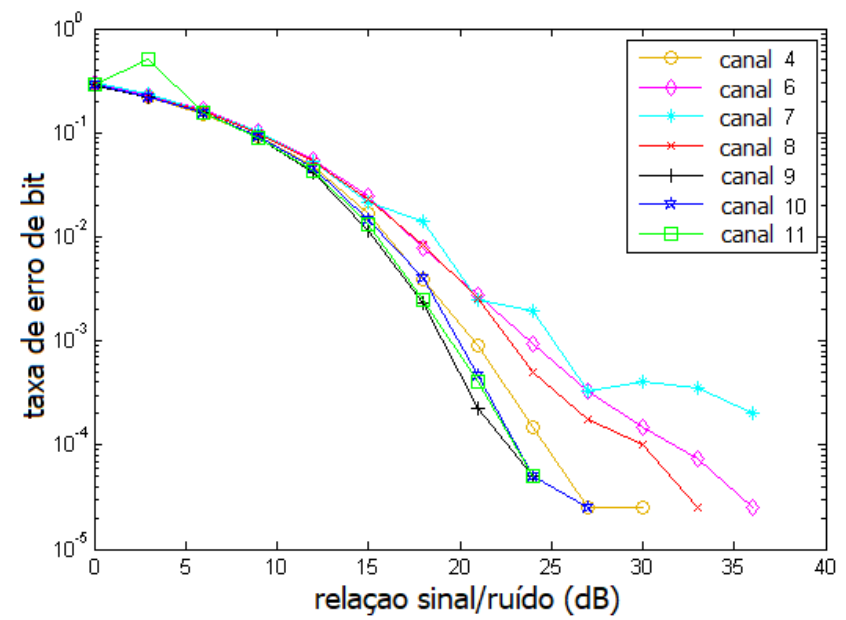

Figura 34 - Taxa de erro de bit em função da relação sinal/ruído da execução do SOM em FPGA para sete diferentes canais da base de dados SPIB.

Para o segundo conjunto de experimentos, implementou-se uma configuração de 8x8 neurônios do SOM para identificação de sinais 64-QAM. A Figura 35 mostra o resultado obtido para o canal 4 SPIB com 35dB de relação sinal/ruído e 5\% de distorção na $2^{\mathrm{a}}$ e $3^{\mathrm{a}}$ harmônicas do sinal, características que impõem um cenário de maior distorção do sinal, semelhante à condição ilustrada nos quadros à esquerda da Figura 31 (símbolos em verde).

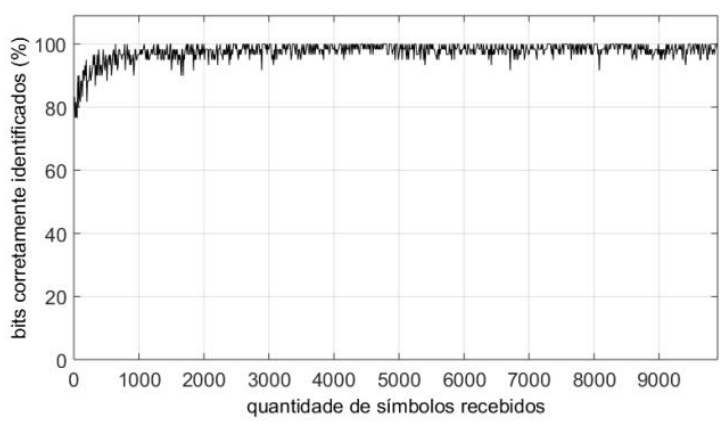

(a)

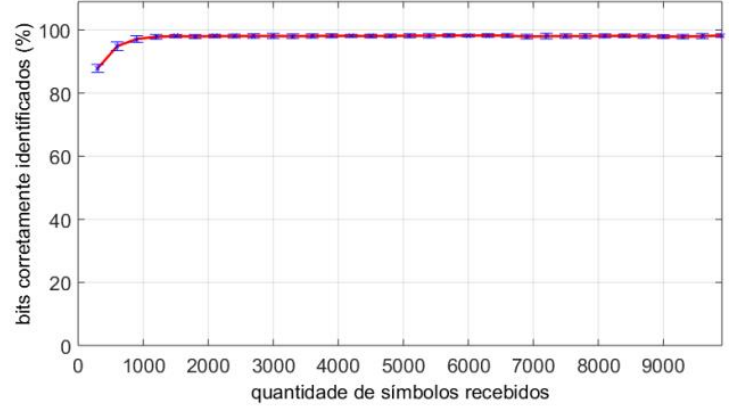

(b)

Figura 35 - Desempenho da implementação do SOM em hardware para reconhecimento de 64QAM distorcido pelo canal 4 SPIB: bits corretamente identificados pela quantidade de símbolos recebidos (a) e repetição do experimento 35 vezes para cálculo da média e do desvio padrão (b).

A Figura 35(a) mostra a porcentagem de bits corretamente identificados pela quantidade de símbolos recebidos ao longo do tempo para um experimento. A porcentagem é calculada usando os 10 símbolos mais recentemente recebidos. Pode-se perceber que, enquanto o sistema recebe os primeiros 1000 símbolos, seu desempenho 
aumenta continuamente, pois o SOM está se ajustando às características de distorção. Após esta fase, o SOM mantém-se em um estado de identificação correta de $90 \%$ a $100 \%$ dos dados recebidos. Para obter resultados estatisticamente robustos, o teste foi repetido 35 vezes mantendo-se as condições constantes e com séries aleatórias diferentes de símbolos. A Figura 35(b) mostra a média da porcentagem de bits corretamente identificados (linha vermelha) e o desvio padrão (barras azuis). Para melhor visualização da figura, cada porcentagem foi calculada usando os 300 símbolos mais recentes. Nota-se que, depois de receber 1000 símbolos iniciais, o desempenho da arquitetura do SOM mantém-se perto de $100 \%$, com desvio muito pequeno. O mesmo conjunto de experimentos foi repetido para o canal 9 da base de dados SPIB, cujas características impõem um cenário de menor distorção do sinal, semelhante à condição ilustrada nos quadros à direita da Figura 31 (símbolos em vermelho). Os resultados estão apresentados na Figura 36.

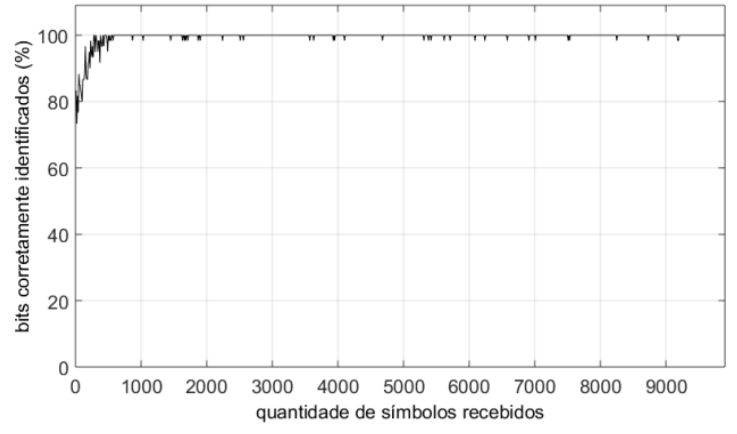

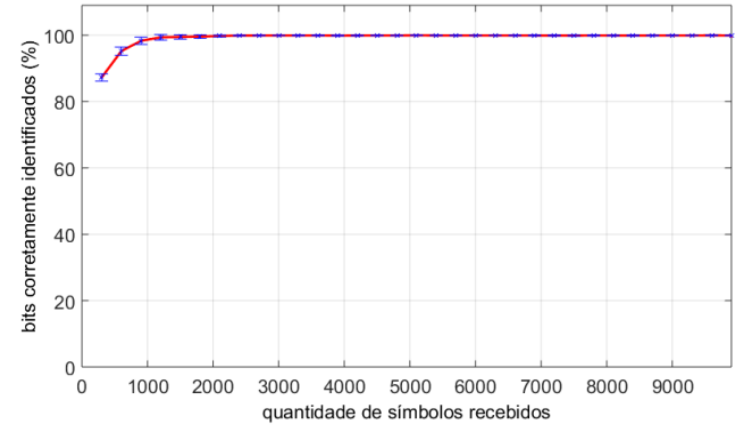

(b)

Figura 36 - Desempenho da implementação do SOM em hardware para reconhecimento de 64QAM distorcido pelo canal 9 SPIB: bits corretamente identificados pela quantidade de símbolos recebidos (a) e repetição do experimento 35 vezes para cálculo da média e do desvio padrão (b).

Pelos resultados mostrados na Figura 36, pode-se verificar que neste experimento a porcentagem de identificação correta de bits é superior à obtida para o canal 4 (Figura 35), pois o cenário de ruído é menor. Para este caso, a estabilização do desempenho da rede ocorre perto de $100 \%$, com pequenos desvios. No decorrer do desenvolvimento desses conjuntos de experimentos, conclui-se que a fundamentação para o uso do modelo SOM para identificar sinais QAM é a representação de dados semelhantes pelos neurônios próximos no mapa obtido após o treinamento, da mesma forma que os símbolos próximos na constelação representam conjuntos similares de bits (como pode ser visto na Figura 28). A Tabela 15 mostra os dados de implementação da arquitetura SOM para identificação de 
sinais 64-QAM no chip FPGA Artix-7 xc7a200 da Xilinx obtidos pela ferramenta de descrição de hardware Vivado (CHURIWALA, 2016).

Tabela 15 - Dados da implementação em FPGA para arquitetura do SOM na identificação de sinais 64-QAM.

\begin{tabular}{|l|l|}
\hline Frequência máxima de operação & $35,7 \mathrm{MHz}$ \\
\hline Área ocupada do chip & 14.758 LUTs das 133.800 LUTs disponíveis \\
\hline Potência consumida & $288 \mathrm{~mW}$ \\
\hline
\end{tabular}

Pela Tabela 15, pode-se perceber que a frequência obtida é suficiente para atender aplicações de telecomunicações que utilizam OFDM, com consumo baixo de energia. Por exemplo, a transmissão de sinais da TV digital Terrestre tem duração de símbolo QAM entre 120 a $4000 \mu$ s, ou seja, requer uma frequência de operação máxima de $8,3 \mathrm{MHz}^{19}$. Além disso, a arquitetura proposta para execução do SOM na identificação de sinais 64-QAM utiliza apenas $11 \%$ dos recursos disponibilizados pelo FPGA Artix-7, que é um chip de densidade moderada (ou seja, possui custo e consumo de energia moderados). A área remanescente do dispositivo permite a inclusão de outros blocos de processamento de um sistema de comunicação OFDM, cujas implementações em FPGA já foram publicadas em trabalhos da literatura, como Lin, Shao e Zhang (2010) sobre filtros casados (em inglês, "matched filters") e Dick e Harris (2002) sobre sincronizadores de fase e frequência da portadora.

\subsection{ARQUITETURA SOM COM APRENDIZADO CONTÍNUO PARA IDENTIFICAÇÃO DE SINAIS QAM NÃO ESTACIONÁRIOS}

A base de dados SPIB utilizado nos experimentos da seção anterior e do Apêndice D contém dados reais obtidos em canais de transmissão com diferentes efeitos de distorção - como, por exemplo, os três cenários apresentados na Figura 30 - porém estes efeitos são estáticos. Com o intuito de se ampliar tais condições para que seja possível estudar o comportamento da arquitetura de circuito desenvolvida para execução

\footnotetext{
${ }^{19}$ Dados obtidos em "Frame stucture channel coding and modulation for the second generation digital terrestrial television broadcasting system (DVB-T2),” DVB Document A122, 2008.
} 
do SOM também em situações dinâmicas, utilizou-se um modelo para calcular a transição entre diferentes condições de distorção. De forma alternativa à condição estática, criaram-se efeitos de distorção que variam com o tempo por um processo de migração gradual entre as condições amostradas das respostas impulsivas de dois canais reais da base de dados SPIB. A proposta deste experimento é, portanto, verificar o desempenho da arquitetura neural executada em FPGA sob circunstâncias dinâmicas. Para tanto, utilizaram-se valores contínuos de fator de aprendizado e abertura da função de vizinhança. A Figura 37(a) mostra a variação ao longo do tempo da constelação QAM - a ser identificada pelo SOM - para uma sequência de 10k símbolos com condições de distorção variando do canal 4 para o canal 6. Pode se notar na figura que os símbolos vão de um posicionamento correspondente ao canal 4 (cores mais claras) para um posicionamento que correspondente ao canal 6 (cores mais escuras). Para obter-se o giro da constelação QAM, seguiu-se a proposta de Sousa, Pires e Del-Moral-Hernandez (2017) na qual se usou as características do canal 4 em 30\% do tempo inicial da produção de símbolos e em 30\% do tempo final, as características do canal 6. No tempo intermediário, fez-se uma transição gradativa entre as características dos dois canais, seguindo o modelo matemático proposto no artigo. Além da transição entre os canais adicionou-se $35 \mathrm{~dB}$ de relação sinal/ruído e $5 \%$ de distorção na $2^{\mathrm{a}}$ e $3^{\mathrm{a}}$ harmônicas do sinal, de acordo com a proposta de Loss et al. (2007). A Figura 37(b) contém a repetição do experimento para os mesmos parâmetros, mas para uma série de apenas $1 \mathrm{k}$ símbolos QAM, para ilustrar o comportamento da constelação sob mudanças rápidas nas condições do canal.

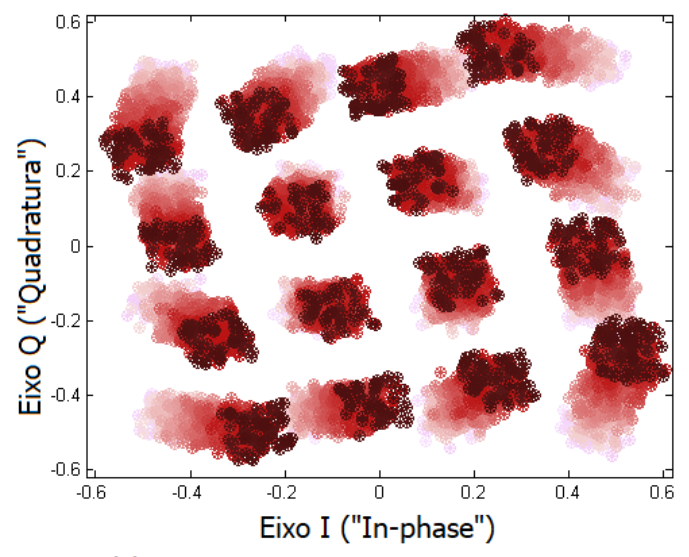

(a)

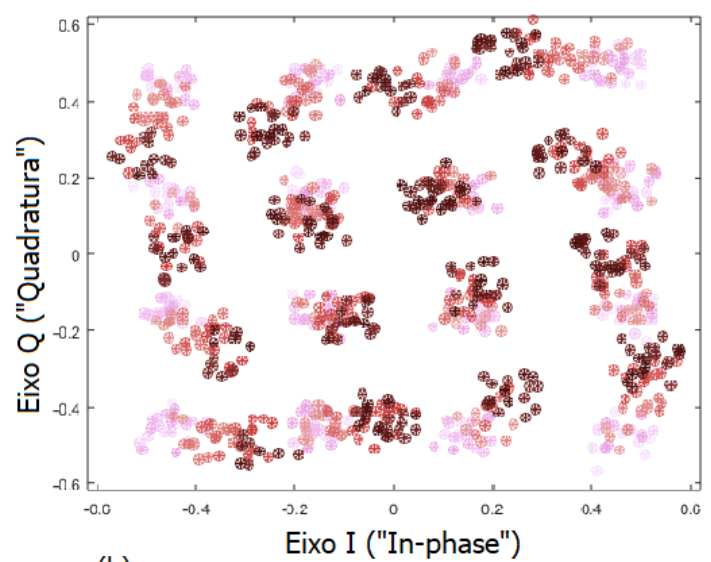

(b)

Figura 37 - Sinais 16-QAM dinâmicos compostos por (a) 10k símbolos e por (b) 1k símbolos. As cores menos intensas identificam o início da sequência transmissão, sujeita às condições de ruído do canal 4; as cores mais intensas identificam o final da sequência transmissão, sujeita às condições de ruído do canal 6; as cores de intensidade intermediária identificam a transição entre ambos os canais. 
Os resultados do desempenho do SOM executado pela arquitetura FPGA proposta são apresentadas na Figura 38, com a taxa identificação correta durante a recepção de $10 \mathrm{k}$ e $1 \mathrm{k}$ símbolos de entrada, respectivamente. Pode-se ver que, igualmente aos experimentos com cenários invariantes no tempo, a implementação do SOM atingiu um melhor desempenho depois de receber as primeiras centenas de símbolos e que conseguiu manter esse desempenho mesmo diante de uma transição entre os canais. Nas condições do experimento da Figura 38(b) usando apenas 1k símbolos, a taxa de símbolos corretos aumentou consistentemente, mesmo o SOM não tendo tempo para estabilização no primeiro modelo de canal (300 símbolos iniciais).

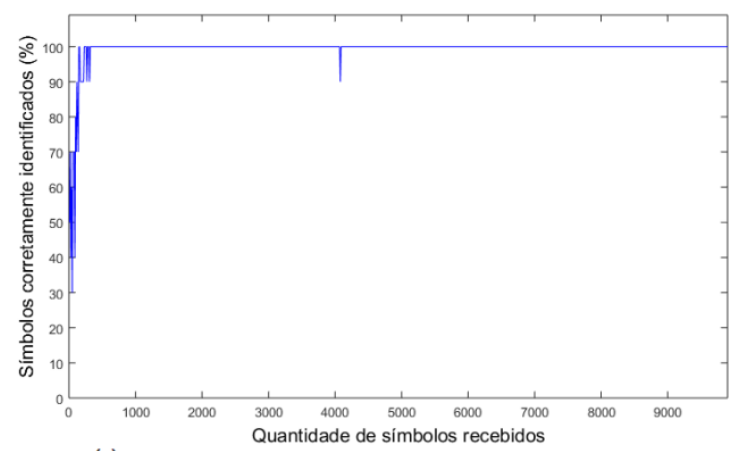

(a)

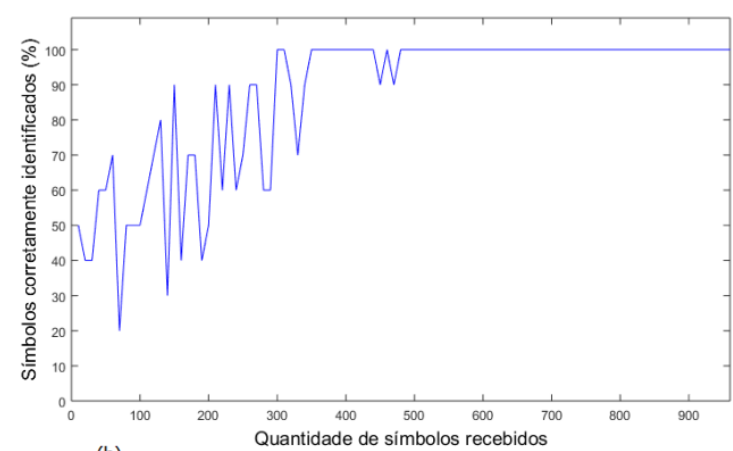

(b)

Figura 38 - Progressão do processo de treinamento do SOM executado em FPGA submetido a uma condição dinâmica de distorção das amostras de entrada: (a) rotação mais lenta, ocorrendo em 10k símbolos e (b) com uma rotação mais rápida, ocorrendo em $1 \mathrm{k}$ símbolos.

Considerando que situações de características dinâmicas - como esta proposta de transição entre dois canais de transmissão - podem servir como plataforma de estudo para a continuação da pesquisa sobre a metodologia de desenvolvimento de execuções diretas do SOM em FPGA sob o paradigma de aprendizado contínuo, cada um desses dois experimentos (10k e 1k símbolos) foi repetido 35 vezes, com diferentes sequências aleatórias de símbolos. Os resultados são mostrados na Figura 39, com a média da porcentagem dos símbolos corretamente identificados (linha vermelha) e o desvio padrão (barras azuis).

A partir dos resultados obtidos, pode-se perceber que a estabilização da implementação do SOM é alcançada após cerca de 500 símbolos e, em sequência, a rede mantém uma tendência de estabilização na taxa do reconhecimento. A repetição do experimento com 1k símbolos, no qual não há tempo para estabilização do SOM antes do início da migração da constelação - Figura 39(b) - confirma o desempenho da 
implementação em situações de mudanças rápidas nas condições de ruído do sinal. Finalmente, a Figura 40 mostra a taxa de erro de bits como uma função da relação sinal/ruído, para três casos de migração das condições de distorção, usando seis canais do repositório SPIB. Para cada caso, realizou-se um experimento com 500 símbolos iniciais de treinamento (sem considerá-los na medição da porcentagem de identificação) e, posteriormente, o processamento de 10k símbolos pelo SOM implementado em FPGA para a medição da taxa de erro de bits. Incrementou-se os valores da relação sinal/ruído entre os valores de 0 a $36 \mathrm{~dB}$, em passos de $3 \mathrm{~dB}$, com $5 \%$ de distorção na $2^{\mathrm{a}} \mathrm{e}$ $3^{\text {a }}$ harmônicas do sinal. No cenário de migração entre o canal 4 e o canal 6 da base de dados SPIB, há uma rotação intensa no sentido anti-horário. Entre o canal 7 e o canal 8 , há uma rotação intensa no sentido horário. Por fim, entre o canal 10 e o canal 11, há uma pequena rotação no sentido horário. A parada precoce da curva de migração do canal 10 para o canal 11 significa que a curva atingiu zero de taxa de erro de bits durante o aumento da relação sinal/ruído. Pela Figura 40, pode-se perceber que a intensidade das rotações naturalmente reflete-se na taxa de erro de bits.

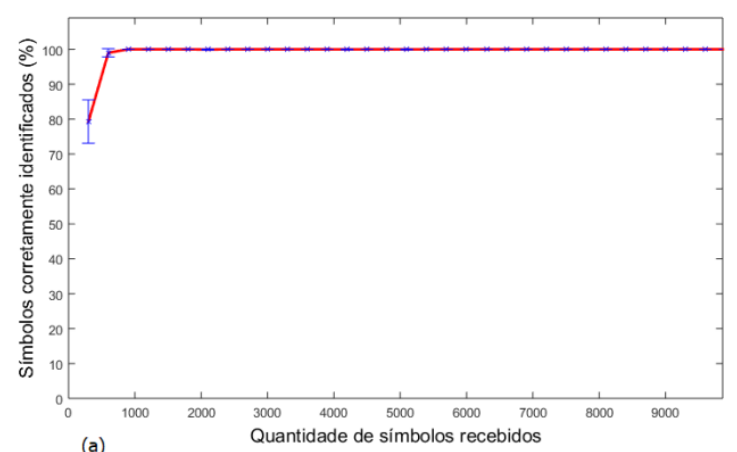

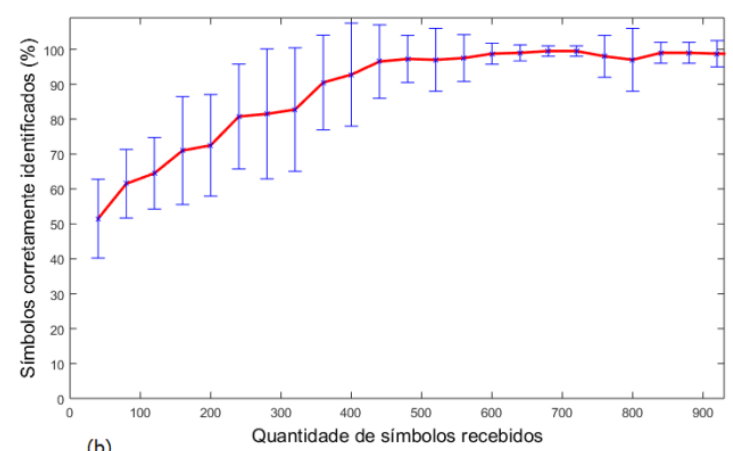

Figura 39 - Repetição dos experimentos anteriores 35 vezes para cálculo da média e do desvio padrão da taxa de acertos sob condições dinâmicas do sinal: 10k símbolos (a) e 10k símbolos (b).

Deve-se destacar que, ao se comparar a Figura 40 com a Figura 34 (experimentos sem transições entre canais), pode-se ver que a relação entre a taxa de erro de bits e o aumento da relação sinal/ruído não foi significativamente degradada com a introdução da dinâmica aos sinais a serem processados pela rede neural. Percebe-se também que a implementação do SOM em FPGA permanece robusta na presença de com características variáveis no tempo. Desta forma, o acompanhamento coerente que a arquitetura de circuito proposta é capaz de realizar da migração dos agrupamentos de símbolos da constelação QAM, quando submetido a condições dinâmicas de distorção, motiva que se realize uma pesquisa sobre o processo 
de aprendizado contínuo da rede neural ${ }^{20}$. Arquiteturas de circuito para modelos de aprendizado dinâmico do SOM não serão estudados com maior profundidade neste trabalho, gerando, assim, uma importante ramificação para trabalhos futuros. A relevância de uma continuação futura dessa pesquisa é possibilitar que o chip opere com aprendizado contínuo em ambientes em que as características das informações a serem processadas sofram modificações ao longo do tempo.

Tendo concluído com êxito os ensaios e experimentos da arquitetura e componentes básicos para a implementação do SOM, o próximo capítulo apresenta a exploração de estratégias computacionais, as quais foram adicionadas a esta arquitetura com o objetivo de potencializar o desempenho dos circuitos de processamento discutidos neste capítulo.

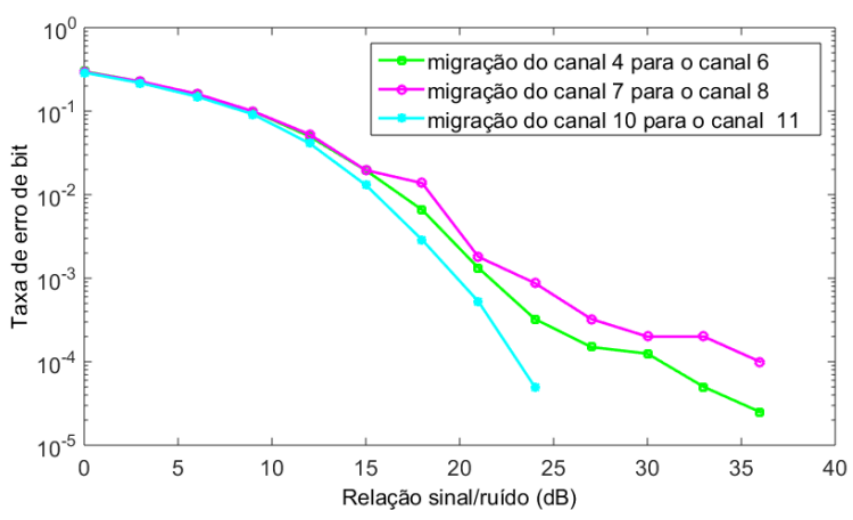

Figura 40 - Taxa de erro de bit em função da relação sinal/ruído para a implementação do SOM em três cenários de migração 16-QAM entre canais SPIB diferentes.

\footnotetext{
${ }^{20}$ Um estudo preliminar sobre a implementação em FPGA do SOM aplicado a condições dinâmicas de distorção do fluxo de dados processados foi publicado na revista Neural Computing and Applications (SOUSA; PIRES; DEL-MORAL-HERNANDEZ, 2017)
} 


\section{DESENVOLVIMENTO DO PROCESSADOR SOM BASEADO EM FPGA - EXPLORAÇÃO DE ESTRATÉGIAS COMPUTACIONAIS PARA POTENCIALIZAR O DESEMPENHO DA IMPLEMENTAÇÃO}

Este capítulo reúne as elaborações discutidas nos dois capítulos anteriores para apresentar o desenvolvimento do processador SOM baseado em FPGA, com a exploração de recursos de processamento para melhoria da taxa de fluxo de dados e otimização dos recursos utilizados no chip. Desta forma, as propriedades da computação do SOM em hardware fundamentadas no capítulo 4 e resumidas na Tabela 8 (métrica de similaridade, cálculos do fator de aprendizagem e função de vizinhança, aritmética binária e representação das variáveis internas) são empregadas na elaboração da arquitetura de circuito. Do mesmo modo, as opções feitas a partir da metodologia e experimentação realizadas no capítulo 5 são adotados na elaboração do processador, tais como, o modelo centralizado de execução do SOM (seção 5.3) e a estrutura de descrição de hardware (seção 5.7). O processador SOM permite implementar o algoritmo de treinamento (Tabela 6) e o algoritmo de operação (Tabela 7) discutidos na seção 4.4. Este capítulo também apresenta, ao final, a aplicação do processador SOM desenvolvido ao processamento imagens para reconhecimento de ações humanas (seção 6.2). A aplicação utiliza uma base de dados de vídeos com gestos executados por diferentes pessoas, de forma livre quanto à sequência de movimentos e à direção de posicionamento em relação à câmera.

O desenvolvimento deste sistema, identificado como SOMprocessor, foi motivado pelos resultados favoráveis obtidos na aplicação preliminar de telecomunicações. Conforme apresentado na seção 5.8, a topologia da rede neural em tal aplicação empregou SOMs com, respectivamente, 32 e 128 conexões neurais $^{21}$. O SOMprocessor foi construído, portanto, para que se possa estudar a arquitetura de circuito em FPGA na implementação de mapas contendo um volume maior de conexões neurais - na ordem de milhares - pois tais configurações são comuns em aplicações de SOM (HAYKIN, 2007). Além de tal motivação - a execução de mapas de maior porte o desenvolvimento do SOMprocessor também objetivou:

\footnotetext{
${ }^{21}$ Esta aplicação de telecomunicações utilizou a arquitetura SOM em FPGA para identificar símbolos de constelações 16-QAM e 64-QAM. Considerando que a topologia da rede neural para cada constelação é de 16 e 64 neurônios, e que os símbolos QAM requerem entradas bidimensionais (sinais IQ - "In-phase e Quatrature"), totalizou-se 32 e 128 conexões neurais, respectivamente.
} 
1. Criar uma arquitetura de circuito para FPGA que pudesse ser empregada em chips de densidade moderada para implementar SOMs com grande número de conexões neurais. Este objetivo é justificado por uma linha de pesquisa que investiga arquiteturas de hardware para serem executadas em chips de baixo e médio custo - ao invés de FPGAs de alto custo - como, por exemplo, os trabalhos de Kurdthongmee (2008); Linares-Barranco et al. (2010); Kurdthongmee (2011) e Séguin-Godin, Mailhot e Rouat (2015).

2. Obter maior velocidade de processamento, principalmente na fase de treinamento do SOM, a fim de possibilitar que se alcance a capacidade de tratamento de informações necessária para a execução das aplicações relacionadas na seção 2.3, tais como a computação embarcada em plataformas móveis que requeiram execução em tempo real e a aceleração do processamento de imagens e vídeos. Este objetivo de velocidade de processamento também faz parte do escopo específico deste trabalho, apresentado na seção 1.2.

Para atender estes propósitos, o SOMprocessor tem como base a arquitetura de circuito apresentada na Figura 16 da seção 5.3 e os componentes de computação básicos de execução do SOM (Figura 17, Figura 20 e Figura 21 da mesma seção), os quais já foram avaliados experimentalmente (na seção 5.8). A partir desta arquitetura básica, o processador foi desenvolvido incorporando-se os seguintes componentes:

- Circuitos multiplexadores para que se possa utilizar alternadamente blocos fixos de processamento por diferentes grupos de dados. Esta adição objetiva atender ao requisito de possibilitar o uso de FPGAs de densidade moderada, abordado no item 1 da página 121. Com o uso da multiplexação, alguns blocos de circuitos existentes na arquitetura SOM, como os componentes de cálculo de distância, por exemplo, podem ser reaproveitados por conjuntos diferentes de vetores peso - de maneira alternada - até que todos os neurônios tenham sido computados por um bloco de cálculo de tamanho fixo. Tal estratégia de multiplexação também é empregada para o reaproveitamento dos circuitos de busca pelo neurônio vencedor e dos circuitos de atualização de pesos, conforme pode ser observado no diagrama de blocos do SOMprocessor na Figura 41. 
Assim, um circuito de controle adicional foi incorporado à arquitetura de processamento do SOM para realizar a seleção ordenada dos multiplexadores.

- Circuitos registradores de armazenamento temporário de valores intermediários de computação para que a estratégia de processamento em pipeline $^{22}$ possa ser empregada na execução do SOM. Esta adição objetiva atender ao requisito de velocidade computacional, abordado no item 2 da página 121. O circuito de controle adicional utilizado na seleção dos multiplexadoers também é usado para realizar a coordenação da sequência de armazenamento de dados. Tal controle é operado pela ativação encadeada dos registradores entre os diferentes circuitos computacionais, conforme pode ser observado na Figura 41.

\section{Diagrama de blocos do sistema SOM}

Pinos de entrada do chip

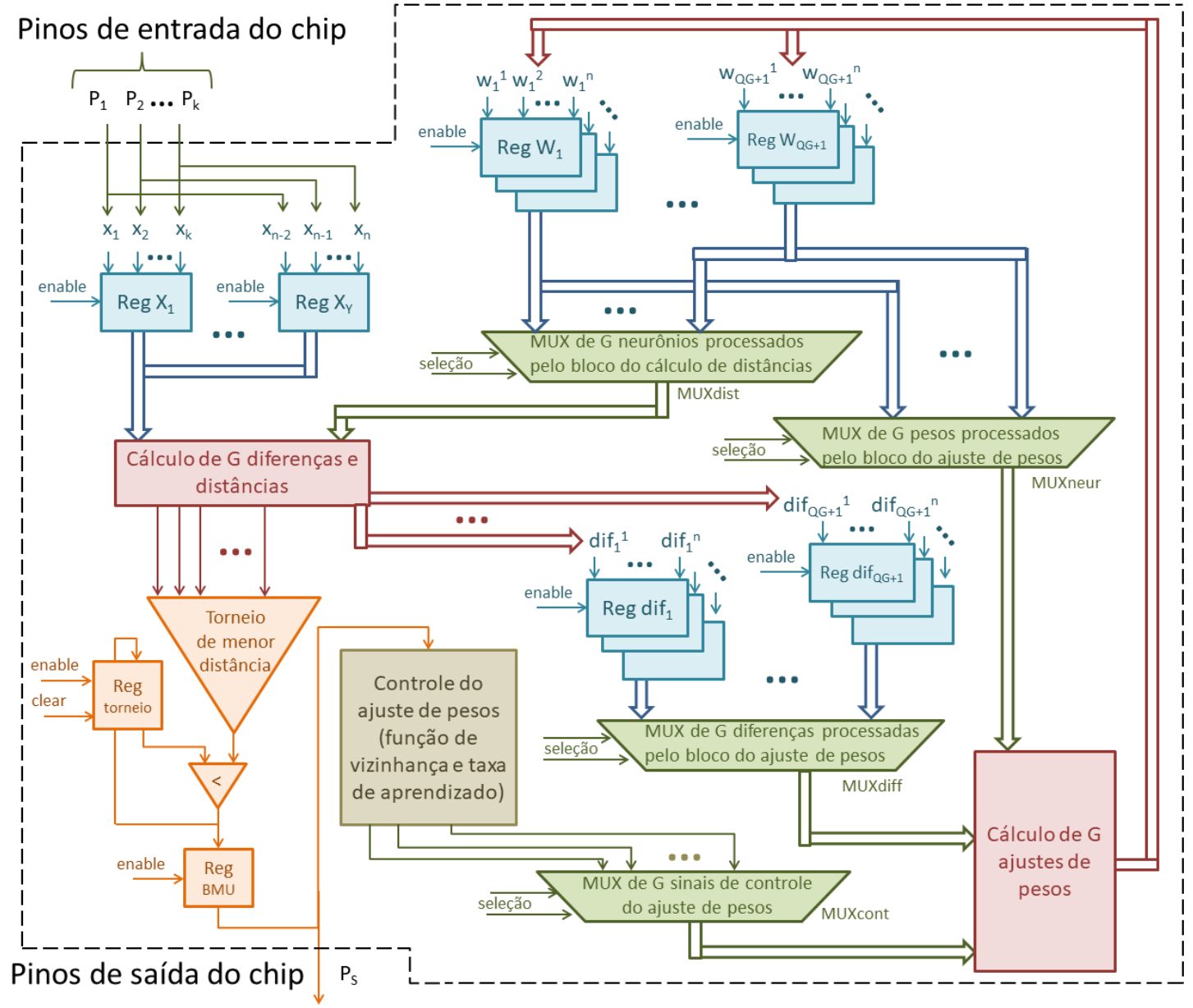

Figura 41 - Diagrama de blocos do SOMprocessor: arquitetura de circuito para processamento de redes com grande volume de conexões neurais pela incorporação de componentes multiplexadores e registradores ao circuito básico de processamento do SOM.

\footnotetext{
${ }^{22}$ A técnica de pipeline pode ser entendida como a subdivisão do processamento em etapas, de modo que cada etapa seja executada por uma parte especializada do circuito computacional, permitindo que mais de um processamento seja calculado simultaneamente (SHEN; LIPASTI, 2013).
} 
A descrição detalhada do funcionamento do diagrama de blocos do SOMprocessor será feita a seguir. Esta descrição está dividida em três partes: Recepção do vetor de entrada/identificação do neurônio vencedor (processo comum tanto à fase de treinamento quanto à fase de operação do SOM), Atualização da matriz de pesos (processo executado apenas durante a fase de treinamento) e Unidade de Controle. Após o detalhamento do funcionamento do processador, será apresentada, na seção 6.2, a aplicação de reconhecimento de vídeos, a qual servirá de plataforma de testes e caracterização do sistema proposto.

\section{Recepção do vetor de entrada/identificação do neurônio vencedor:}

As primeiras três etapas de processamento realizadas pelo SOMprocessor são responsáveis pela recepção dos valores de entrada da rede, cálculo dos valores de distância e identificação do vetor peso mais similar ao vetor de entrada. Conforme pode ser visto na Figura 41, a informação $\left(\boldsymbol{x}_{\boldsymbol{i}}\right)$ a ser processada pelo SOM é admitida no FPGA por $\boldsymbol{P}_{\mathbf{1}}$ até $\boldsymbol{P}_{\boldsymbol{k}}$ com $k$ representando o número de componentes vetoriais recepcionados por 1 registrador de entrada. Cada um destes $\boldsymbol{P}_{\boldsymbol{i}}$ é composto, inicialmente, por um conjunto de 16 pinos para possibilitar a entrada paralela de dados de 16 bits, totalizando i $x 16$ portas de entrada. A opção por 16 bits está detalhada no capítulo 4 sobre as propriedades da computação do SOM em hardware e pode ser alterada pela configuração do parâmetro de resolução de representação de dados, descrito usando VHDL em alto nível, conforme a discussão realizada na seção 5.7. Dispositivos FPGA contam com uma grande quantidade de portas ${ }^{23}$ de entrada e saída, contudo foram incluídos os registradores de entrada $\operatorname{Reg} X_{1}$ até $\operatorname{Reg} X y$ para possibilitar a memorização de partes do vetor de entrada quando sua admissão inteiramente paralela não for possível (a Figura 42, extraída do diagrama de blocos da Figura 41, destaca em detalhes os registradores de entrada). A ativação desses registradores - assim como todos os outros registradores do sistema - é coordenada pelo circuito de controle, cujo funcionamento está detalhado ao final desta seção.

O dado de entrada armazenado pelos registradores $\operatorname{Reg} X_{1}$ a $\operatorname{Reg} X y$ é disponibilizado para o bloco seguinte, identificado na Figura 41 como Cálculo de $G$ diferenças e distâncias. O circuito do utilizado na arquitetura deste bloco é o mesmo circuito apresentado na seção 5.3 (Figura 17) para cálculo da distância de Manhattan, exceto por ser configurado para computar paralelamente os vetores de um subgrupo de

\footnotetext{
23 A quantidade de postas de chips FPGA varia desde 100 pinos nos modelos mais simples até aproximadamente 1500 pinos nos dispositivos de maior capacidade.
} 


\section{$G$ neurônios. O identificador $G$ aponta a quantidade de neurônios que será} processado simultaneamente pelo SOMprocessor. Além do bloco de Cálculo de distâncias, este subgrupo de $G$ neurônios é constante para outros dois blocos computacionais fundamentais do sistema: Busca pelo neurônio vencedor e Atualização de pesos. Por exemplo, em uma implementação de uma rede com SOM 10x10 - um total de 100 neurônios - e com $G=20$, o SOMprocessor será configurado para computar cinco blocos de 20 neurônios a fim de concluir uma iteração completa de processamento (em cinco ciclos) a cada entrada admitida no FPGA.

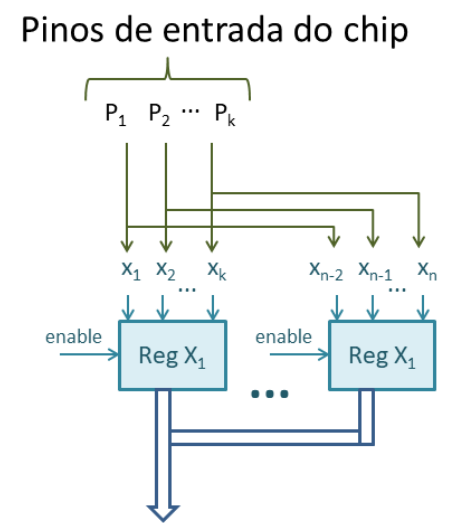

Figura 42 - Detalhe do registradores de entrada (inteiramente ilustrado no diagrama de blocos do SOMprocessor da Figura 41).

Além de receber o vetor de entrada $\left(\boldsymbol{x}_{\boldsymbol{i}}\right)$, o bloco de Cálculo de $G$ diferenças $e$ distâncias também recebe um subgrupo de $G$ vetores peso para poder iniciar sua computação (como pode ser visto na Figura 43, que detalha parte do diagrama de blocos do SOMprocessor apresentado inteiramente na Figura 41). Os vetores peso são armazenados pelos registrados de peso $^{24} \operatorname{Reg} W_{l}$ até $\operatorname{Reg} W_{j}$ e um componente multiplexador seleciona qual subgrupo de $G$ vetores será processado. Este componente está identificado na Figura 41 e na Figura 43 como MUX de G neurônios processados pelo bloco do cálculo de distâncias, cuja seleção ordenada é realizada pelo circuito controlador. Na sequência, o conjunto de resultados de $G$ cálculos de distância é enviado para o circuito de busca pelo neurônio vencedor: o Torneio de menor distância.

A arquitetura do bloco Torneio de menor distância é a mesma do circuito apresentado na Figura 18 (seção 5.3), exceto por admitir $G$ valores de distância para serem processados simultaneamente (de maneira semelhante ao circuito de Cálculo de

\footnotetext{
${ }^{24}$ Os pesos iniciais da rede são configurados juntamente com os demais parâmetros do SOM na etapa de síntese do circuito. Na inicialização do SOMprocessor, os registrados de peso Reg $W_{l}$ até $\operatorname{Reg} W_{j}$ são carregados com os valores dos pesos iniciais definidos pelo projetista do sistema e, durante a fase de treinamento, o conteúdo desses registradores é atualizado de acordo com o cálculo dos novos valores.
} 
distâncias já descrito). Outra diferença em relação à especificação da arquitetura realizada na seção 5.3, é que a saída do circuito de busca pelo neurônio vencedor é armazenada por um registrador do neurônio vencedor do torneio para que este seja comparada aos resultados dos demais torneios, a fim de identificar o menor valor de distância de toda a rede. Na Figura 44 pode-se identificar o circuito responsável por este processo no laço existente entre o Registrador de torneio e o comparador Menor de dois (identificado no diagrama de blocos por "<"), cuja arquitetura interna pode ser vista na Figura 20 da seção 5.3. Ao final do ciclo de comparações, o índice do neurônio vencedor é armazenado pelo Reg $B M U$ para ser disponibilizado para o circuito de controle do processo de atualização de pesos.

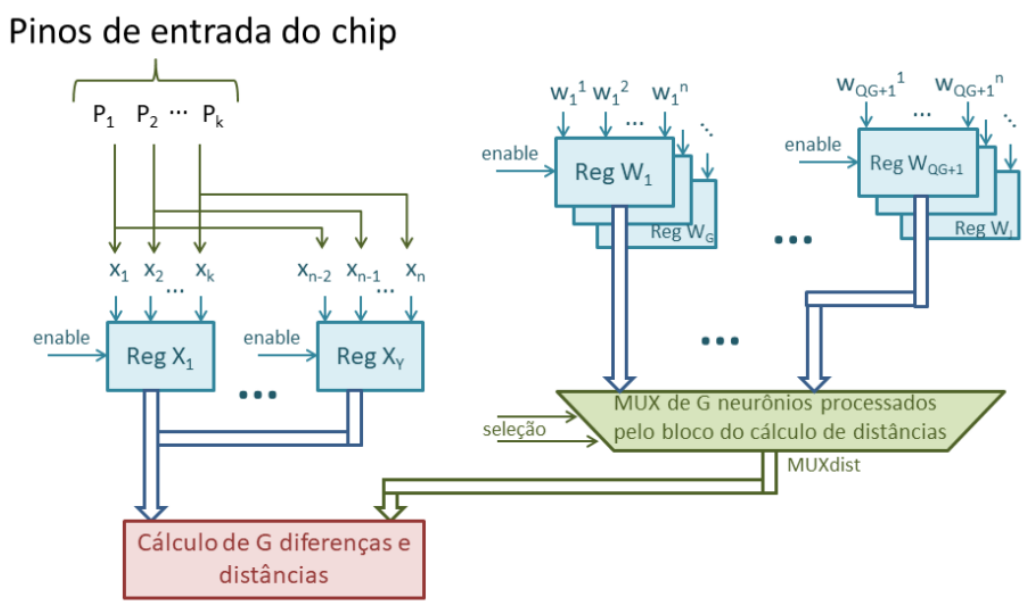

Figura 43 - Detalhe do bloco de Cálculo de $G$ diferenças e distâncias e suas entradas (inteiramente ilustrado no diagrama do SOMprocessor da Figura 41).

\section{Atualização da matriz de pesos da rede neural:}

As etapas seguintes de processamento são executadas para computar os cálculos de atualização de pesos, efetuados apenas na fase de treinamento do SOM. A primeira etapa é realizada pelo circuito de Controle do ajuste de pesos, cuja arquitetura é idêntica à descrição feita na seção 5.3 sobre o modelo centralizado de execução do SOM. Conforme desenvolvido na referida seção, a unidade de controle tem a função de distribuição dos sinais de distância de vizinhança $-\operatorname{dist}(c, j)$ - a todos os neurônios da rede, para serem usados na computação da função de vizinhança $h_{c_{j}}(t)$, de acordo com a descrição da Equação (3) da seção 3.4. Este bloco também dispõe de um contador de épocas de treinamento $(t)$ para poder computar os valores instantâneos do fator de aprendizagem $\alpha(t)$ e abertura da função de vizinhança $\beta(t)$, conforme a discussão sobre as propriedades de computação do SOM realizada no capítulo 4. O circuito de 
controle do ajuste de pesos é responsável, portanto, pela geração dos sinais de atualização dos vetores peso para todos os neurônios da rede (tanto os sinais coletivos, como o fator de aprendizagem, quanto os sinais particulares de cada neurônio, como o valor da função de vizinhança, dependente da distância entre cada neurônio e o neurônio vencedor). Como detalhado na seção 5.3, a produção dos sinais por este bloco especifica se o SOM está em modo de treinamento ou em modo de operação. Os sinais originados pela unidade de controle também determinam a configuração de arranjo de neurônios na grade de saída da rede: a dimensão $\boldsymbol{d}$ do espaço matricial $\mathbb{Z}^{\boldsymbol{d}}$ de saída, o formato do mapa e o modelo de interligação entre os neurônios do SOM (quadrado e hexagonal, por exemplo).

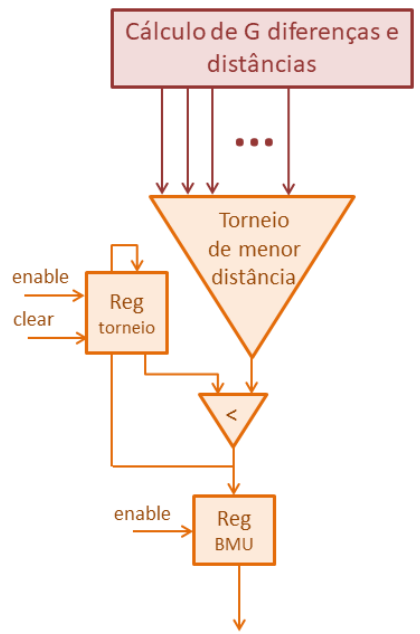

Figura 44 - Detalhe do bloco de busca pelo neurônio vencedor (inteiramente ilustrado no diagrama do SOMprocessor da Figura 41).

No entanto, da mesma forma que descrito anteriormente nos processos de recepção dos vetores de entrada e busca pelo neurônio vencedor, o ajuste de pesos realizado pelo SOMprocessor atualiza um subconjunto $G$ de vetores peso, alternadamente, até concluir a computação de todo o conjunto de neurônios da rede. Para tanto, também é utilizado um componente multiplexador para selecionar o subgrupo de sinais - gerados coletivamente pelo bloco de controle - que serão disponibilizados para o circuito de atualização dos vetores peso. Este multiplexador está identificado na Figura 45, que apresenta a parte do circuito responsável pelo ajuste de pesos, como MUX de G sinais de controle do ajuste de pesos. O circuito responsável pela computação dos novos valores de peso tem arquitetura idêntica ao circuito descrito na seção 5.3, exceto por ser configurado para executar a atualização de $G$ vetores peso por vez, e está identificado na Figura 45 como Cálculo de $G$ ajustes de pesos. Como 
pode ser visto na Figura 17, a operação de cada bloco depende da recepção de três sinais: vetor de diferenças $\left(\boldsymbol{d i} \boldsymbol{f}_{\boldsymbol{j}}\right.$ ), valor atual do vetor peso do neurônio $\boldsymbol{w}_{\boldsymbol{j}}$, e os sinais $\alpha(t)$ e $\beta(t)$, relacionados ao processo de treinamento, os quais são gerados pelo bloco de controle, para a computação da Equação (5) detalhada na seção 3.4. O vetor de diferenças $\left(\boldsymbol{d i f}_{\boldsymbol{j}}\right)$ é gerado pelo bloco de Cálculo de distâncias (detalhado no início da descrição deste diagrama de blocos), como parte da computação realizada no cálculo da distância, e seu valor é armazenado, desde então, para poder ser empregado no processo final de atualização de pesos. O circuito de computação dos novos valores de peso utiliza cada componente do vetor de diferenças do neurônio individualmente para poder ajustar todos os componentes do vetor peso (de forma a calcular a Equação (5) apresentada na seção 3.4 sobre as definições matemática e algorítmica do SOM). Como todos os vetores de diferenças são computados na etapa de cálculo de distância, eles são armazenados pelos registradores $\operatorname{Reg} \operatorname{dif}_{l}$ até $\operatorname{Reg} \operatorname{dif}_{j}$, e um componente multiplexador seleciona quais destes valores são processados pelo bloco Cálculo de G ajustes de pesos. Como pode ser visto no detalhe do diagrama de blocos apresentado na Figura 45, tal componente é identificado como MUX de G diferenças processadas pelo bloco do ajuste de pesos. Da mesma forma, se emprega um componente multiplexador para selecionar os valores de pesos atuais (subconjunto de $G$ vetores peso $\boldsymbol{w}_{\boldsymbol{j}}$ ) que serão atualizados, este componente é identificado por MUX de G pesos processados pelo bloco do ajuste de pesos. Em resumo, o bloco Cálculo de G ajustes de pesos recebe como entrada subgrupos de $G$ vetores de diferenças, $G$ vetores peso e $G$ sinais de controle (selecionados por três conjuntos de multiplexadores) para computar os novos valores de peso de $\boldsymbol{G}$ neurônios, alternadamente, até completar a atualização de todos os vetores peso do SOM. Os novos valores produzidos pelo bloco Cálculo de $G$ ajustes de pesos são armazenados pelos registradores de peso $\operatorname{Reg} W_{l}$ até $\operatorname{Reg} W_{j} \mathrm{e}$ disponibilizados, novamente, para comparação com um novo vetor de entrada. No instante de inicialização do SOMprocessor, estes registradores são carregados com os pesos iniciais, definidos na etapa de síntese do circuito e, após a inicialização, estes registradores têm seus valores sobrescritos a cada iteração da fase de treinamento.

A saída do SOMprocessor - em ambas as fases, treinamento e operação - é composta pelo índice do neurônio vencedor, registrado pelo Reg BMU (Figura 41), e é fornecida pelo FPGA por $\boldsymbol{P}_{\boldsymbol{s}}$, com $s$ representando o conjunto de 16 pinos de saída, de forma a possibilitar a comunicação paralela de valores de 16 bits. Novamente, a escolha 
por 16 bits como padrão está justificada na seção 4.3 e pode ser alterada pela configuração do parâmetro de resolução de representação de dados, conforme apresentado na seção 5.7.

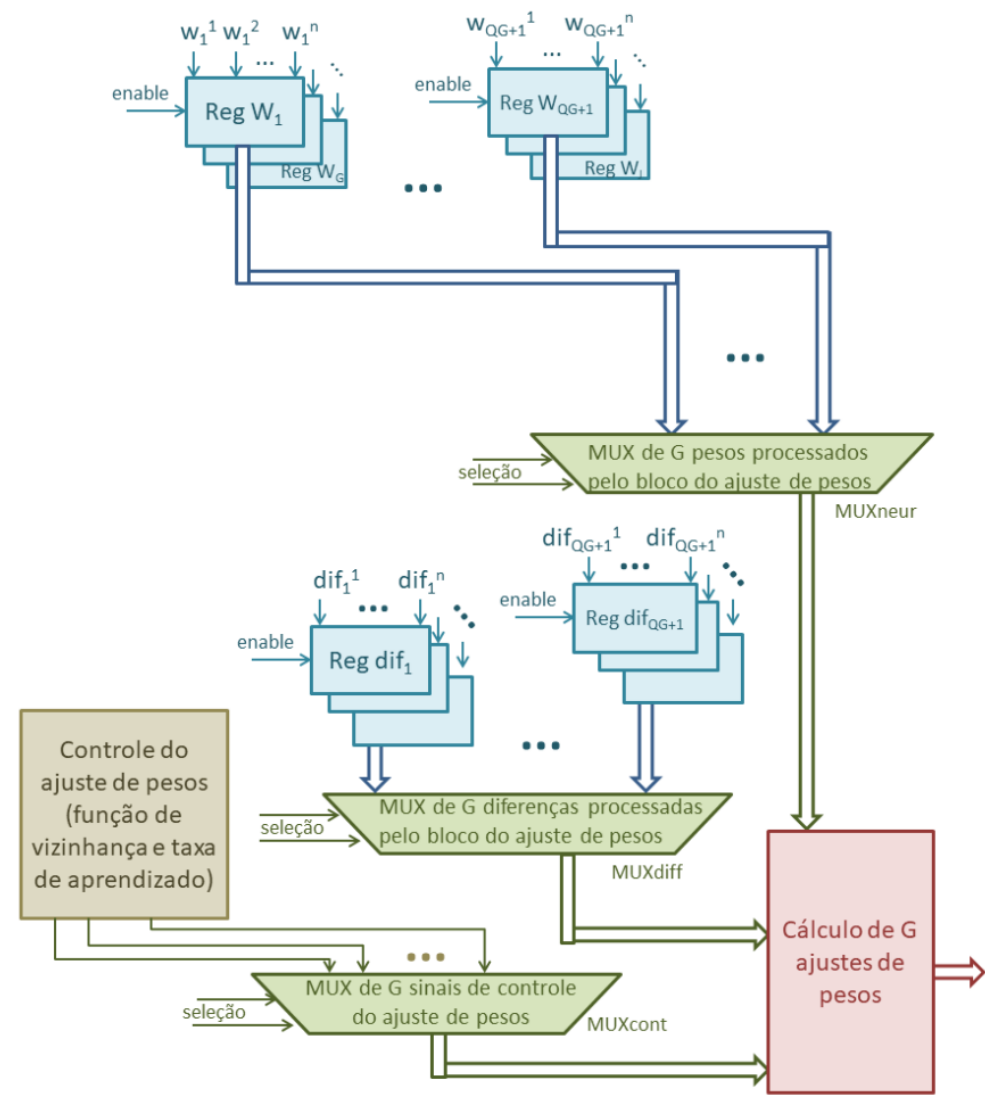

Figura 45 - Detalhe do bloco Cálculo de $\mathrm{G}$ ajustes de pesos (inteiramente ilustrado no diagrama do SOMprocessor da Figura 41)

\section{Unidade de controle:}

A Unidade de controle tem a função de distribuir os sinais de gerenciamento do fluxo de dados do diagrama de blocos apresentado na Figura 36. Os sinais de controle gerados são aplicados às entradas de seleção dos componentes multiplexadores e às entradas de clear e enable dos componentes registradores. Conforme apresentado na Tabela 16, a Unidade de controle opera por uma sequência de etapas identificadas por números de estados. A exploração das estratégias computacionais de multiplexação e pipeline, descritas no objetivo deste capítulo, é obtida pela distribuição ordenada dos sinais de gerenciamento originados pela Unidade de controle.

Como pode ser observado no pseudocódigo da operação da Unidade de controle, descrito na Tabela 16, o estágio inicial de funcionamento - identificado como estado 0 carrega os valores dos pesos iniciais nos registradores $\operatorname{Reg} W_{l}$ a $\operatorname{Reg} W_{j}$ e aguarda o sinal de reset para iniciar o treinamento do SOMprocessor. O restante do pseudocódigo, 
por simplicidade, está descrito para dois grupos de $G$ neurônios sendo processados de forma alternada pelo sistema.

Tabela 16 - Pseudocódigo da unidade de controle do diagrama de blocos do SOMprocessor (Figura 41) exemplificado para dois grupos de neurônios processados alternadamente.

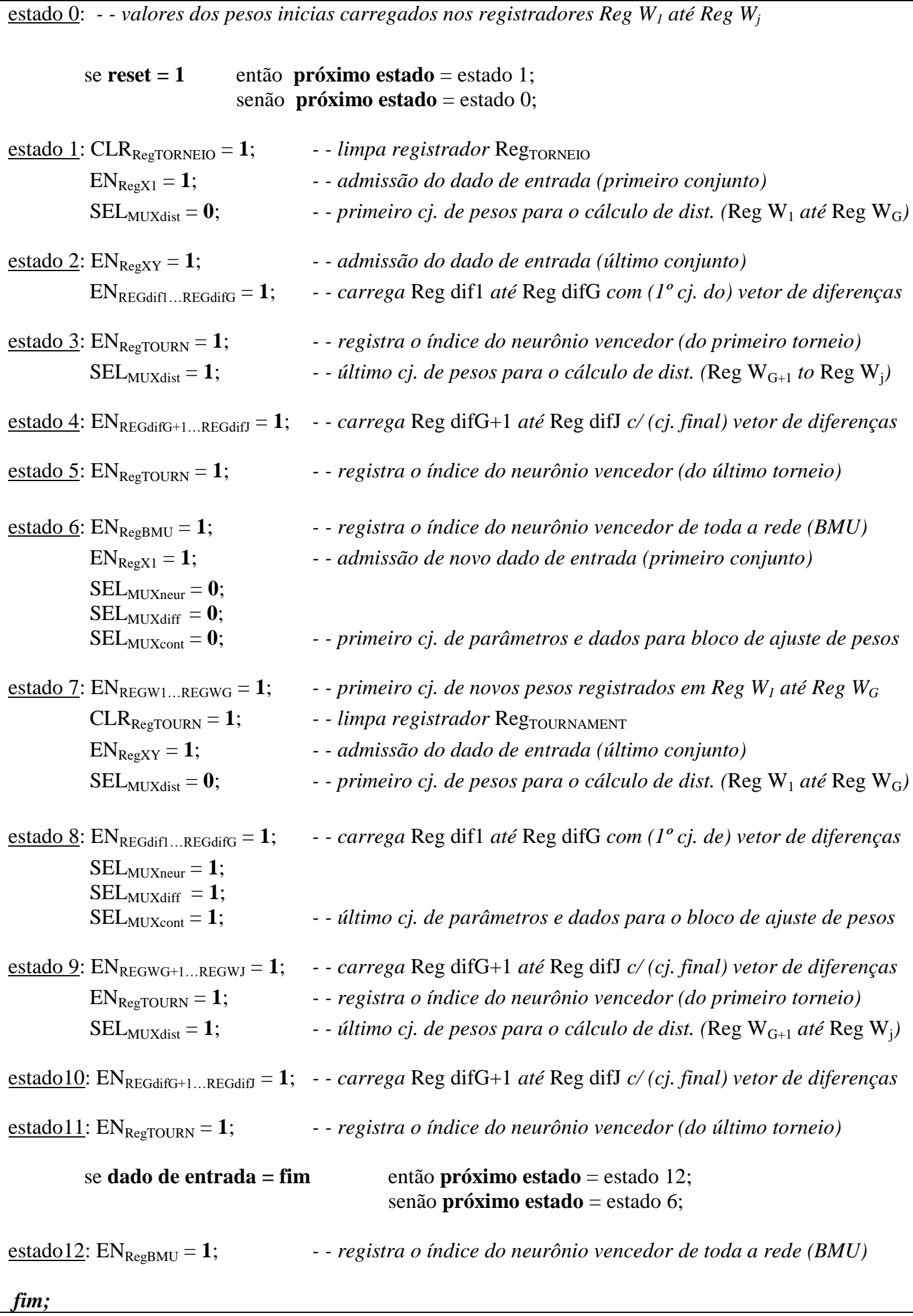


A sequência de estados de 1 a 6 são visitados apenas uma vez - na admissão do primeiro vetor de entrada (estado 1) - e representam a latência do sistema, quando o índice do primeiro neurônio vencedor é armazenado no Reg BMU (estado 6) e apresentado à saída pelos pinos $\boldsymbol{P}_{\boldsymbol{s}}$ do FPGA (Figura 41). O restante do processamento ocorre iterativamente entre os estados 6 a 11 e, finalmente, após a recepção do último vetor de entrada, atinge-se o estado terminal 12.

A sucessão dos estados de 1 a 6 tem por função computar a distância entre o vetor de entrada e todos os vetores peso da rede e determinar qual destas distâncias é a menor - processo comum às fases de treinamento e operação do SOM - conforme apresentado na Equação (1), seção 3.4. Para tanto, o estado 1 realiza a limpeza do registrador Reg BMU para possibilitar o armazenamento do índice do próximo neurônio vencedor $\left(\mathrm{CLR}_{\text {RegTORNEIO }}=\mathbf{1}\right.$ no pseudocódigo da Tabela 16), registra o primeiro conjunto de componentes do vetor de entrada $\left(\mathrm{EN}_{\mathrm{RegX1}}=1\right)$ e habilita o primeiro ${ }^{25}$ conjunto de $\mathrm{G}$ pesos para o bloco de cálculo de distâncias $\left(\mathrm{SEL}_{\mathrm{MUXdist}}=\mathbf{0}\right)$. $\mathrm{O}$ estado 2 registra o último conjunto de componentes do vetor de entrada $\left(\mathrm{EN}_{\mathrm{RegXY}}=\mathbf{1}\right.$, supondo $\left.\mathrm{Y}=2\right)$ e armazena $\mathrm{o}$ resultado do cálculo do primeiro conjunto de $G$ vetores de diferenças $\left(E_{\text {REGdif1 }}\right.$ até $\mathrm{EN}_{\mathrm{REGdifG}}=1$ ). Dispondo do primeiro grupo de $\mathrm{G}$ distâncias já computadas, o estado 3 registra o índice do neurônio vencedor do primeiro conjunto de torneios de menores distâncias $\left(\mathrm{EN}_{\mathrm{RegTOURN}}=1\right)$ para comparação com os vencedores dos futuros torneios, conjuntamente com a habilitação do último conjunto de $\mathrm{G}$ pesos para o bloco de cálculo de distâncias $\left(\mathrm{SEL}_{\mathrm{MUXdist}}=\mathbf{1}\right)$, mantendo o valor de entrada $\boldsymbol{x}_{\boldsymbol{i}}$ fixo nos registradores de entrada. A exploração deste circuito - Cálculo de $G$ diferenças e distâncias alternadamente por diferentes grupos de neurônios (juntamente com os circuitos Busca pelo neurônio vencedor e Cálculo de G ajustes de pesos), permite alcançar um dos objetivos do desenvolvimento do processador SOM propostos neste capítulo: criar uma arquitetura de circuito que possa ser utilizada em FPGAs de densidade moderada para executar SOMs com grande número de conexões neurais. Na sequência, o estado 4 armazena o último conjunto de $\mathrm{G}$ vetores de diferenças ( $\mathrm{EN}_{\mathrm{REGdifG+1}}$ até $\mathrm{EN}_{\mathrm{REGdifJ}}=1$ ) e o estado 5 registra o índice do neurônio vencedor do último conjunto de torneios de menores distância $\left(\mathrm{EN}_{\mathrm{Reg} T O U R N}=1\right)$ para comparação com os vencedores dos torneios anteriores.

\footnotetext{
${ }^{25}$ Os termos "primeiro" e "último" supõem $Q=2$, isto é, o número de neurônios da rede está dividido em dois grupos de processamento nesta explicação do funcionamento da Unidade de controle.
} 
O estado 6 completa o ciclo de recepção do vetor de entrada/identificação do neurônio vencedor - descrito no início deste capítulo - ao registrar o índice do neurônio mais semelhante ao dado de entrada $\left(\mathrm{EN}_{\mathrm{RegBMU}}=\mathbf{1}\right)$. Simultaneamente, mais um primeiro conjunto de componentes do vetor de entrada é registrado $\left(\mathrm{EN}_{\mathrm{RegX} 1}=1\right)$ para iniciar a admissão de um novo dado a ser processado pelo SOM. Desta forma, o processo de controle para admissão de entradas e busca pelo neurônio vencedor, realizado pela sequência de estados de 1 a 6 é novamente repetido pelos estados 6 e 11 . Entretanto, há uma diferença: concomitantemente com os processos de recepção do vetor de entrada/identificação do neurônio vencedor, os estados 6 a 11 também executam o processo de atualização da matriz de pesos da rede neural procedimento descrito anteriormente neste capítulo. O início do processo de ajuste de pesos ocorre, ainda no estado 6, pela seleção do primeiro conjunto de parâmetros e dados $\left(\mathrm{SEL}_{\mathrm{MUXneur}}=\mathbf{0} ; \mathrm{SEL}_{\mathrm{MUXdiff}}=\mathbf{0} ; \mathrm{SEL}_{\mathrm{MUX} \text { cont }}=\mathbf{0}\right)$ para ser computado pelo bloco de ajuste de pesos (sinais de pesos atuais, vetor de diferenças e sinais de controle de treinamento), conforme ilustrado no diagrama de blocos da Figura 41.

A sequência de estados de 6 a 11 é ciclicamente visitada e repete o conjunto de sinais detalhados na descrição dos estados 1 a 6. Além destes sinais já discutidos no funcionamento dos estados de 1 a 6 , o estado 7 carrega os novos vetores de $\mathrm{G}$ pesos nos registradores $\operatorname{Reg} W_{l}$ a $\operatorname{Reg} W_{G}\left(\mathrm{EN}_{\mathrm{REGW}}\right.$ até $\left.\mathrm{EN}_{\mathrm{REGWG}}=1\right)$ computados pelo bloco Cálculo de $G$ ajustes de pesos. $\mathrm{O}$ estado 8 permite a seleção do último conjunto de parâmetros e dados para ser computado pelo bloco de ajuste de pesos $\left(\mathrm{SEL}_{\mathrm{MUXneur}}=\mathbf{1} ; \mathrm{SEL}_{\mathrm{MUXdiff}}=\mathbf{1}\right.$; SEL $_{\text {MUXcont }}=1$ ) e o estado 9 armazena os últimos vetores de $\mathrm{G}$ novos pesos nos registradores $\operatorname{Reg} W_{G+1}$ a $\operatorname{Reg} W_{J}\left(\mathrm{EN}_{\mathrm{REGWG}+1} \text { até } \mathrm{EN}_{\mathrm{REGWJ}}=\mathbf{1}\right)^{26}$.

Em resumo, a admissão de novos vetores de entrada pelo SOMprocessor ocorre simultaneamente com o ajuste do primeiro conjunto de pesos neurais, segundo o resultado de processamento da entrada anterior. Assim, os processos de cálculo de distância e busca pelo neurônio vencedor (para este conjunto de vetores recém atualizados) podem ser executados paralelamente ao processo de ajuste de pesos do próximo conjunto de vetores de peso. Desta forma, uma iteração completa de processamento de entrada e ajuste de pesos neurais ocorre também em seis estados da Unidade de controle. Esta sequência de seis etapas, aliada a informação de frequência de operação do chip - obtida na síntese do circuito para o FPGA, descrita no

\footnotetext{
${ }^{26}$ Novamente, o pseudocódigo do funcionamento da unidade de controle está descrito aqui, sem perda de generalidade com dois conjuntos de neurônios processados alternadamente pelo SOMprocessor.
} 
capítulo 7 sobre a caracterização do sistema - permite determinar a taxa de processamento de dados do SOMprocessor. O paralelismo das operações (recepção do vetor de entrada/identificação do neurônio vencedor e atualização da matriz de pesos) possibilita a exploração da estratégia computacional pipeline e permite alcançar o último dos objetivos propostos para o desenvolvimento do processador SOM neste capítulo: obter maior velocidade de processamento na fase de treinamento do SOM.

O detalhamento do diagrama de blocos do SOMprocessor e de sua Unidade de controle, feito neste capítulo, visa apresentar as estratégias computacionais exploradas para potencializar o processamento neural a fim de possibilitar a implementação de redes com maior número de conexões neurais e acelerar o processamento do SOM. O sistema elaborado com a inclusão de tais recursos computacionais tem seu comportamento testado, a seguir, em dois experimentos com fluxos de dados sinteticamente gerados para controle do processo de treinamento. Em sequência, na seção 6.2, o SOMprocessor é utilizado em uma aplicação de reconhecimento de vídeos de ações humanas.

\subsection{TESTE DO SOMPROCESSOR COM DADOS SINTÉTICOS CONTROLADOS}

Com o objetivo de se observar o comportamento do SOMprocessor durante um processo controlado de aprendizagem, realizaram-se dois experimentos com conjuntos de dados de entrada sintéticos. Da mesma forma apresentada na seção 5.7, utilizou-se o padrão proposto por Peña, Vanegas e Valencia (2006) como base para geração dos vetores de entrada para teste da arquitetura de implementação do SOM. O software Matlab foi usado para produzir os conjuntos de treinamento em formato binário (configurados como fluxos contínuos de dados) e o simulador de hardware Xilinx ISim (PEDRONI, 2010) foi usado para verificar o comportamento do processador elaborado durante o processo de aprendizagem. Foram gerados, portanto, dois grupos de dados compostos por 6000 vetores bidimensionais, conforme as configurações mostradas pela Figura 46 e pela Figura 47. A configuração do SOM de 100 neurônios (10x10) usada nos experimentos está relacionada com os requisitos da aplicação de reconhecimento de imagens, apresentada a seguir na seção 6.2. Os quadros identificados como (a) em 
ambas as figuras apresentam o posicionamento aleatório inicial dos vetores peso da rede.

Para o primeiro teste, foi gerado um conjunto de dados de treinamento composto por dois grupos de vetores bidimensionais distribuídos dentro dos limites de um quadrado e de um círculo, conforme ilustrado na Figura 46. Foram definidas densidades de dados diferentes para os grupos: a região quadrada tem maior densidade que a região circular. Confirmando o esperado, pode-se perceber uma distribuição da rede por toda a extensão do conjunto de dados - quadros (b) e (c) - com maior concentração de neurônios na região quadrada, ao final do processo de treinamento - quadro (d).
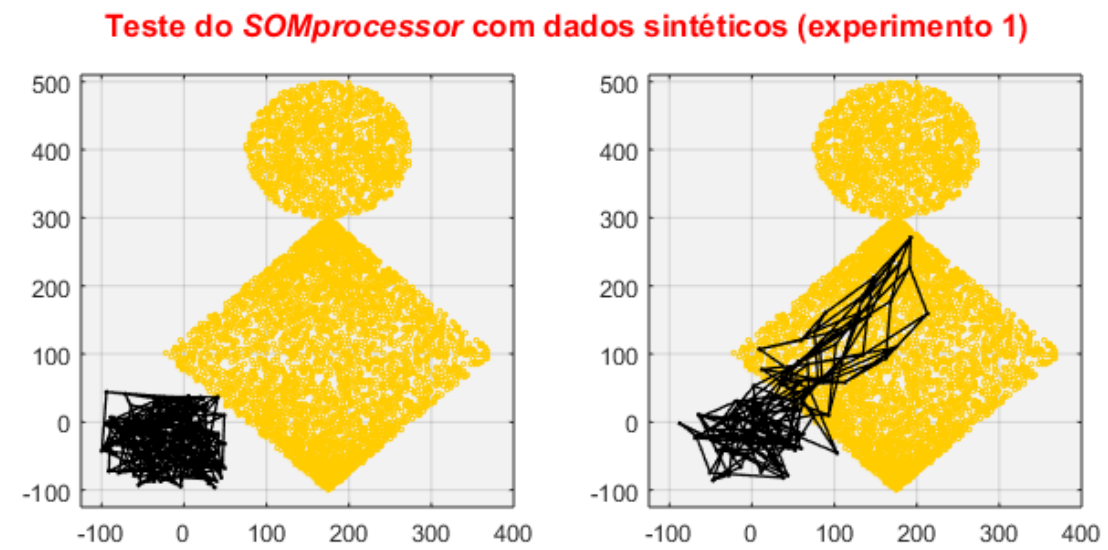

(a) inicialização de vetores peso aleatórios (b) após 100 amostras de treinamento

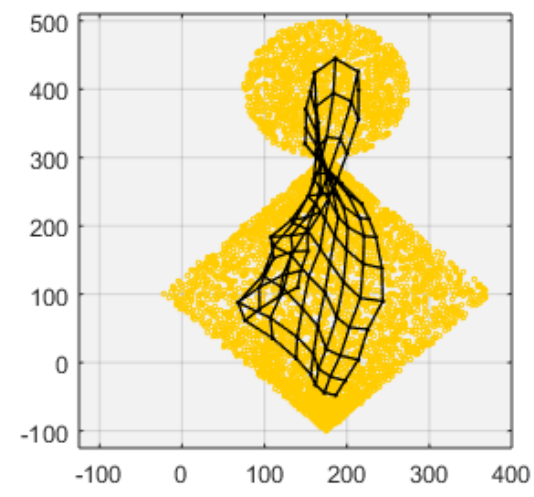

(c) após 200 amostras de treinamento

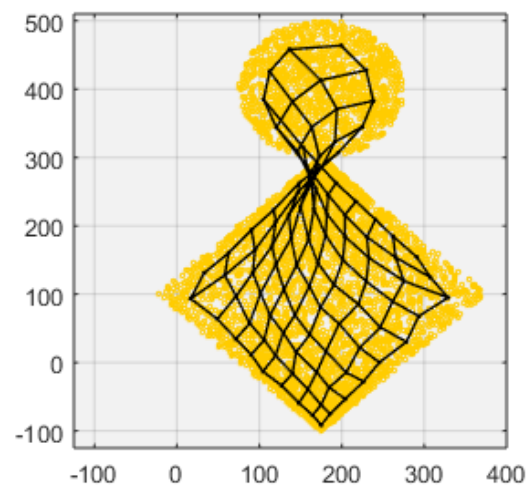

(d) após 6000 amostras de treinamento

Figura 46 - Progressão da fase de aprendizagem do SOMprocessor durante o $1^{\circ}$ experimento com dados controlados.

De forma semelhante ao primeiro teste, o segundo experimento também é constituído por um conjunto de dados de treinamento formado por dois grupos, porém estes grupos são disjuntos e a região circular agora possui maior densidade de dados. Como pode ser visto nos quadros (b) e (c) da Figura 47, também ocorre uma organização da rede por toda a extensão do conjunto de dados. O quadro (d) mostra uma 
configuração final de neurônios adequada, com maior concentração de neurônios na área do círculo.

Teste do SOMprocessor com dados sintéticos (experimento 2)
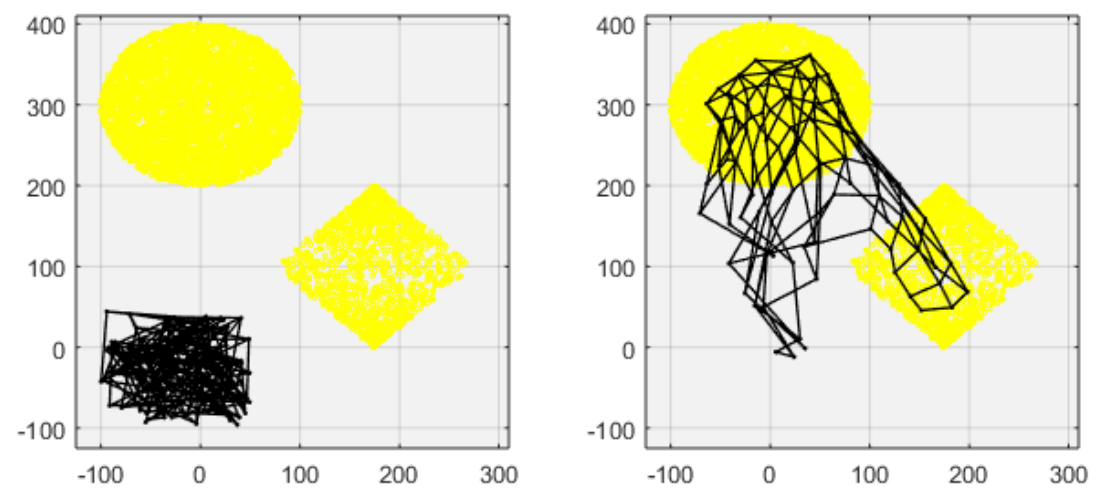

(a) inicialização de vetores peso aleatórios (b) após 100 amostras de treinamento

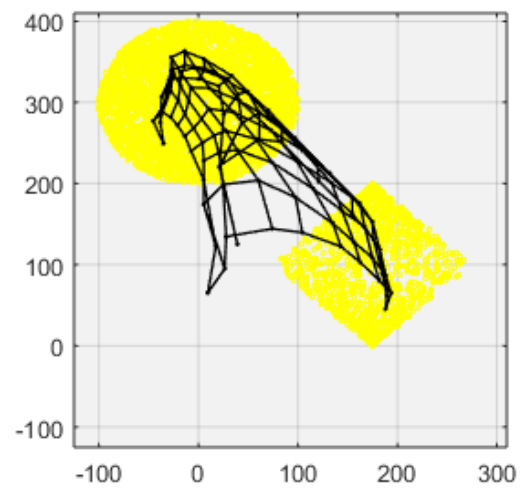

(c) após 200 amostras de treinamento

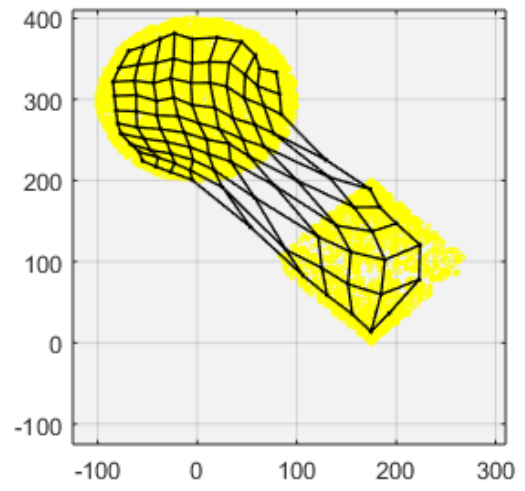

(d) após 6000 amostras de treinamento

Figura 47 - Progressão da fase de aprendizagem do SOMprocessor durante o $2^{\circ}$ experimento com dados controlados.

Tendo obtido resultados adequados nos experimentos de aprendizagem com dados sintéticos e controlados, o SOMprocessor foi empregado em uma aplicação de identificação de imagens em vídeo, detalhada a seguir. Esta aplicação também tem como objetivo se caracterizar as metodologias desenvolvidas e as estratégias computacionais utilizadas na elaboração do sistema em FPGA.

\subsection{APLICAÇÃO DO SOMPROCESSOR NA IDENTIFICAÇÃO DE VÍDEOS DE AÇÕES HUMANAS}

A meta do conjunto de experimentos realizados nesta seção é utilizar o circuito do SOM desenvolvido para FPGA em uma aplicação que demande uma rede com maior 
número de conexões neurais quando comparada à aplicação já desenvolvida na seção 5.8. Enquanto o primeiro uso empregava mapas com 32 e 128 conexões neurais, esta aplicação de reconhecimento de imagens utiliza sequências de SOMs com até 7900 conexões neurais. Ademais, esta experimentação também objetiva caracterizar e avaliar o desempenho do SOMprocessor sob circunstâncias reais de execução que, tipicamente, requisitem grandes velocidades computacionais.

Para tanto, foi escolhido o contexto de processamento de imagens, o qual representa a segunda categoria de aplicação mais frequente ${ }^{27}$ de dispositivos FPGA nas publicações do IEEE entre os anos 2000 e 2015 (ROMOTH; PORRMANN; RÜCKERT, 2017). O processamento autônomo de imagens e vídeos requer grande capacidade computacional e é importante em ambientes onde há multiplicidade de câmeras constantemente fornecendo informações sobre locais e pessoas, cenário identificado nas publicações de Sammoud et al. (2017) e Lin et al. (2017) como IoVT (em inglês, "Internet of Video Things"). Sistemas de processamento de vídeos autônomos usualmente incluem, principalmente, segmentação de imagens (DELIBASIS; GOUDAS; MAGLOGIANNIS, 2016), rastreamento (YASUKAWA et al., 2016) e classificação (RAMIREZ-ALONSO; CHACON-MURGUIA, 2016). A aplicação do SOM escolhida foi a classificação de vídeos, baseada no trabalho de Buonamente, Dindo e Johnsson (2016) sobre o uso de hierarquias de SOMs para processamento de imagens. $O$ artigo concentra-se na identificação de vídeos de ações humanas (cujas capturas de algumas imagens estão na Figura 48) e sua motivação de pesquisa é possibilitar o desenvolvimento de sistemas autônomos de segurança. Para tanto, a continuidade do estudo requer que o sistema proposto pelos pesquisadores seja implementado diretamente em hardware (situação semelhante às descritas na seção 2.3 sobre contextualização desta pesquisa). Esta aplicação, portanto, se adequa à proposta do presente estudo sobre execuções em FPGA em dois aspectos: portabilidade (relacionada à ubiquidade de câmeras de vídeo, as quais podem ser diretamente conectadas a chips de processamento autônomo de imagens) e alta capacidade computacional (devido à velocidade de processamento necessária para atender demandas de execuções em tempo real). Desta forma, optou-se por utilizar o modelo de

\footnotetext{
${ }^{27}$ Comunicações é o tipo de aplicação mais frequente nas publicações do IEEE entre os anos de 2000 e 2015 usando FPGA e foi escolhido como o primeiro ambiente de experimentação do circuito SOM (identificação de sinais QAM), apresentado na seção 5.8.
} 
processamento do proposto pelo artigo original e implementá-lo com o uso do SOMprocessor, conforme detalhado a seguir.

O trabalho de reconhecimento de vídeos com hierarquias de SOMs (BUONAMENTE; DINDO; JOHNSSON, 2016) propõe a identificação de 13 ações comumente realizadas por pessoas: olhar o relógio, cruzar os braços, coçar a cabeça, sentar, levantar, dar uma volta, andar, acenar, socar, chutar, apontar, pegar e arremessar. Os vídeos possuem constância do cenário de fundo e iluminação estável. As ações são realizadas por diferentes indivíduos - homens e mulheres - de maneira livre quanto à direção, posicionamento e forma de execução, isto é, os atores não recebem instruções de como executar os movimentos, apenas o nome de identificação das ações a serem executadas. A coleção de vídeos está disponibilizada na base de dados público INRIA 4D IXMAS (WEINLAND; RONFARD; BOYER, 2006).

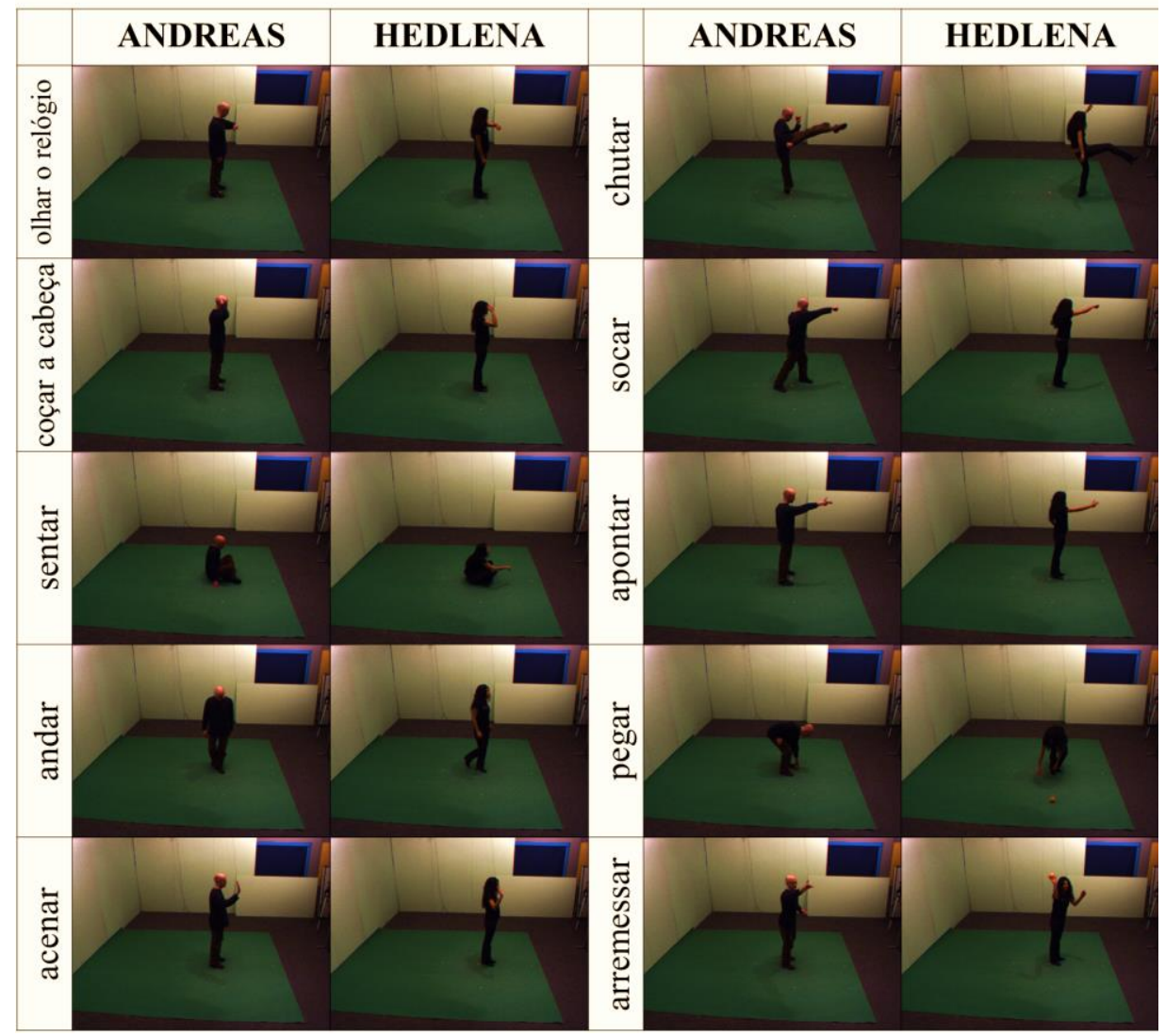

Figura 48 - Exemplos de imagens pertencentes aos vídeos do repositório público INRIA 4D IXMAS com ações humanas, utilizados no treinamento e teste do SOMprocessor.

Para a produção do conjunto de entradas de treinamento e operação dos SOMs, artigo propõe a realização de uma sequência de cinco etapas de pré-processamento dos vídeos, relacionados a seguir: 
- Segmentação das imagens em preto e branco: utilização do conjunto de imagens, quadro a quadro, dos vídeos já disponibilizados pela base de dados, com os corpos das pessoas que executam as ações segmentadas em branco com o fundo preto.

- Seleção de 10 quadros de cada um dos vídeos das ações. Os quadros são espaçados em intervalos regulares, abrangendo todo o filme da ação. Esta etapa visa eliminar os quadros muito próximos na sequência do filme, por serem muito semelhantes.

- Em cada conjunto de 10 quadros correspondente a uma ação, a diferença entre dois quadros consecutivos são calculadas pixel por pixel, gerando, assim, nove quadros de diferença. Um quadro de diferença contém pixels brancos apenas onde há variações entre dois quadros consecutivos, e pixels pretos onde não há variações. A Figura 49 mostra dois quadros consecutivos de uma ação e a respectiva diferença resultante.

- Um retângulo de limite fixo é usado para cortar os quadros de diferença para reduzir as imagens e eliminar as bordas que não estejam envolvidas na ação.

- Os nove quadros binários são, por fim, reduzidos para matrizes de 50 x 50 pixels e representados como um vetor. Consequentemente, vetores de 2500 componentes constituem uma entrada da rede neural.

Para adequação à implementação em hardware, contudo, a última etapa de préprocessamento foi alterada em relação à proposta do artigo original da seguinte forma: cada quadro de diferenças é dividido em faixas horizontais e verticais com larguras de quatro pixels e a quantidade de pixels brancos de cada faixa é então somada. Portanto, um vetor de características - que compõe o conjunto de entradas do SOMprocessor - é composto por 79 elementos, cada um destes elementos representando a quantidade de pixels brancos de uma faixa (horizontal ou vertical) do quadro de diferenças.
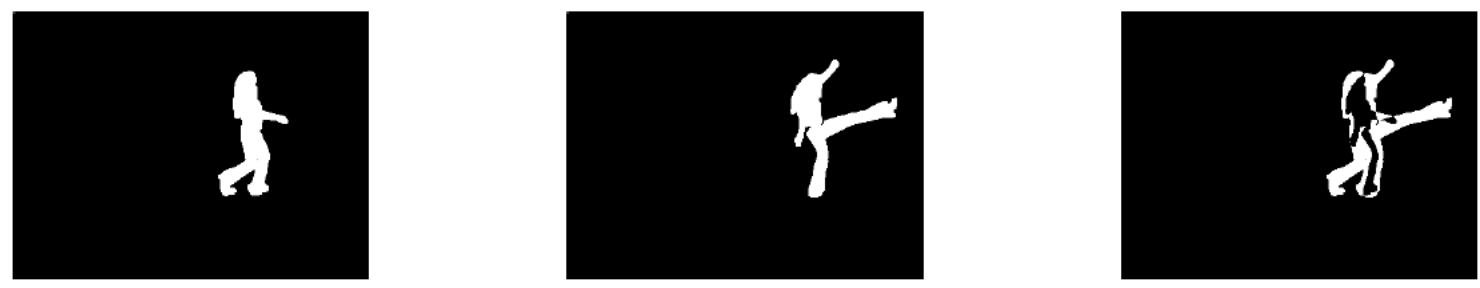

Figura 49 - Dois quadros consecutivos selecionados da ação chutar (imagens esquerda e central) e a diferença resultante entre eles (imagem à direita). 
Para identificação dos vídeos (já dispondo dos vetores de entrada do SOM, cada um contendo dados sobre o quadro de diferenças entre duas imagens representativas de uma ação a ser reconhecida), a hierarquia de SOMs proposta pelo artigo original (BUONAMENTE; DINDO; JOHNSSON, 2016) utiliza um encadeamento de três mapas com as seguintes funções:

- O primeiro SOM é treinado com o conjunto de todos os vetores representativos dos quadros de todas as 13 ações a serem reconhecidas. Após a convergência do treinamento desta primeira camada do mapa, os nove vetores (representando os nove quadros de diferença de uma ação) são aplicados em sequência à entrada do SOM, resultando em uma sucessão de neurônios vencedores para cada vídeo. Os nove índices dos neurônios vencedores são chamados pelos autores do artigo original de "trajetória". O conjunto das trajetórias de todas as ações compõe os vetores de treinamento do segundo SOM da hierarquia de reconhecimento de vídeos (ilustrado pela Figura 50).

- O segundo SOM é treinado com o conjunto de 13 trajetórias - geradas pelos índices dos neurônios vencedores do primeiro mapa - cada uma representando uma ação a ser reconhecida. Após a convergência do processo de aprendizagem do segundo SOM, cada trajetória é usada na operação da rede, ou seja, registra-se o neurônio vencedor correspondente a cada trajetória. Os índices dos neurônios vencedores identificam, na segunda camada, a ação a ser reconhecida e são usados como as entradas de treino da última camada (ilustrados na Figura 51).

- A última camada da hierarquia é composta por uma rede chamada de WTANN $^{28}$, uma variação do SOM para treinamento supervisionado na qual se pode relacionar as entradas a um neurônio específico de saída. Esta última rede é usada apenas para associação de cada índice de neurônio vencedor da segunda camada - representativo de uma ação a ser reconhecida - a uma saída desejada. Portanto, a última camada da hierarquia é composta por 13 neurônios (arranjo de grade neuronal de 13x1), cada um representando uma

\footnotetext{
${ }^{28}$ A rede WTANN (Winner-Take-All Neural Network), é derivada do modelo SOM (AZUMA; HIKAWA, 2014). Em seu processo de treinamento, apenas o neurônio vencedor tem seu peso alterado e o valor de $\mathbf{w}_{\mathbf{j}}$ no cálculo da diferença $\left[\mathbf{x}_{\mathbf{i}}-\mathbf{w}_{\mathbf{j}}\right]$, existente na Equação (5) de ajuste de pesos do SOM, é fixado com o valor do neurônio especificado para identificar a entrada processada.
} 
das ações da base de dados a serem identificadas pelo modelo neural de computação proposto pelo artigo original.

Os experimentos realizados para testes do SOMprocessor também utilizaram uma sequência de três SOMs com a mesma função proposta no artigo original, porém com uma diferença na transferência de dados entre os mapas: ao invés de se compor os vetores de entrada da próxima camada da hierarquia com os índices dos neurônios vencedores da camada anterior, utilizaram-se as coordenadas das posições dos neurônios vencedores na grade de saída do SOM. Esta modificação é importante porque neurônios próximos na grade têm valores de coordenadas semelhantes, mesmo que seus índices sejam muito desiguais. A Tabela 17 resume as condições dos experimentos realizados e compara a proposta do artigo original (BUONAMENTE; DINDO; JOHNSSON, 2016) com a implementação em FPGA feita neste trabalho.

Tabela 17 - Condições do experimento de teste do SOMprocessor no reconhecimento de vídeos.

\begin{tabular}{|c|c|c|}
\hline & Artigo original & Experimento realizado \\
\hline $\begin{array}{l}\text { Quantidade de camadas da } \\
\text { hierarquia de SOMs }\end{array}$ & 3 & 3 \\
\hline $\begin{array}{l}\text { Número de entradas da } \\
\text { hierarquia de SOMs }\end{array}$ & $\begin{array}{c}2500 \text { (uma para cada pixel da } \\
\text { imagem de entrada) }\end{array}$ & $\begin{array}{l}79 \text { (uma para cada faixa de } \\
\text { pixels da imagem de entrada) }\end{array}$ \\
\hline $\begin{array}{l}\text { Quantidade de neurônios da } \\
\text { primeira e segunda camada }\end{array}$ & $225(15 \times 15)$ & $100(10 \times 10)$ \\
\hline $\begin{array}{l}\text { Quantidade de neurônios da } \\
\text { última camada }\end{array}$ & $13(13 \times 1)$ & $13(13 \times 1)$ \\
\hline Épocas de treinamento & 20000 & 2000 \\
\hline $\begin{array}{l}\text { Fator de aprendizagem } \alpha \\
\text { inicial e final }\end{array}$ & 0,1 a 0,01 & 0,5 a 0,0625 \\
\hline $\begin{array}{l}\text { Abertura inicial e final da } \\
\text { função de vizinhança }\end{array}$ & 7 a 1 o na Equação (4) & 1 a $4 \beta$ na Equação (11) \\
\hline $\begin{array}{l}\text { Arquivos de vídeos da base } \\
\text { de dados para treinamento }\end{array}$ & $\begin{array}{c}\text { “Andreas2" } \\
\text { (em INRIA 4D XMAS) }\end{array}$ & $\begin{array}{c}\text { “Andreas2” } \\
\text { (em INRIA 4D XMAS) }\end{array}$ \\
\hline $\begin{array}{l}\text { Arquivos de vídeos da base } \\
\text { de dados para teste }\end{array}$ & $\begin{array}{c}\text { "Hedlena2" } \\
\text { (em INRIA 4D XMAS) }\end{array}$ & $\begin{array}{c}\text { "Hedlena2" } \\
\text { (em INRIA 4D XMAS) }\end{array}$ \\
\hline
\end{tabular}


De forma geral, procurou-se realizar os experimentos de forma semelhante aos descritos no artigo original, a fim de se obter resultados de operação do SOMprocessor que possam servir como avaliação de seu funcionamento. As principais diferenças entre experimentos ocorreram em virtude das propriedades específicas da computação do SOM em hardware adotadas, conforme discussão realizada no capítulo 4. Os resultados obtidos foram, portanto, bem semelhantes aos reportados no trabalho original. A Figura 50 mostra o resultado de operação da primeira camada SOM do experimento conduzido, ao processar os vídeos "Andreas2" da base de dados (Tabela 17). A composição das trajetórias - sucessão de neurônios ativados, após a estabilização do treinamento, quando se apresenta a sequências de quadros descritivos das ações à entrada da rede - são similares ao reportado no trabalho que se utilizou como base.

Pode-se observar, na Figura 50, que as trajetórias das ações que possuem movimentos compostos quase que totalmente apenas por deslocamento de braços (olhar o relógio, acenar, cruzar os braços, apontar, coçar a cabeça e arremessar) têm configurações semelhantes entre si e bem distintas das trajetórias de ações que envolvem movimentos corporais mais completos (sentar, levantar, dar uma volta, andar, socar, chutar e pegar). Pode-se notar também que as ações opostas sentar e levantar possuem trajetórias com configurações aproximadamente inversas.

A Figura 51 mostra o resultado da operação da segunda camada SOM do experimento conduzido ao processar as informações de saída produzidas pela primeira camada. A configuração final do SOM foi obtida após a convergência do processo de treinamento com as trajetórias contidas na Figura 50 e de acordo com os parâmetros relacionados na Tabela 17. Pode-se observar, na Figura 51, que há razoável dispersão no mapeamento das trajetórias geradas pelo SOM da primeira camada, exceto pelas ativações dos neurônios ' $J$ ' e ' $E$ ', que são vizinhos imediatos na grade de saída.

Por fim, as coordenadas dos neurônios ativados no segundo SOM são ordenados pela camada de saída da hierarquia, para produzir uma associação entre a ação de entrada e a saída desejada. Desta forma, a terceira camada possui 13 neurônios, em configuração 13x1, para que se possa realizar uma identificação estruturada das ações apresentadas à entrada da rede. A Tabela 18 apresenta os resultados obtidos nos testes do SOMprocessor para o reconhecimento dos conjuntos de vídeos identificados na base de dados INRIA 4D XMAS como “Andreas2" e "Hedlena2", os mesmos usados nos experimentos do artigo original. Para comparação, a Tabela 18 também apresenta os 
resultados reportados pelos autores da pesquisa usada como base (BUONAMENTE; DINDO; JOHNSSON, 2016).

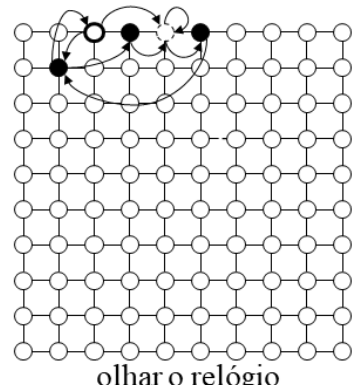

olhar o relógio

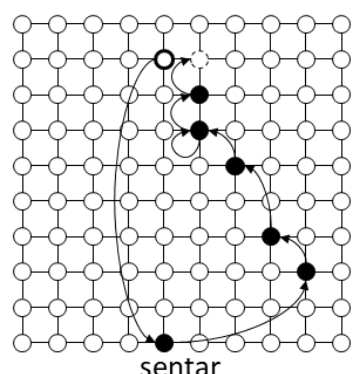

sentar
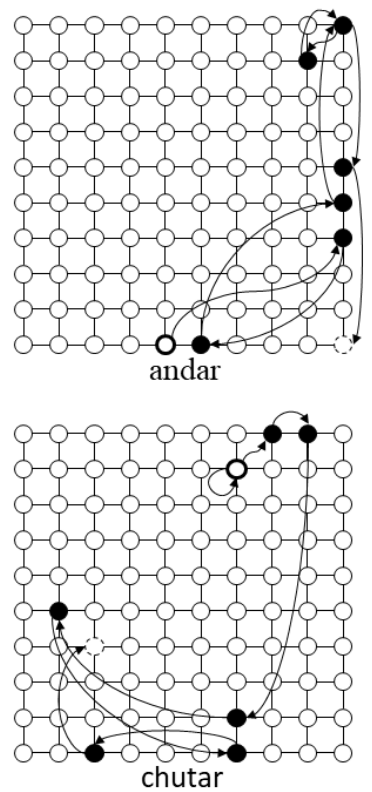

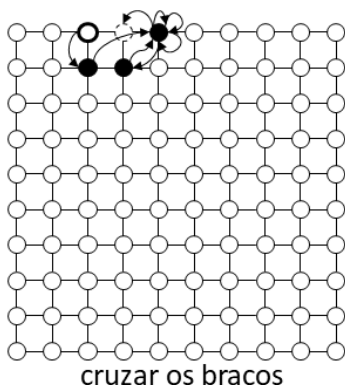

cruzar os braços
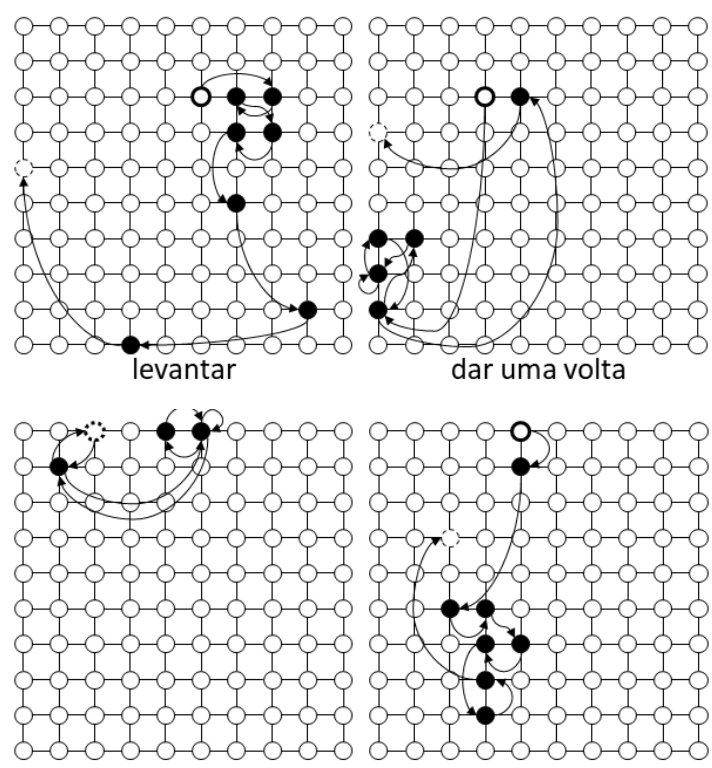

acenar
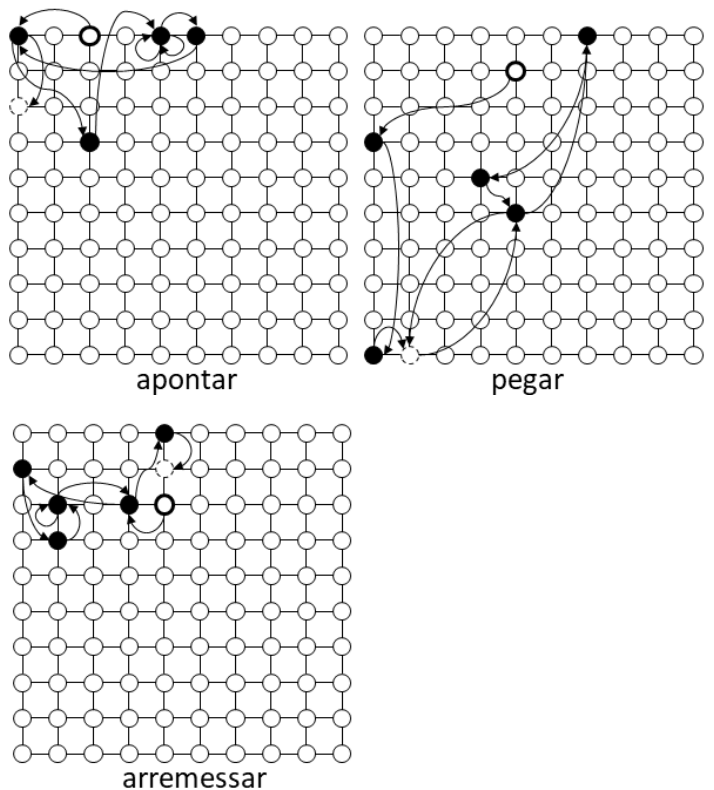

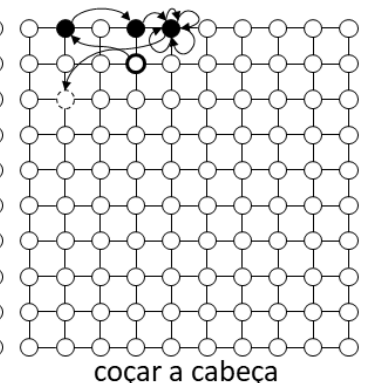

coçar a cabeça

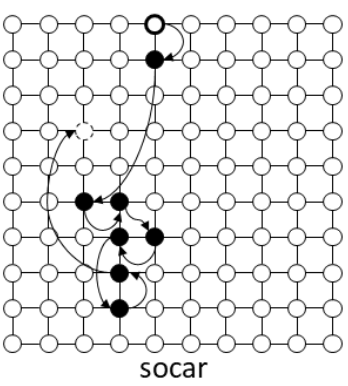

pegar

Figura 50 - Sucessão de neurônios ativados na primeira camada SOM treinado para reconhecimento de ações, chamadas de trajetórias. O círculo com borda destacada contínua representa o primeiro neurônio da trajetória e o circulo com borda segmentada, o último (exceto na ação acenar, na qual um mesmo círculo com borda segmentada representa o primeiro e o último neurônio da trajetória). 


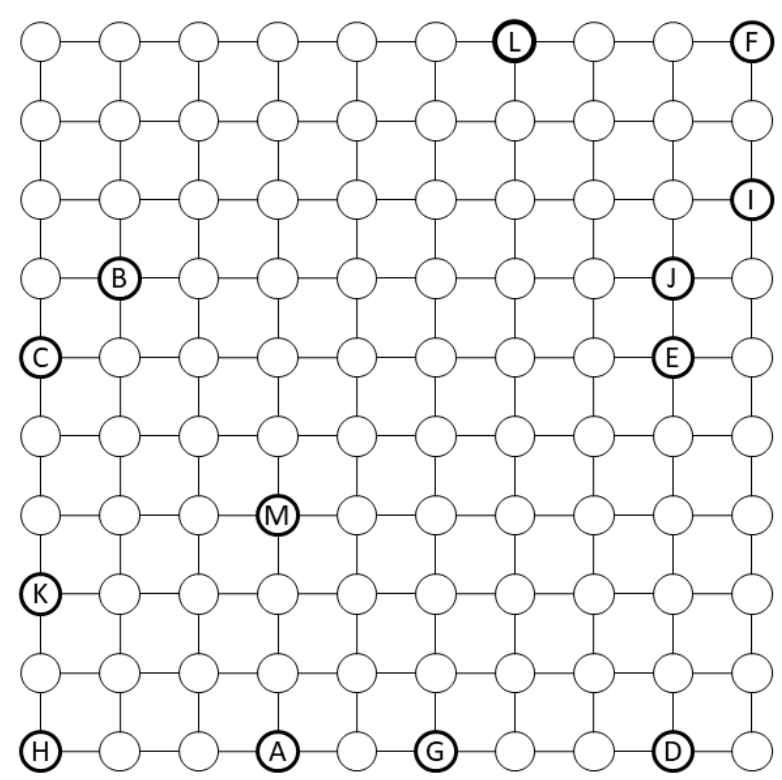

Figura 51 - Neurônios ativados na segunda camada SOM para reconhecimento das ações (identificados por letras): A. olhar o relógio, B. cruzar os braços, C. coçar a cabeça, D. sentar, E. levantar, F. dar uma volta, G. andar, H. acenar, I. socar, J. chutar, K. apontar, L. pegar e M. arremessar.

Pode-se perceber, pela Tabela 18, que o desempenho do SOMprocessor no reconhecimento de ações em vídeo foi semelhante ao desempenho do artigo original, que executa as três camadas neurais em C++ (BUONAMENTE; DINDO; JOHNSSON, 2016). Da tabela, destacam-se as seguintes observações:

- Ambas as implementações obtiveram a mesma taxa global de reconhecimento: $100 \%$ dos vídeos "Andreas2" - usados no treinamento foram corretamente identificados e 53\% dos vídeos "Hedlena2" - não utilizados no treinamento - foram corretamente identificados.

- Ambos os sistemas, em software e em hardware, concordaram na identificação correta de quatro vídeos de teste "Hedlena2": cruzar os braços, sentar, dar uma volta e andar.

- Um dos vídeos de teste foi identificado incorretamente pelos dois sistemas, porém com concordância no reconhecimento: a ação chutar da "Hedlena2" foi classificada como sentar por ambas as implementações.

- Apenas sobre o SOMprocessor, pode-se também perceber, na última coluna da Tabela 18, que três das ações identificadas incorretamente pelo sistema são compostas majoritariamente por movimentos apenas de braços: coçar $a$ cabeça, acenar e apontar foram classificadas como cruzar os braços. 
- Ainda apenas sobre a implementação em FPGA, nota-se - também na última coluna da tabela - que a ação pegar foi reconhecida como levantar pelo SOMprocessor. Esta imprecisão pode ser entendida porque no vídeo da base de dados "Hedlena2" a ação pegar é executada ao se apanhar um objeto do solo, o que também inclui o movimento de levantar.

Tabela 18 - Ações identificadas e taxas de reconhecimento correto do artigo original e do experimento realizado com o SOMprocessor.

\begin{tabular}{lcccc}
\hline \hline & \multicolumn{2}{c}{ “Andreas2" (treinamento) } & \multicolumn{2}{c}{ "Hedlena2” (teste) } \\
\hline \hline $\begin{array}{l}\text { Ação a ser } \\
\text { reconhecida }\end{array}$ & $\begin{array}{c}\text { Identificação do } \\
\text { artigo original }\end{array}$ & $\begin{array}{c}\text { Identificação do } \\
\text { SOMprocessor }\end{array}$ & $\begin{array}{c}\text { Identificação do } \\
\text { artigo original }\end{array}$ & $\begin{array}{c}\text { Identificação do } \\
\text { SOMprocessor }\end{array}$ \\
\hline olhar o relógio & olhar o relógio & olhar o relógio & arremessar & olhar o relógio \\
\hline cruzar os braços & cruzar os braços & cruzar os braços & cruzar os braços & cruzar os braços \\
\hline coçar a cabeça & coçar a cabeça & coçar a cabeça & coçar a cabeça & cruzar os braços \\
\hline sentar & sentar & sentar & sentar & sentar \\
\hline levantar & levantar & levantar & dar uma volta & levantar \\
\hline dar uma volta & dar uma volta & dar uma volta & dar uma volta & dar uma volta \\
\hline andar & andar & andar & andar & andar \\
\hline acenar & acenar & acenar & coçar a cabeça & cruzar os braços \\
\hline socar & socar & socar & socar & andar \\
\hline chutar & chutar & chutar & sentar & sentar \\
\hline apontar & apontar & apontar & apontar & cruzar os braços \\
\hline pegar & pegar & pegar & coçar a cabeça & levantar \\
\hline arremessar & arremessar & arremessar & levantar & arremessar \\
\hline \hline Taxa de & $\mathbf{1 0 0 \%}$ & $\mathbf{1 0 0 \%}$ & $\mathbf{5 3 \%}$ & $\mathbf{5 3 \%}$ \\
\hline \hline
\end{tabular}

Apesar das semelhanças dos resultados obtidos, conforme apresentado na Tabela 18, os processos computacionais realizados pelo sistema executado em FPGA não são idênticos aos cálculos realizados em $\mathrm{C}++$. As propriedades da implementação do SOMprocessor estão discutidas em detalhes no capítulo 4, e a Tabela 19 resume as diferenças fundamentais entre as particularidades da implementação do SOM em hardware e em software. 
Tabela 19 - Principais diferenças entre as características computacionais da execução do SOM no artigo original e da implementação em FPGA.

\begin{tabular}{lcc}
\hline $\begin{array}{l}\text { Propriedades } \\
\text { Computacionais }\end{array}$ & $\begin{array}{c}\text { Execução em C++ } \\
\text { (BUONAMENTE; DINDO; } \\
\text { JOHNSSON, 2016) }\end{array}$ & $\begin{array}{c}\text { Execução em FPGA } \\
\text { (SOMprocessor) }\end{array}$ \\
\hline Métrica de similaridade & Distância Euclidiana & Distância de Manhattan \\
\hline Fator de aprendizagem & $\begin{array}{c}\text { Função exponencial } \\
\text { monótona decrescente }\end{array}$ & $\begin{array}{c}\text { Deslocamento binário (valor } \\
\text { restrito a potências negativas }\end{array}$ \\
& com o tempo & de base dois: $1 / 2,1 / 4, \ldots)$ \\
\hline Função de vizinhança & Função gaussiana com & $h_{c_{j}}(t)=2^{-(\text {dist }(c, j) . \beta(t))}$ \\
& raio em função monótona & com abertura da função $\beta(t)$ \\
decrescente do tempo & em patamares decrescentes \\
\hline Aritmética empregada & Ponto flutuante & Ponto fixo (16 bits) \\
\hline
\end{tabular}

A semelhança entre os resultados reportados no trabalho original (no qual os cálculos são realizados em $\mathrm{C++}$ e o desempenho do SOMprocessor é importante porque as camadas de SOMs implementadas em FPGA executam computações similares, porém não idênticas às computações executadas em software. Esta semelhança indica que as mudanças incluídas no modelo, devido às propriedades da computação do SOM em hardware, produzem impacto limitado no comportamento da rede. Este resultado se deve, possivelmente, à complexidade do modelo SOM, cujo formalismo é capaz de absorver as alterações realizadas e ainda produzir padrões de auto-organizações e agrupamento de dados coerentes. $O$ capítulo 7 descreve a análise realizada sobre a caracterização das redes executadas em hardware e em software com o objetivo de se investigar, com maior profundidade, o impacto das diferenças computacionais elaboradas na implementação em FPGA, frente ao comportamento obtido pelo modelo tradicional do SOM. 


\section{CARACTERIZAÇÃO DAS METODOLOGIAS PESQUISADAS E ANÁLISES DOS RESULTADOS}

Este capítulo expõe as investigações realizadas para se caracterizar o comportamento do SOM executado em FPGA em relação à implementação típica da rede em software e em relação a outras arquiteturas de execução em hardware publicadas na literatura. Para a comparação com software, realizou-se a caracterização dos processos de treinamento das redes executadas em FPGA e em Matlab pela análise do erro de quantização e do erro topográfico das duas implementações, segundo discutido nas seções 3.5.1 e 3.5.2. Após a análise dos resultados dos erros de quantização e topográfico, apresentados nas seções $7.1,7.2$ e 7.3 deste capítulo, a seção 7.4 contém a caracterização da velocidade computacional do SOMprocessor. Tal caracterização é importante porque é um dos objetivos da pesquisa desenvolvida neste trabalho (seção 1.2) e porque é o parâmetro mais comum para comparação das diferentes arquiteturas de execução do SOM em hardware publicadas, como, por exemplo, Długosz, Kolasa e Szulc (2011), Papadonikolakis e Bouganis (2012), Lachmair et al. (2013), Hikawa e Maeda (2015), Sousa, Pires e Del-Moral-Hernandez (2017) e Huang et al. (2017).

O contexto empregado nas diferentes caracterizações do SOM é a aplicação de reconhecimento de vídeos descrita na seção 6.26.1. As implementações do SOM foram avaliadas sob as condições da primeira camada da hierarquia usada na identificação de ações, a qual recebe as imagens pré-processadas e gera as trajetórias de descrição dos movimentos envolvidos (comportamento ilustrado pela Figura 50). A execução em software elaborada para esta investigação possui as características computacionais reportadas pelo artigo original que propõe uma hierarquia de SOMs para identificação de ações humanas registradas por câmeras de vídeo (BUONAMENTE; DINDO; JOHNSSON, 2016). Tais características computacionais são as mesmas que se utilizam no modelo tradicional de implementação do SOM (HAYKIN, 2007 e KOHONEN, 2013). Contudo, a execução em FPGA possui características computacionais diferentes, as quais foram discutidas no capítulo 4 sobre as propriedades dos cálculos neurais realizados diretamente em circuitos elétricos. As principais semelhanças e diferenças entre os cálculos efetuados pelas duas implementações - hardware e software - e a configuração da rede neural executada por ambas estão resumidas a seguir: 
- O SOM possui uma grade de 10x10 neurônios e os vetores de peso $\boldsymbol{w}_{\boldsymbol{j}}$ contêm 79 elementos - conforme o processo de pré-processamento das imagens, descrito no início da seção 6.1 - totalizando assim uma rede com 7900 conexões neurais. A rede foi treinada por 1000 épocas e ambas as execuções possuem mesmo conjunto de pesos inicias.

- A implementação em software utiliza a distância Euclidiana para determinar o neurônio vencedor (ou seja, a cada vetor de entrada admitido qual é, dentre o conjunto de vetores peso da rede, o mais semelhante ao vetor de entrada) e a implementação em hardware utiliza a métrica de Manhattan para o mesmo processo.

- A função $\alpha(t)$ que determina o fator de aprendizagem na execução em software é exponencial decrescente - descrita na Equação (2) - com valor inicial $\alpha_{i}=0,1$ e valor final $\alpha_{f}=0,01$. Conforme detalhado na seção 4.2, o fator de aprendizagem da implementação em hardware é computado pela operação erroj sra fatorAprendizado, com o operador sra indicando deslocamento aritmético à direita ("shift right"), erroj representando o vetor de diferenças $\left[\mathbf{x}_{\mathbf{i}}-\mathbf{w}_{\mathbf{j}}\right]$ e o fatorAprendizado denotando o valor de $\alpha$ no instante $t$. Semelhante ao ilustrado na Figura 7, o fatorAprendizado implementado em FPGA possui 4 patamares - com 1 a 4 bits deslocados à direita - o que resulta em $\alpha=\frac{1}{2}, \frac{1}{4}, \frac{1}{8} \mathrm{e} \frac{1}{16}\left(\alpha_{i}=0,5\right.$ e $\left.\alpha_{f}=0,0625\right)$.

- A função de vizinhança $h_{\mathrm{c}_{\mathrm{j}}}(\mathrm{t})$ que determina a moderação da amplitude de ajuste dos pesos nos neurônios vizinhos na grade ao neurônio vencedor c na execução em software é a função gaussiana, descrita na Equação (3). O valor da abertura $\sigma(t)$ da função gaussiana decai exponencialmente, conforme a Equação (4), com seu valor inicial $\sigma_{i}=7$ e valor final $\sigma_{f}=1$. A implementação da função de vizinhança em hardware também é realizada pela operação de deslocamento aritmético à direita (conforme apresentado na seção 4.3), a qual executa a expressão matemática $h_{c_{j}}(t)=2^{-(\operatorname{dist}(c, j) \cdot \beta(t))}$, com $\operatorname{dist}(c, j)$ representando a distância entre o neurônio vencedor $c$ e o neurônio $j$ a ter seu peso ajustado e $\beta$, o coeficiente de abertura da função no instante $t$ do processo de treinamento. Na implementação em FPGA, $\beta(t)$ 
tem função similar a $\sigma(t)$ da curva gaussiana e, no experimento foi configurado com os valores 1 a 4 .

- Os cálculos executados na implementação do SOM em software foram feitos com aritmética em ponto flutuante. Na execução em hardware, os cálculos foram executados com aritmética binária em ponto fixo com representação numérica de 16 bits em complemento de dois, conforme discutido na seção 4.3 .

Em resumo, a execução da rede neural em software foi feita da maneira que o modelo SOM é tradicionalmente implementado e a execução da mesma rede em FPGA empregou as metodologias existentes de computação em hardware em conjunto com as propostas elaboradas no desenvolvimento deste trabalho, ambas discutidas em detalhes no capítulo 4.

\subsection{AVALIAÇÃO DA RESOLUÇÃO DO MAPA PRODUZIDO PELO SOMPROCESSOR}

Conforme discutido em detalhes na seção 3.5.1, a medida de erro de quantização objetiva avaliar a resolução dos agrupamentos realizados pelo mapa e é obtido pela quantificação das distâncias entre todos os vetores de entrada e seus respectivos neurônios vencedores (BMUs). A Figura 52 apresenta o declínio do erro de quantização de acordo com a progressão do processo de treinamento do SOM implementado em software e em hardware. As curvas foram obtidas em 11 observações durante a fase de aprendizado da rede neural: a primeira no instante zero do processo de treinamento e as demais a cada 100 épocas de apresentação das amostras de entrada.

Pela Figura 52, pode-se perceber que as duas curvas iniciam no mesmo ponto. Isto pode ser entendido porque ambas as implementações possuem pesos iniciais aleatórios idênticos, logo, a distância entre os vetores de entradas e seus respectivos neurônios vencedores (inicialmente aleatórios, pois o processo de aprendizagem não foi iniciado) é a mesma para o SOMprocessor e para a execução em Matlab. É importante notar que, embora a implementação em FPGA utilize a métrica de Manhattan em suas computações, o cálculo de seu erro de quantização foi feito utilizando a métrica Euclidiana para avaliar a distância entre o vetor de entradas e o neurônio vencedor, 
conforme a Equação (6) da seção 3.5.1. Desta forma, tanto o mapa implementado em software quanto o mapa implementado em hardware foram avaliados pela mesma métrica. Nota-se que o declínio do erro de quantização do SOMprocessor ocorre em patamares (curva azul da Figura 52). A variação entre estes patamares está associada às alterações de valores do fator de aprendizagem e abertura da função de vizinhança $\alpha(t)$ e $\beta(t)$ - da implementação em FPGA. Destaca-se também que o SOMprocessor obteve um erro de quantização final menor que a execução em software, com ambas as implementações sob as mesmas condições. Este resultado se manteve com a repetição dos experimentos com diferentes valores de pesos iniciais, aleatoriamente definidos, conforme o Apêndice E. É importante salientar que os menores valores finais do erro de quantização da implementação em hardware nos experimentos realizados somam-se e apoiam trabalhos que indicam o bom desempenho do uso da distância de Manhattan em processos de agrupamento ("clustering") de dados com muitas dimensões (AGGARWAL et al., 2001; KRIEGEL et al., 2009; DŁUGOSZ et al., 2011 e KARKARE; GIBSON; MARKOVIĆ, 2013).

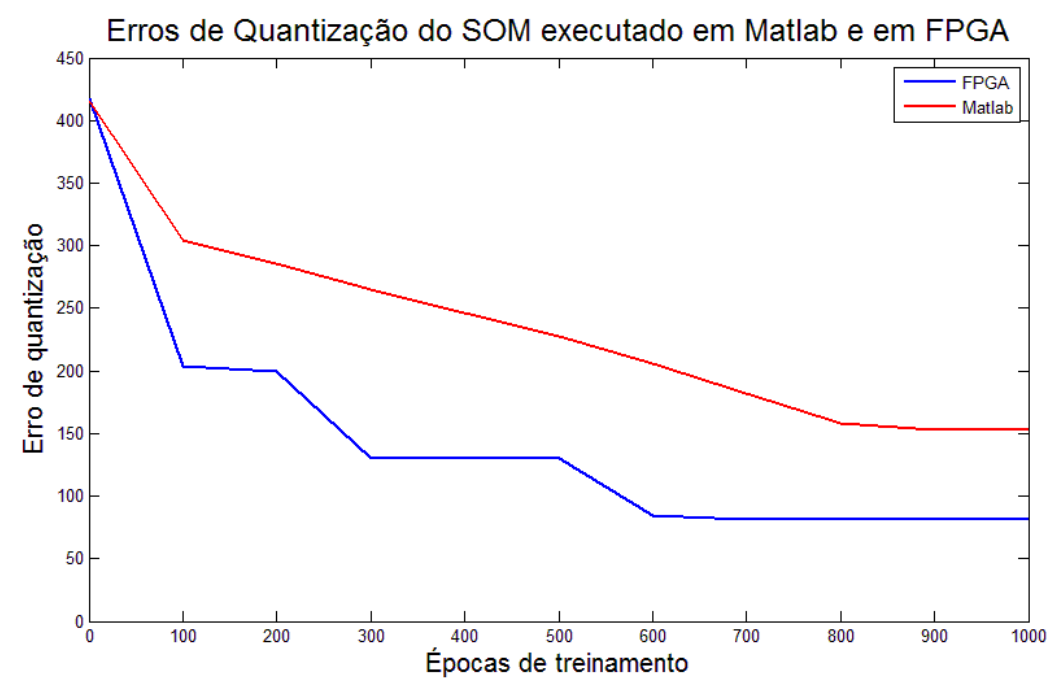

Figura 52 - Decréscimo do erro de quantização em função do processo de aprendizagem do SOM para as implementações da mesma rede em software e em hardware. 


\subsection{AVALIAÇÃO DA ESTRUTURA DE RELAÇÃO ENTRE AS POSIÇÕES MAPEADAS PELO SOMPROCESSOR}

Conforme discutido em detalhes na seção 3.5.2, a medida do erro topográfico avalia quanto a configuração final do mapa aproxima padrões de entrada semelhantes no espaço vetorial multidimensional $\mathbb{R}^{\boldsymbol{n}}$ original. Esta avaliação é feita pela verificação da vizinhança imediata entre o primeiro e segundo neurônios vencedores, na configuração final do mapa, para cada vetor de entrada apresentado à rede. Diferente do erro de quantização, o erro topográfico objetiva mensurar a relação entre as posições dos dados na configuração final do mapa, portanto, seus cálculos não envolvem computações explícitas de métricas de distância, conforme apresentado na Equação (7) da seção 3.5.2. A Figura 53 apresenta as curvas dos erros topográficos em função épocas de treinamento do SOM implementado em software e em hardware. Da mesma forma que o erro de quantização, os dados foram obtidos em 11 observações do processo de aprendizagem: a primeira na época zero do treinamento e as demais a cada 100 épocas de ajuste de pesos da rede neural.

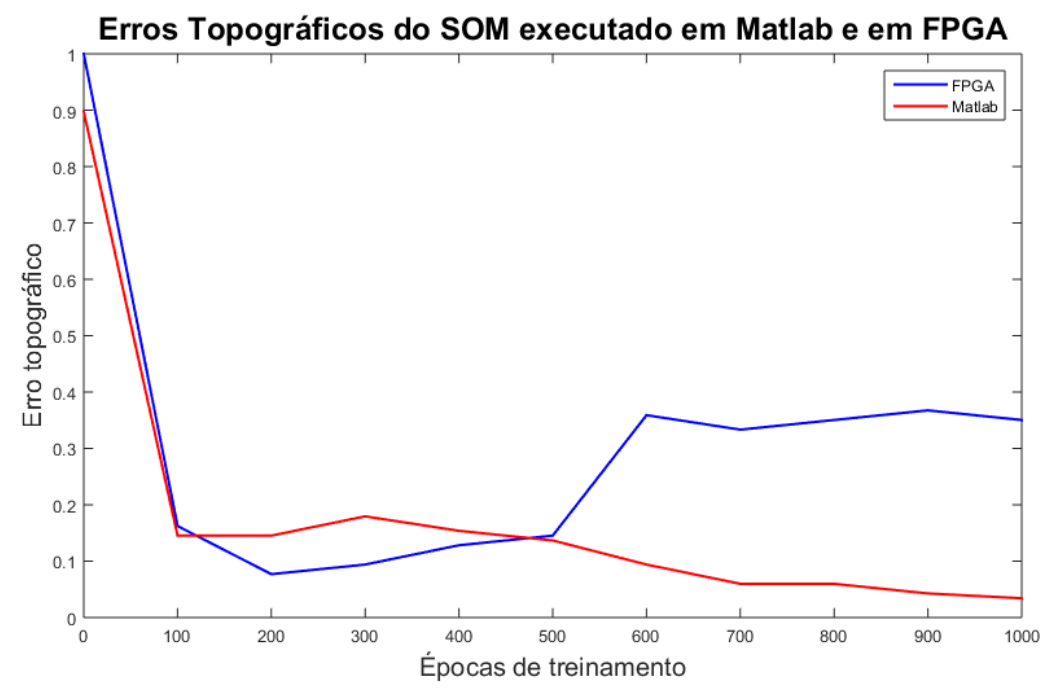

Figura 53 - Curva dos erros topográficos do SOM para as implementações em software e em hardware da mesma rede conforme progressão do processo de treinamento.

Pode-se perceber, na Figura 53, que as duas curvas não iniciam no mesmo ponto, apesar de possuírem conjuntos idênticos de pesos iniciais (aleatórios) e de serem avaliados com o mesmo grupo de dados de entrada. Esta diferença ocorre porque a determinação do primeiro e segundo neurônios vencedores na execução em software se dá pelos valores resultados da computação da distância Euclidiana, enquanto a execução 
em hardware utiliza a métrica de Manhattan neste mesmo processo. Consequentemente, nem sempre há combinação do primeiro e segundo neurônios mais semelhantes entre as duas implementações. Nota-se também que, logo em seguida, nas primeiras épocas da aprendizagem, ambas as curvas atingem um erro topográfico pequeno. Isto se deve ao fato de que o processo de treinamento está em seu princípio e a medida do erro está avaliando mapas ainda prematuros. Por exemplo, no começo da aprendizagem da rede, tipicamente um dos neurônios vence consecutivamente os torneios de busca pelo vetor peso mais semelhante (processo de ordenação inicial do SOM) e este neurônio tende a agrupar a representação da maior parte dos dados de entrada. Desta forma, a medida precoce do erro topográfico não reflete ainda as estruturas de relação entre os posicionamentos das amostras do problema em questão. Entretanto, com o maior refinamento da estrutura de mapeamento, os valores dos erros topográficos tendem a uma estabilização, com o valor obtido pela implementação em hardware superior ao valor obtido pelo software. Durante o desenvolvimento dos dois experimentos práticos do SOM executado diretamente em FPGA (aplicação de telecomunicações na seção 5.8 e aplicação de reconhecimento de imagens na seção 6.1), não se percebeu deformações topológicas nos mapas produzidos pelas execuções em hardware. Motivado por tais resultados, aprofundou-se a investigação da avalição do erro topográfico, e os resultados obtidos estão apresentados a seguir na seção 7.3.

\subsection{PROPOSTA DE ALTERAÇÃO DA CARACTERIZAÇÃO DO MAPA SOM PELO ERRO TOPOGRÁFICO}

Dado que uma das principais características do SOM é constituir um método de aprendizagem que permita que a manutenção topológica ocorra conjuntamente com o agrupamento de dados (conforme detalhado na seção 3.3 sobre os fundamentos do SOM) é importante que se verifique a propriedade de continuidade no mapeamento realizado. Para quantificar tal continuidade, Kimmo Kiviluoto propôs em 1996 a métrica de erro topográfico (KIVILUOTO, 1996). Esta tradicional medida de avaliação do SOM penaliza a caracterização da rede se o segundo neurônio vencedor não for um dos quatro neurônios adjacentes ao neurônio vencedor, independente se eles estiverem próximos na grade de saída ou não. Desta maneira, considera-se que há manutenção 
topológica apenas se o segundo neurônio vencedor estiver em uma das quatro posições ilustradas pela Figura 54 em relação ao neurônio vencedor $c$.

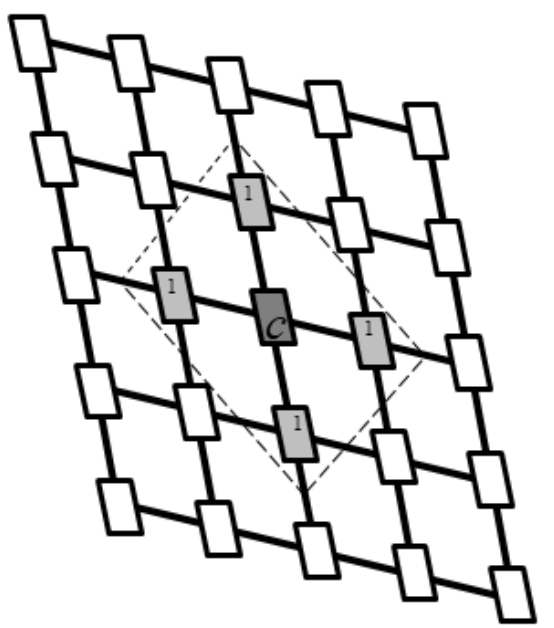

Figura 54 - Os quatro primeiros vizinhos ao neurônio vencedor $c$ considerados no cálculo da medida tradicional do erro topográfico.

Pode-se considerar então, de forma alternativa, uma extensão da região dos neurônios classificados como próximos ao neurônio vencedor para computação do erro topográfico. A Figura 55 ilustra uma configuração de oito neurônios próximos a $c$ considerados como preservadores da continuidade do mapa para uma medida de erro topográfico alternativo.

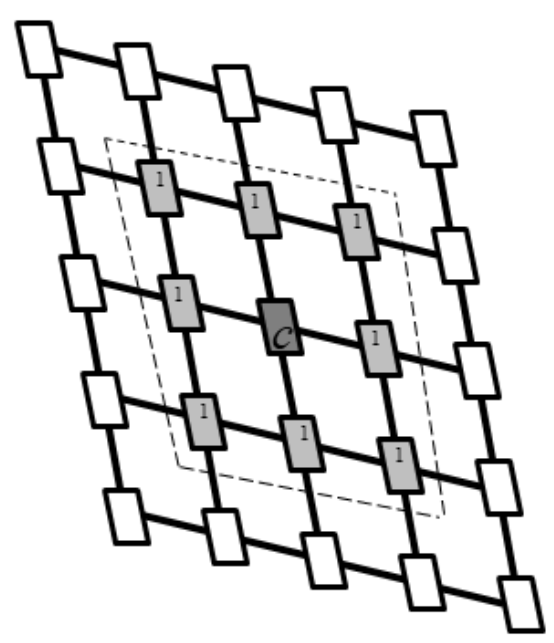

Figura 55 - Ilustração das oito posições consideradas como possível segundo neurônio vencedor próximo a $c$ na proposta da medida de erro topográfico alternativo.

A fórmula para cálculo do erro topográfico apresentado pela Equação (7) pode, portanto, ser alterada para a seguinte proposta: 


$$
T_{e r r}=1-\frac{1}{I} \sum_{i=1}^{I} \lambda\left(x_{i}\right)
$$

na qual, para todo o conjunto de $I$ entradas de treinamento:

$\lambda\left(x_{i}\right)=1$, caso os dois neurônios mais semelhantes ao vetor de entrada $x_{i}$ sejam um dos oito vizinhos no mapa.

$\lambda\left(x_{i}\right)=0$, caso contrário.

Utilizando-se a medida de erro topográfico alternativo, descrito pela Equação (16), para avaliação da estrutura de mapeamento dos dados tanto para implementação em software quanto pela implementação em hardware resulta nas curvas apresentadas pela Figura 56.

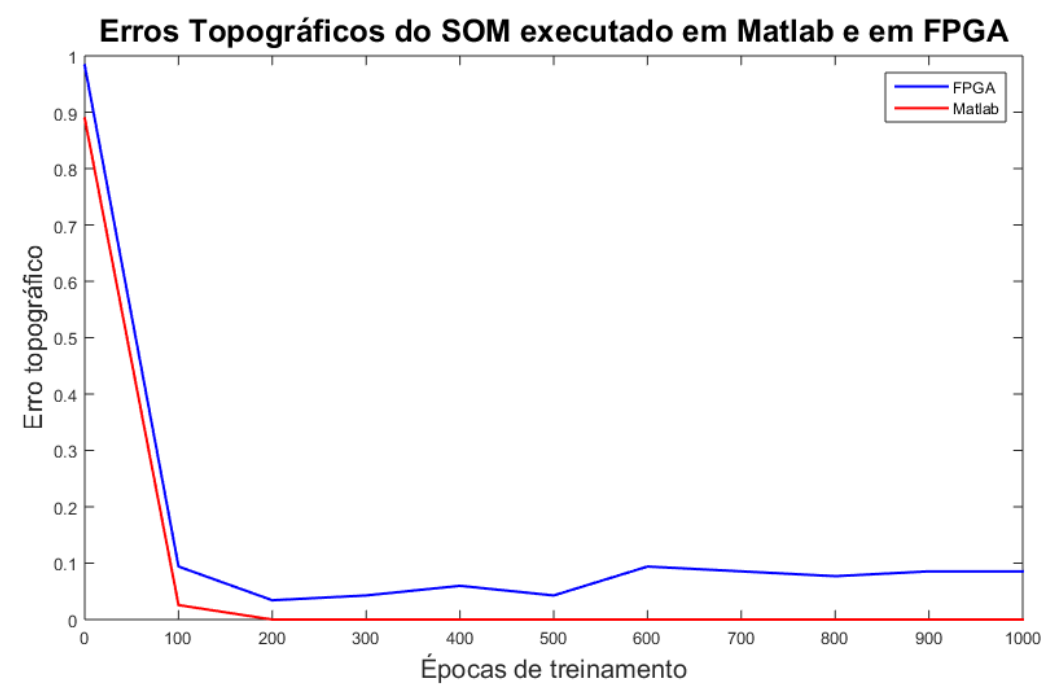

Figura 56 - Curva para as implementações do SOM em software e em hardware do erro topográfico alternativo em função da progressão do processo de treinamento.

Pode-se perceber, pela Figura 56 que o erro topográfico apresentado pela implementação em FPGA ainda é superior ao erro topográfico atingido pela configuração final do SOM executado em Matlab. No entanto, a diferença dos valores de estabilização entre as duas implementações é pequena, o que condiz com os resultados obtidos nas aplicações do SOMprocessor (como, por exemplo, descrito na Tabela 18). Este resultado se manteve com a repetição dos experimentos com diferentes valores de pesos iniciais, aleatoriamente definidos, conforme o Apêndice E. O mesmo padrão de comportamento do início do processo de treinamento obtido com o cálculo 
tradicional do erro topográfico - conforme a Figura 55 - também se apresenta nas curvas produzidas pelo erro topográfico alternativo. Como descrito na seção 7.2, este comportamento preliminar apresenta valores diferentes de erro topográfico no instante inicial da aprendizagem (devido às avaliações diferentes que as métricas Euclidiana e Manhattan fazem para determinação do primeiro e segundo neurônios mais semelhantes ao vetor de entrada) e diminuição precoce do valor do erro nas primeiras épocas do processo de treinamento, causada por uma avaliação prematura do mapeamento realizado pelo SOM. É importante salientar que os menores valores computados pela métrica de erro topográfico alternativo, quando comparados com o cálculo tradicional, são coerentes com a função de vizinhança proposta para execução do ajuste de pesos em FPGA na Equação (11). Conforme pode ser percebido na Figura 8 (página 71), a função de vizinhança utilizada é mais "larga" do que a função gaussiana, tradicionalmente utilizada nas implementações do SOM em software (também usada nos experimentos comparativos desta pesquisa). Portanto, o ajuste de pesos dos neurônios vizinhos ao BMU executado em hardware decresce com menor intensidade, causando estruturas de relação entre as posições finais do mapa com topologias concordantes com as ilustradas pela Figura 55.

\subsection{AVALIAÇÃO DA VELOCIDADE COMPUTACIONAL E DAS PROPRIEDADES DE OPERAÇÃO DO SOMPROCESSOR}

Após a caracterização do SOMprocessor, realizada com as medidas de erros de quantização e erros topográficos e suas respectivas análises comparativas com a execução do SOM em Matlab - descrita nas seções anteriores deste capítulo - realizouse a análise das propriedades de operação do chip. As propriedades investigadas foram a área ocupada no FPGA para implementação da lógica descrita no diagrama de blocos (Figura 41), a energia consumida e a velocidade de operação do sistema. Maior relevância foi dada a esta última característica pois é considerada padrão de comparação entre as arquiteturas de hardware desenvolvidas para execução de diversos modelos neurais de computação publicadas na literatura, incluindo o SOM. Conforme descrito em detalhes na seção 4.5 sobre as propriedades computacionais das redes neurais em hardware, pode-se utilizar a unidade de medida CUPS ("Connection Updates Per Second") como métrica de velocidade de processamento. Esta métrica quantifica o 
número de ajustes de pesos neurais que o sistema executa por segundo durante seu processo de aprendizagem. A importância da unidade de medida CUPS se deve à necessidade de um curto período de treinamento que diversas aplicações diretas em hardware requerem para poderem tratar a taxa de entrada de dados (conforme discutido na seção 1.3 e no capítulo 2). A métrica em CUPS já foi utilizada neste estudo, quando se realizou a comparação entre os diferentes modelos de execução do SOM em FPGA - distribuído, centralizado e híbrido - na seção 5.5.

A caracterização da área ocupada no chip pelas diferentes implementações foi realizada pela comparação da quantidade de LUTs utilizadas na execução do SOM, conforme discutido na seção 3.1. Esta forma de quantização já foi usada neste trabalho, no capítulo 5, durante o desenvolvimento da arquitetura de circuito e dos componentes básicos de implementação em hardware. O consumo estimado de energia do SOMprocessor está apresentado em Watts.

Como detalhado na seção 3.2, os experimentos foram executados usando a plataforma de descrição de hardware Vivado na Xilinx (CHURIWALA, 2016), cuja funcionalidade permite executar a síntese do projeto, a implementação do FPGA e simulação dos circuitos desenvolvidos. Esta ferramenta também forneceu os relatórios sobre a frequência de operação, área utilizada e consumo de energia do chip que estão apresentadas nesta seção. $\mathrm{O}$ dispositivo escolhido para ser configurado com $\mathrm{o}$ SOMprocessor foi o FPGA Virtex-U xcvu440-flga2892-3-e, também do fabricante Xilinx. O sistema implementado é composto pelo diagrama de blocos e pela unidade de controle descrita no capítulo 6, possui 7900 conexões neurais (conforme a topologia da rede neural descrita no início deste capítulo 7), com vetores iniciais armazenados nos registradores de pesos e entradas recebidas paralelamente pelo conjunto de pinos externos do FPGA (79 entradas e 16 bits por entrada). $O$ SOMprocessor foi configurado para processar, alternadamente, dois blocos de neurônios (de acordo com a ilustração da Figura 41 na página 122), o que totaliza 3950 pesos neurais ajustados concomitantemente.

A Tabela 20 mostra os dados obtidos pelos relatórios de sete diferentes implementações do sistema em FPGA. As distintas implementações estão relacionadas aos diferentes períodos de clock definidos na plataforma Vivado (característica padrão de projeto estipulada pelo usuário a ser alcançada pela ferramenta de síntese). O período mínimo especificado, com o qual a plataforma completou com sucesso a implementação do SOMprocessor, foi de $21 \mathrm{~ns}$. Os experimentos foram realizados com o sistema 
configurado para três patamares de fator de aprendizagem e abertura da função de vizinhança $-\alpha(t)$ e $\beta(t)$, respectivamente, de forma semelhante à Figura 7. Diferentes configurações do processo de ajuste de pesos estão apresentadas posteriormente. Na Tabela 20, a taxa de admissão de dados refere-se à frequência de um ciclo completo de processamento do sistema, na qual este recebe um vetor de entrada, ajusta todo seu conjunto de pesos e apresenta o valor de saída do SOM, de acordo com as estratégias computacionais apresentadas no capítulo 6. Esta taxa é equivalente a 1/6 da frequência de operação do chip pois a unidade de controle do sistema requer 6 estados para executar o conjunto completo de computações (segundo o pseudocódigo apresentado na Tabela 16), cada estado processado em 1 ciclo de clock. A velocidade de processamento do sistema é calculada pela Equação (12), apresentada na seção 5.5, $V s=(F m . J m \cdot N m) /($ Cclock $)$, com $F m=$ frequência de operação do chip, $J m=100$ neurônios, $N m=79$ dimensões (valores conforme a topologia da rede neural descrita no início deste capítulo 7) e Cclock $=6$ ciclos para completar o processamento.

Tabela 20 - Dados da implementação do SOMprocessor para 3 níveis de $\alpha$ e $\beta$ durante o treinamento.

\begin{tabular}{cccccc}
\hline $\begin{array}{c}\text { Período } \\
\text { de } \text { clock }\end{array}$ & $\begin{array}{c}\text { Frequência de } \\
\text { operação do } \text { chip }\end{array}$ & $\begin{array}{c}\text { Taxa de admissão } \\
\text { de dados }\end{array}$ & $\begin{array}{c}\text { Ocupação do } \\
\text { FPGA }\end{array}$ & $\begin{array}{c}\text { Potência } \\
\text { consumida }\end{array}$ & $\begin{array}{c}\text { Velocidade de } \\
\text { processamento }\end{array}$ \\
\hline $50 \mathrm{~ns}$ & $20 \mathrm{MHz}$ & $3,33 \mathrm{MHz}$ & $450136 \mathrm{LUTs}$ & $3,842 \mathrm{~W}$ & $26,33 \mathrm{GCUPS}$ \\
\hline $45 \mathrm{~ns}$ & $22,22 \mathrm{MHz}$ & $3,70 \mathrm{MHz}$ & $450138 \mathrm{LUTs}$ & $3,946 \mathrm{~W}$ & $29,26 \mathrm{GCUPS}$ \\
\hline $40 \mathrm{~ns}$ & $25 \mathrm{MHz}$ & $4,17 \mathrm{MHz}$ & $450138 \mathrm{LUTs}$ & $4,105 \mathrm{~W}$ & $32,92 \mathrm{GCUPS}$ \\
\hline $35 \mathrm{~ns}$ & $28,57 \mathrm{MHz}$ & $4,76 \mathrm{MHz}$ & $450141 \mathrm{LUTs}$ & $4,267 \mathrm{~W}$ & $37,62 \mathrm{GCUPS}$ \\
\hline $30 \mathrm{~ns}$ & $33,33 \mathrm{MHz}$ & $5,55 \mathrm{MHz}$ & $450145 \mathrm{LUTs}$ & $4,492 \mathrm{~W}$ & $43,88 \mathrm{GCUPS}$ \\
\hline $25 \mathrm{~ns}$ & $40 \mathrm{MHz}$ & $6,66 \mathrm{MHz}$ & $450139 \mathrm{LUTs}$ & $4,842 \mathrm{~W}$ & $52,67 \mathrm{GCUPS}$ \\
\hline $21 \mathrm{~ns}$ & $47,62 \mathrm{MHz}$ & $7,94 \mathrm{MHz}$ & $450144 \mathrm{LUTs}$ & $5,248 \mathrm{~W}$ & $62,70 \mathrm{GCUPS}$ \\
\hline
\end{tabular}

Pode-se perceber, pela Tabela 20, que a área ocupada no chip permanece constante nas diferentes implementações. Isto se deve ao fato da quantidade de LUTs utilizadas no FPGA estar ligada à arquitetura de circuito implementada (os blocos computacionais e unidade de controle do SOMprocessor). Percebe-se, também, uma relação diretamente proporcional entre a velocidade de processamento do sistema e a estimativa da energia consumida (duas últimas colunas da tabela). Esta proporcionalidade está evidenciada pela Figura 57, fato que confirma a relação entre a potência consumida e a capacidade de processamento do sistema, demonstrado também 
por outras pesquisas, como, por exemplo, Indiveri et al. (2011). Os valores obtidos contrastam com a previsão de potência consumida, calculada pela ferramenta de simulação da Xilinx, para a implementação de redes com configurações menores, conforme apresentada na Tabela 14 (seção 5.7) e na Tabela 15 (seção 5.8).

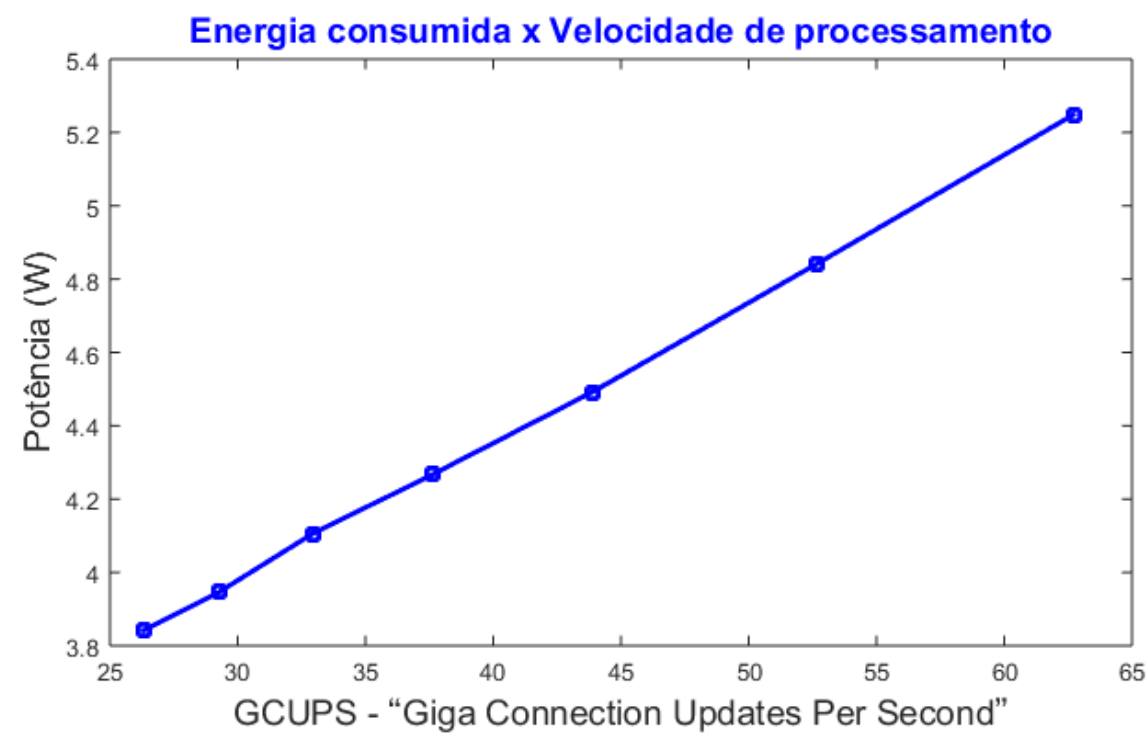

Figura 57 - Relação direta entre a potência do chip e a quantidade de ajustes de pesos por segundo obtida na sequência de experimentos realizados.

Em sequência, repetiram-se os experimentos apresentados na Tabela 20 para diferentes configurações de patamares de fator de aprendizagem e abertura da função de vizinhança (a Tabela 21 mostra os resultados obtidos nos demais procedimentos experimentos). Tal procedimento é relevante porque as configurações estão diretamente associadas com a complexidade dos blocos de Controle de atualização de pesos e Cálculo de G grupos de pesos (Figura 41, na página 122), os quais compõem parte importante do processador. Essa importância fica evidenciada no gráfico da Figura 58.

Tabela 21 - Dados da implementação para 4 e 5 níveis de $\alpha$ e $\beta$ durante o treinamento.

SOMprocessor com 4 patamares do fator de aprendizagem e da abertura da função de vizinhança

\begin{tabular}{cccccc}
\hline $\begin{array}{c}\text { Período } \\
\text { de } \text { clock }\end{array}$ & $\begin{array}{c}\text { Frequência de } \\
\text { operação do } \text { chip }\end{array}$ & $\begin{array}{c}\text { Taxa de admissão } \\
\text { de dados }\end{array}$ & $\begin{array}{c}\text { Ocupação do } \\
\text { FPGA }\end{array}$ & $\begin{array}{c}\text { Potência } \\
\text { consumida }\end{array}$ & $\begin{array}{c}\text { Velocidade de } \\
\text { processamento }\end{array}$ \\
\hline $35 \mathrm{~ns}$ & $28,57 \mathrm{MHz}$ & $4,76 \mathrm{MHz}$ & $458308 \mathrm{LUTs}$ & $4,307 \mathrm{~W}$ & $37,62 \mathrm{GCUPS}$ \\
\hline $30 \mathrm{~ns}$ & $33,33 \mathrm{MHz}$ & $5,55 \mathrm{MHz}$ & $458310 \mathrm{LUTs}$ & $4,561 \mathrm{~W}$ & $43,88 \mathrm{GCUPS}$ \\
\hline $25 \mathrm{~ns}$ & $40 \mathrm{MHz}$ & $6,66 \mathrm{MHz}$ & $458311 \mathrm{LUTs}$ & $4,889 \mathrm{~W}$ & $52,67 \mathrm{GCUPS}$ \\
\hline \hline
\end{tabular}

SOMprocessor com 5 patamares do fator de aprendizagem e da abertura da função de vizinhança

$\begin{array}{llllll}35 \mathrm{~ns} & 28,57 \mathrm{MHz} & 4,76 \mathrm{MHz} & 463685 \mathrm{LUTs} & 4,306 \mathrm{~W} & 37,62 \mathrm{GCUPS}\end{array}$


Pode-se notar que há uma coerência entre os dados obtidos no conjunto de experimentos apresentados pela Tabela $21 \mathrm{com}$ as análises feitas nos experimentos anteriores, cujas informações foram expostas na Tabela 20. A quantidade de LUTs utilizadas permanece constante dentro das faixas de implementações (mesmo $\alpha$ e $\beta$ ). Tal fato - em conjunto com os dados obtidos nos experimentos discutidos na seção 5.5 reforça o entendimento de que a ocupação do FPGA está principalmente relacionada à complexidade do SOMprocessor implementado, e não à sua frequência de operação do chip. Pode-se perceber também que, nestes experimentos, o valor estimado da potência consumida se manteve aproximadamente equivalente aos valores expostos na Tabela 20. Esta ocorrência fortalece o conceito de que a energia dissipada está mais associada à velocidade de processamento - e, portanto, à frequência requisitada de operação do FPGA - e menos relacionada com a complexidade do sistema. Por fim, de maneira semelhante ao experimento anterior, a Tabela 21 contém informações até o período mínimo especificado, com os quais a plataforma Vivado completou com sucesso a implementação do sistema. Desta forma, plotou-se o gráfico da Figura 58, com as velocidades máximas de processamento obtidas de acordo com os diferentes fatores de aprendizagem $-\alpha(t)$ - e aberturas da função de vizinhança $-\beta(t)$.

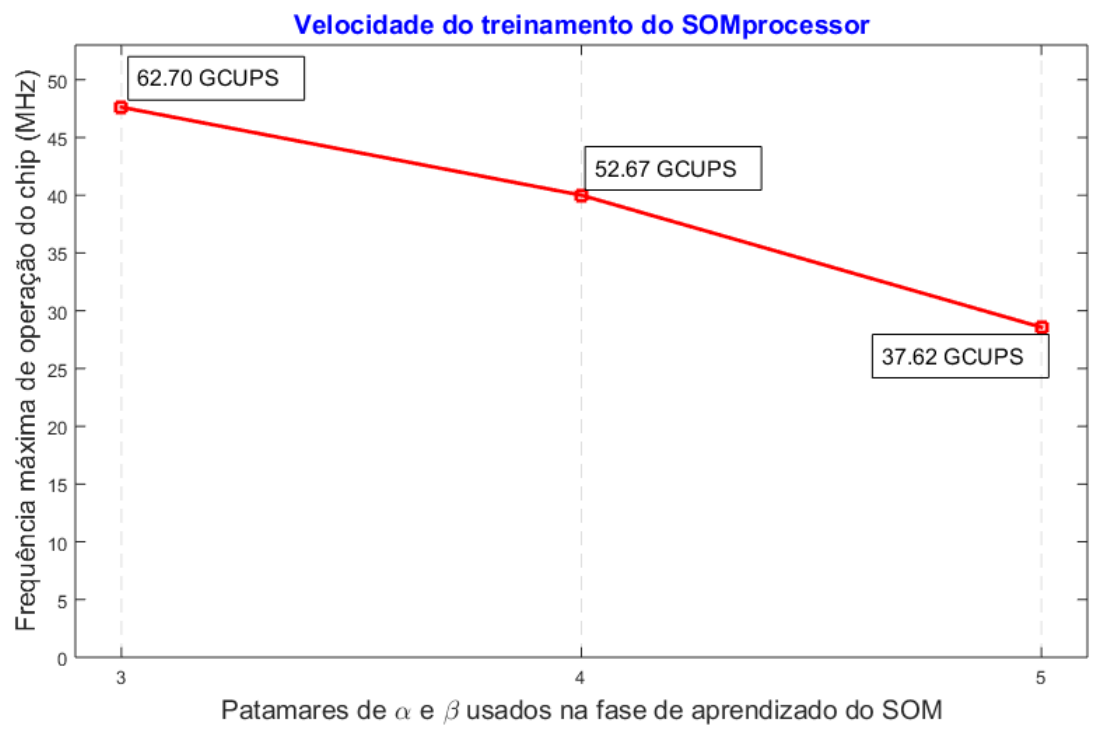

Figura 58 - Taxa de ajuste de pesos ("Connection Updates Per Second") do SOMprocessor segundo a quantidade de níveis de $\alpha$ e $\beta$ usados durante o treinamento.

Com o objetivo de se comparar as metodologias desenvolvidas por esta pesquisa com outros trabalhos publicados na literatura, reuniu-se na Tabela 22 informações sobre diversas arquiteturas para implementação do SOM em hardware apresentadas tanto pelos grupos de pesquisa que realizam estudos continuados sobre execuções deste 
modelo neural em circuitos elétricos (relacionados no capítulo 1), quanto por pesquisas independentes divulgadas em congressos e revistas científicas. Para esta comparação, inclui-se ao final da Tabela 22, os dados referentes ao SOMprocessor com maior complexidade $(28,57 \mathrm{MHz}$ e 5 níveis de $\alpha$ e $\beta$ ). Esta escolha foi feita porque um dos trabalhos publicados (HIKAWA; MAEDA, 2015) possui a análise da arquitetura com decréscimo dos valores do fator de aprendizagem e da abertura da função de vizinhança, os quais estão restritos a um máximo de 4 níveis. $O$ referido trabalho possui o estado-da-arte publicado em velocidade de processamento do SOM em hardware. A Tabela 22 mostra que o SOMprocessor supera o trabalho de Hikawa e Maeda (2015) em velocidade de processamento e também excede-o em complexidade de implementação.

Pode-se perceber, ainda pela Tabela 22, que há uma sucessão de diferentes pesquisas sobre implementações do SOM em diversos tipos de circuitos elétricos e com pluralidade de metodologias. Há uma concentração de trabalhos que optam pelo FPGA como hardware de execução e por uma representação dos vetores de entrada e pesos com 16 bits. Por fim, destaca-se que a proposta de arquitetura de processamento do SOMprocessor permite atingir a maior velocidade computacional publicada na literatura.

A última caracterização realizada nesta pesquisa é uma comparação da velocidade do processo de aprendizagem em FPGA e em software, ambos com a mesma configuração de rede neural. A execução em software utilizou a linguagem compilada $\mathrm{C}++$ para executar a fase de treinamento do SOM da primeira camada da hierarquia neural para reconhecimento de imagens, descrita em detalhes no início deste capítulo 7 (grade de 10x10, 7900 conexões neurais e 1000 épocas de treinamento). Os treinamentos em software foram executados em duas máquinas com processadores de uso geral diferentes:

- Microcomputador Intel Core i5-7200U 64 bits Dual Core 3,1 GHz com memória cache $3 M B$ L3 e memória RAM $8 G B$ DDR4 executando o sistema operacional Linux Ubuntu 16.04;

- Microcomputador portátil Raspberry Pi 3B System-on-Chip (SoC) com processador Broadcom BCM2837 64 bits e memória cache $32 K B L 1$ e 512KB L2 executando o sistema operacional Raspbian (Kernel v. 4.9). 
Tabela 22 - Comparação entre publicações sobre execução de SOM em diferentes hardwares.

\begin{tabular}{|c|c|c|c|c|c|}
\hline Publicação & $\begin{array}{l}\text { Tamanho } \\
\text { do mapa }\end{array}$ & $\begin{array}{c}\text { Dimen. } \\
\text { dos pesos }\end{array}$ & $\begin{array}{c}\text { Qte. } \\
\text { de bits }\end{array}$ & Tipo de hardware & MCUPS \\
\hline Asanović (1997) & $20 \times 20$ & 12 & 16 & $\begin{array}{l}\text { Microprocessador } \\
\text { Spert-II }\end{array}$ & 100,3 \\
\hline $\begin{array}{l}\text { Hendry, Duncan, } \\
\text { Lightowler (2003) }\end{array}$ & 256 (total) & 16 & 8 & $\begin{array}{c}\text { ASIC } \\
0.65-\mu \mathrm{m}\end{array}$ & 660 \\
\hline $\begin{array}{c}\text { Porrmann, Witkowski e } \\
\text { Rückert (2003) }\end{array}$ & $16 \times 8$ & 128 & 8 & $\begin{array}{c}\text { ASIC } \\
0.8-\mu \mathrm{m} \text { standard cell }\end{array}$ & 1318 \\
\hline Tamukoh et al. (2004) & 64 (total) & 4 & 16 & $\begin{array}{c}\text { FPGA } \\
\text { Virtex II xczv6000 }\end{array}$ & 17500 \\
\hline Hikawa (2005) & $5 \times 5$ & 2 & - & $\begin{array}{c}\text { FPGA } \\
\text { Virtex II xc2v250 }\end{array}$ & 4,89 \\
\hline $\begin{array}{l}\text { Peña, Vanegas e } \\
\text { Valencia (2006) }\end{array}$ & $5 \times 5$ & - & - & $\begin{array}{c}\text { FPGA } \\
\text { Spartan II xc2s400 }\end{array}$ & 28,38 \\
\hline $\begin{array}{c}\text { Porrmann, Witkowski e } \\
\text { Rückert (2006) }\end{array}$ & $250 \times 250$ & 9 & - & $\begin{array}{c}4 \text { x FPGA } \\
\text { Virtex xcv812e }\end{array}$ & 665 \\
\hline $\begin{array}{c}\text { Porrmann, Witkowski e } \\
\text { Rückert (2006) }\end{array}$ & 384 & 1024 & - & $\begin{array}{c}4 \text { x FPGA } \\
\text { Virtex II xc2v10000 }\end{array}$ & 4338 \\
\hline $\begin{array}{c}\text { Manolakos e Logaras } \\
\text { (2007) }\end{array}$ & 100 (total) & 2048 & 8 & $\begin{array}{c}\text { FPGA } \\
\text { Virtex II xc2v6000 }\end{array}$ & 3467 \\
\hline $\begin{array}{c}\text { Ramirez-Agundis et al. } \\
\text { (2008) }\end{array}$ & 256 & 16 & 8 & $\begin{array}{c}\text { FPGA } \\
\text { Virtex II xczv6000 }\end{array}$ & 6372 \\
\hline $\begin{array}{c}\text { Ramirez-Agundis et al. } \\
\text { (2008) }\end{array}$ & 256 & 16 & 8 & $\begin{array}{c}\text { ASIC } \\
0.35-\mu \mathrm{m} \text { standard cell }\end{array}$ & 9102 \\
\hline $\begin{array}{l}\text { Długosz, Kolasa e } \\
\text { Szulc (2011) }\end{array}$ & $7 \times 7$ & 2 & - & $\begin{array}{c}\text { FPGA } \\
\text { Virtex } 5 \text { xc5vlx110t }\end{array}$ & 300 \\
\hline Lachmair et al. (2013) & 6050 & 194 & 16 & $\begin{array}{c}\text { Microprocessador } \\
\text { Core-i7 }\end{array}$ & 1628 \\
\hline Lachmair et al. (2013) & 6050 & 194 & 16 & $\begin{array}{c}6 \times \text { FPGA } \\
\text { Virtex-4 fx100 }\end{array}$ & 20604 \\
\hline $\begin{array}{c}\text { Hikawa e Maeda (2015) } \\
\text { (4 níveis de } \boldsymbol{\alpha} \text { e } \boldsymbol{\beta} \text { ) }\end{array}$ & $16 \times 16$ & 3 & 16 & $\begin{array}{c}\text { FPGA } \\
\text { Virtex } 6 \text { xc6vsx315t }\end{array}$ & 25344 \\
\hline Abadi et al. (2016) & $16 \times 16$ & 3 & - & $\begin{array}{c}\text { FPGA } \\
\text { Virtex-7 vc707 }\end{array}$ & 480 \\
\hline Huang et al. (2017) & 256 & 16 & - & $\begin{array}{c}\text { FPGA } \\
\text { Stratic IV (Altera) }\end{array}$ & 21845 \\
\hline $\begin{array}{c}\text { SOMprocessor } \\
\text { (5 níveis de } \alpha \text { e } \beta \text { ) }\end{array}$ & $10 \times 10$ & 79 & 16 & $\begin{array}{c}\text { FPGA Virtex-U } \\
\text { xcvu440-flga2892-3-e }\end{array}$ & 37620 \\
\hline
\end{tabular}


A Tabela 23 mostra os resultados de tempo de execução e os compara com as informações apresentadas na Tabela 20 e na Tabela 21 sobre a implementação do SOMprocessor no FPGA Virtex-U xcvu440-flga2892-3-e com diferentes níveis de $\alpha$ e $\beta$, segundo os dados obtidos na plataforma de descrição de hardware Vivado da Xilinx.

Tabela 23 - Tempos de treinamento para 1 vídeo (“Andreas") da base de dados INRIA 4D para implementações do SOM em software e em FPGA.

\begin{tabular}{|l|c|}
\hline Tipo de execução & Tempo de execução \\
\hline $\begin{array}{l}\text { C++ em Microcomputador } \\
(\text { i5-7200U 64 bits Dual Core 3,1 GHz) }\end{array}$ & $22839 \mathrm{~ms}$ \\
\hline $\begin{array}{l}\text { C++ em Raspberry Pi } \\
\text { (Raspberry Pi } 3 \text { Model B Broadcom BCM2837 } 64 \text { bits) }\end{array}$ & $163610 \mathrm{~ms}$ \\
\hline $\begin{array}{l}\text { SOMprocessor com } 3 \text { níveis de } \alpha \text { e } \beta \\
\text { (período de 21ns na Tabela } 20 \text { e } 6 \text { ciclos de controle da Tabela 16) }\end{array}$ & $14,74 \mathrm{~ms}$ \\
\hline $\begin{array}{l}\text { SOMprocessor com } 4 \text { níveis de } \alpha \text { e } \beta \\
\text { (período de 25ns na Tabela } 21 \text { e } 6 \text { ciclos de controle da Tabela 16) }\end{array}$ & $17,55 \mathrm{~ms}$ \\
\hline $\begin{array}{l}\text { SOMprocessor com } 5 \text { níveis de } \alpha \text { e } \beta \\
\text { (período de 31ns na Tabela } 21 \text { e } 6 \text { ciclos de controle da Tabela 16) }\end{array}$ & $24,57 \mathrm{~ms}$ \\
\hline
\end{tabular}

Conforme a Tabela 23, o tempo gasto no processo de aprendizado do SOM implementado em FPGA é aproximadamente 1000 vezes menor do que o seu treinamento executado em software. Esta taxa de aceleração de 1000 vezes é obtida comparando-se a implementação mais complexa (5 níveis) do SOMprocessor com a execução em C++ em um computador com processador i5-7200U. O ganho de velocidade de processamento fica mais evidente quando se compara a frequência de clock do FPGA $(28,57 \mathrm{MHz}$ para 5 níveis de $\alpha$ e $\beta$ ) com a frequência de clock do microprocessador $(3,1 \mathrm{GHz})$. Deve-se destacar também, que a tecnologia de FPGA ainda está em desenvolvimento e maiores frequência de operação são esperadas em chips futuros (DUNDAR et al., 2017).

Em uma comparação geral da Tabela 23, a metodologia realizada neste trabalho permite acelerar de 3 a 4 ordens de grandeza o processamento realizado em software. A obtenção desta aceleração computacional é importante por diversos motivos: 
- Possibilita empregar o SOM em contextos em que haja restrição do tempo de processamento, conforme discutido na seção 1.3 sobre a justificativa da presente pesquisa. Por exemplo, em uma aplicação de reconhecimento autônomo de vídeos de ações humanas (como a apresentada na seção 6.2), admitindo-se que a taxa de captura é de 30 quadros por segundo (uma imagem a cada 33,33 ms), o SOMprocessor permite executar a fase de treinamento para 1 vídeo completo $(24,57 \mathrm{~ms})$ a cada imagem adquirida pela câmera;

- Permite atender às diversas aplicações descritas no capítulo 2 sobre a contextualização desta pesquisa, nas quais a demanda por velocidade computacional esteja aliada aos requisitos de portabilidade, como nas áreas de IoT e robótica móvel;

- Completa um dos objetivos de pesquisa propostos para este trabalho, conforme enunciado na seção 1.2.

O último capítulo desta tese, a seguir, apresenta as conclusões da pesquisa realizada e as possibilidades de continuidade de desenvolvimentos em trabalhos futuros. 


\section{CONCLUSÕES E TRABALHOS FUTUROS}

Este trabalho apresentou as possibilidades que diferentes arquiteturas de processamento do SOM em FPGA oferecem em relação à velocidade computacional, ao consumo de recursos do chip e à consistência com a teoria que fundamenta o modelo de rede neural artificial estudado.

A pesquisa inicial sobre trabalhos da área de Engenharia de Sistema Neurais mostrou que suas principais motivações e demandas são a aceleração computacional do aprendizado e operação da rede, em conjunto com a diminuição dos consumos de espaço físico e energia, com o intuito de viabilizar tempos reais de resposta e permitir o embarque do processamento (seção 1.3). Mais especificamente, sobre os objetos de pesquisa escolhidos - o SOM e o FPGA - notou-se que o alinhamento de ambos possibilita a implementação de aplicações oriundas de diversas áreas do conhecimento, as quais, em geral, realizam categorizações de dados de forma autônoma, ou seja, sem interpretações humanas do mapa (capítulo 2).

Em sequência, realizou-se uma pesquisa de avaliação das características específicas de processamento do SOM diretamente em circuitos elétricos que estão reportadas na literatura científica. Como resultado desta fase do trabalho, tem-se uma das principais contribuições desta tese: a fundamentação teórica das propriedades computacionais do SOM em hardware, discutidas no capítulo 4. Esta fundamentação tornou possível a elaboração das novas propostas apresentadas no capítulo 5, tais como, os diferentes modelos de arquitetura de circuito para implementação do SOM (SOUSA; DEL-MORAL-HERNANDEZ, 2017a) e uma função de vizinhança adequada à execução do processo de aprendizagem em FPGA (SOUSA; DEL-MORALHERNANDEZ, 2017b).

Para validação de tais propostas, aplicou-se a arquitetura básica de processamento do SOM na identificação de sinais de telecomunicações recepcionados com ruído (seção 5.8). Esta aplicação alcançou uma taxa adequada de reconhecimento de símbolos 16-QAM e 64-QAM, inclusive para sinais de entrada não estacionários (seção 5.9). Além disso, obteve-se uma velocidade de operação do chip compatível com os requisitos das aplicações de telecomunicações e com baixo consumo dos recursos do FPGA, o que possibilita que outras etapas do processo de recepção de sinais sejam incluídas no mesmo dispositivo (SOUSA; PIRES; DEL-MORAL-HERNANDEZ, 2017). 
Destaca-se também como contribuição deste trabalho, a descrição detalhada feita na seção 5.3 dos blocos computacionais básicos da arquitetura do processador e dos circuitos de seus componentes internos para síntese em FPGA (SOUSA et al., 2018).

Para continuação do desenvolvimento da arquitetura de circuito proposta, adicionaram-se técnicas computacionais com o intuito de possibilitar que o processador SOM possuísse alta taxa de fluxo de dados e otimização dos recursos disponibilizados pelo chip (capítulo 6). Desta exploração de recursos computacionais, originou-se a arquitetura nomeada como SOMprocessor, um processador SOM implementado em FPGA cuja velocidade de treinamento é aproximadamente $100 \%$ maior do que o estadoda-arte dos trabalhos publicados na literatura (Tabela 22 da seção 7.4).

O cenário de testes escolhido para a experimentação do SOMprocessor foi o reconhecimento de ações humanas capturadas por câmeras de vídeo. Nesta aplicação, procurou-se replicar a proposta feita pelo artigo de Buonamente, Dindo e Johnsson (2016) para o reconhecimento de imagens, conforme apresentado na seção 6.2. O SOMprocessor atingiu uma taxa de acertos idêntica à reportada pelo artigo original e a velocidade computacional alcançada pelo sistema em FPGA permite que a rede seja completamente treinada, para um dos vídeos utilizados, a cada imagem adquirida pela câmera. Destaca-se também que a aceleração permitida pelo SOMprocessor é de três a quatro ordens de grandeza em relação a implementações em software da rede com a mesma configuração (Tabela 23 da seção 7.4).

A última contribuição do trabalho, considerada como de maior impacto, é a caracterização do sistema proposto e sua avaliação comparativa com implementações em software. A importância desta avaliação é possibilitar que se mensurem os impactos que as adequações realizadas para uma execução eficiente em hardware causam. Como resultado, nota-se que o SOMprocessor tem medidas de avaliação semelhantes à execução tradicional do algoritmo do SOM em software (capítulo 7).

Finalmente, ressalta-se que, nas Ciências Aplicadas - como é o caso da Engenharia e da Ciência da Computação - são necessários diferentes classes de esforços de investigação, após a formulação de um paradigma teórico, até que seja possível se aplicar o novo formalismo na solução de problemas reais. Pode-se exemplificar esta afirmação com a proposta teórica do SOM por Kohonen (1982) e as subsequentes provas matemáticas das condições de sua convergência e auto-organização (FORT; PAGÈS, 1995), as quais foram feitas após o modelo obter certo interesse de pesquisa. Desde então, foi possível fundamentar a utilização do SOM e atingir uma situação de 
êxito do modelo neural, avaliada por sua diversidade de aplicações em diferentes áreas de pesquisa (PÖLLÄ; HONKELA; KOHONEN, 2009). Da mesma forma, também é essencial - em muitos cenários de pesquisa - uma progressão da investigação realizada, para que reais implementações do formalismo sejam, de fato, alcançadas (GOMES, 2017). A presente tese procurou desenvolver metodologias que aliassem esforços com a finalidade de viabilizar esta continuidade de pesquisa, para que seja feita uma ponte entre propostas e aplicações. De maneira semelhante, outros esforços futuros de investigação ainda são necessários, tais como, as integrações físicas e lógicas que os dispositivos periféricos requerem para que a operabilidade da rede neural artificial se torne possível em diversas situações do mundo real.

\subsection{TRABALHOS FUTUROS}

No decorrer do desenvolvimento deste trabalho, surgiram possibilidades de continuação da pesquisa em diferentes direções. Estas possibilidades estão descritas a seguir:

- Ampliar a investigação comparativa entre o uso das distâncias Euclidiana e de Manhattan como métrica de similaridade na execução do SOM. Os bons resultados obtidos nesta pesquisa com o uso da distância de Manhattan - em conjunto com outros trabalhos já publicados - sugerem um estudo mais aprofundado sobre os efeitos do emprego de ambas as métricas, inclusive nas execuções tradicionais do algoritmo do SOM em software. Destaca-se, principalmente, a caracterização das medidas de distância citadas em função do crescimento dimensional dos vetores de entrada a serem processados pelo SOM.

- Caracterizar melhor a nova proposta de erro topográfico, a qual não considera apenas os quatro vizinhos imediatos do neurônio vencedor. Outras configurações podem permitir diferentes avaliações da manutenção das relações na estrutura de mapeamento dos dados, tais como a utilização de oito vizinhos (como a proposta apresentada) ou de uma intensidade atenuada gradualmente conforme a distância para o neurônio vencedor.

- Produção de uma ferramenta para a geração automática do código em VHDL de diferentes configurações do SOMprocessor, segundo a tarefa em que a rede será aplicada. Tendo em vista que os usuários do processador SOM 
desenvolvido podem não estar familiarizados com a descrição de circuitos em VHDL, pode-se produzir um software com interface que permita ao usuário especificar, de forma simples, os pré-requisitos do SOM, de forma que este gere a arquitetura de hardware correspondente em VHDL. Desta forma, o usuário pode configurar o FPGA, sem que, necessariamente, tenha de lidar com os aspectos de projeto de hardware.

- Alterar a arquitetura do SOMprocessor para permitir que os pesos iniciais dos neurônios sejam armazenados nos registradores internos ao FPGA pelas portas de comunicação do chip. Esta conexão adicional - em conjunto com uma alteração da sequência de estados da Unidade de controle - pode permitir que, durante o reset do sistema, seja definido outro conjunto de pesos iniciais para um novo processo de treinamento da rede.

- Como apresentado nas seções 4.2 e 4.3 e experimentado na seção 5.9, sobre variações dinâmicas do fator de aprendizado e abertura da função de vizinhança, sugere-se o estudo de alternativas à segmentação das duas fases de computação - treinamento e operação - do SOM. O objetivo do aprendizado contínuo é permitir uma progressão no ajuste nos valores dos pesos neurais, mesmo durante o processo de operação da rede, para que seja possível tanto um maior refinamento de tais valores, quanto possíveis adequações às mudanças de classes ou características que estejam ocorrendo com as amostras a serem processadas pela rede. Durante o desenvolvimento deste trabalho, notou-se que este processo de continuidade de treinamento tem capacidade de ser associado com a metodologia de execução direta do SOM em hardware, pois o componente eletrônico pode ser empregado em aplicações que demandem operações autônomas ou adaptações às informações processadas de forma independente em seu ambiente de execução. $\mathrm{O}$ direcionamento inicial da pesquisa sobre aprendizado contínuo pode ser feito por trabalhos como Silva; Sandmann e Del-Moral-Hernandez (2008), Araujo; Rego (2013), Rumbell; Denham e Wennekers (2014), Zliobaite et al. (2014) e Dai; Wang e Wang (2014). 


\section{REFERÊNCIAS}

ABADI, M.; JOVANOVIC, S.; KHALIFA, K. B.; WEBER, S.; BEDOUI, M. H. A hardware configurable self-organizing map for real-time color quantization. In IEEE INTERNATIONAL CONFERENCE ON ELECTRONICS, CIRCUITS AND SYSTEMS (ICECS), 2016, Monte Carlo, Mônaco. Proceedings. 2016, p. 336-339.

ABADI, M.; JOVANOVIC, S.; KHALIFA, K. B.; WEBER, S.; BEDOUI, M. H. A scalable and adaptable hardware NoC-based self-organizing map. Microprocessors and Microsystems, v. 57, p. 1-14, 2018.

ABRAHAM, A.; FALCON, R.; KOEPPEN, M. (Eds.). Computational Intelligence in Wireless Sensor Networks: Recent Advances and Future Challenges. Springer, v. 676, p. 209, 2017.

AGGARWAL, C. C.; HINNEBURG, A.; KEIM, D. A. On the surprising behavior of distance metrics in high dimensional spaces. In: Van den Bussche, J.; Vianu, V. (eds), Database Theory - ICDT 2001, v.1, p. 420-434, 2001.

ALHONIEMI, E. Analysis of pulping data using the self-organizing map. TAPPI Journal, v. 83, n. 7, p. 66-73, 2000.

ALLAHYAR, A.; YAZDI, H. S.; HARATI, A. Constrained semi-supervised growing self-organizing map. Neurocomputing, v. 147, p. 456-471, 2015.

ALUR, R.; ARZEN, K. E.; BAILlIEUL, J.; HENZINGER, T. A. Handbook of networked and embedded control systems. HRISTU-VARSAKELIS. D.; LEVINE, W. S. Boston: Springer Science \& Business Media, 2007. 488p.

AGOSTINI, F. D.; CARBOnI, S.; DE CASTRO, M. C.; DE CASTRO, F. C.; TRINDADE, D. Adaptive concurrent equalization applied to multicarrier OFDM systems. IEEE Transactions on Broadcasting, v. 54, n. 3, p. 441-447, 2008.

APPIAH, K.; HUNTER, A.; MENG, H.; Yue, S. ; HOBDEN, M.; PRIESTLEY, N.; HOBDEN, P.; PETTIT, C. A binary Self-Organizing Map and its FPGA implementation. In: INTERNATIONAL JOINT CONFERENCE ON NEURAL NETWORKS (IJCNN), 2009, Atlanta, EUA. Proceedings. 2009, p. 164-171.

APPIAH, K.; HUNTER, A.; DICKINSON, P.; MENG, H. Binary object recognition system on FPGA with bSOM. In: IEEE INTERNATIONAL SOC CONFERENCE (SOCC), 2010, Las Vegas, EUA. Proceedings. 2010, p. 254-259.

APPIAH, K.; HUNTER, A.; DICKINSON, P.; MENG, H. Implementation and Applications of Tri-State Self-Organizing Maps on FPGA. IEEE Transactions on Circuits and Systems for Video Technology, v. 22, n. 8, p. 1150-1160, 2012.

ARAUJO, A. F. R.; REGO, R. L. M. E. Self-organizing maps with a time-varying structure. ACM Computing Surveys (CSUR), v. 46, n. 1, p. 7, 2013. 
ARAUJO, A. F. R.; SANTANA, O. V. Self-organizing map with time-varying structure to plan and control artificial locomotion. IEEE Transactions on Neural Networks and Learning Systems, v. 26, n. 8, p. 1594-1607, 2015.

ASANO, S.; MARUYAMA, T.; YAMAGUCHI, Y. Performance comparison of FPGA, GPU and CPU in image processing. In INTERNATIONAL CONFERENCE ON FIELD PROGRAMMABLE LOGIC AND APPLICATIONS (FPL), 2009, Praga, República Checa. Proceedings. 2009, p. 126-131.

ASANOVIĆ, K. A fast Kohonen net implementation for Spert-II. In: INTERNATIONAL WORK-CONFERENCE ON ARTIFICIAL NEURAL NETWORKS. Proceedings. Springer, Berlin, Heidelberg, 1997. p. 792-800.

ASHENDEN, P. J. The Designer's Guide to VHDL. 2. ed. San Francisco: Morgan Kauman Publisher, 2008. 739p.

ASHMAWY, D.; BANOVIC, K.; ABDEL-RAHEEM, E.; YOUSSIF, M.; MANSOUR, H.; MOHANNA, M. Joint MCMA and DD blind equalization algorithm with variablestep size. In: IEEE INTL. CONFERENCE ON ELECTRO-INFORMATION TECHNOLOGY (EIT), 2009, Windsor, Canadá. Proceedings. 2009, p. 174-177.

AZEVEDO, C. R.; BOOS, C. F.; AZEVEDO, F. M. Classification of epileptiform events in EEG signals using neural classifier based on SOM. In: IEEE INT. CONF. ON ELECTRICAL ENGINEERING AND INFORMATION COMMUNICATION TECHNOLOGY (ICEEICT), 2015, Dhaka, Bangladesh. Proceedings. 2015, p. 1-5.

AZUMA, M.; HIKAWA, H. Supervised Learning of DPLL Based Winner-Take-All Neural Network. In: IEEE INTERNATIONAL CONFERENCE ON EVOLVABLE SYSTEMS (ICES), 2014, Orlando, USA. Proceedings. 2014, p. 117-124.

BAKO, L. Real-Time Clustering of Datasets with Hardware Embedded Neuromorphic Neural Network. In: INTL. WORKSHOP ON HIGH PERFORMANCE COMPUT. SYSTEMS BIOLOGY, 2009, Trento, Itália. Proceedings. 2009, p. 13-22.

BARRON-ZAMBRANO, J. H.; TORRES-HUITZIL, C. FPGA implementation of a configurable neuromorphic CPG-based locomotion controller. Neural Networks, v. 45, p. 50-61, 2013.

BASTERRETXEA, K.; ECHANOBE, J.; DEL CAMPO, I. A Wearable Human Activity Recognition System on a Chip. In: CONF. ON DESIGN AND ARCHIT. FOR SIGNAL AND IMAGE PROC., 2014, Madri, Espanha. Proceedings. 2014, p. 1-8.

BEHI, T.; AROUS, N.; ELLOUZE, N. Self-organization map of spiking neurons evaluation in phoneme classification. In: IEEE INT. CONF. ON SCIENCES OF ELECTRONICS, TECHNOLOGIES OF INFORMATION AND TELEC. (SETIT), 2012, Sousse, Tunísia. Proceedings. 2012, p. 701-705.

BELHADJ, H.; AGGRAWAL, V.; PRADHAN, A.; ZERROUKI, A. Power-aware FPGA design. Actel Corporation White Paper, v. 75, 2009. 
BLOSSOM Team (Japan). SOM Japan Co., Ltd. The BLOSSOM software package, 2005. Disponível em: http://www.somj.com/. Acesso em: 24 jan. 2018.

BORA, A.; RAO, A.; RAJENDRAN, B. Mimicking the worm - an adaptive spiking neural circuit for contour tracking inspired by $C$. Elegans thermotaxis. In: INTERNATIONAL JOINT CONFERENCE ON NEURAL NETWORKS (IJCNN), 2014, Beijing, China. Proceedings. 2014, p. 2079-2086.

BORGESE, G.; PACE, C.; PANTANO, P.; BILOTTA, E. FPGA-Based Distributed Computing Microarchitecture for Complex Physical Dynamics Investigation. IEEE Transactions on Neural Networks and Learning Syst., v. 24, n. 9, p. 1390-1399, 2013.

BRASSAI, S. T.; IANTOVICS, B.; ENĂCHESCU, C.. Artificial Intelligence in the path planning optimization of mobile agent navigation. Procedia Economics and Finance, v. 3, p. 243-250, 2012.

BRASSAI, S. T. FPGA Based Hardware Implementation of a Self-Organizing Map. In: IEEE INTERNATIONAL CONFERENCE ON INTELLIGENT ENGINEERING SYSTEMS (INES), 2014, Tihany, Hungria. Proceedings. 2014, p. 101-104.

BUONAMENTE, M.; DINDO, H.; JOHNSSON, M. Hierarchies of Self-Organizing Maps for Action Recognition. Cognitive Systems Research, v. 39, p. 33-41, 2016.

CAI, Q.; CHEN, S.; LI, X.; HU, N.; HE, H.; YAO, Y. D.; MITOLA, J. An integrated incremental self-organizing map and hierarchical neural network approach for cognitive radio learning. In: INTERNATIONAL JOINT CONFERENCE ON NEURAL NETWORKS (IJCNN), 2010, Barcelona, Espanha. Proceedings. 2010, p. 1-6.

CAO, B.; CHANG, L.; LI, H. Implementation of the RBF neural network on a SOPC for maximum power point tracking. In: IEEE CONF. ON ELECT. AND COMPUTER ENGINEER. (CCECE), 2008, Niagara Falls, Canadá. Proceedings. 2008, p. 981-986.

CHURAMANI, N.; KERZEL, M.; STRAHL, E.; BARROS, P.; WERMTER, S. Teaching emotion expressions to a human companion robot using deep neural architectures. In: INTERNATIONAL JOINT CONFERENCE ON NEURAL NETWORKS (IJCNN), 2017, Anchorage, EUA. Proceedings. 2017, p. 627-634.

CHKLOVSKII, D. B.; KOULAKOV, A. A. Maps in the brain: what can we learn from them. Annual Review of Neuroscience, v. 27, p. 369-392, 2004.

CHURIWALA, S. Designing with Xilinx FPGAs: Using Vivado. Hyderabad, India: Springer, 2016.

COLOMBINI, G. C.; ABREU, I. B. M.; CERRI, R. A Self-Organizing Map-based Method for Multi-Label Classification. In: INT. JOINT CONFERENCE ON NEURAL NETWORKS (IJCNN), 2017, Anchorage, EUA. Proceedings. 2017, p. 4291-4298.

CRAENEN, B. G. W.; NANDI, A. K.; RISTANIEMI, T. A novel heuristic memetic clustering algorithm. In: IEEE INTL. WORKSHOP ON MACHINE LEARNING FOR SIGNAL PROCESSING, 2013, Southampton, Reino Unido. Proceedings. 2013, p. 1-6. 
DAVIES, M.; SRINIVASA, N.; LIN, T. H.; CHINYA, G.; CAO, Y.; CHODAY, S. H.; LIAO, Y. Loihi: A Neuromorphic Manycore Processor with On-Chip Learning. IEEE Micro, v. 38, n.1, p. 82-99, 2018.

DAI, S. L.; WANG, C.; WANG, M. Dynamic learning from adaptive neural network control of a class of nonaffine nonlinear systems. IEEE Transactions on Neural Networks and Learning Systems, v. 25, n. 1, p. 111-123, 2014.

DE, A.; ZHANG, Y.; GUO, C. A parallel adaptive segmentation method based on SOM and GPU with application to MRI image processing. Neurocomputing, v. 198, p. 180$189,2016$.

DE DINECHIN, F.; PASCA, B. Designing custom arithmetic data paths with FloPoCo. IEEE Design \& Test of Computers, v. 28, n. 4, p. 18-27, 2011.

DELIBASIS, K. K.; GOUDAS, T.; MAGLOGIANNIS, I. A novel robust approach for handling illumination changes in video segmentation. Engineering Applications of Artificial Intelligence, v. 49, p. 43-60, 2016.

DICK, C.; HARRIS, F. FPGA QAM demodulator design. In: Field-programmable logic and applications: Reconfigurable computing is going mainstream. Heidelberg: Springer Berlin. 2002, p. 112-121.

DŁUGOSZ, R.; KOLASA, M.; PEDRYCZ, W.; SZULC, M. Parallel Programmable Asynchronous Neighborhood Mechanism for Kohonen SOM Implemented in CMOS Technology. IEEE TRANSACTIONS ON NEURAL NETWORKS. v. 22, n. 12, p. 2091-2104, 2011.

DŁUGOSZ, R.; KOLASA, M.; SZULC, M. An FPGA Implementation of the Asynchronous Programmable Neighborhood Mechanism for WTM Self-Organizing Map. In: INTERNATIONAL CONFERENCE MIXED DESIGN OF INTEGRATED CIRCUITS AND SYSTEMS, 2011, Gliwice, Polônia. Proceedings. 2011, p. 258-263.

DUNDAR, A.; JIN, J.; MARTINI, B.; CULURCIELLO, E. Embedded streaming deep neural networks accelerator with applications. IEEE Transactions on Neural Networks and Learning Systems. v. 28, n. 7, p. 1572-1583, 2017.

EKLUND, C.; MARKS, R. B.; STANWOOD, K. L.; WANG, S. IEEE standard 802.16: a technical overview of the WirelessMAN/sup TM/air interface for broadband wireless access. IEEE communications magazine, v. 40, n. 6, p. 98-107, 2002.

ESMAEILZADEH, H.; FARZAN, F.; SHAHIDI, N.; FAKHRAIE, S. M.; LUCAS, C.; TEHRANIPOOR, M. Neural network stream processing core (NnSP) for embedded systems. In: IEEE INTERNATIONAL SYMPOSIUM ON CIRCUITS AND SYSTEMS (ISCAS), 2006, Kos, Grécia. Proceedings. 2006, p. 2776-2779.

FORT, J. C.; PAGÈS, G. On the A.S. Convergence of the Kohonen Algorithm with a General Neighborhood Function. The Annals of Applied Probability, v. 5, n. 4, p. 1177-1216, 1995. 
FORT, J. C.; LETREMY, P.; COTTRELL, M. Advantages and drawbacks of the Batch Kohonen algorithm. In: EUROPEAN SYMPOSIUM ON ARTIFICIAL NEURAL NETWORKS (ESANN), 2005, Bruges, Bruxelas. Proceedings. 2005, p. 223-230.

FREY, C. W. Monitoring of complex industrial processes based on self-organizing maps and watershed transformations. In: IEEE INTL. CONF. ON INDUSTRIAL TECHNOLOGY (ICIT), 2012, Atenas, Grécia. Proceedings. 2012, p. 1041-1046.

FURBER, S.; TEMPLE, S. Neural systems engineering. Journal of the Royal Society Interface. n. 4, p. 193-206, 2007.

GHOSH, S.; BHATTACHARYYA, N.; TUDU, B.; BANDYOPADHYAY, R. Electronic nose for on-line quality evaluation of black tea using incremental SOM techniques. In: IEEE INT. SYMP. ON PHYSICS AND TECHNOLOGY OF SENSORS (ISPTS), 2015, Pune, Índia. Proceedings. 2015, p. 273-277.

GOMES, L. The neuromorphic chip's make-or-break moment. In: IEEE Spectrum special report: Can we copy the brain?, v. 54, n. 6, p. 52-57, 2017.

GONÇALVES, L. F.; SCHNEIDER, E. L.; HENRIQUES; R. V. B., LUBASZEWSKI, M.; BOSA, J. L.; ENGEL, P. M. Fault prediction in electrical valves using temporal Kohonen maps. In: IEEE LATIN AMERICAN TEST WORKSHOP (LATW), 2010, Punta del Este, Uruguai. Proceedings. 2010, p. 1-6.

GOnÇAlveZ, N. A.; MARTINI, J. A. Princípios de VHDL. Maringá, UEM. 2009. $178 \mathrm{p}$.

GOODHILL, G. J.; e XU, J. The development of retinotectal maps: A review of models based on molecular gradients. Computation in Neural Network Systems, v. 16, n. 1, p. 5-34, 2005.

GUILLAUME, H.; DUBOIS, M.; EMMANUELLE, F.; TARROUX, P. Temporal bagof-words-a generative model for visual place recognition using temporal integration. In INT. CONF. ON COMPUTER VISION THEORY AND APPLICATIONS (VISAPP), 2011, Vilamoura, Portugal. Proceedings. 2011.

HAILESELLASIE, M.; HASAN, S. R. A fast FPGA-based deep convolutional neural network using pseudo parallel memories. In: IEEE INTL. SYMPOS. ON CIRCUITS AND SYSTEMS (ISCAS), 2017, Baltimore, USA. Proceedings. 2017, p. 1-4.

HAMMERSTRON, D. Digital VLSI neural networks. In: The Handbook of Brain Theory and Neural Networks. Cambridge: MIT Press, 2003, p. 349-352.

HAN, S. W. Self-organizing map for blind channel equalization. Journal of information and communic. convergence engineering, v. 8, n. 6, p. 609-617, 2010.

HAUCK, S. The roles of FPGAs in reprogrammable systems. Proceedings of the IEEE, v. 86, n. 4, p. 615 - 638, 1998. 
HAYKIN, S. Redes Neurais - Princípios e Práticas. Porto Alegre: Bookman, 2007. $903 \mathrm{p}$.

HE, W.; ZHOU, X. Application of the wavelet-SOFM network in roll bearing defect diagnosis. In: IEEE GLOBAL CONGRESS ON INTELLIGENT SYSTEMS (GCIS), 2009, Xiamen, China. Proceedings. 2009, p. 8-12.

HENDRY, D. C.; DUNCAN, A. A.; LIGHTOWLER, N. IP core implementation of a self-organizing neural network. IEEE Transactions on Neural Networks, v. 14, n. 5, p. 1085-1096, 2003.

HIKAWA, H. FPGA implementation of self-organizing map with digital phase locked loops. Neural Networks, v. 18, p. 514-522, 2005.

HIKAWA, H.; KAIDA, K. Novel FPGA Implementation of hand sign recognition system with SOM-Hebb classifier. IEEE Transactions on Circuits and Systems for Video Technology, v. 25, n. 1, p. 153-166, 2015.

HIKAWA, H. Winner-Take-All neural network with digital frequency-locked loop In: IEEE INTERNATIONAL SYMPOSIUM ON CIRCUITS AND SYSTEMS (ISCAS), 2015, Lisboa, Portugal. Proceedings. 2015, p. 2517-2520.

HIKAWA, H.; MAEDA, Y. Improved learning performance of hardware selforganizing map using a novel neighborhood function. IEEE Transactions on Neural Networks and Learning Systems, v. 26, n. 11, p. 2861-2873, 2015.

HIKAWA, H.; TAMAKI, M.; ITO, H. Off-Chip Training with Additive Perturbation for FPGA-Based Hand Sign Recognition System. IEICE Transactions on Fundamentals of Electronics, Communications and Computer Sciences, v. 101, n. 2, p. 499-506, 2018.

HIROSE, A.; NAGASHIMA, T. Predictive self-organizing map for vector quantization of migratory signals and its application to mobile communications. IEEE Transactions on Neural Networks, v. 14, n. 6, p. 1532-1540, 2003.

HOLT, J.; BAKER, T. Back propagation simulations using limited precision calculations. In: INTERNATIONAL JOINT CONFERENCE ON NEURAL NETWORKS (IJCNN), 1991, Seattle, EUA. Proceedings. 1991, p. 121-126.

HORTA, E. L. Dispositivos lógicos programáveis: implementação de sistemas digitais em FPGAS. São Paulo: Editora Mackenzie, 2013. 180 p.

HSIEH, H. Y.; TANG, K. T. Hardware friendly probabilistic spiking neural network with long-term and short-term plasticity. IEEE Transactions on Neural Networks and Learning Systems. v. 24, n. 12, p. 2063-2074, 2013.

HUANG, Z.; ZHANG, X.; CHEN, L.; ZHU, Y.; AN, F.; WANG, H.; FENG, S. A Hardware-Efficient Vector Quantizer Based on Self-Organizing Map for High-Speed Image Compression. Applied Sciences, v. 7, n. 11, 2017. 
HUDA, S.; ANDERSON, J. Circuits and Architectures for Low-Power FPGAs. Reconfigurable Logic: Architecture, Tools, and Applications, v. 48, 2015.

HUSSAIN, Z; PARVIN, K. N. Q-Format Data Representation and Its Arithmetic. Intl. Journal of Electronics \& Communication Tech. (IJECT), v. 7, n. 2, p. 57-62, 2016.

INDIVERI, G.; LINARES-BARRANCO, B.; HAMILTON, T. J.; VAN SCHAIK, A.; ETIENNE-CUMMINGS, R.; DELBRUCK, T.; LIU, S. C.; DUDEK, P.; HÄFLIGER, P.; RENAUD, S.; SCHEMMEL, J.; CAUWENBERGHS, G.; ARTHUR, J.; HYNNA, K.; FOLOWOSELE, F.; SAIGHI, S.; SERRANO-GOTARREDONA, T.; WIJEKOON, J.; WANG, Y.; BOAHEN, K. Neuromorphic silicon neuron circuits. Frontiers in Neuroscience, v. 73, n. 5, p. 01-23, 2011.

JAVIDI, F.; KHOSHBIN, H. Performance of back-propagation and self-organizing map neural equalizers for asymmetrically clipped optical OFDM. In: CONFERENCE ON ELECTRICAL ENGINEER. (ICEE), 2013, Mashhad, Irã. Proceedings. 2013, p. 01-06.

JEWAJINDA, Y.; CHONGSTITVATANA, P. FPGA-based online-learning using parallel genetic algorithm and neural network for ECG signal classification. In: INT. CONF. ON ELECTRICAL ENGINEERING/ ELECTRONICS COMPUTER TELECOM. AND INF. TECH. (ECTI-CON), 2010. Proceedings. 2010, p. 1050-1054.

KAWAI, Y. M.; MORI, K.; NAOI, N; KOJIMA, S. Neural Attunement Processes in Infants during the Acquisition of a Language-Specific Phonemic Contrast. Journal of Neuroscience, v. 27, n. 2, p. 315-321, 2007.

KARKARE, V.; GIBSON, S.; MARKOVIĆ, D. A 75- $\mu \mathrm{W}, 16-$ channel neural spikesorting processor with unsupervised clustering. IEEE Journal of Solid-State Circuits. v. 48 , n. 9 , p. $2230-2238,2013$.

KIM, S. K.; MCAFEE, L. C.; MCMAHON, P. L.; OLUKOTUN K. A highly scalable Restricted Boltzmann Machine FPGA implementation. In: INTERNATIONAL CONFERENCE ON FIELD PROGRAMMABLE LOGIC AND APPLICATIONS (FPL), 2009, Praga, República Checa. Proceedings. 2009, p. 367-372.

KITANI, E. C.; DEL-MORAL-HERNANDEZ, E.; SILVA, L. A. Learning embedded data structure with self-organizing maps. In: Advances in Self-Organizing Maps. Springer: Berlin, Heidelberg, p. 225-234, 2013.

KIVILUOTO, K. Topology preservation in self-organizing maps. In: INTERNATIONAL JOINT CONFERENCE ON NEURAL NETWORKS (IJCNN), 1996, Washington, EUA. Proceedings. 1996, p. 294-299.

KOHONEN, T. Self-Organized Formation of Topologically Correct Feature Maps. Biological Cybernetics, v. 43, n. 1, p. 59-69, 1982.

KOHONEN, T.; KANGAS, J.; LAAKSONEN, J. SOM_PAK: The self-organizing map program package. Report A31, Helsinki University of Technology, Espoo, Finlândia, 1992. 
KOHONEN, T. Essentials of the self-organizing map. Neural Networks, v. 37, p. 52$65,2013$.

KOHONEN, T. MATLAB Implementations and Applications of the SelfOrganizing Map. Helsinki: Unigrafia Oy, 2014. 193 p.

KOLASA, M.; DŁUGOSZ, R.; PEDRYCZ, W.; SZULC, M. A programmable triangular neighborhood function for a Kohonen self-organizing map implemented on chip. Neural Networks, v. 25, n. 9, p. 146-160, 2012.

KOLASA, M.; DŁUGOSZ, R.; TALAŚKA, T.; PEDRYCZ, W. Efficient methods of initializing neuron weights in self-organizing networks implemented in hardware. Applied Mathematics and Computation. 2017.

KOLASA, M.; TALAŚKA, T.; DŁUGOSZ, R. A serial distance calculation circuit for the application in artificial neural networks and pattern recognition. In: INTERNATIONAL CONFERENCE MIXED DESIGN OF INTEGRATED CIRCUITS AND SYSTEMS, 2017, Bydgoszcz, Polônia. Proceedings. 2017, p. 501-504.

KRIEGEL, H. P.; KRÖGER, P.; ZIMEK, A. Clustering high-dimensional data: A survey on subspace clustering, pattern-based clustering, and correlation clustering. ACM Trans. on Knowledge Discovery from Data (TKDD), v. 3, n. 1, p. 1-54, 2009.

KUHL, P. K.; TSAO, F. M.; LIU, H.M. Foreign-language experience in infancy: Effects of short-term exposure and social interaction on phonetic learning. Proceedings of the National Academy of Sciences of the United States of America, v. 100, n. 15, p. 9096-9101, 2003.

KUMAR, V.; ALBERT, S. K.; CHANDRASEKHAR, N.; JAYAPANDIAN, J.; VENKATESAN, M. V. Performance analysis of arc welding parameters using selforganizing maps and probability density distributions. In: IEEE INTL. CONF. ON CONTROL, MEASUREMENT AND INSTRUMENTATION (CMI), 2016, Kolkata, Índia. Proceedings. 2016, p. 196-200.

KURDTHONGMEE, W. A novel hardware-oriented Kohonen SOM image compression algorithm and its FPGA implementation. Journal of Systems Architecture, v. 54, p. 983-994, 2008.

KURDTHONGMEE, W. Utilization of a rational-based representation to improve the image quality of a hardware-based K-SOM quantizer. Journal of Real-Time Image Processing, v. 6, p. 199-211, 2011.

KUREMOTO, T.; OTANI, T.; OBAYASHI, M.; KOBAYASHI, K.; MABU, S. A hand shape instruction recognition and learning system using growing SOM with asymmetric neighborhood function. Neurocomputing, v. 188, p. 31-41, 2016.

LACHMAIR, J.: MERÉNYI, E.; PORRMANN, M.; RÜCKERT, U. gNBXe-a Reconfigurable Neuroprocessor for Various Types of Self-Organizing Maps. In: EUROPEAN SYMP. ON ARTIFICIAL N. NET., COMP. INTELIGENCE, MACHINE LEARNING (ESANN), 2012, Bruges, Bélgica, Proceedings. 2012, v. 20, p. 645-650. 
LACHMAIR, J.; MERÉNYI, E.; PORRMANN, M.; RÜCKERT, U. A reconfigurable neuroprocessor for self-organizing feature maps. Neurocomputing, v. 112, p. 189-199, 2013.

LACHMAIR, J.; MIETH, T.; GRIESSL, R.; HAGEMEYER, J.; PORRMANN, M. From CPU to FPGA - Acceleration of Self-Organizing Maps for Data Mining. In: INTERNATIONAL JOINT CONFERENCE ON NEURAL NETWORKS (IJCNN), 2017, Anchorage, EUA. Proceedings. 2017, p. 4299-4308.

LAPIDOT, I.; GUTERMAN, H.; COHEN, Ar. Unsupervised speaker recognition based on competition between self-organizing maps. IEEE Transactions on Neural Networks, v. 13, n. 4, p. 877-887, 2002.

LIN, C.; SHAO, B.; ZHANG, J. A high data rate parallel demodulator suited to FPGA implementation. In: INTL. SYMP. ON INTELLIGENT SIGNAL PROCESSING AND COMMUN. SYSTEMS (ISPACS), 2010, Chengdu, China. Proceedings. 2010, p. 1-4.

LIN, S. T.; LIAO, Y. H.; TSAO, Y.; CHIEN, S. Y. Object-based on-line video summarization for internet of video things. In: IEEE INTERNATIONAL SYMPOSIUM ON CIRCUITS AND SYSTEMS (ISCAS), 2017, Baltimore, USA. Proceedings. 2017, p. 68-71.

LIN, Z.; DONG, Y.; LI, Y.; WATANABE, T. A Hybrid Architecture for Efficient FPGA-based Implementation of Multilayer Neural Network. In: IEEE INTERNATIONAL SYMPOSIUM ON CIRCUITS AND SYSTEMS (ISCAS), 2010, Paris, França. Proceedings. 2010, p. 616-619.

LINARES-BARRANCO, A.; PAZ-VICENTE， R.; GÓMEZ-RODRÍGUEZ， F.; JIMÉNEZ, A.; RIVAS, M.; JIMÉNEZ, G.; CIVIT, A. On the AER convolution processors for FPGA. In: IEEE INTERNATIONAL SYMPOSIUM ON CIRCUITS AND SYSTEMS (ISCAS), 2010, Paris, França. Proceedings. 2010, p. 4237-4240.

LINDE, Y.; BUZO, A.; GRAY, R. M. An algorithm for vector quantizer design. IEEE Transactions on Communications, v. 28, n. 1, p. 84-95, 1980.

LO, C. A FPGA Implementation of Large Restricted Boltzmann Machines. 2010. 48p. Tese (Doutorado) - Electrical and Computer Engineering Department, University of Toronto, Toronto, 2010.

LORRENTZ, P.; HOWELLS, W.; MCDONALD-MAIER, K. D. A fingerprint identification system using adaptive FPGA-based enhanced probabilistic convergent network. In: NASA/ESA CONFERENCE ON ADAPTIVE HARDWARE AND SYSTEMS, 2009, San Francisco, EUA. Proceedings. 2009, p. 204-211.

LOSS, D. V.; CASTRO, M. C. F. D.; FRANCO, P. R. G.; CASTRO, F. C. C. D. Concurrent blind channel equalization with phase transmittance RBF neural networks. Journal of the Brazilian Computer Society, v. 12, n.4, p. 17-24, 2007. 
MANOLAKOS, I; LOGARAS, E. High throughput systolic SOM IP core for FPGAs. In: IEEE INTL. CONFERENCE ON ACOUSTIC, SPEECH AND SIGNAL PROCESSING (ICASSP), 2007, Honolulu, EUA. Proceedings. 2007, p. II-61-II-64.

MANSOUR, W.; AYOUBI, R.; ZIADE, H.; VELAZCO, R.; FALOU, W. An Optimal Implementation on FPGA of a Hopfield Neural Network. Advances in Artificial Neural Systems, v. 2011, p. 1-9, 2011.

MCCULLOCH, W. S.; PITTS, W. H. A logical calculus of the ideas immanent in nervous activity. Bulletin of Mathematical Biophysics, v. 5, p.115-133, 1943.

MCELROY, B.; HOWELLS, G. Evaluating the application of simple weightless networks to complex patterns. In: IEEE INTL. CONF. ON EMERGING SECURITY TECHNOLOGIES, 2010, Canterbury, Reino Unido. Proceedings, 2010, p. 67-70.

MEROLLA, P. A.; ARTHUR, J. V.; ALVAREZ-ICAZA, R.; CASSIDY A. S.; SAWADA, J.; AKOPYAN F.; JACKSON B. L.; IMAM, N.; GUO, C.; NAKAMURA, Y.; BREZZO, B.; VO, I.; ESSER, S. K.; APPUSWAMY, R.; TABA, B.; AMIR, A.; FLICKNER, M. D.; RISK, W. P.; MANOHAR, R.; MODHA, D.S. A Million SpikingNeuron Integrated Circuit with a Scalable Communication Network and Interface. Science, v. 345, n. 6197, p. 668-673, 2014.

MISRA, J.; SAHA, I. Artificial neural networks in hardware: A survey of two decades of progress. Neurocomputing, v. 74, n. 1, p. 239-255, 2010.

MOLINA-CABELLO, M. A., LÓPEZ-RUBIO, E., LUQUE-BAENA, R. M., \& DOMÍNGUEZ, E. Neural Controller for PTZ cameras based on nonpanoramic foreground detection. In: INTERNATIONAL JOINT CONFERENCE ON NEURAL NETWORKS (IJCNN), 2017, Anchorage, EUA. Proceedings. 2017, p. 404-411.

MOUZINHO, L. F.; FONSECANETO, J. V.; LUCIANO, B. A.; FREIRE, R. C. S.; CATUNDA, S. Y. Induction machine neural estimator using embedded system. In: IEEE INSTRUMENTATION AND MEASUREMENT TECHNOLOGY CONFERENCE, 2005, Ottawa, Canadá. Proceedings, 2005, p. 1291-1296.

MUHAMMAD, I.G.; TEPE, K.E.; ABDEL-RAHEEM, E. QAM Equalization and Symbol Detection in OFDM Systems Using Extreme Learning Machine. Neural Computing and Applications, v. 22, p. 491-500, 2013.

NAJJAR, A.; REIGNIER, P. Constructivist ambient intelligent agent for smart environments. In: IEEE PERVASIVE COMPUTING AND COMMUNICATIONS WORKSHOPS (PERCOM), 2013, San Diego, EUA. Proceedings. 2013, p. 356-359.

NAKAMURA, Y.; HASEGAWA, O. Nonparametric density estimation based on selforganizing incremental neural network for large noisy data. IEEE transactions on neural networks and learning systems, v. 28, n. 1, p. 8-17, 2017.

NOORI, S. M. R.; MIKAEILI, M. Detecting driving drowsiness using EEG, EOG and driving quality signals. In: IEEE CONF. ON BIOMEDICAL ENGINEERING (ICBME), 2015, Teerã, Irã. Proceedings. 2015, p. 210-215. 
OJA, M.; SOMERVUO, P.; KASKI, S.: KOHONEN, T. Clustering of human endogenous retrovirus sequences with median self-organizing map. In: WORKSHOP ON SELF-ORGANIZING MAPS (WSOM), 2003, Hibikino, Japão, 2003. Proceedings. 2003, p. 1-7.

OLDFIELD, J. V.; DORF, R. C. Field-programmable gate arrays: reconfigurable logic for rapid prototyping and implementation of digital systems. Chichester: Wiley Interscience, 1994.

OMONDI, A. R.; RAJAPAKSE, J. C. FPGA implementations of neural networks. Netherlands: Springer, 2006. 360 p.

ORCHARD, G; MARTIN, J. G.; VOGELSTEIN, R. J.; ETIENNE-CUMMINGS, R. Fast Neuromimetic Object Recognition using FPGA Outperforms GPU Implementations. IEEE Transactions on Neural Networks and Learning Systems, v. 24, n. 8, p. 1239-1252, 2013.

PALOMO, E. J.; DOMINGUEZ, E. Image compression based on growing hierarchical self-organizing maps. In: INTERNATIONAL JOINT CONFERENCE ON NEURAL NETWORKS (IJCNN), 2012, Brisbane, Australia. Proceedings, 2012, p. 1624-1628.

PAPADONIKOLAKIS, M.; BOUGANIS, C. S. Novel cascade FPGA accelerator for Support Vector Machines classification. IEEE Transactions on Neural Networks and Learning Systems, v. 23, n. 7, p. 1040-1052, 2012.

PARTZSCH, J.; SCHÜFFNY, R. Analyzing the scaling of connectivity in neuromorphic hardware and in models of neural networks. IEEE Transactions on Neural Networks and Learning Systems, v. 22, n. 6, p. 919-935, 2011.

PAUWELS, K.; TOMASI, M.; DIAZ ALONSO, J.; ROS, E.; VAN HULLE, M. M. A comparison of FPGA and GPU for real-time phase-based optical flow, stereo, and local image features. IEEE Transactions on Computers, v.61, n.7, p. 999-1012, 2012.

PEDRONI, V. A. Circuit design and simulation with VHDL. Cambridge, Massachusetts: MIT Press, 2010.

PEÑA, J.; VANEGAS, M.; VALENCIA, A. Digital Hardware Architectures of Kohonen's Self Organizing Feature Maps with Exponential Neighboring Function. In: IEEE INTERNATIONAL CONFERENCE ON RECONFIGURABLE COMPUTING AND FPGA'S, 2006, San Luis Potosi, México. Proceedings. 2006, p. 1-8.

POIKONEN, J. H; LAIHO, M. A mixed-mode array computing architecture for online dictionary learning. In: IEEE INTERNATIONAL SYMPOSIUM ON CIRCUITS AND SYSTEMS (ISCAS), 2017, Baltimore, USA. Proceedings. 2017, p. 1302-1305.

PÖLLÄ, M.; HONKELA, T.; KOHONEN, T. Bibliography of self-organizing map (SOM) papers: 2002-2005 addendum. Neural Computing Surveys, 2009. 
PÖLZLBAUER, G. Survey and comparison of quality measures for self-organizing maps. In: FIFTH WORKSHOP ON DATA ANALYSIS (WDA'04), 2004. Proceedings. 2004, p. 67-82.

PORRMANN, M.; WITKOWSKI, U.; RÜCKERT, U. A massively parallel architecture for self-organizing feature maps. IEEE Transactions on Neural Networks, v. 14, n. 5, p. 1110-1121, 2003.

PORRMANN, M.; WITKOWSKI, U.; RÜCKERT, U. Implementation of selforganizing feature maps in reconfigurable hardware. In FPGA implementations of neural networks. Netherlands: Springer, 2006. pp. 247-269.

PRADO, R. N. A.; MELO, J. D.; OLIVEIRA, J. A. N.; NETO, A. D. D. FPGA based implementation of a fuzzy neural network modular architecture for embedded systems. In: IEEE WORLD CONGRESS ON COMPUTATIONAL INTELLIGENCE, 2012, Brisbane, Austrália. Proceedings. 2012, p. 1-7.

PROAKIS, J. Digital Communications, 4th ed. Nova York: McGraw-Hill, 2000. 1024 p.

PRZEDWOJSKI, P.; DALECKI, J.; TALAŚKA, T.; DŁUGOSZ, R. Kohonen winner takes all neural network realized on microcontrollers with AVR and ARM cores. In: Mixed Design of Integrated Circuits and Systems (MIXDES), 2010, Wroclaw, Polônia. Proceedings. 2010, p 273-276.

RABBA, S.; HE, Y.; KYAN, M.; GUAN, L. Pupil localization for gaze estimation using unsupervised graph-based model. In: IEEE INTL. SYMPOSIUM ON CIRCUITS AND SYSTEMS (ISCAS), 2017, Baltimore, USA. Proceedings. 2017, p. 1559-1562.

RAMIREZ-AGUNDIS, A.; GADEA-GIRONES, R.; COLOM-PALERO, R. A hardware design of a massive-parallel, modular NN-based vector quantizer for real-time video coding. Microprocessors and Microsystems, v. 32, n. 1, p. 33-44, 2008.

RAMIREZ-ALONSO, G.; CHACON-MURGUIA, M. I. Object detection in video sequences by a temporal modular self-adaptive SOM. Neural Computing and Applications, v. 27, n. 2, p. 411-430, 2016.

RAST, A.; GALLUPPI, F.; DAVIES, S.; PLANA, L.; PATTERSON, C.; SHARP, T.; LESTER, D.; FURBER, S. Concurrent heterogeneous neural model simulation on realtime neuromimetic hardware. Neural Networks, v. 24, n. 9, p. 961-978, 2011.

RATHKANTHIWAR, S.; DETHE, C. G.; KULAT, K. D. A neural approach for overall improvement of OFDM system. In: INTERNATIONAL CONFERENCE ON SUSTAINABLE ENERGY AND INTELLIGENT SYSTEMS, 2011, Chennai, Índia. Proceedings. 2011, p. 764-769.

RATHKANTHIWAR, S.; DETHE, C.; DAKHOLE, P.; KULAT, K. Parameterless selforganizing map for improving OFDM system performance. In: INTERNATIONAL CONFERENCE ON SUSTAINABLE ENERGY AND INTELLIGENT SYSTEMS, 2011, Chennai, Índia. Proceedings. 2011, p.114-119. 
REZVANI, R.; KATIRAEE, M.; JAMALIAN, A. H.; MEHRABI, S. H. ; VEZVAEI, A. A New Method for Hardware Design of Multi-Layer Perceptron Neural Networks with Online Training. IN: IEEE INTL. CONF. ON COGNITIVE INFORMATICS \& COGNITIVE COMPUTING, 2012, Kyoto, Japão. Proceedings. 2012, p. 527-534.

ROBERSON, D.; DAVIDOFF, J. B.; DAVIES, I.; SHAPIRO, L. Colour categories and category acquisition in Himba and English. In: Progress in Colour Studies. Amsterdam: John Benjamins Publishing Company, 2006. p. 159-172.

RODRIGUEZ, L.; MIRAMOND, B.; GRANADO, B. Toward a sparse self-organizing map for neuromorphic architectures. ACM Journal on Emerging Technologies in Computing Systems, v. 11, n. 4, p. 33.1-33.25.

ROMOTH, J.; PORRMANN, M.; RÜCKERT, U. Survey of FPGA applications in the period 2000-2015. Technical Report CITEC - Cognitive Interaction Technology, Bielefeld University, p. 42, 2017.

ROSTRO-GONZALEZ, H.; GARREAU, G.; ANDREOU, A.; GEORGIOU, J.; BARRON-ZAMBRANO, J. H.; TORRES-HUITZIL, C. An FPGA-based approach for parameter estimation in spiking neural networks. In: IEEE INTERNATIONAL SYMPOSIUM ON CIRCUITS AND SYSTEMS (ISCAS), 2012, Seul, Coreia do Sul. Proceedings. 2012, p. 2897-2900.

RUMBELL, T.; DENHAM, S. L.; WENNEKERS, T. A spiking self-organizing map combining stdp, oscillations, and continuous learning. IEEE Transactions on Neural Networks and Learning Systems, v. 25, n. 5, p. 894-907, 2014.

RÜPING, S.; RÜCKERT, U.; GOSER, K. Hardware design for self-organizing feature maps with binary input vectors. New Trends in Neural Computation, v. 686, p. 488493, 1993.

SALEH, S. A. M.; SUANDI, S. A.; IBRAHIM, H. Recent survey on crowd density estimation and counting for visual surveillance. Engineering Applications of Artificial Intelligence, v. 41, p. 103-114, 2015.

SAMMOUD, A; KUMAR, A.; BAYOUMI, M.; ELARABI, T. Real-time streaming challenges in Internet of Video Things (IoVT), In: IEEE INTL. SYMP. ON CIRCUITS AND SYSTEMS (ISCAS), 2017, Baltimore, USA. Proceedings. 2017, p. 1-4.

SCHÄFFER, L.; NAGY, Z.; KINCSES, Z.; FIÁTH, R. FPGA-based neural probe positioning to improve spike sorting with Osort algorithm. In: IEEE INTERNATIONAL SYMPOSIUM ON CIRCUITS AND SYSTEMS (ISCAS), 2017, Baltimore, USA. Proceedings. 2017, p. 1375-1378.

SCHILLACI, G.; HAFNER, V. V.; LARA, B. Online learning of visuo-motor coordination in a humanoid robot. a biologically inspired model. In: IEEE INT. CONF. ON DEVELOPMENT AND LEARNING AND EPIGENETIC ROBOTICS (ICDLEpirob), 2014, Genoa, Itália. Proceedings. 2014, p. 130-136. 
SCHUMAN, C. D.; POTOK, T. E.; PATTON, R. M.; BIRDWELL, J. D.; DEAN, M. E.; ROSE, G. S.; PLANK, J. S. A Survey of Neuromorphic Computing and Neural Networks in Hardware. arXiv preprint arXiv:1705.06963, 2017.

SÉGUIN-GODIN, G. ; MAILHOT, F.; ROUAT, J. Efficient event-driven approach using synchrony processing for hardware spiking neural networks In: IEEE INTERNATIONAL SYMPOSIUM ON CIRCUITS AND SYSTEMS (ISCAS), 2015, Lisboa, Portugal. Proceedings. 2015, p. 2696-2699.

SENEVIRATHNA, H. M. S. B.; YAMASHITHA, K.; LIN, H. Self-organizing map based channel prediction for OFDMA. In: IEEE INTL. SYMPOSIUM ON CIRCUITS AND SYSTEMS (ISCAS), 2005, Kobe, Japão. Proceedings. 2005, p. 2506-2509.

SHAN, H.; SINGH, J. P.; OLIKER, L.; BISWAS, R. A comparison of three programming models for adaptive applications on the Origin2000. Journal of Parallel and Distributed Computing, v. 62, n. 2, p. 241-266, 2002.

SHEN, J. P.; LIPASTI, M. H. Modern processor design: fundamentals of superscalar processors. Estados Unidos: Waveland Press, p. 642, 2013.

SILVA, A. J.; LUDERMIR, T. B.; OLIVEIRA, W. R. On the universality of quantum logical neural networks. In: BRAZILIAN SYMPOSIUM ON NEURAL NETWORKS (SBRN), 2012, Curitiba, Brasil. Proceedings. 2012, p. 102-106.

SILVA, L. A.; SANDMANN, H.; DEL-MORAL-HERNANDEZ, E. A self-organizing architecture of recursive elements for continuous learning. In: IEEE 2008, INTERNATIONAL JOINT CONFERENCE ON NEURAL NETWORKS (IJCNN), Hong Kong, China. Proceedings. 2008, p. 2784-2791.

SMITH, K. A.; NG, A. Web page clustering using a self-organizing map of user navigation patterns. Decision Support Systems, v. 35, n. 2, p. 245-256, 2003.

SOUSA, M. A. A.; TORRES, T. F. J. Modeling of pain on a FPGA-based neural network. In: INTERNATIONAL CONFERENCE ARTIFICIAL INTELLIGENCE AND APPLICATIONS, 2013, Innsbruck, Austria. Proceedings. 2013, p. 64-69.

SOUSA, M. A. A.; HORTA, E. L.; KOFUJI, S. T.; DEL-MORAL-HERNANDEZ, E. Architecture Analysis of an FPGA-Based Hopfield Neural Network. Advances in Artificial Neural Systems, v. 2014, p. 1-10, 2014.

SOUSA, M. A. A.; DEL-MORAL-HERNANDEZ, E. An FPGA distributed implementation model for embedded SOM with on-line learning. In: INTERNATIONAL JOINT CONFERENCE ON NEURAL NETWORKS (IJCNN), 2017, Anchorage, EUA. Proceedings. 2017a, p. 3930-3937.

SOUSA, M. A. A.; DEL-MORAL-HERNANDEZ, E. Comparison of three FPGA architectures for embedded multidimensional categorization through Kohonen's Selforganizing Maps. In: IEEE INTERNATIONAL SYMPOSIUM ON CIRCUITS AND SYSTEMS (ISCAS), 2017, Baltimore, USA. Proceedings. 2017b, p. 2042-2045. 
SOUSA, M. A. A.; PIRES, R.; DEL-MORAL-HERNANDEZ, E. OFDM symbol identification by an unsupervised learning system under dynamically changing channel effects. Neural Computing and Applications, v. 2017, p. 1-13, 2017.

SOUSA, M. A. A.; PIRES, R.; PERSEGHINI, S. D. S.; DEL-MORAL-HERNANDEZ, E. An FPGA-based SOM circuit architecture for online learning of 64-QAM data streams. In: IEEE WORLD CONGRESS ON COMPUTATIONAL INTELLIGENCE (WCCI), 2018, Rio de Janeiro, Brasil. Proceedings. 2018. No prelo.

STRANNEBY, D.; WALKER, W. Digital Signal Processing and Applications, Burlington: Elsevier, 2004. 357 p.

SU, M. C. An SOM-Based Motion Trajectory Recognition Algorithm and Its Application in Monitoring Therapeutic Exercises. In: IEEE COMPUTER SOFT. AND APPL. CONF. (COMPSAC), 2015, Taichung, Taiwan. Proceedings. 2015, p. 732-732.

TAKASU, R.; TOMIOKA, Y.; ISHIGAKI, Y.; NING, L. I.; SHIBATA, T.; NAKANISHI, M.; KITAZAWA, H. An FPGA Implementation of the TwoDimensional FDTD Method and Its Performance Comparison with GPGPU. IEICE Transactions on Electronics, v. 97, n.7, p. 697-706, 2014.

TAMAKI, M.; HIKAWA, H. Off-chip learning for hardware hand-sign recognition system. In: IEEE INTERNATIONAL SYMPOSIUM ON CIRCUITS AND SYSTEMS (ISCAS), 2016, Montreal, Canadá. Proceedings. 2016, p. 2575-2578.

TAMUKOH, H.; ASO, T.; HORIO, K.; YAMAKAWA, T. Self-organizing map hardware accelerator system and its application to realtime image enlargement. In: INTERNATIONAL JOINT CONFERENCE ON NEURAL NETWORKS (IJCNN), 2004, Budapeste, Hungria. Proceedings. 2004, pp. 2683-2687.

TERAHARA, N.; OBA, Y., HIKAWA, H. Color-space image compression with hardware Self-organizing Map. In: IEEE INT. SYMPOSIUM ON INTELLIGENT SIGNAL PROC. AND COMMUNICATIONS SYSTEMS (ISPACS), 2013. Proceedings. 2013, p. 11-16.

THIEMJARUS, S.; LO, B.; YANG, G. Z. A spatio-temporal architecture for context aware sensing. In: IEEE INTL. WORKSHOP ON WEARABLE AND IMPLANTABLE BODY SENSOR NETWORKS (BSN), 2006, Cambridge, EUA. Proceedings. 2006, p. 190-194.

THURNHOFER-HEMSI, K., LÓPEZ-RUBIO, E., DOMÍNGUEZ, E., LUQUEBAENA, R. M., \& MOLINA-CABELLO, M. A. Panoramic Background Modeling for PTZ Cameras with Competitive Learning Neural Networks. In: INTL. JOINT CONF. ON NEURAL NET. (IJCNN), 2017, Anchorage, EUA. Proceedings. 2017, p. 396-403.

TORRES-HUITZIL, C.; GIRAU, B.; CASTELLANOS-SÁNCHEZ, C. On-chip visual perception of motion: A bio-inspired connectionist model on FPGA. Neural Networks, v. 18 , p. 557-565, 2005. 
TSAI, T. H.; CHANG, C. H. Design for an intelligent surveillance system based on system-on-a-programmable-chip platform. In: IEEE INTERNATIONAL SYMPOSIUM ON CIRCUITS AND SYSTEMS (ISCAS), 2015, Lisboa, Portugal. Proceedings. 2015, p. 2049-2052.

TU, F.; YIN, S.; OUYANG, P.; LIU, L.; WEI, S. Neural Approximating Architecture Targeting Multiple Application Domains. In: IEEE INTL. SYMPOS. ON CIRCUITS AND SYSTEMS (ISCAS), 2015, Lisboa, Portugal. Proceedings. 2015, p. 2509-2512.

ULLAH, M. M.; ORABONA, F.; CAPUTO, B. Continuous Learning of Visual Places with a Forgetting Mechanism. In: IEEE INTERNATIONAL CONFERENCE ON INTELLIGENT ROBOTS AND SYSTEMS, 2009, St. Louis, EUA. Proceedings. 2009, p. 3154-3161.

VESANTO, J.; HIMBERG, J.; ALHONIEMI, E.; PARHANKANGAS, J. Selforganizing map in Matlab: the SOM Toolbox. In: Matlab DSP Conference, 1999, Espoo, Finland. Proceedings. 1999, p. 35-40.

WANG, X.; LU, J.; SEKIYA, H.; YAHAGI, T. A compensating method based on SOM for nonlinear distortion in 16 QAM-OFDM system. In: IEEE INTL. CONFERENCE ON MULTIMEDIA AND EXPO, 2004. Proceedings. vol. 3, 2004, p. 1899-1902.

WANG, Y.; WANG, L.; LI, D.; CHENG, X.; XIAO, Y. Self-organizing map neural network-based depth-of-interaction determination for continuous crystal PET detectors. IEEE Transactions on Nuclear Science, v. 62, n. 3, p. 766-772, 2015.

WANG, Y.; XIAO, Y.; CHENG, X.; LI, D.; WANG, L. An FPGA-Based Real-Time Maximum Likelihood 3D Position Estimation for a Continuous Crystal PET Detector. IEEE Transactions on Nuclear Science, v. 63, n. 1, p. 37-43, 2016.

WAKERLY, J. F. Digital Design: Principles and Practices. 5a . ed. (vol. 3). Pearson, 2017, p. 912.

WEBER, R. F. Fundamentos de arquitetura de computadores. $4^{\mathrm{a}}$. ed. Porto Alegre: Bookman, 2012, p. 72.

WEINLAND, D.; RONFARD, R.; BOYER, E. Free viewpoint action recognition using motion history volumes. Computer Vision and Image Understanding, vol. 104, n. 2, p. 249-257, 2006.

XIAOJIAN, X.; XINPING, Y. ; JIANGBIN, Z. ; CHENXING, S. ; CHENGQING, Y. ; DONGZHI, M. Remote fault diagnostic model for tribological systems in marine diesel engine with two-level self-organizing map network. In: PROGNOSTICS AND SYSTEM HEALTH MANAGEMENT CONFERENCE, 2014, Zhangiiaijie, China. Proceedings. 2014, p. 261-265.

YASUKAWA, S; OKUNO, H; ISHII, K.; YAGI, T. Real-time object tracking based on scale-invariant features employing bio-inspired hardware. Neural Networks, v. 5, n. 2, 2016. 
ZHAI, X.; APPIAH, K.; EHSAN, S.; CHEUNG, W. M.; HOWELLS, G.; HU, H.; GU, D.; MCDONALD-MAIER, K. Detecting Compromised Programs for Embedded System Applications. In: Architecture of Computing Systems (ARCS 2014). 2014, Luebeck, Alemanha. 2014, p. 221-232.

ZHANG, H.; CHOW, T. W. S.; WU, Q. M. J. Organizing Books and Authors by Multilayer SOM. IEEE Transactions on Neural Networks and Learning Systems, v. 27, n. 12, p. 2537-2550, 2016.

ZHANG, X.; NG, K. W. A review of high-level synthesis for dynamically reconfigurable FPGAs. Microprocessors and Microsystems, v. 24, p. 199-211, 2000.

ZHEN, L.; CHENG, G.; QIANG, X. A survey of some classic self-organizing maps with incremental learning. In: IEEE INTERNATIONAL CONFERENCE ON SIGNAL PROCESSING SYSTEMS, 2010, Dalian, China. Proceedings. 2010, p. v1-804-v1-809.

ZHU, J.; MILNE, G. J.; GUNTHER, B. K. Towards An FPGA Based Reconfigurable Computing Environment for Neural Network Implementations. In: INTERNATIONAL JOINT CONFERENCE ON NEURAL NETWORKS (IJCNN), 1999, Washington, DC., EUA. Proceedings. 1999, p. 2079-2086.

ZHU, J.; SUTTON, P. FPGA implementations of neural netwroks - a survey of a decade of progress. Field Progr. Logic and Application, v. 2778, p. 1062-1066, 2003.

ZLIOBAITE, I.; BIFET, A.; PFAHRINGER, B.; HOLMES, G. Active learning with drifting streaming data. IEEE Transactions on Neural Networks and Learning Systems, v. 25, n. 1, p. 27-39, 2014. 


\title{
APÊNDICE A - MODELO DISTRIBUÍDO EM VHDL
}

\author{
Modelo distribuído de execução do SOM em FPGA.
}

-- SOM: mapa 5x5, dados de dimensão 2 (4 bits cada). Cálculo da distância de Manhattan, -- difusão de neurônio vencedor, difusão de vizinhança e ajuste de pesos feitos em rede paralela.

-- Todos os neurônios da rede são ajustados em decaimento linear de vizinhança (1 bit / raio).

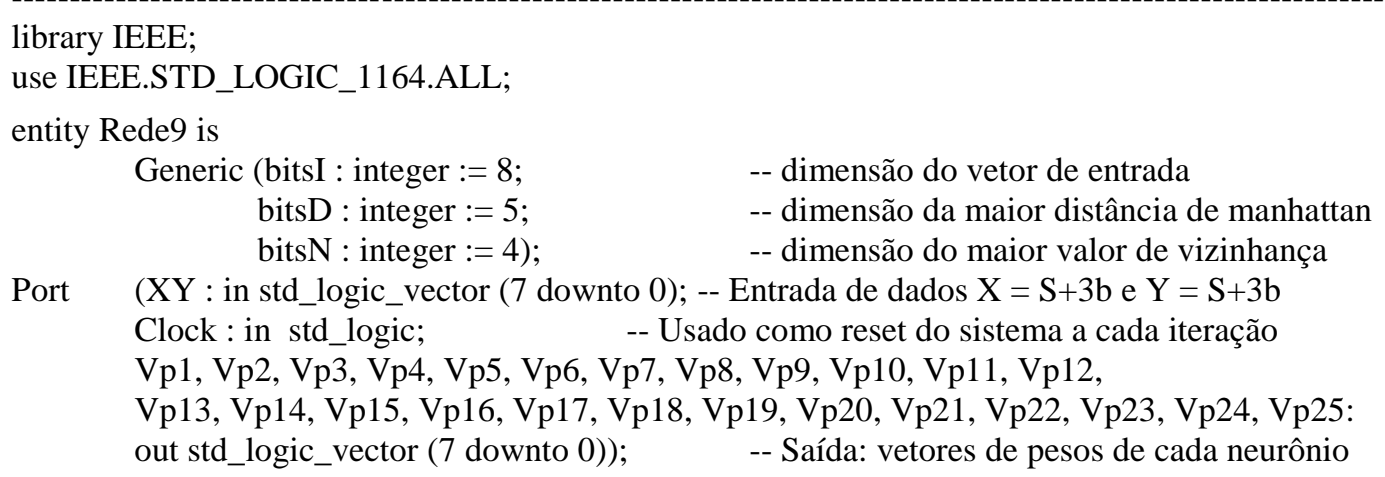
end Rede9;

architecture Behavioral of Rede9 is

component Neuron

Port (Data : in std_logic_vector(bitsI-1 downto 0); $\quad$-- Entrada de dados 2x4bits com sinal $\mathrm{R}$ : in std_logic; -- Reset

VectorIn : in std_logic_vector (bitsI-1 downto 0); -- Peso do neurônio

VectorOut : out std_logic_vector (bitsI-1 downto 0); -- Peso ajustado do neurônio

N, S, E, W: in std_logic_vector (bitsD+bitsN-1 downto 0);-- Entradas de dist. e vizinh. end component;

NOut : out std_logic_vector (bitsD+bitsN-1 downto 0)); $\quad$-- Saídas de dist. e vizinhança

-- Sinais de interligação entre os neurônios

signal N1, N2, N3, N4, N5, N6, N7, N8, N9, N10, N11, N12, N13, N14, N15, N16, N17, N18, N19, N20, N21, N22, N23, N24, N25 : std_logic_vector (bitsD+bitsN-1 downto 0);

-- Sinais de interligação de pesos

signal Wout1, Wout2, Wout3, Wout4, Wout5, Wout6, Wout7, Wout8, Wout9, Wout10, Wout11, Wout12, Wout13, Wout14, Wout15, Wout16, Wout17, Wout18, Wout19, Wout20, Wout21, Wout22, Wout23, Wout24, Wout25 : std_logic_vector (bitsI-1 downto 0);

-- Vetores iniciais dos neurônios signal Win1 : std_logic_vector (bitsI-1 downto 0) :="00000100"; -- coordenadas: $0,+4$ signal Win2 : std_logic_vector (bitsI-1 downto 0) :="00010100"; -- coordenadas: $+1,+4$ signal Win3 : std_logic_vector (bitsI-1 downto 0) :="00100100"; -- coordenadas: $+2,+4$ signal Win 4 : std_logic_vector (bitsI-1 downto 0) :="00110100"; -- coordenadas: $+3,+4$ signal Win5 : std_logic_vector (bitsI-1 downto 0) :="01000100"; -- coordenadas: $+4,+4$ signal Win6 : std_logic_vector (bitsI-1 downto 0) :="00000011"; -- coordenadas: $0,+3$ signal Win7 : std_logic_vector (bitsI-1 downto 0) :="00010011"; -- coordenadas: $+1,+3$ signal Win8 : std_logic_vector (bitsI-1 downto 0) :="00100011"; -- coordenadas: $+2,+3$ signal Win9 : std_logic_vector (bitsI-1 downto 0) :="00110011"; -- coordenadas: $+3,+3$ signal Win10 : std_logic_vector (bitsI-1 downto 0) :="01000011"; -- coordenadas: $+4,+3$ signal Win1 1 : std_logic_vector (bitsI-1 downto 0) :="00000010"; -- coordenadas: $0,+2$ signal Win12 : std_logic_vector (bitsI-1 downto 0) :="00010010"; -- coordenadas: $+1,+2$ signal Win13 : std_logic_vector (bitsI-1 downto 0) :="00100010"; -- coordenadas: $+2,+2$ signal Win14 : std_logic_vector (bitsI-1 downto 0) :="00110010"; -- coordenadas: $+3,+2$ signal Win 15 : std_logic_vector (bitsI-1 downto 0) :="01000010"; -- coordenadas: $+4,+2$ signal Win 16 : std_logic_vector (bitsI-1 downto 0) :="00000001"; -- coordenadas: $0,+1$ signal Win17 : std_logic_vector (bitsI-1 downto 0) :="00010001"; -- coordenadas: $+1,+1$ signal Win18 : std_logic_vector (bitsI-1 downto 0) :="00100001"; -- coordenadas: $+2,+1$ signal Win19 : std_logic_vector (bitsI-1 downto 0) :="00110001"; -- coordenadas: $+3,+1$ 
signal Win20 : std_logic_vector (bitsI-1 downto 0) :="01000001"; -- coordenadas: $+4,+1$ signal Win21 : std_logic_vector (bitsI-1 downto 0) :="00000000"; -- coordenadas: 0, 0 signal Win22 : std_logic_vector (bitsI-1 downto 0) :="00010000"; -- coordenadas: +1, 0 signal Win23 : std_logic_vector (bitsI-1 downto 0) :="00100000"; -- coordenadas: 2, 0 signal Win24 : std_logic_vector (bitsI-1 downto 0) :="00110000"; -- coordenadas: +3, 0 signal Win25 : std_logic_vector (bitsI-1 downto 0) :="01000000"; -- coordenadas: +4, 0 constant endmap : std_logic_vector (bitsD+bitsN-1 downto 0) := "111111111";

begin

-- Declaração da rede de interligação dos neurônios

Neuron1: Neuron port map (Data $=>$ XY, VectorIn $\Rightarrow$ Win1, R $=>$ Clock, VectorOut $=>$ Wout1, $\mathrm{N}=>$ endmap, $\mathrm{S}=>\mathrm{N} 6, \quad \mathrm{E}=>\mathrm{N} 2, \quad \mathrm{~W}=>$ endmap, NOut $=>\mathrm{N} 1)$;

Neuron2: Neuron port map $\quad($ Data $=>X Y$, VectorIn $\Rightarrow$ Win2, R $\Rightarrow>$ Clock, VectorOut $=>$ Wout2, $\mathrm{N}=>$ endmap, $\mathrm{S}=>\mathrm{N} 7, \quad \mathrm{E}=>\mathrm{N} 3, \quad \mathrm{~W}=>\mathrm{N} 1, \quad$ NOut $\Rightarrow>\mathrm{N} 2)$;

Neuron3: Neuron port map $\quad($ Data $=>X Y$, VectorIn $\Rightarrow$ Win3, R $\Rightarrow>$ Clock, VectorOut $=>$ Wout3, $\mathrm{N}=>$ endmap, $\mathrm{S}=>\mathrm{N} 8, \quad \mathrm{E}=>\mathrm{N} 4, \quad \mathrm{~W}=>\mathrm{N} 2, \quad$ NOut $=>\mathrm{N} 3$ );

Neuron4: Neuron port map $\quad($ Data $=>$ XY, VectorIn $\Rightarrow$ Win4, R $=>$ Clock, VectorOut $=>$ Wout4, $\mathrm{N} \Rightarrow$ endmap, $\mathrm{S}=>\mathrm{N} 9, \quad \mathrm{E}=>\mathrm{N} 5, \quad \mathrm{~W}=>\mathrm{N} 3, \quad$ NOut $\Rightarrow>\mathrm{N} 4)$;

Neuron5: Neuron port map $\quad$ (Data $=>$ XY, VectorIn $\Rightarrow$ Win5, R $\Rightarrow>$ Clock, VectorOut $=>$ Wout5, $\mathrm{N}=>$ endmap, $\mathrm{S}=>\mathrm{N} 10, \mathrm{E}=>$ endmap, $\mathrm{W} \Rightarrow \mathrm{N} 4, \quad$ NOut $\Rightarrow$ N5);

Neuron6: Neuron port map $\quad$ (Data $=>$ XY, VectorIn $\Rightarrow$ Win6, R $\Rightarrow>$ Clock, VectorOut $=>$ Wout6, $\mathrm{N}=>\mathrm{N} 1, \quad \mathrm{~S}=>\mathrm{N} 11, \quad \mathrm{E}=>\mathrm{N} 7, \quad \mathrm{~W}=>$ endmap, NOut $\Rightarrow>\mathrm{N} 6$ );

Neuron7: Neuron port map $\quad($ Data $=>$ XY, VectorIn $=>$ Win7, R $=>$ Clock, VectorOut $=>$ Wout7, $\mathrm{N}=>\mathrm{N} 2, \quad \mathrm{~S}=>\mathrm{N} 12, \quad \mathrm{E}=>\mathrm{N} 8, \quad \mathrm{~W}=>\mathrm{N} 6, \quad$ NOut $=>\mathrm{N} 7)$;

Neuron8: Neuron port map $\quad($ Data $=>X Y$, VectorIn $\Rightarrow>$ Win8, R $=>$ Clock, VectorOut $=>$ Wout8, $\mathrm{N}=>\mathrm{N} 3, \quad \mathrm{~S}=>\mathrm{N} 13, \quad \mathrm{E}=>\mathrm{N} 9, \quad \mathrm{~W}=>\mathrm{N} 7, \quad$ NOut $=>\mathrm{N} 8$ );

Neuron9: Neuron port map $\quad($ Data $\Rightarrow X Y$, VectorIn $\Rightarrow$ Win9, R $\Rightarrow$ Clock, VectorOut $\Rightarrow$ Wout9,N $\Rightarrow$ N4, S $\Rightarrow$ N14, E $\Rightarrow$ N10, W $\Rightarrow$ N8, NOut $=>$ N9);

Neuron10: Neuron port map $\quad($ Data $\Rightarrow X Y$, VectorIn $\Rightarrow$ Win10, R $\Rightarrow$ Clock, VectorOut $\Rightarrow$ Wout10, $=>\mathrm{N} 5, \quad \mathrm{~S}=>\mathrm{N} 15, \quad \mathrm{E}=>$ endmap, $\mathrm{W}=>\mathrm{N} 9, \quad$ NOut $=>\mathrm{N} 10)$;

Neuron11: Neuron port map $\quad($ Data $\Rightarrow X Y$, VectorIn $\Rightarrow$ Win11, R $\Rightarrow$ Clock, VectorOut $\Rightarrow$ Wout11, N $\Rightarrow$ N6, $\mathrm{S}=>\mathrm{N} 16, \quad \mathrm{E}=>\mathrm{N} 12, \quad \mathrm{~W}=>$ endmap, NOut $=>\mathrm{N} 11)$;

Neuron12: Neuron port map $\quad($ Data $\Rightarrow$ XY, VectorIn $\Rightarrow$ Win12, R $\Rightarrow$ Clock, VectorOut $\Rightarrow$ Wout12, N $\Rightarrow$ N7, $\mathrm{S}=>\mathrm{N} 17, \quad \mathrm{E}=>\mathrm{N} 13, \quad \mathrm{~W}=>\mathrm{N} 11, \quad$ NOut $=>\mathrm{N} 12)$;

Neuron13: Neuron port map $\quad($ Data $\Rightarrow X Y$, VectorIn $\Rightarrow$ Win13, R $\Rightarrow$ Clock, VectorOut $\Rightarrow$ Wout13, N $\Rightarrow$ N8, $\mathrm{S}=>\mathrm{N} 18, \quad \mathrm{E}=>\mathrm{N} 14, \quad \mathrm{~W}=>\mathrm{N} 12, \quad$ NOut $=>\mathrm{N} 13)$;

Neuron14: Neuron port map $\quad($ Data $\Rightarrow$ XY, VectorIn $\Rightarrow$ Win14, R $\Rightarrow$ Clock, VectorOut $\Rightarrow$ Wout14, N $\Rightarrow$ N9, $\mathrm{S}=>\mathrm{n} 19, \quad \mathrm{E}=>\mathrm{N} 15, \quad \mathrm{~W}=>\mathrm{N} 13, \quad$ NOut $=>\mathrm{N} 14)$;

Neuron15: Neuron port map $\quad($ Data $\Rightarrow X Y$, VectorIn $\Rightarrow$ Win15, R $\Rightarrow$ Clock, VectorOut $\Rightarrow$ Wout15, N $\Rightarrow$ N10, $\mathrm{S}=>\mathrm{N} 20, \quad \mathrm{E}=>$ endmap, $\mathrm{W}=>\mathrm{N} 14, \quad$ NOut $=>\mathrm{N} 15)$;

Neuron16: Neuron port map $\quad($ Data $\Rightarrow$ XY, VectorIn $\Rightarrow$ Win16, R $\Rightarrow$ Clock, VectorOut $\Rightarrow$ Wout16, N $\Rightarrow$ N11, $\mathrm{S}=>\mathrm{N} 21, \quad \mathrm{E}=>\mathrm{N} 17, \quad \mathrm{~W}=>$ endmap, NOut $=>\mathrm{N} 16)$;

Neuron17: Neuron port map $\quad($ Data $\Rightarrow>X Y$, VectorIn $=>$ Win7, R $\Rightarrow>$ Clock, VectorOut $=>$ Wout17, $\mathrm{N}=>\mathrm{N} 12, \quad \mathrm{~S}=>\mathrm{N} 22, \quad \mathrm{E}=>\mathrm{N} 18, \quad \mathrm{~W} \Rightarrow \mathrm{N} 16, \quad$ NOut $\Rightarrow$ N17);

Neuron18: Neuron port map $\quad($ Data $=>$ XY, VectorIn $=>$ Win8, R $=>$ Clock, VectorOut $=>$ Wout18, $\mathrm{N}=>\mathrm{N} 13, \quad \mathrm{~S}=>\mathrm{N} 23, \quad \mathrm{E}=>\mathrm{N} 19, \quad \mathrm{~W}=>\mathrm{N} 17, \quad$ NOut $\Rightarrow$ N18);

Neuron19: Neuron port map $\quad($ Data $\Rightarrow>X Y$, VectorIn $=>$ Win9, R $=>$ Clock, VectorOut $=>$ Wout19, $\mathrm{N}=>\mathrm{N} 14, \quad \mathrm{~S}=>\mathrm{N} 24, \quad \mathrm{E}=>\mathrm{N} 20, \quad \mathrm{~W}=>\mathrm{N} 18, \quad$ NOut $\Rightarrow$ N19);

Neuron20: Neuron port map $\quad$ (Data $\Rightarrow$ XY, VectorIn $\Rightarrow$ Win10, R $\Rightarrow$ Clock, VectorOut $\Rightarrow$ Wout20, N $\Rightarrow$ N15, $\mathrm{S}=>\mathrm{N} 25, \quad \mathrm{E}=>$ endmap, $\mathrm{W} \Rightarrow \mathrm{N} 19, \quad$ NOut $=>\mathrm{N} 20$ );

Neuron21: Neuron port map $\quad$ (Data $\Rightarrow X Y$, VectorIn $\Rightarrow$ Win11, R $\Rightarrow$ Clock, VectorOut $\Rightarrow$ Wout21, $\mathrm{N} \Rightarrow \mathrm{N} 16, \mathrm{~S}=>$ endmap, $\mathrm{E} \Rightarrow>\mathrm{N} 22, \quad \mathrm{~W}=>$ endmap, NOut $=>\mathrm{N} 21$ ); 
Neuron22: Neuron port map $\quad($ Data $\Rightarrow X Y$, VectorIn $\Rightarrow$ Win12, R $\Rightarrow$ Clock, VectorOut $\Rightarrow$ Wout22, $\mathrm{N}=>\mathrm{N} 17, \mathrm{~S}=>$ endmap, $\mathrm{E}=>\mathrm{N} 23, \mathrm{~W}=>\mathrm{N} 21, \quad$ NOut $=>\mathrm{N} 22)$;

Neuron23: Neuron port map $\quad$ (Data $\Rightarrow$ XY, VectorIn $\Rightarrow$ Win13, R $\Rightarrow$ Clock, VectorOut $\Rightarrow$ Wout23, N => N18, S $\Rightarrow$ endmap, E => N24, W => N22, NOut => N23);

Neuron24: Neuron port map $\quad($ Data $\Rightarrow$ XY, VectorIn $\Rightarrow$ Win14, R $\Rightarrow$ Clock, VectorOut $\Rightarrow$ Wout24, N => N19, $\mathrm{S}=>$ endmap, $\mathrm{E}=>\mathrm{N} 25, \quad \mathrm{~W}=>\mathrm{N} 23, \quad$ NOut $=>\mathrm{N} 24)$;

Neuron25: Neuron port map $\quad($ Data $\Rightarrow X Y$, VectorIn $\Rightarrow$ Win15, R $\Rightarrow$ Clock, VectorOut $\Rightarrow$ Wout25, $\mathrm{N} \Rightarrow \mathrm{N} 20, \mathrm{~S}=>$ endmap, $\mathrm{E}=>$ endmap, $\mathrm{W}=>\mathrm{N} 24, \quad$ NOut $=>\mathrm{N} 25$ );

-- o processo de atualização de pesos ocorre na borda de subida do clock

process (Clock) begin

if $($ Clock'event and Clock $=$ '1') then

Win $<=$ Wout 1 ; Win $<<=$ Wout2; Win $<<=$ Wout 3 ; Win $4<=$ Wout 4 ; Win $5<=$ Wout 5 ;

Win6 <= Wout6; Win7 <= Wout7; Win8 <= Wout8; Win9 <= Wout9; Win10 <= $\quad$ Wout10;

Win11 <= Wout11; Win12 <= Wout12; Win13 <= Wout13; Win14<= $\quad$ Wout14; $\quad$ Win15 <= Wout15; Win16 <= Wout16; Win17<=Wout17; Win18 <= Wout18; Win19 <= Wout19; Win20 $<=$ Wout20; Win21 <= Wout21; Win22 <= Wout22; Win23 <= Wout23; Win24 <= Wout24; Win25 <= Wout 25;

end if;

end process;

-- Composição das saídas

Vp1 <= Win1; Vp2 <= Win2; Vp3 <= Win3; Vp4 <= Win4; Vp5 <= Win5;

Vp6 <= Win6; Vp7 <= Win7; Vp8 <=Win8; Vp9<=Win9; Vp10<=Win10;

Vp11 <= Win11; Vp12<=Win12; Vp13<=Win13; Vp14<=Win14; Vp15 <= Win15;

Vp16 <= Win16; Vp17 <= Win17; Vp18 <= Win18; Vp19<= Win19; Vp20<= Win20;

Vp21 <= Win21; Vp22<= Win22; Vp23<=Win23;

end Behavioral;

Vp24<= Win24; Vp25 <= Win25;

-- Módulo padrão do neurônio que realiza: cálculo da distância de Manhattan,

-- determinação do neurônio vencedor e região de vizinhança.

library IEEE;

use IEEE.STD_LOGIC_1164.ALL;

use IEEE.STD_LOGIC_UNSIGNED.all;

entity Neuron is

Generic (bitsI : integer :=8;

bitsD : integer : $=5$

bitsN : integer $:=4)$;

-- dimensão do vetor de entrada

-- dimensão da maior distância de manhattan

-- dimensão do maior valor de vizinhança

Port (Data : in std_logic_vector(bitsI-1 downto 0); $\quad$-- Entrada de dados 2x4bits com sinal

$\mathrm{R}$ : in std_logic;

-- Reset

VectorIn : in std_logic_vector (bitsI-1 downto 0); -- Peso do neurônio

VectorOut : out std_logic_vector (bitsI-1 downto 0);-- Peso ajustado do neurônio

N, S, E, W : in std_logic_vector (bitsD+bitsN-1 downto 0); -- Ent. de distância e vizinhança end Neuron;

NOut : out std_logic_vector (bitsD+bitsN-1 downto 0));-- Saídas de distância e vizinhança

architecture modulo of Neuron is

component Mdist -- Bloco para cálculo da distância de Manhattan

port (X, Y : in std_logic_vector(bitsI-1 downto 0);

Dif1, Dif2 : out std_logic_vector (bitsD-1 downto 0);

$\mathrm{Z}$ : out std_logic_vector(bitsD-1 downto 0$)$ );

end component;

-- Bloco para cálculo do neurônio vencedor

component MenorDe5CL is

Port (N, S, E, W, Inner : in std_logic_vector (bitsD-1 downto 0);

$\mathrm{R}$ : in std_logic;

Equal : out std_logic;

Minor : out std_logic_vector (bitsD-1 downto 0)); 
end component;

-- Bloco para cálculo da região de vizinhança

component MenorDe5 is

Port (N, S, E, W, Inner : in std_logic_vector (bitsN-1 downto 0);

$\mathrm{R}$ : in std_logic;

Minor : out std_logic_vector (bitsN-1 downto 0));

end component;

-- Mux de apoio ao cálculo da região de vizinhança, para fixação do vencedor

component mux $2 \times B$ ITS is

Port (in_A, in_B : in std_logic_vector (bitsN-1 downto 0);

sel : in std_logic;

mux : out std_logic_vector (bitsN-1 downto 0));

end component;

-- Bloco para ajuste dos pesos

component Adjust is

Port ( $\mathrm{R}:$ in std_logic;

Neighbour : in std_logic_vector (bitsN-1 downto 0);

Dif1, Dif2 : in std_logic_vector (bitsD-1 downto 0);

InVector : in std_logic_vector (bitsI-1 downto 0);

OutVector : out std_logic_vector (bitsI-1 downto 0));

end component;

-- Sinais de interligação dos blocos

signal Distance, Diff1, Diff2, Min_dist : std_logic_vector (bitsD-1 downto 0); signal InNeigh, OutNeigh, IncNeigh : std_logic_vector (bitsN-1 downto 0); signal Winner : std_logic;

begin

M_dist:

Mdist port $\operatorname{map}(\mathrm{X}=>$ Data, Y => VectorIn, Dif1 => Diff1, Dif2 => Diff2, Z => Distance);

MenorD:

MenorDe5CL port map ( $\mathrm{N}=>\mathrm{N}(($ bitsD+bitsN-1) downto bitsN),

$\mathrm{S}=>\mathrm{S}($ (bitsD+bitsN-1) downto bitsN),

$\mathrm{E} \Rightarrow \mathrm{E}(($ bitsD+bitsN-1) downto bitsN),

$\mathrm{W}=>\mathrm{W}(($ bitsD+bitsN-1) downto bitsN),

Inner $=>$ Distance, R => R, Equal => Winner, Minor => Min_dist);

MuxViz:

mux2xBITS port map (in_A => OutNeigh, in_B => "0001", sel => Winner, mux => InNeigh);

Vizinh: MenorDe5 port map $\quad(\mathrm{N}=>\mathrm{N}($ bitsN-1 downto 0$)$,

$\mathrm{S}=>\mathrm{S}$ (bitsN-1 downto 0 ),

$\mathrm{E} \Rightarrow \mathrm{E}$ (bitsN-1 downto 0$)$,

$\mathrm{W}=>\mathrm{W}$ (bitsN-1 downto 0 ),

Inner $=>$ InNeigh, R => R, Minor $=>$ OutNeigh);

IncNeigh <= OutNeigh +1 after 1 ps; -- incremento do índice de vizinhança dos neurônios próximos NOut(bitsD+bitsN-1 downto bitsN) <= Min_dist; NOut(bitsN-1 downto 0) <= IncNeigh;

NewW: Adjust port map $(R=>R$, Neighbour $=>$ InNeigh, Dif1 => Diff1, Dif2 => Diff2,

InVector $=>$ VectorIn, OutVector $=>$ VectorOut);

end modulo;

-- Circuito fixo para cálculo da distância de Manhattan entre dois vetores de 8 bits

-- Cada vetor de entrada possui duas coordenadas de 4 bits cada ( 1 sinal +3 bits)

library IEEE;

use IEEE.STD_LOGIC_1164.ALL;

use IEEE.STD_LOGIC_SIGNED.all;

entity Mdist is

Port (X, Y : in std_logic_vector (7 downto 0); -- Vetores de entrada 
Dif1, Dif2 : out std_logic_vector (4 downto 0); -- Valores de subtração de cada dim. end Mdist;

Z : out std_logic_vector (4 downto 0)); -- Valor de saída de distância de manhattan

architecture componente of Mdist is

signal SubOut1, SubOut2 : std_logic_vector (4 downto 0);

begin

process $(\mathrm{X}, \mathrm{Y})$ begin

SubOut1 <=(X(7)\&X (7 downto 4)) - (Y(7)\&Y (7 downto 4));

SubOut $2<=(\mathrm{X}(3) \& \mathrm{X}(3$ downto 0$))-(\mathrm{Y}(3) \& \mathrm{Y}(3$ downto 0$))$;

end process;

Dif1 <= SubOut1; Dif2 <= SubOut2;

$\mathrm{Z}<=\operatorname{abs}($ SubOut 1$)+\operatorname{abs}($ SubOut2);

end componente;

-- Módulo que gera na saída o menor número binário positivo dentre as cinco entradas.

-- Quatro entradas são conexões externas dos neurônios vizinhos e mais uma com

-- o valor interno do neurônio.

-- Projeto genérico com padrão de 4 bits.

library IEEE;

use IEEE.STD_LOGIC_1164.ALL;

entity MenorDe5CL is

Generic (bitsD : integer :=5);

Port ( N, S, E, W, Inner : in std_logic_vector (bitsD-1 downto 0);

$\mathrm{R}:$ in std_logic;

Equal : out std_logic;

end MenorDe5CL;

Minor : out std_logic_vector (bitsD-1 downto 0));

architecture hierarquica of MenorDe5CL is

signal Minor_tmp : std_logic_vector (bitsD-1 downto 0);

signal Equal_tmp : std_logic;

begin

process $(\mathrm{N}, \mathrm{S}, \mathrm{E}, \mathrm{W}$, Inner, $\mathrm{R})$ begin

if $\left(\mathrm{R}={ }^{\prime} 11^{\prime}\right)$ then

Minor_tmp <= "11111";

elsif $((\mathrm{N}<=\mathrm{S})$ and $(\mathrm{N}<=\mathrm{E})$ and $(\mathrm{N}<=\mathrm{W})$ and $(\mathrm{N}<=$ inner $))$ then Minor_tmp $<=\mathrm{N}$; Equal_tmp $<=$ ' 0 ';

elsif $((\mathrm{S}<=\mathrm{N})$ and $(\mathrm{S}<=\mathrm{E})$ and $(\mathrm{S}<=\mathrm{W})$ and $(\mathrm{S}<=$ inner $))$ then Minor_tmp $<=\mathrm{S}$; Equal_tmp $<={ }^{\prime} 0^{\prime}$;

elsif $((\mathrm{E}<=\mathrm{N})$ and $(\mathrm{E}<=\mathrm{S})$ and $(\mathrm{E}<=\mathrm{W})$ and $(\mathrm{E}<=$ inner $))$ then Minor_tmp $<=\mathrm{E}$; Equal_tmp $<=$ ' 0 ';

elsif $((\mathrm{W}<=\mathrm{N})$ and $(\mathrm{W}<=\mathrm{S})$ and $(\mathrm{W}<=\mathrm{E})$ and $(\mathrm{W}<=$ inner $))$ then Minor_tmp $<=\mathrm{W}$; Equal_tmp $<=$ ' 0 ';

else Minor_tmp $<=$ inner; Equal_tmp $<=$ '1';

end if;

end process;

Minor <= Minor_tmp; Equal <= Equal_tmp;

end hierarquica;

-- MUX de 2 entradas e quantidade de bits genérico

library IEEE;

use IEEE.STD_LOGIC_1164.ALL;

entity mux $2 \times B I T S$ is

Generic (bitsN : integer :=4);

Port( in_A, in_B : in std_logic_vector (bitsN-1 downto 0);

sel : in std_logic;

mux : out std_logic_vector (bitsN-1 downto 0));

end mux $2 \times B I T S$;

architecture componente of mux $2 \times B$ ITS is

begin

process (sel, in_A, in_B) 


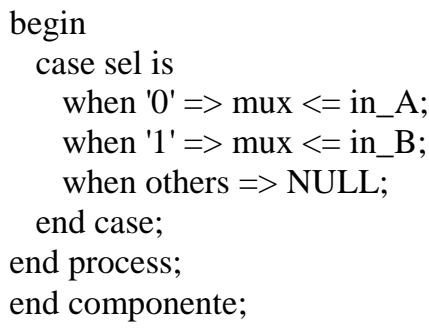

-- Módulo que gera na saída o menor número binário positivo dentre as cinco entradas.

-- Quatro entradas são conexões externas dos neurônios vizinhos

-- e mais uma com o valor interno do neurônio.

-- Projeto genérico com padrão de 4 bits.

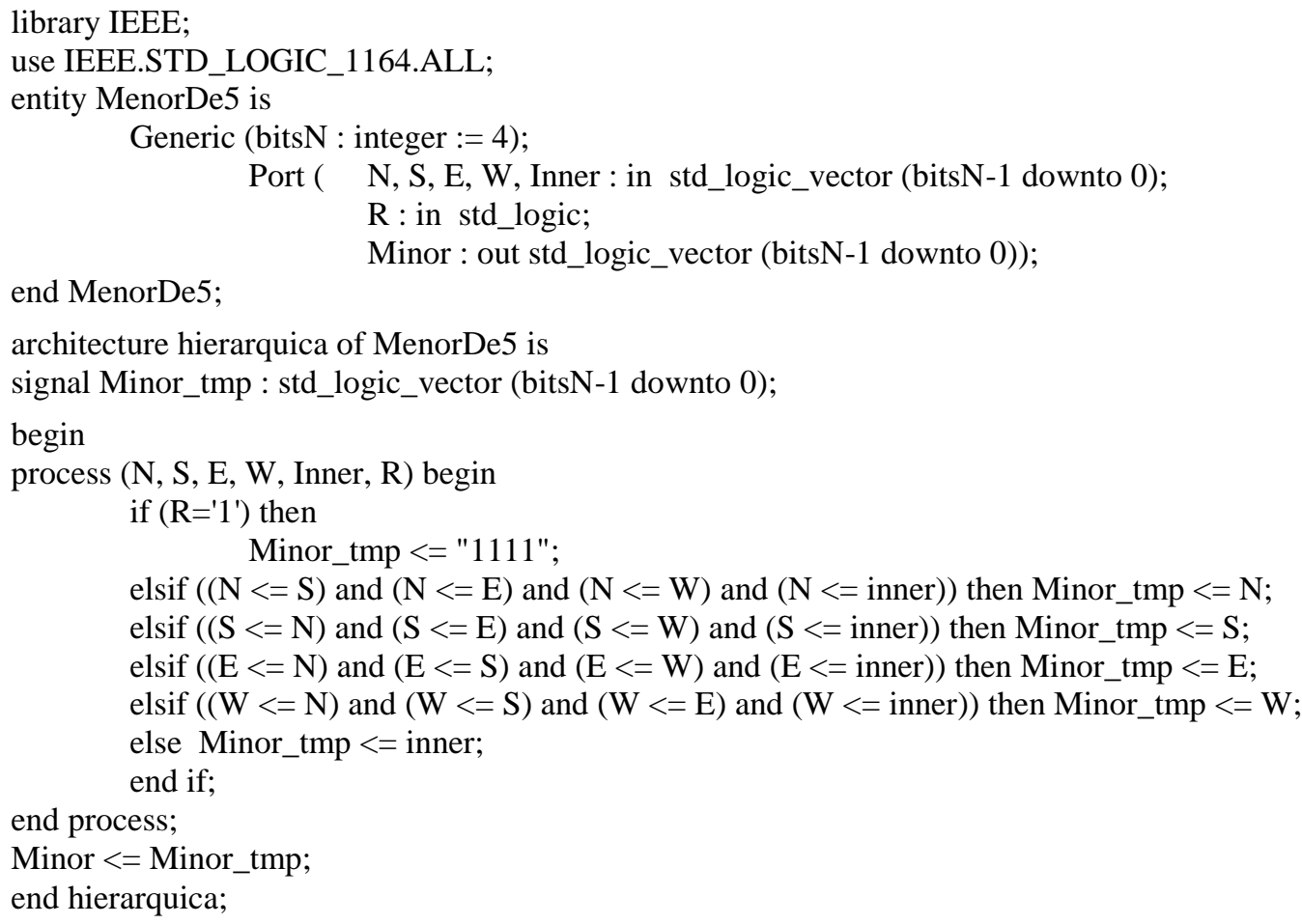

-- Bloco para ajuste simples de peso, todos os neurônios têm seus pesos alterados

-- da seguinte forma: incremento ou decremento de bits em cada coordenada do peso

-- de acordo com o valor do erro entre os vetores de entrada e do neurônio calculado

-- pelo bloco de distância de manhattan. O neurônio vencedor ajusta a quantidade

-- máxima de bits e há decaimento de 1 bit a cada degrau de distância de vizinhança.

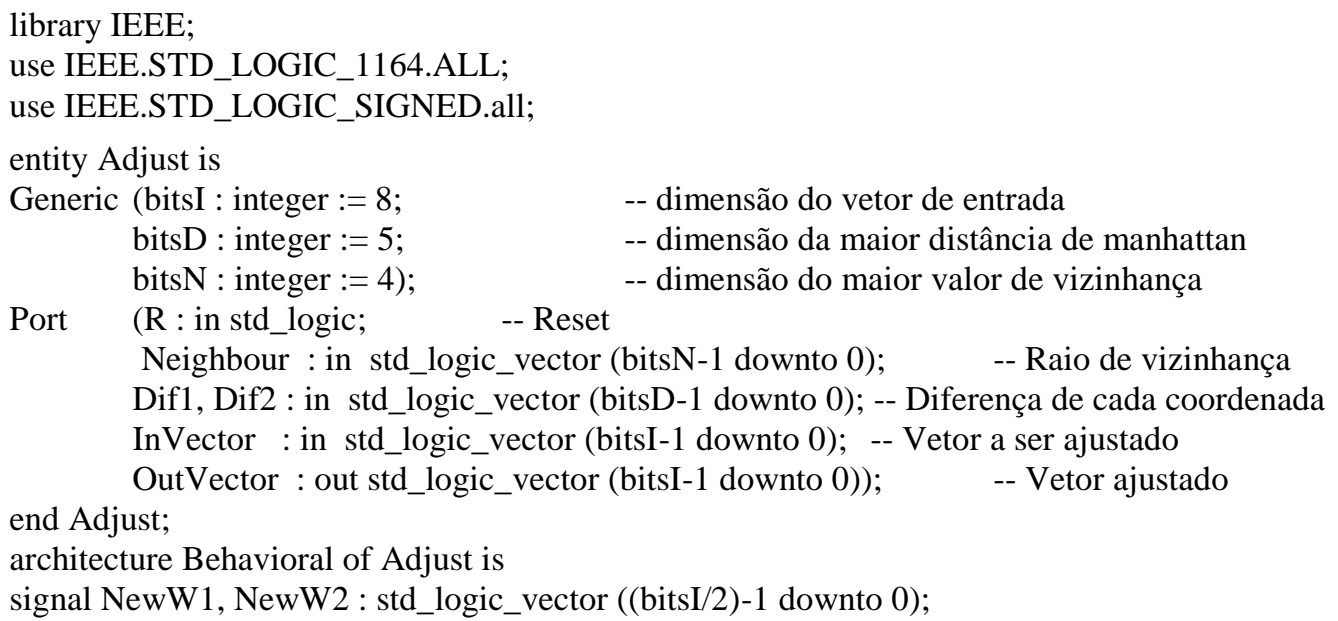


signal Neighbourhood : std_logic_vector (bitsN-1 downto 0);

begin

Neighbourhood <= "0111" - Neighbour;

process(R, Neighbourhood, Dif1, Dif2, InVector) begin if $\left(\mathrm{R}={ }^{\prime} 0^{\prime}\right)$ then

if $($ Neighbour $=$ "0000") then

NewW1 <= InVector(bitsI-1 downto bitsI/2); NewW2 <= InVector((bitsI/2)-1 downto 0); else

case Dif1(bitsD-1) is

when '0' $\Rightarrow \quad$ if (Dif1 = "0000") then NewW1 <= InVector(bitsI-1 downto bitsI/2);

else NewW1 <= InVector(bitsI-1 downto bitsI/2) + Neighbourhood; end if;

when '1' $\Rightarrow \quad$ NewW1 <= InVector(bitsI-1 downto bitsI/2) - Neighbourhood;

when others $=>$ NULL;

end case;

case Dif2(bitsD-1) is

when '0' $\Rightarrow \quad$ if (Dif2 = "0000") then NewW2 <= InVector((bitsI/2)-1 downto 0);

else NewW2 <= InVector((bitsI/2)-1 downto 0) + Neighbourhood; end if;

when '1' => NewW2 <= InVector((bitsI/2)-1 downto 0) - Neighbourhood;

when others $=>$ NULL;

end case;

end if;

end if;

end process;

OutVector(bitsI-1 downto bitsI/2) <= NewW1 after 1 ps;

OutVector((bitsI/2)-1 downto 0) <= NewW2 after 1 ps;

end Behavioral; 


\section{APÊNDICE B - MODELO CENTRALIZADO EM VHDL}

Modelo centralizado de execução do SOM em FPGA.

-- SOM: mapa 5x5, dados de dimensão 2 (4 bits cada).

-- CCt: Controle centralizado de cálculo de neurônio vencedor e vizinhança.

-- Cálculo da distância de Manhattan e ajuste de pesos feito em rede paralela

-- Todos os neurônios da rede são ajustados em decaimento linear de vizinhança (1 bit / raio)

library IEEE;

use IEEE.STD_LOGIC_1164.ALL;

package SOM_pkg is

type vetor_pesos is array( 1 downto 0$)$ of std_logic_vector(15 downto 0$)$;

type matriz_pesos is array( 15 downto 0$)$ of vetor_pesos;

end package;

type vetor_dif is array(1 downto 0$)$ of std_logic_vector(16 downto 0$)$;

entity Rede9CCt is

Generic (bitsI : integer $:=8$;

bitsD : integer $:=5$

-- dimensão do vetor de entrada

bitsX : integer $:=5$;

-- dimensão da maior distância de manhattan

bitsN : integer :=4;

QuantN: integer := 25;

-- dimensão do indexador de neurônios

epocas_ini: integer $:=100$;

-- dimensão do maior valor de vizinhança

-- Quantidade de neurônios

epocas_tot: integer :=970); $\quad$-- Quantidade total de iterações de treinamento

Port (XY : in std_logic_vector (7 downto 0); -- Entrada de dados $\mathrm{X}=\mathrm{S}+3 \mathrm{~b}$ e $\mathrm{Y}=\mathrm{S}+3 \mathrm{~b}$

Clock : in std_logic; $\quad$-- Usado como reset do sistema a cada iteração

Vp0, Vp1, Vp2, Vp3, Vp4, Vp5, Vp6, Vp7, Vp8, Vp9, Vp10,

Vp11, Vp12, Vp13, Vp14, Vp15, Vp16, Vp17, Vp18, Vp19, Vp20,

end Rede9CCt;

Vp21, Vp22, Vp23, Vp24: out std_logic_vector (7 downto 0));

architecture Behavioral of Rede9CCt is

-- Saída: vetores de pesos de cada neurônio

-- Bloco para cálculo da distância de Manhattan

component Mdist

port(X, Y : in std_logic_vector(bitsI-1 downto 0);

Dif1, Dif2 : out std_logic_vector (bitsD-1 downto 0);

Z : out std_logic_vector(bitsD-1 downto 0));

end component;

-- Bloco para cálculo do neurônio de menor distância

component MenorDe2

Port (In1, In 2 : in std_logic_vector (bitsD-1 downto 0);

Index 1, Index 2 : in std_logic_vector (bitsX-1 downto 0);

Minor : out std_logic_vector (bitsD-1 downto 0);

IndexMinor: out std_logic_vector (bitsX-1 downto 0));

end component;

-- Bloco para ajuste de pesos

component Adjust is

Port(R : in std_logic;

Neighbour : in std_logic_vector (bitsN-1 downto 0);

Dif1, Dif2 : in std_logic_vector (bitsD-1 downto 0);

InVector : in std_logic_vector (bitsI-1 downto 0);

OutVector : out std_logic_vector (bitsI-1 downto 0));

end component;

signal cont_epocas : integer $:=0 ; \quad$-- Contador de iterações de aprendizado signal Minor : std_logic_vector (bitsX-1 downto 0); -- Índice do neurônio vencedor

-- Sinais tipo "one hot" para sinalização do neurônio vencedor 
type Win_bus is array (QuantN-1 downto 0) of std_logic;

signal Win : Win_bus;

-- Sinais internos do bloco de torneio da menor distância

type distance_array is array (QuantN-1 downto 0) of std_logic_vector (bitsD-1 downto 0);

signal Distance, Dif1, Dif2 : distance_array;

type connectw_array is array (30 downto 0) of std_logic_vector (bitsD-1 downto 0);

signal connectW : connectw_array;

-- Matriz de pesos iniciais e sinais de valores de pesos ajustáveis

type weight_array is array (0 to QuantN-1) of std_logic_vector (bitsI-1 downto 0);

signal Wout : weight_array;

signal Weight : weight_array :=("00000100", -- coordenadas: $0,+4$

"00010100", -- coordenadas: $+1,+4$

"00100100", -- coordenadas: $+2,+4$

"00110100", -- coordenadas: $+3,+4$

"01000100", -- coordenadas: $+4,+4$

"00000011", -- coordenadas: $0,+3$

"00010011", -- coordenadas: $+1,+3$

"00100011", -- coordenadas: $+2,+3$

"00110011", -- coordenadas: $+3,+3$

"01000011", -- coordenadas: $+4,+3$

"00000010", -- coordenadas: $0,+2$

"00010010", -- coordenadas: $+1,+2$

"00100010", -- coordenadas: $+2,+2$

"00110010", -- coordenadas: $+3,+2$

"01000010", -- coordenadas: $+4,+2$

"00000001", -- coordenadas: $0,+1$

"00010001", -- coordenadas: $+1,+1$

"00100001", -- coordenadas: $+2,+1$

"00110001", -- coordenadas: $+3,+1$

"01000001", -- coordenadas: $+4,+1$

"00000000", -- coordenadas: 0, 0

"00010000", -- coordenadas: +1, 0

"00100000", -- coordenadas: 2, 0

"00110000", -- coordenadas: +3, 0

"01000000"); -- coordenadas: +4, 0

-- Sinais de região de vizinhança

type Neigh_array is array (0 to QuantN-1) of std_logic_vector (bitsN-1 downto 0);

signal Neighbour : Neigh_array;

-- Sinais internos do bloco de torneio da menor distância (índices do neurônio)

type index_array is array (0 to 30) of std_logic_vector (bitsX-1 downto 0);

signal Index : index_array := ("00000", "00001", "00010", "00011", "00100", "00101", "00110", "00111", "01000", "01001", "01010", "01011", "01100", "01101", "01110", "01111", "10000", "10001", "10010", "10011", "10100", "10101", "10110", "10111", "11000", "11001", "11010", "11011", "11100", "11101", "11110");

-- Sinais internos do bloco de torneio da menor distância (índices do neurônio)

type connectI_array is array (0 to 30) of std_logic_vector (bitsX-1 downto 0);

signal connectI : connectI_array;

begin

-- Blocos para cálculo paralelo da distância de Manhattan

Gera_M_dist: for i in (QuantN-1) downto 0 generate M_distX:

Mdist port map (X $\Rightarrow$ XY, Y $\Rightarrow$ Weight(i), Dif1 => Dif1(i), Dif2 => Dif2(i), Z => Distance(i)); end generate Gera_M_dist;

-- Torneio de busca da menor distância entre 16: oitavas, quartas, semis e final

T16_0: MenorDe2 port map (In1 $\Rightarrow>$ Distance(0), In2 $\Rightarrow$ Distance(1), Index1 $\Rightarrow$ Index(0), Index2

$\Rightarrow$ Index $(1)$, Minor $=>$ connectW(0), IndexMinor $=>$ connectI $(0))$;

T16_1: MenorDe2 port map (In1 $\Rightarrow$ Distance(2), In2 $\Rightarrow$ Distance(3), Index1 $\Rightarrow$ Index(2), Index2

$\Rightarrow$ Index(3), Minor $=>$ connectW(1), IndexMinor $=>$ connectI(1)); 
T16_2: MenorDe2 port map (In1 => Distance(4), In2 => Distance(5), Index1 => Index(4), $\Rightarrow$ Index (5), Minor $=>$ connectW(2), IndexMinor $=>$ connectI(2));

T16_3: MenorDe2 port map (In1 => Distance(6), In2 => Distance(7), Index1 => Index(6), $\Rightarrow$ Index(7), Minor $=>$ connectW(3), IndexMinor $=>$ connectI(3));

T16_4: MenorDe2 port map (In1 => Distance(8), In2 => Distance(9), Index1 => Index(8),

Index 2

$\Rightarrow$ Index(9), Minor $\Rightarrow>$ connectW(4), IndexMinor $=>$ connectI(4));

T16_5: MenorDe2 port map (In1 => Distance(10), In2 $\Rightarrow$ Distance(11), Index1 => Index(10), $\Rightarrow$ Index (11), Minor $=>$ connectW(5), IndexMinor $=>$ connectI(5));

T16_6: MenorDe2 port map (In1 => Distance(12), In2 $\Rightarrow$ Distance(13), Index1 => Index(12), $\Rightarrow$ Index (13), Minor $=>$ connectW(6), IndexMinor $=>$ connectI(6));

T16_7: MenorDe2 port map (In1 => Distance(14), In2 $\Rightarrow$ Distance(15), Index1 => Index(14), $\Rightarrow$ Index (15), Minor $=>$ connectW(7), IndexMinor $=>$ connectI(7));

T16_8: MenorDe2 port map (In1 => Distance(16), In2 $\Rightarrow$ Distance(17), Index1 $\Rightarrow$ Index(16), Index2 $\Rightarrow$ Index (17), Minor $=>$ connectW(8), IndexMinor $=>$ connectI $(8)$ );

T16_9: MenorDe2 port map (In1 $\Rightarrow$ Distance(18), In2 $\Rightarrow$ Distance(19), Index1 $\Rightarrow$ Index(18), Index2 $\Rightarrow$ Index(19), Minor $=>$ connectW(9), IndexMinor $=>$ connectI(9));

T16_10: MenorDe2 port map (In1 $\Rightarrow$ Distance(20), In2 $\Rightarrow$ Distance(21), Index1 $\Rightarrow$ Index(20), Index2 $\Rightarrow$ Index(21), Minor $=>$ connectW(10), IndexMinor $=>$ connectI(10));

T16_11: MenorDe2 port map (In1 => Distance(22), In2 => Distance(23), Index1 => Index(22), Index2 $\Rightarrow$ Index (23), Minor $=>$ connectW(11), IndexMinor $=>$ connectI(11));

T16_12: MenorDe2 port map (In1 => Distance(24), In2 => "11111", Index1 => Index(24), Index2 $\Rightarrow$ "11111", Minor $=>$ connectW(12), IndexMinor $=>$ connectI(12));

T16_13: MenorDe2 port map (In1 => "11111", In2 => "11111", Index1 => "11111", Index2 $\Rightarrow>$ "11111", Minor $=>$ connectW(13), IndexMinor $=>$ connectI(13));

T16_14: MenorDe2 port map (In1 => "11111", In2 => "11111", Index1 => "11111", Index $2 \Rightarrow>11111 "$, Minor $=>$ connectW(14), IndexMinor $=>$ connectI(14));

T16_15: MenorDe2 port map (In1 => "11111", In2 => "11111", Index1 => "11111", Index $2 \Rightarrow>$ "11111", Minor $=>$ connectW(15), IndexMinor $=>$ connectI(15));

T8_0: MenorDe2 port map (In1 $\Rightarrow>$ connectW(0), In $\Rightarrow>$ connectW(1), Index $1 \Rightarrow>$ connectI(0), Index2 $\Rightarrow>$ connectI(1), Minor $=>$ connectW(16), IndexMinor $=>$ connectI(16));

T8_1: MenorDe2 port map (In1 $\Rightarrow>$ connectW(2), In $2 \Rightarrow$ connectW(3), Index $1 \Rightarrow$ connectI(2), Index2 $\Rightarrow$ connectI(3), Minor $=>$ connectW(17), IndexMinor $=>$ connectI(17));

T8_2: MenorDe2 port map (In1 $\Rightarrow>$ connectW(4), In $\Rightarrow$ connectW(5), Index $1 \Rightarrow$ connectI(4), Index2 $\Rightarrow>$ connectI(5), Minor $=>$ connectW(18), IndexMinor $\Rightarrow>\operatorname{connectI}(18))$;

T8_3: MenorDe2 port map (In1 $\Rightarrow>$ connectW(6), In 2 $>>$ connectW(7), Index $1 \Rightarrow>$ connectI(6), Index2 $\Rightarrow>\operatorname{connectI}(7)$, Minor $=>$ connectW(19), IndexMinor $=>$ connectI(19));

T8_4: MenorDe2 port map (In1 $\Rightarrow>$ connectW(8), In2 $\Rightarrow$ connectW(9), Index $1 \Rightarrow>$ connectI(8), Index2 $\Rightarrow>$ connectI(9), Minor $=>$ connectW(20), IndexMinor $=>$ connectI $(20))$;

T8_5: MenorDe2 port map (In1 => connectW(10), In2 $\Rightarrow$ connectW(11), Index1 $\Rightarrow$ connectI(10), Index $2 \Rightarrow$ connectI(11), Minor $=>$ connectW(21), IndexMinor $=>$ connectI(21));

T8_6: MenorDe2 port map (In1 $\Rightarrow$ connectW(12), In2 $\Rightarrow$ connectW(13), Index1 $\Rightarrow$ connectI(12), Index $2 \Rightarrow$ connectI(13), Minor $=>$ connectW(22), IndexMinor $=>\operatorname{connectI}(22))$;

T8_7: MenorDe2 port map (In1 => connectW(14), In2 $\Rightarrow>$ connectW(15), Index1 => connectI(14), Index $2 \Rightarrow>$ connectI(15), Minor $=>$ connectW(23), IndexMinor $=>\operatorname{connectI}(23))$;

T4_0: MenorDe2 port map (In1 $\Rightarrow$ connectW(16), In2 $\Rightarrow$ connectW(17), Index1 $\Rightarrow$ connectI(16), Index $2 \Rightarrow$ connectI(17), Minor $=>$ connectW(24), IndexMinor $\Rightarrow>$ connectI(24));

T4_1: MenorDe2 port map (In1 $\Rightarrow$ connectW(18), In2 $\Rightarrow$ connectW(19), Index1 $\Rightarrow$ connectI(18), Index $2 \Rightarrow$ connectI(19), Minor $=>$ connectW(25), IndexMinor $=>\operatorname{connectI}(25))$;

T4_2: MenorDe2 port map (In1 $\Rightarrow$ connectW(20), In2 $\Rightarrow$ connectW(21), Index1 $\Rightarrow \operatorname{connectI}(20)$, Index $2 \Rightarrow$ connectI(21), Minor $=>$ connectW(26), IndexMinor $\Rightarrow>$ connectI(26));

T4_3: MenorDe2 port map (In1 $\Rightarrow$ connectW(22), In2 $\Rightarrow$ connectW(23), Index1 $\Rightarrow$ connectI(22), Index $2 \Rightarrow$ connectI(23), Minor $=>$ connectW(27), IndexMinor $=>\operatorname{connectI}(27))$;

T2_0: MenorDe2 port map (In1 $\Rightarrow$ connectW(24), In2 $\Rightarrow$ connectW(25), Index1 $\Rightarrow$ connectI(24), Index $2 \Rightarrow$ connectI(25), Minor $=>$ connectW(28), IndexMinor $\Rightarrow>\operatorname{connectI}(28))$;

T2_1: MenorDe2 port map (In1 $\Rightarrow$ connectW(26), In2 $\Rightarrow$ connectW(27), Index1 $\Rightarrow$ connectI(26), Index $2 \Rightarrow>$ connectI(27), Minor $=>$ connectW(29), IndexMinor $=>$ connectI(29));

T1_0: MenorDe2 port map (In1 $\Rightarrow$ connectW(28), In2 $\Rightarrow$ connectW(29), Index1 $\Rightarrow$ connectI(28), Index $2 \Rightarrow>\operatorname{connectI}(29)$, Minor $=>$ connectW(30), IndexMinor $=>\operatorname{connectI}(30))$;

Minor $<=$ connectI $(30)$; 
-- Composição tipo "one hot" para sinalização do neurônio vencedor com lógica combinacional $\operatorname{Win}(0)<=(($ not Minor(4)) and (not Minor(3)) and (not Minor(2)) and (not Minor(1)) and (not Minor(0))); Win(1) <=((not Minor(4)) and (not Minor(3)) and (not Minor(2)) and (not Minor(1)) and Minor(0)); $\operatorname{Win}(2)<=(($ not Minor(4)) and (not Minor(3)) and (not Minor(2)) and Minor(1) and (not Minor(0))); Win(3) <= ((not Minor(4)) and (not Minor(3)) and (not Minor(2)) and Minor(1) and Minor(0)); Win(4) <= ((not Minor(4)) and (not Minor(3)) and Minor(2) and (not Minor(1)) and (not Minor(0))); Win(5) <= ((not Minor(4)) and (not Minor(3)) and Minor(2) and (not Minor(1)) and Minor(0)); Win(6) $<=(($ not Minor(4)) and (not Minor(3)) and Minor(2) and Minor(1) and (not Minor(0))); $\operatorname{Win}(7)<=(($ not Minor(4)) and (not Minor(3)) and Minor(2) and Minor(1) and Minor(0));

Win(8) <= ((not Minor(4)) and Minor(3) and (not Minor(2)) and (not Minor(1)) and (not Minor(0))); $\operatorname{Win}(9)<=(($ not Minor(4)) and Minor(3) and (not Minor(2)) and (not Minor(1)) and Minor(0)); Win(10) $<=(($ not Minor(4)) and Minor(3) and (not Minor(2)) and Minor(1) and (not Minor(0))); Win(11) <= ((not Minor(4)) and Minor(3) and (not Minor(2)) and Minor(1) and Minor(0));

Win(12) $<=(($ not Minor(4)) and Minor(3) and Minor(2) and (not Minor(1)) and (not Minor(0))); Win(13) <= ((not Minor(4)) and Minor(3) and Minor(2) and (not Minor(1)) and Minor(0)); Win(14) <= ((not Minor(4)) and Minor(3) and Minor(2) and Minor(1) and (not Minor(0))); $\operatorname{Win}(15)<=(($ not Minor(4)) and Minor(3) and Minor(2) and Minor(1) and Minor(0));

Win(16) < $=((\operatorname{Minor}(4))$ and (not Minor(3)) and (not Minor(2)) and (not Minor(1)) and (not Minor(0))); Win(17) $<=((\operatorname{Minor}(4))$ and (not Minor(3)) and (not Minor(2)) and (not Minor(1)) and Minor(0)); Win(18) <= ((Minor(4)) and (not Minor(3)) and (not Minor(2)) and Minor(1) and (not Minor(0))); Win(19) <= ((Minor(4)) and (not Minor(3)) and (not Minor(2)) and Minor(1) and Minor(0));

$\operatorname{Win}(20)<=((\operatorname{Minor}(4))$ and (not Minor(3)) and Minor(2) and (not Minor(1)) and (not Minor(0))); $\operatorname{Win}(21)<=((\operatorname{Minor}(4))$ and (not Minor(3)) and Minor(2) and (not Minor(1)) and Minor(0)); $\operatorname{Win}(22)<=((\operatorname{Minor}(4))$ and (not Minor(3)) and Minor(2) and Minor(1) and (not Minor(0))); Win(23) <= ((Minor(4)) and (not Minor(3)) and Minor(2) and Minor(1) and Minor(0));

Win(24) <= ((Minor(4)) and Minor(3) and (not Minor(2)) and (not Minor(1)) and (not Minor(0)));

Neighbour <= ("0001", "0010", "0011", "0100", "0101", "0010", "0011", "0100", "0101", "0110", "0011", "0100", "0101", "0110", "0111", "0100", "0101", "0110", "0111", "1000", "0101", "0110", "0111", "1000", "1001") when $(\operatorname{Win}(0)=$ '1') else ("0010", "0001", "0010", "0011", "0100", "0011", "0010", "0011", "0100", "0101", "0100", "0011", "0100","0101", "0110", "0101", "0100", "0101", "0110", "0111", "0110", "0101", "0110", "0111", "1000") when (Win(1) = '1') else ("0011", "0010", "0001", "0010", "0011", "0100", "0011", "0010", "0011", "0100", "0101", "0100", "0011",0100", "0101", "0110", "0101", "0100", "0101", "0110", "0111", "0110", "0101", "0110", "0111") when (Win(2) = '1') else

("0100", "0011", "0010", "0001", "0010", "0101", "0100", "0011", "0010", "0011", "0110", "0101", "0100", "0011", "0100", "0111", "0110", "0101", "0100", "0101", "1000", "0111", "0110", "0101", "0110") when (Win(3) = '1') else

("0101", "0100", "0011", "0010", "0001", "0110", "0101", "0100", "0011", "0010", "0111", "0110", "0101",0100", "0011", "1000", "0111", "0110", "0101", "0100", "1001", "1000", "0111", "0110", "0101") when (Win(4) = '1') else

("0010", "0011", "0100", "0101", "0110", "0001", "0010", "0011", "0100", "0101", "0010", "0011", "0100", "0101", "0110", "0011", "0100", "0101", "0110", "0111", "0100", "0101", "0110", "0111", "1000") when (Win(5) = '1') else

("0011", "0010", "0011", "0100", "0101", "0010", "0001", "0010", "0011", "0100", "0011", "0010", "0011", "0100", "0101", "0100", "0011", "0100", "0101", "0110", "0101", "0100", "0101", "0110", "0111") when (Win(6) = '1') else

("0100", "0011", "0010", "0011", "0100", "0011", "0010", "0001", "0010", "0011", "0100", "0011", "0010", "0011", "0100", "0101", "0100", "0011", "0100", "0101", "0110", "0101", "0100", "0101", "0110") when (Win(7) = '1') else ("0101", "0100", "0011", "0010", "0011", "0100", "0011", "0010", "0001", "0010", "0101", "0100", "0011", "0010", "0001", "0110", "0101", "0100", "0011", "0100", "0111", "0110", "0101", "0100", "0101") when (Win(8) = '1') else

("0110", "0101", "0100", "0011", "0010", "0101", "0100", "0011", "0010", "0001", "0110", "0101", "0100", "0011", "0010", "0100", "0110", "0101", "0100", "0011", "1000", "0111", "0110", "0101", "0100") when (Win(9) = '1') else

("0011", "0100", "0101", "0110", "0100", "0010", "0011", "0100", "0101", "0110", "0001", "0010", "0011", "0100", "0101", "0010", "0011", "0100", "0101", "0110", "0011", "0100", "0101", "0110", "0100") when (Win(10) = '1') else 
("0100", "0011", "0100", "0101", "0110", "0011", "0010", "0011", "0100", "0101", "0010", "0001", "0010", "0011", "0100", "0011", "0010", "0011", "0100", "0101", "0100", "0011", "0100", "0101", "0110") when (Win(11) = '1') else

("0101", "0100", "0011", "0100", "0101", "0100", "0011", "0010", "0011", "0100", "0011", "0010", "0001", "0010", "0011", "0100", "0011", "0010", "0011", "0100", "0101", "0100", "0011", "0100", "0101") when (Win(12) = '1') else

("0110", "0101", "0100", "0011", "0100", "0101", "0100", "0011", "0010", "0011", "0100", "0011", "0010", "0001", "0010", "0101", "0100", "0011", "0010", "0011", "0110", "0101", "0100", "0011", "0100") when (Win(13) = '1') else

("0111", "0110", "0101", "0100", "0011", "0110", "0101", "0100", "0011", "0010", "0101", "0100", "0011", "0010", "0001", "0110", "0101", "0100", "0011", "0010", "0111", "0110", "0101", "0100", "0011") when (Win(14) = '1') else

("0100", "0101", "0110", "0111", "0100", "0011", "0100", "0101", "0110", "0111", "0010", "0011", "0100", "0101", "0110", "0001", "0010", "0011", "0100", "0101", "0010", "0011", "0100", "0101", "0110") when (Win(15) = '1') else

("0101", "0100", "0101", "0110", "0111", "0100", "0011", "0100", "0101", "0110", "0011", "0010", "0011", "0100", "0101", "0010", "0001", "0010", "0011", "0100", "0011", "0010", "0011", "0100", "0101") when (Win(16) = '1') else

("0110", "0101", "0100", "0101", "0110", "0101", "0100", "0011", "0100", "0101", "0100", "0011", "0010", "0011", "0100", "0011", "0010", "0001", "0010", "0011", "0100", "0011", "0010", "0011", "0100") when (Win(17) = '1') else

("0111", "0110", "0101", "0100", "0101", "0110", "0101", "0100", "0011", "0100", "0101", "0100", "0011", "0010", "0011", "0100", "0011", "0010", "0001", "0010", "0101", "0100", "0011", "0010", "0011") when (Win(18) = '1') else

("1000", "0111", "0110", "0101", "0100", "0111", "0110", "0101", "0100", "0011", "0110", "0101", "0100, "0011", "0010", "0101", "0100", "0011", "0010", "0001", "0110", "0101", "0100", "0011", "0010") when (Win(19) = '1') else

("0101", "0110", "0111", "1000", "1001", "0100", "0101", "0110", "0111", "1000", "0011", "0100", "0101", "0110", "0111", "0010", "0011", "0100", "0101", "0110", "0001", "0010", "0011", "0100", "0101") when (Win(20) = '1') else

("0110", "0101", "0110", "0111", "1000", "0101", "0100", "0101", "0110", "0111", "0100", "0011", "0100", "0101", "0110", "0011", "0010", "0011", "0100", "0101", "0010", "0001", "0010", "0011", "0100")when (Win(21) = '1') else

("0111", "0110", "0101", "0110", "0111", "0110", "0101", "0100", "0101", "0110", "0101", "0100", "0011",0100", "0101", "0100", "0011", "0010", "0011", "0100", "0011", "0010", "0001", "0010", "0011") when (Win(22) = '1') else

("1000", "0111", "0110", "0101", "0110", "0111", "0110", "0101", "0100", "0101", "0110", "0101", "0100", "0011", "0100", "0101", "0100", "0011", "0010", "0011", "0100", "0011", "0010", "0001", "0010") when (Win(23) = '1') else

("1001", "1000", "0111", "0110", "0101", "1000", "0111", "0110", "0101", "0100", "0111", "0110", "0101", "0100", "0011", "0110", "0101", "0100", "0011", "0010", "0101", "0100", "0011", "0010", "0001") when (Win(24) = '1') else

("1001", "1000", "0111", "0110", "0101", "1000", "0111", "0110", "0101", "0100", "0111", "0110", "0101", "0100", "0011", "0110", "0101", "0100", "0011", "0010", "0101", "0100", "0011", "0010", "0001");

-- Blocos para cálculo dos novos valores dos vetores de peso

Gera_Adjust: for i in (QuantN-1) downto 0 generate AdjustX: Adjust port map

( $\mathrm{R}=>$ Clock, Dif1 => Dif1(i), Dif2 => Dif2(i),

Neighbour $=>$ Neighbour(i), InVector $=>$ Weight(i), OutVector $=>$ Wout(i));

end generate Gera_Adjust;

-- o processo de atualização de pesos ocorre na borda de subida do clock

process (Clock) begin

if $($ Clock'event and Clock = '1') and (cont_epocas < epocas_tot) then Weight $<=$ Wout; end if; cont_epocas $<=$ cont_epocas +1 ;

end process;

-- Composição das saídas

Vp0 <= Weight(0); Vp1 <=Weight(1); Vp2 <=Weight(2); Vp3 <=Weight(3); Vp4 <=Weight(4); Vp5 $<=$ Weight(5); Vp6 <= Weight(6); Vp7 <= Weight(7); Vp8 <=Weight(8); Vp9 <= Weight(9); Vp10<= 
Weight(10); Vp11 <= Weight(11); Vp12 <= Weight(12); Vp13 <= Weight(13); Vp14 <= Weight(14); Vp15 <= Weight(15); Vp16 <= Weight(16); Vp17 <= Weight(17); Vp18 <= Weight(18); Vp19 <= Weight(19); Vp20 <= Weight(20); Vp21 <= Weight(21); Vp22 <= Weight(22); Vp23 <= Weight(23); Vp24 <= Weight(24);

end Behavioral;

-- Bloco de cálculo de distância de Manhattan

entity Mdist is

Port (X, Y : in std_logic_vector (7 downto 0); -- Vetores de entrada

Dif1, Dif2 : out std_logic_vector (4 downto 0); -- Valores de subtração de cada dimen. end Mdist;

Z : out std_logic_vector (4 downto 0)); -- Valor de saída de distância de manhattan

architecture componente of Mdist is

signal SubOut1, SubOut2 : std_logic_vector (4 downto 0);

begin

process $(\mathrm{X}, \mathrm{Y})$ begin

SubOut1 <=(X(7)\&X (7 downto 4)) - (Y(7)\&Y (7 downto 4));

SubOut $2<=(\mathrm{X}(3) \& \mathrm{X}(3$ downto 0$))-(\mathrm{Y}(3) \& \mathrm{Y}(3$ downto 0$))$;

end process;

Dif1 <= SubOut1; Dif2 <= SubOut2;

$\mathrm{Z}<=\operatorname{abs}($ SubOut 1$)+\operatorname{abs}($ SubOut2);

end componente;

-- Bloco de identificação de menor valor entre dois para composição do torneio de

-- busca do neurônio vencedor de transmissão do índice e peso do neurônio vencedor

library IEEE;

use IEEE.STD_LOGIC_1164.ALL;

entity MenorDe2 is

Generic (bitsD : integer $:=5$;

bitsX : integer :=5);

Port ( In1, In $2:$ in std_logic_vector (bitsD-1 downto 0);

Index 1 , Index 2 : in std_logic_vector (bitsX-1 downto 0);

Minor : out std_logic_vector (bitsD-1 downto 0);

end MenorDe2;

IndexMinor: out std_logic_vector (bitsX-1 downto 0));

architecture componente of MenorDe2 is

component MenorDe2_bit

Port (a, b : in std_logic;

carrier_in : in std_logic_vector (1 downto 0);

carrier_out : out std_logic_vector (1 downto 0$)$ );

end component;

component mux $2 \times B I T S b$ is

Port( in_A, in_B : in std_logic_vector (bitsD+bitsX-1 downto 0);

sel : in std_logic;

mux : out std_logic_vector (bitsD+bitsX-1 downto 0));

end component;

type connect_array is array (bitsD-1 downto 0) of std_logic_vector ( 1 downto 0$)$;

signal connect : connect_array; -- Matriz de sinais de conexões entre os blocos.

signal mux_sel : std_logic_vector (1 downto 0);

signal menoreindex : std_logic_vector (bitsD+bitsX-1 downto 0);

signal inputA, inputB : std_logic_vector (bitsD+bitsX-1 downto 0);

begin

inputA $<=\operatorname{In} 1 \&$ Index 1 ;

inputB $<=\operatorname{In} 2 \&$ Index 2 ; 
MenorMSB: MenorDe2_bit port map

( $\mathrm{a}=>$ In1(bitsD-1), b => In2(bitsD-1), carrier_in => "00", carrier_out => connect(bitsD-1));

Gera_MenorDe2:

for $\mathrm{i}$ in (bitsD-2) downto 0 generate MenorDe2X: MenorDe2_bit port map

( $\mathrm{a}=>$ In1(i), $\mathrm{b}=>$ In2(i), carrier_in $=>$ connect(i+1), carrier_out => connect(i));

end generate Gera_MenorDe2;

mux_sel <= connect $(0)$;

MUX: mux2xBITSb port map

(in_A $=>$ inputA, in_B $=>$ inputB, sel $=>$ mux_sel(0), mux $\Rightarrow$ menoreindex);

Minor $<=$ menoreindex (bitsD+bitsX-1 downto bitsX);

IndexMinor $<=$ menoreindex (bitsX-1 downto 0 );

end componente;

Bloco MenorDe2_bit

library IEEE;

use IEEE.STD_LOGIC_1164.ALL;

entity MenorDe2_bit is

Port ( $\mathrm{a}, \mathrm{b}$ : in std_logic;

carrier_in : in std_logic_vector (1 downto 0$)$;

end MenorDe2_bit;

carrier_out : out std_logic_vector (1 downto 0$))$;

architecture Behavioral of MenorDe2_bit is

begin

carrier_out $(1)<=($ carrier_in $(1)$ or $(($ not carrier_in $(0))$ and (not a) and b) $)$;

carrier_out $(0)<=($ carrier_in $(0)$ or $(($ not carrier_in $(1))$ and a and (not b)) $)$;

end Behavioral;

-- MUX de 2 entradas e quantidade de bits genérico

library IEEE;

use IEEE.STD_LOGIC_1164.ALL;

entity mux $2 \times B I T S b$ is

Generic (bitsD : integer $:=5$;

bitsX : integer $:=5)$;

Port( in_A, in_B : in std_logic_vector (bitsD+bitsX-1 downto 0); sel : in std_logic;

end mux2xBITSb;

mux : out std_logic_vector (bitsD+bitsX-1 downto 0));

architecture componente of mux $2 \times \mathrm{BITSb}$ is

begin

process (sel, in_A, in_B)

begin

case sel is

when ' 0 ' $\Rightarrow$ mux $<=$ in_A;

when ' 1 ' $\Rightarrow$ mux $<=$ in_B;

when others $=>$ NULL;

end case;

end process;

end componente;

-- Bloco comportamental genérico para ajuste dos vetores de peso.

-- Também converte a quantidade de bits do Dif (maior para evitar estouro)

-- na quantidade de bits de cada dimensão do vetor de peso.

-- Computa: $\quad \mathrm{Wi}(\mathrm{t}+1)=\mathrm{Wi}(\mathrm{t})+$ alpha*Hci*$[\mathrm{X}(\mathrm{t})-\mathrm{Wi}(\mathrm{t})]$

-- Com: $\quad$ alpha $=$ variável e Hci $=2^{\wedge}$-[Mdist $(\mathrm{c}, \mathrm{i}) *$ BETA] 


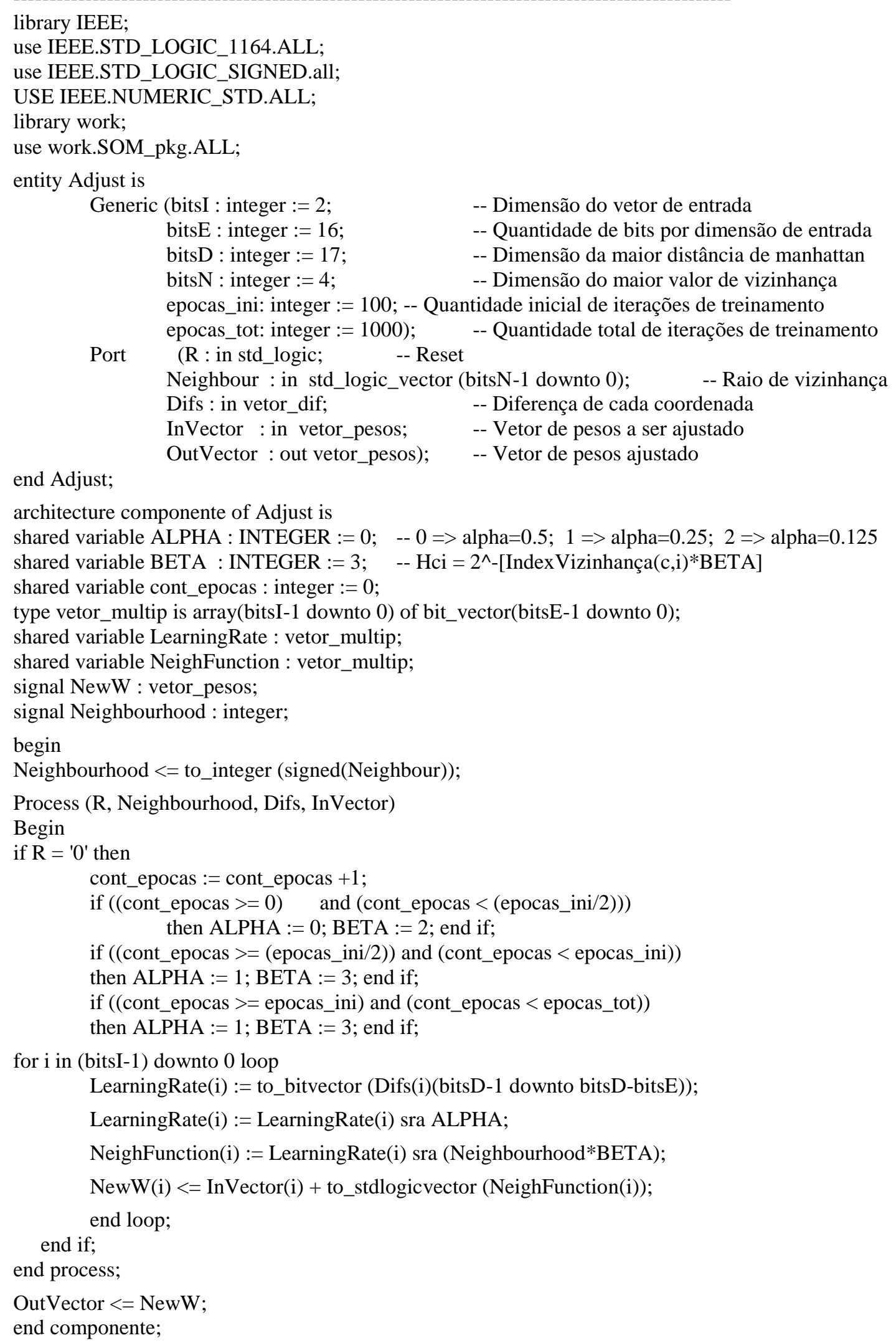




\title{
APÊNDICE C - MODELO HÍBRIDO EM VHDL
}

\author{
Modelo híbrido de execução do SOM em FPGA.
}

-- SOM: mapa 5x5, dados de dimensão 2 (4 bits cada).

-- CC: Controle centralizado para determinação do neurônio vencedor.

-- Difusão de vizinhança e ajuste de pesos feitos em rede paralela.

-- Cálculo da distância de Manhattan em concorrência.

-- Todos os neurônios da rede são ajustados em decaimento linear de vizinhança

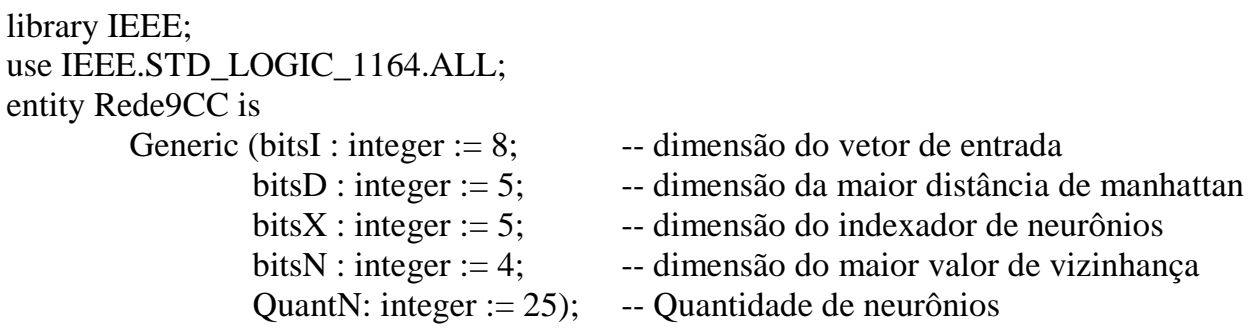

architecture Behavioral of Rede9CC is

-- Bloco para cálculo da distância de Manhattan component Mdist

port( X, Y : in std_logic_vector(bitsI-1 downto 0);

Dif1, Dif2 : out std_logic_vector (bitsD-1 downto 0);

$\mathrm{Z}$ : out std_logic_vector(bitsD-1 downto 0));

end component;

-- Bloco para cálculo do neurônio de menor distância component MenorDe2

Port ( In1, In 2 : in std_logic_vector (bitsD-1 downto 0);

Index 1 , Index 2 : in std_logic_vector (bitsX-1 downto 0);

Minor : out std_logic_vector (bitsD-1 downto 0);

end component;

IndexMinor: out std_logic_vector (bitsX-1 downto 0));

-- Neurônio Híbrido (parte do cálculo feito pelo controle central) component HNeuron

Port ( Diff1, Diff2 : in std_logic_vector(bitsD-1 downto 0);

$\mathrm{R}$, Winner : in std_logic;

VectorIn : in std_logic_vector (bitsI-1 downto 0);

VectorOut : out std_logic_vector (bitsI-1 downto 0);

N, S, E, W : in std_logic_vector (bitsN-1 downto 0);

NOut : out std_logic_vector (bitsN-1 downto 0));

end component;

signal Minor : std_logic_vector (bitsX-1 downto 0); -- Índice do neurônio vencedor

-- Sinais tipo "one hot" para sinalização do neurônio vencedor

type Win_bus is array (QuantN-1 downto 0) of std_logic;

signal Win : Win_bus;

-- Sinais de interligação entre os neurônios signal N0, N1, N2, N3, N4, N5, N6, N7, N8, N9, N10, N11, N12, N13, N14, N15, N16, N17, N18, N19, N20, N21, N22, N23, N24 : std_logic_vector (bitsN-1 downto 0);

-- Sinais de valores de distância de Manhattan e diferença em cada coordenada do vetor 
-- Sinais internos do bloco de torneio da menor distância

type distance_array is array (QuantN-1 downto 0) of std_logic_vector (bitsD-1 downto 0);

signal Distance, Dif1, Dif2 : distance_array;

type connectw_array is array (30 downto 0) of std_logic_vector (bitsD-1 downto 0);

signal connectW : connectw_array;

-- Matriz de pesos iniciais e sinais de valores de pesos ajustáveis

type weight_array is array (0 to QuantN-1) of std_logic_vector (bitsI-1 downto 0);

signal Wout : weight_array;

signal Weight : weight_array :=("00000100", -- coordenadas: $0,+4$

"00010100", -- coordenadas: $+1,+4$

"00100100", -- coordenadas: $+2,+4$

"00110100", -- coordenadas: $+3,+4$

"01000100", -- coordenadas: $+4,+4$

"00000011", -- coordenadas: $0,+3$

"00010011", -- coordenadas: $+1,+3$

"00100011", -- coordenadas: $+2,+3$

"00110011", -- coordenadas: $+3,+3$

"01000011", -- coordenadas: $+4,+3$

"00000010", -- coordenadas: $0,+2$

"00010010", -- coordenadas: $+1,+2$

"00100010", -- coordenadas: $+2,+2$

"00110010", -- coordenadas: $+3,+2$

"01000010", -- coordenadas: $+4,+2$

"00000001", -- coordenadas: $0,+1$

"00010001", -- coordenadas: $+1,+1$

"00100001", -- coordenadas: $+2,+1$

"00110001", -- coordenadas: $+3,+1$

"01000001", -- coordenadas: $+4,+1$

"00000000", -- coordenadas: 0, 0

"00010000", -- coordenadas: +1, 0

"00100000", -- coordenadas: 2, 0

"00110000", -- coordenadas: +3, 0

"01000000"); -- coordenadas: +4, 0

-- Sinais internos do bloco de torneio da menor distância (índices do neurônio)

type index_array is array (0 to 30) of std_logic_vector (bitsX-1 downto 0);

signal connectI : index_array;

signal Index : index_array := ("00000", "00001", "00010", "00011", "00100", "00101", "00110", "00111", "01000", "01001", "01010", "01011", "01100", "01101", "01110", "01111", "10000", "10001", "10010", "10011", "10100", "10101", "10110", "10111", "11000", "11001", "11010", "11011", "11100", "11101", "11110");

constant endmap : std_logic_vector (bitsN-1 downto 0) := "1111";

begin

-- Blocos para cálculo paralelo da distância de Manhattan

Gera_M_dist: for i in (QuantN-1) downto 0 generate M_distX:

Mdist port map (X $=>X Y, Y=>$ Weight(i), Dif1 $\Rightarrow$ Dif1(i), Dif2 $\Rightarrow$ Dif2(i), Z => Distance(i)); end generate Gera_M_dist;

-- Torneio de busca da menor distância entre 16: oitavas, quartas, semis e final

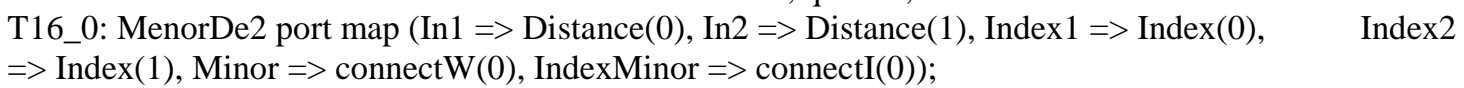

T16_1: MenorDe2 port map (In1 $=>$ Distance(2), In2 $\Rightarrow>$ Distance(3), Index1 $\Rightarrow$ Index(2), Index2

$\Rightarrow$ Index(3), Minor $=>$ connectW(1), IndexMinor $=>$ connectI $(1))$;

T16_2: MenorDe2 port map (In1 $\Rightarrow>$ Distance(4), In2 $\Rightarrow$ Distance(5), Index1 => Index(4), Index2

$\Rightarrow$ Index(5), Minor $=>$ connectW(2), IndexMinor $=>$ connectI(2));

T16_3: MenorDe2 port map (In1 $\Rightarrow$ Distance(6), In2 $\Rightarrow$ Distance(7), Index1 $\Rightarrow$ Index(6), Index2

$\Rightarrow$ Index(7), Minor $=>$ connectW(3), IndexMinor $=>$ connectI(3));

T16_4: MenorDe2 port map (In1 $\Rightarrow$ Distance(8), In2 $\Rightarrow$ Distance(9), Index1 $\Rightarrow$ Index(8), Index2

$\Rightarrow$ Index(9), Minor $=>$ connectW(4), IndexMinor $\Rightarrow>$ connectI(4));

T16_5: MenorDe2 port map (In1 $\Rightarrow$ Distance(10), In2 $\Rightarrow$ Distance(11), Index $1 \Rightarrow$ Index(10), Index2

$\Rightarrow$ Index(11), Minor $=>$ connectW(5), IndexMinor $=>\operatorname{connectI}(5))$; 
T16_6: MenorDe2 port map (In1 $\Rightarrow$ Distance(12), In2 $\Rightarrow$ Distance(13), Index1 $\Rightarrow$ Index(12), Index2 $\Rightarrow$ Index(13), Minor $=>$ connectW(6), IndexMinor $=>$ connectI(6));

T16_7: MenorDe2 port map (In1 => Distance(14), In2 => Distance(15), Index1 => Index(14), Index2 $\Rightarrow$ Index (15), Minor $=>$ connectW(7), IndexMinor $=>$ connectI(7));

T16_8: MenorDe2 port map (In1 $\Rightarrow$ Distance(16), In2 $\Rightarrow$ Distance(17), Index1 $\Rightarrow$ Index(16), Index2 $\Rightarrow$ Index(17), Minor $=>$ connectW(8), IndexMinor $=>$ connectI $(8)$ );

T16_9: MenorDe2 port map (In1 => Distance(18), In2 => Distance(19), Index1 => Index(18), Index2 $\Rightarrow$ Index(19), Minor $=>$ connectW(9), IndexMinor $\Rightarrow>$ connectI(9));

T16_10: MenorDe2 port map (In1 => Distance(20), In2 => Distance(21), Index1 => Index(20), Index2 $\Rightarrow$ Index (21), Minor $=>$ connectW(10), IndexMinor $=>$ connectI(10));

T16_11: MenorDe2 port map (In1 => Distance(22), In2 => Distance(23), Index1 $\Rightarrow$ Index(22), Index2 $\Rightarrow$ Index (23), Minor $=>$ connectW(11), IndexMinor $=>$ connectI(11));

T16_12: MenorDe2 port map (In1 => Distance(24), In2 => "11111", Index1 => Index(24), Index2 $\Rightarrow$ "11111", Minor $=>$ connectW(12), IndexMinor $=>$ connectI(12));

T16_13: MenorDe2 port map (In1 => "11111", In2 => "11111", Index1 => "11111", Index $2 \Rightarrow$ "11111", Minor $=>$ connectW(13), IndexMinor $=>$ connectI(13));

T16_14: MenorDe2 port map (In1 => "11111", In2 => "11111", Index1 => "11111", Index $2 \Rightarrow$ "11111", Minor $=>$ connectW(14), IndexMinor $=>$ connectI(14));

T16_15: MenorDe2 port map (In1 => "11111", In2 => "11111", Index1 => "11111", Index $2 \Rightarrow$ "11111", Minor $=>$ connectW(15), IndexMinor $=>$ connectI(15));

T8_0: MenorDe2 port map (In1 $\Rightarrow>$ connectW(0), In $\Rightarrow>$ connectW(1), Index $1 \Rightarrow>$ connectI(0), Index2 $\Rightarrow>$ connectI(1), Minor $=>$ connectW(16), IndexMinor $\Rightarrow>\operatorname{connectI}(16))$;

T8_1: MenorDe2 port map (In1 $\Rightarrow>$ connectW(2), In $2 \Rightarrow$ connectW(3), Index $1 \Rightarrow$ connectI(2), Index2 $\Rightarrow$ connectI(3), Minor $=>$ connectW(17), IndexMinor $=>$ connectI(17));

T8_2: MenorDe2 port map (In1 $\Rightarrow>$ connectW(4), In $\Rightarrow>$ connectW(5), Index $1 \Rightarrow>$ connectI(4), Index2 $\Rightarrow>$ connectI(5), Minor $=>$ connectW(18), IndexMinor $=>\operatorname{connectI}(18))$;

T8_3: MenorDe2 port map (In1 $\Rightarrow>$ connectW(6), In2 $\Rightarrow$ connectW(7), Index1 $\Rightarrow$ connectI(6), Index2 $\Rightarrow>$ connectI(7), Minor $=>$ connectW(19), IndexMinor $=>$ connectI(19));

T8_4: MenorDe2 port map (In1 $\Rightarrow>$ connectW(8), In2 $\Rightarrow$ connectW(9), Index1 $\Rightarrow$ connectI(8), Index2 $\Rightarrow>$ connectI(9), Minor $=>$ connectW(20), IndexMinor $=>$ connectI $(20))$;

T8_5: MenorDe2 port map (In1 => connectW(10), In2 $\Rightarrow>\operatorname{connectW(11),~Index1~} \Rightarrow$ connectI(10), Index $2 \Rightarrow>$ connectI(11), Minor $=>$ connectW(21), IndexMinor $=>$ connectI(21));

T8_6: MenorDe2 port map (In1 => connectW(12), In2 $\Rightarrow$ connectW(13), Index1 $\Rightarrow$ connectI(12), Index $2 \Rightarrow$ connectI(13), Minor $=>$ connectW(22), IndexMinor $=>$ connectI(22));

T8_7: MenorDe2 port map (In1 => connectW(14), In2 $\Rightarrow>$ connectW(15), Index1 => connectI(14), Index $2 \Rightarrow>\operatorname{connectI}(15)$, Minor $=>$ connectW(23), IndexMinor $=>\operatorname{connectI}(23))$;

T4_0: MenorDe2 port map (In1 $\Rightarrow$ connectW(16), In2 $\Rightarrow$ connectW(17), Index1 $\Rightarrow$ connectI(16), Index $2 \Rightarrow$ connectI(17), Minor $=>$ connectW(24), IndexMinor $\Rightarrow>$ connectI(24));

T4_1: MenorDe2 port map (In1 => connectW(18), In2 $\Rightarrow$ connectW(19), Index1 $\Rightarrow$ connectI(18), Index $2 \Rightarrow$ connectI(19), Minor $=>$ connectW(25), IndexMinor $=>$ connectI(25));

T4_2: MenorDe2 port map (In1 $\Rightarrow$ connectW(20), In2 $\Rightarrow$ connectW(21), Index1 $\Rightarrow \operatorname{connectI}(20)$, Index $2 \Rightarrow$ connectI(21), Minor $=>$ connectW(26), IndexMinor $=>$ connectI(26));

T4_3: MenorDe2 port map (In1 $\Rightarrow$ connectW(22), In2 $\Rightarrow$ connectW(23), Index1 $\Rightarrow$ connectI(22), Index $2 \Rightarrow$ connectI(23), Minor $=>$ connectW(27), IndexMinor $=>\operatorname{connectI}(27))$;

T2_0: MenorDe2 port map (In1 => connectW(24), In2 $\Rightarrow$ connectW(25), Index1 $\Rightarrow$ connectI(24), Index $2 \Rightarrow$ connectI(25), Minor $=>\operatorname{connectW}(28)$, IndexMinor $=>\operatorname{connectI}(28))$;

T2_1: MenorDe2 port map (In1 $\Rightarrow$ connectW(26), In2 $\Rightarrow \operatorname{connectW(27),~Index1~} \Rightarrow \operatorname{connectI}(26)$, Index $2 \Rightarrow$ connectI(27), Minor $\Rightarrow>$ connectW(29), IndexMinor $=>$ connectI(29));

T1_0: MenorDe2 port map (In1 $\Rightarrow$ connectW(28), In2 $\Rightarrow$ connectW(29), Index1 $\Rightarrow$ connectI(28), Index $2 \Rightarrow>$ connectI(29), Minor $=>$ connectW(30), IndexMinor $=>$ connectI(30));

Minor <= connectI $(30)$;

-- Composição tipo "one hot" para sinalização do neurônio vencedor com lógica combinacional $\operatorname{Win}(0)<=(($ not Minor(4)) and (not Minor(3)) and (not Minor(2)) and (not Minor(1)) and (not Minor(0))); Win(1) <=((not Minor(4)) and (not Minor(3)) and (not Minor(2)) and (not Minor(1)) and Minor(0)); Win(2) <= ((not Minor(4)) and (not Minor(3)) and (not Minor(2)) and Minor(1) and (not Minor(0))); Win(3) <= ((not Minor(4)) and (not Minor(3)) and (not Minor(2)) and Minor(1) and Minor(0)); Win(4) <= ((not Minor(4)) and (not Minor(3)) and Minor(2) and (not Minor(1)) and (not Minor(0))); Win(5) <= ((not Minor(4)) and (not Minor(3)) and Minor(2) and (not Minor(1)) and Minor(0)); 
Win(6) <= ((not Minor(4)) and (not Minor(3)) and Minor(2) and Minor(1) and (not Minor(0))); $\operatorname{Win}(7)<=(($ not Minor(4)) and (not Minor(3)) and Minor(2) and Minor(1) and Minor(0)); Win(8) <= ((not Minor(4)) and Minor(3) and (not Minor(2)) and (not Minor(1)) and (not Minor(0))); Win(9) <= ((not Minor(4)) and Minor(3) and (not Minor(2)) and (not Minor(1)) and Minor(0)); Win(10) <= ((not Minor(4)) and Minor(3) and (not Minor(2)) and Minor(1) and (not Minor(0))); $\operatorname{Win}(11)<=(($ not Minor(4)) and Minor(3) and (not Minor(2)) and Minor(1) and Minor(0)); $\operatorname{Win}(12)<=((\operatorname{not} \operatorname{Minor}(4))$ and Minor(3) and Minor(2) and (not Minor(1)) and (not Minor(0))); Win(13) <= ((not Minor(4)) and Minor(3) and Minor(2) and (not Minor(1)) and Minor(0)); Win(14) $<=(($ not Minor(4)) and Minor(3) and Minor(2) and Minor(1) and (not Minor(0))); Win(15) $<=(($ not Minor(4)) and Minor(3) and Minor(2) and Minor(1) and Minor(0)); $\operatorname{Win}(16)<=((\operatorname{Minor}(4))$ and $($ not Minor(3)) and (not Minor(2)) and (not Minor(1)) and (not Minor(0))); Win(17) $<=((\operatorname{Minor}(4))$ and (not Minor(3)) and (not Minor(2)) and (not Minor(1)) and Minor(0)); Win(18) <= ((Minor(4)) and (not Minor(3)) and (not Minor(2)) and Minor(1) and (not Minor(0))); Win(19) <= ((Minor(4)) and (not Minor(3)) and (not Minor(2)) and Minor(1) and Minor(0)); $\operatorname{Win}(20)<=((\operatorname{Minor}(4))$ and (not Minor(3)) and Minor(2) and (not Minor(1)) and (not Minor(0))); $\operatorname{Win}(21)<=((\operatorname{Minor}(4))$ and (not Minor(3)) and Minor(2) and (not Minor(1)) and Minor(0)); $\operatorname{Win}(22)<=((\operatorname{Minor}(4))$ and (not Minor(3)) and Minor(2) and Minor(1) and (not Minor(0))); $\operatorname{Win}(23)<=((\operatorname{Minor}(4))$ and (not Minor(3)) and Minor(2) and Minor(1) and Minor(0)); $\operatorname{Win}(24)<=((\operatorname{Minor}(4))$ and Minor(3) and (not Minor(2)) and (not Minor(1)) and (not Minor(0)));

-- Declaração da rede de interligação dos neurônios híbridos (difusão / controle central) Neuron0: HNeuron port map (Diff1 $\Rightarrow$ Dif1(0), Diff2 $\Rightarrow$ Dif2(0), R $\Rightarrow$ Clock, Winner $=>$ Win(0), VectorIn $\Rightarrow>$ Weight(0), N => endmap, S $\Rightarrow$ N5, E $\Rightarrow$ N1, W $\Rightarrow$ endmap, NOut $\Rightarrow>$ N0, VectorOut $=>$ Wout $(0)$ );

Neuron1: HNeuron port map(Diff1 $\Rightarrow$ Dif1(1), Diff2 $\Rightarrow$ Dif2(1), R $\Rightarrow$ Clock, Winner $=>$ Win(1), VectorIn $=>$ Weight(1), N $\Rightarrow$ endmap, $\mathrm{S} \Rightarrow \mathrm{N6}, \quad \mathrm{E}=>\mathrm{N} 2, \quad \mathrm{~W} \Rightarrow \mathrm{N} 0, \quad$ NOut $\Rightarrow$ N1, VectorOut $\Rightarrow$ Wout(1));

Neuron2: HNeuron port map(Diff1 => Dif1(2), Diff2 $\Rightarrow$ Dif2(2), R => Clock, Winner => Win(2), VectorIn => Weight(2), N $\Rightarrow$ endmap, S $\Rightarrow$ N7, E $=>\mathrm{N} 3, \quad \mathrm{~W} \Rightarrow \mathrm{N1}, \quad$ NOut $\Rightarrow>\mathrm{N} 2$, VectorOut $=>$ Wout(2));

Neuron3: HNeuron port map(Diff1 $\Rightarrow$ Dif1(3), Diff2 $\Rightarrow$ Dif2(3), R $\Rightarrow$ Clock, Winner $=>$ Win(3), VectorIn $\Rightarrow$ Weight(3), $\mathrm{N} \Rightarrow$ endmap, $\mathrm{S} \Rightarrow \mathrm{N} 8, \quad \mathrm{E}=>\mathrm{N} 4, \quad \mathrm{~W} \Rightarrow \mathrm{N} 2, \quad \mathrm{NOut} \Rightarrow \mathrm{N} 3$, VectorOut $\Rightarrow$ Wout(3));

Neuron4: HNeuron port map(Diff1 $\Rightarrow$ Dif1(4), Diff2 $\Rightarrow$ Dif2(4), R $\Rightarrow$ Clock, Winner $=>$ Win(4), VectorIn $\Rightarrow>$ Weight(4), N => endmap, S => N9, E => endmap, W => N3, NOut => N4, VectorOut $=>$ Wout(4));

Neuron5: HNeuron port map(Diff1 $\Rightarrow$ Dif1(5), Diff2 $\Rightarrow$ Dif2(5), R $\Rightarrow>$ Clock, Winner $=>$ Win(5), VectorIn $\Rightarrow>$ Weight(5), N $\Rightarrow$ N0, S $=>$ N10, E => N6, W $\Rightarrow$ endmap, NOut $=>$ N5, VectorOut $=>$ Wout(5));

Neuron6: HNeuron port map(Diff1 $\Rightarrow$ Dif1(6), Diff2 $\Rightarrow$ Dif2(6), R $\Rightarrow>$ Clock, Winner $=>$ Win(6), VectorIn $\Rightarrow>$ Weight(6), N $\Rightarrow>\mathrm{N} 1, \quad \mathrm{~S}=>\mathrm{N11}, \mathrm{E}=>\mathrm{N} 7, \mathrm{~W}=>\mathrm{N} 5, \quad$ NOut $\Rightarrow>\mathrm{N} 6$, VectorOut $=>\operatorname{Wout}(6))$;

Neuron7: HNeuron port map(Diff1 $\Rightarrow$ Dif1(7), Diff2 $\Rightarrow$ Dif2(7), R => Clock, Winner => Win(7), VectorIn => Weight(7), N $\Rightarrow>\mathrm{N} 2, \quad \mathrm{~S}=>\mathrm{N} 12, \quad \mathrm{E}=>\mathrm{N} 8, \quad \mathrm{~W}=>\mathrm{N} 6, \quad$ NOut $=>\mathrm{N} 7$, VectorOut $=>\operatorname{Wout}(7)$ );

Neuron8: HNeuron port map(Diff1 $\Rightarrow$ Dif1(8), Diff2 $\Rightarrow$ Dif2(8), R $\Rightarrow$ Clock, Winner $\Rightarrow>$ Win(8), VectorIn $\Rightarrow>$ Weight(8), N=> N3, S $\Rightarrow$ N13, E $\Rightarrow>N 9, \quad W=>N 7, \quad$ NOut $\Rightarrow>N 8$, VectorOut $=>$ Wout(8));

Neuron9: HNeuron port map(Diff1 $\Rightarrow$ Dif1(9), Diff2 $\Rightarrow$ Dif2(9), R $\Rightarrow$ Clock, Winner $=>$ Win(9), VectorIn $\Rightarrow>$ Weight(9), N => N4, S => N14, E => endmap, W => N8, $\quad$ NOut => N9, VectorOut $=>$ Wout(9));

Neuron10: HNeuron port map(Diff1 $\Rightarrow>$ Dif1(10), Diff2 $\Rightarrow$ Dif2(10), R => Clock, Winner $=>$ Win(10), VectorIn $\Rightarrow$ Weight(10), N $\Rightarrow$ N5, S $\Rightarrow$ N15, E $\Rightarrow$ N11, W $\Rightarrow$ endmap, NOut $\Rightarrow>$ N10, VectorOut $\Rightarrow$ Wout $(10)$ );

Neuron11: HNeuron port map(Diff1 $\Rightarrow$ Dif1(11), Diff2 $\Rightarrow$ Dif2(11), R $\Rightarrow$ Clock, Winner $=>$ Win(11), VectorIn $\Rightarrow$ Weight(11), N $\Rightarrow$ N6, $\mathrm{S}=>\mathrm{N} 16, \quad \mathrm{E}=>\mathrm{N12}, \mathrm{W}=>\mathrm{N10}, \quad$ NOut $\Rightarrow$ N11, VectorOut $\Rightarrow$ Wout $(11)$ );

Neuron12: HNeuron port map(Diff1 $\Rightarrow$ Dif1(12), Diff2 $\Rightarrow$ Dif2(12), R => Clock, Winner $=>$ Win(12), VectorIn $\Rightarrow$ Weight(12), N $\Rightarrow$ N7, $S \Rightarrow$ N17, E $\Rightarrow$ N13, W $\Rightarrow$ N11, NOut $\Rightarrow>N 12$, VectorOut $=>$ Wout $(12)$ );

Neuron13: HNeuron port map(Diff1 $=>$ Dif1(13), Diff2 $\Rightarrow$ Dif2(13), R $\Rightarrow$ Clock, Winner $=>$ Win(13), VectorIn $\Rightarrow$ Weight(13), N $\Rightarrow$ N8, $\mathrm{S}=>\mathrm{N} 18, \quad \mathrm{E}=>\mathrm{N} 14, \quad \mathrm{~W}=>\mathrm{N} 12, \quad$ NOut $\Rightarrow>\mathrm{N13}$, VectorOut $=>$ Wout $(13)$ );

Neuron14: HNeuron port map(Diff1 $\Rightarrow$ Dif1(14), Diff2 $\Rightarrow$ Dif2(14), R $\Rightarrow$ Clock, Winner $=>$ Win(14), VectorIn $\Rightarrow$ Weight(14), N $\Rightarrow$ N9, $\mathrm{S}=>\mathrm{N} 19, \quad \mathrm{E} \Rightarrow$ endmap, $\mathrm{W}=>\mathrm{N13}, \quad$ NOut $\Rightarrow$ N14, VectorOut $\Rightarrow$ Wout(14));

Neuron15: HNeuron port map(Diff1 $\Rightarrow$ Dif1(15), Diff2 $\Rightarrow$ Dif2(15), R $\Rightarrow$ Clock, Winner $=>$ Win(15), VectorIn $\Rightarrow$ Weight(15), N $\Rightarrow$ N10, S $\Rightarrow$ N20, E $\Rightarrow$ N16, W $\Rightarrow$ endmap, NOut $=>$ N15, VectorOut $\Rightarrow$ Wout(15));

Neuron16: HNeuron port map(Diff1 $=>$ Dif1(6), Diff2 $\Rightarrow$ Dif2(6), R $\Rightarrow$ Clock, Winner $=>$ Win(16), VectorIn $=>$ Weight(16), N $\Rightarrow>$ N11, S $=>$ N21, E $\Rightarrow$ N17, W $=>$ N15, NOut $=>$ N16, VectorOut $=>$ Wout(16)); 
Neuron17: HNeuron port map(Diff1 $=>$ Dif1(7), Diff2 $\Rightarrow$ Dif2(7), R $\Rightarrow$ Clock, Winner $=>$ Win(17), VectorIn $=>$ Weight(17), N $\Rightarrow$ N12, $\mathrm{S} \Rightarrow \mathrm{N} 22, \quad \mathrm{E}=>\mathrm{N} 18, \quad \mathrm{~W} \Rightarrow \mathrm{N16}, \quad$ NOut $\Rightarrow$ N17, VectorOut $=>$ Wout(17));

Neuron18: HNeuron port map(Diff1 $\Rightarrow$ Dif1(8), Diff2 $\Rightarrow$ Dif2(8), R $\Rightarrow$ Clock, Winner $=>$ Win(18), VectorIn $\Rightarrow>$ Weight(18), N $\Rightarrow$ N13, $\mathrm{S} \Rightarrow \mathrm{N} 23, \quad \mathrm{E} \Rightarrow \mathrm{N19}, \mathrm{W} \Rightarrow \mathrm{N17}, \quad$ NOut $\Rightarrow>\mathrm{N} 18$, VectorOut $\Rightarrow$ Wout(18));

Neuron19: HNeuron port map(Diff1 $=>$ Dif1(9), Diff2 $\Rightarrow$ Dif2(9), R $\Rightarrow$ Clock, Winner $=>$ Win(19), VectorIn $=>$ Weight(19), N $\Rightarrow$ N14, $S \Rightarrow$ N24, E $\Rightarrow$ endmap, W $\Rightarrow$ N18, $\quad$ NOut $\Rightarrow>$ N19, VectorOut $\Rightarrow$ Wout(19));

Neuron20: HNeuron port map(Diff1 $\Rightarrow$ Dif1(10), Diff2 $\Rightarrow$ Dif2(10), R $\Rightarrow$ Clock, Winner $=>$ Win(20), VectorIn => Weight(20), N $\Rightarrow$ N15, S $\Rightarrow$ endmap, E $\Rightarrow$ N21, W $\Rightarrow$ endmap, NOut $\Rightarrow$ N20, VectorOut $\Rightarrow$ Wout(20));

Neuron21: HNeuron port map(Diff1 $\Rightarrow$ Dif1(11), Diff2 $\Rightarrow$ Dif2(11), R $\Rightarrow$ Clock, Winner $=>$ Win(21), VectorIn $\Rightarrow$ Weight(21), N $\Rightarrow$ N16, S $=>$ endmap, E $\Rightarrow>$ N22, W $=>$ N20, NOut $=>$ N21, VectorOut $=>$ Wout $(21)$ );

Neuron22: HNeuron port map(Diff1 $\Rightarrow$ Dif1(12), Diff2 $\Rightarrow$ Dif2(12), R $\Rightarrow$ Clock, Winner $=>$ Win(22), VectorIn $\Rightarrow$ Weight(22), N $\Rightarrow$ N17, S $\Rightarrow>$ endmap, E $\Rightarrow>$ N23, W $\Rightarrow$ N21, NOut $=>$ N22, VectorOut $=>$ Wout(22));

Neuron23: HNeuron port map(Diff1 $\Rightarrow$ Dif1(13), Diff2 $\Rightarrow$ Dif2(13), R => Clock, Winner $=>$ Win(23), VectorIn $\Rightarrow$ Weight(23), N $\Rightarrow$ N18, $\mathrm{S} \Rightarrow$ endmap, $\mathrm{E} \Rightarrow \mathrm{N} 24, \mathrm{~W} \Rightarrow \mathrm{N} 22, \quad$ NOut $\Rightarrow>\mathrm{N} 23$, VectorOut $\Rightarrow$ Wout(23));

Neuron24: HNeuron port map (Diff1 $\Rightarrow$ Dif1(14), Diff2 $\Rightarrow$ Dif2(14), R $\Rightarrow$ Clock, Winner $=>$ Win(24), VectorIn $\Rightarrow$ Weight(24), N $\Rightarrow$ N19, $\mathrm{S} \Rightarrow$ endmap, E $\Rightarrow$ endmap, W $\Rightarrow$ N23, NOut $\Rightarrow$ N24, VectorOut $\Rightarrow$ Wout(24));

-- o processo de atualização de pesos ocorre na borda de subida do clock

process (Clock) begin

if (Clock'event and Clock = '1') then

end if; Weight $<=$ Wout;

end process;

-- Composição das saídas

Vp0 <= Weight(0); Vp1 <= Weight(1); Vp2 <=Weight(2); Vp3 <=Weight(3); Vp4 <= Weight(4); Vp5 $<=$ Weight(5); Vp6 <= Weight(6); Vp7 <=Weight(7); Vp8 <=Weight(8); Vp9 <= Weight(9); Vp10 <= Weight(10); Vp11 <= Weight(11); Vp12 <= Weight(12); Vp13 <= Weight(13); Vp14 <= Weight(14); Vp15 <= Weight(15); Vp16 <= Weight(16); Vp17 <= Weight(17); Vp18 <= Weight(18); Vp19 <= Weight(19); Vp20 <= Weight(20); Vp21 <=Weight(21); Vp22 <=Weight(22); Vp23 <= Weight(23); Vp24<= Weight(24);

end Behavioral;

-- Bloco de cálculo de distância de Manhattan

entity Mdist is

Port (X, Y : in std_logic_vector (7 downto 0); -- Vetores de entrada

Dif1, Dif2 : out std_logic_vector (4 downto 0);

-- Valores de subtração de cada dimensão

Z : out std_logic_vector (4 downto 0$)$ );

-- Valor de saída de distância de manhattan

end Mdist;

architecture componente of Mdist is

signal SubOut1, SubOut2 : std_logic_vector (4 downto 0);

begin

process $(\mathrm{X}, \mathrm{Y})$ begin

SubOut $<=(\mathrm{X}(7) \& \mathrm{X}(7$ downto 4$))-(\mathrm{Y}(7) \& \mathrm{Y}(7$ downto 4$))$;

SubOut $2<=(\mathrm{X}(3) \& \mathrm{X}(3$ downto 0$))-(\mathrm{Y}(3) \& \mathrm{Y}(3$ downto 0$))$;

end process;

Dif1 <= SubOut1; Dif2 <= SubOut2;

$\mathrm{Z}<=\operatorname{abs}($ SubOut 1$)+\operatorname{abs}($ SubOut2);

end componente;

-- Bloco de identificação de menor valor entre dois para composição do torneio de

-- busca do neurônio vencedor de transmissão do índice e peso do neurônio vencedor

library IEEE;

use IEEE.STD_LOGIC_1164.ALL;

entity MenorDe2 is 
Generic (bitsD : integer $:=5$;

bitsX : integer :=5);

Port ( In1, In2 : in std_logic_vector (bitsD-1 downto 0);

Index 1, Index 2 : in std_logic_vector (bitsX-1 downto 0);

Minor : out std_logic_vector (bitsD-1 downto 0);

end MenorDe2;

IndexMinor: out std_logic_vector (bitsX-1 downto 0));

architecture componente of MenorDe2 is

component MenorDe2_bit

Port (a, b : in std_logic;

carrier_in : in std_logic_vector (1 downto 0);

end component; carrier_out : out std_logic_vector (1 downto 0$))$;

component mux $2 \times B I T S b$ is

Port ( in_A, in_B : in std_logic_vector (bitsD+bitsX-1 downto 0);

sel : in std_logic;

mux : out std_logic_vector (bitsD+bitsX-1 downto 0));

end component;

type connect_array is array (bitsD-1 downto 0) of std_logic_vector (1 downto 0);

signal connect : connect_array; -- Matriz de sinais de conexões entre os blocos.

signal mux_sel : std_logic_vector (1 downto 0);

signal menoreindex : std_logic_vector (bitsD+bitsX-1 downto 0);

signal inputA, inputB : std_logic_vector (bitsD+bitsX-1 downto 0);

begin

inputA $<=\operatorname{In} 1 \&$ Index 1 ;

inputB $<=\operatorname{In} 2 \&$ Index 2 ;

MenorMSB: MenorDe2_bit port map

( $\mathrm{a}=>$ In1(bitsD-1), b => In2(bitsD-1), carrier_in => "00", carrier_out => connect(bitsD-1));

Gera_MenorDe2:

for $\mathrm{i}$ in (bitsD-2) downto 0 generate MenorDe2X: MenorDe2_bit port map

( $\mathrm{a}=>\operatorname{In} 1(\mathrm{i}), \mathrm{b}=>$ In2(i), carrier_in $=>$ connect(i+1), carrier_out $\Rightarrow$ connect(i)); end generate Gera_MenorDe2;

mux_sel <= connect $(0)$;

MUX: mux2xBITSb port map

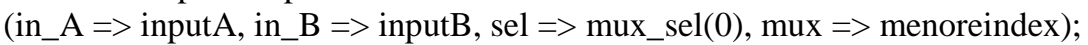

Minor $<=$ menoreindex (bitsD+bitsX-1 downto bitsX);

IndexMinor <= menoreindex (bitsX-1 downto 0);

end componente;

-- Neurônio Híbrido: Recebe do controle central o neurônio vencedor e os valores da diferença -- em cada coordenada do vetor. Difunde valores de vizinhança e realiza o ajuste de pesos.

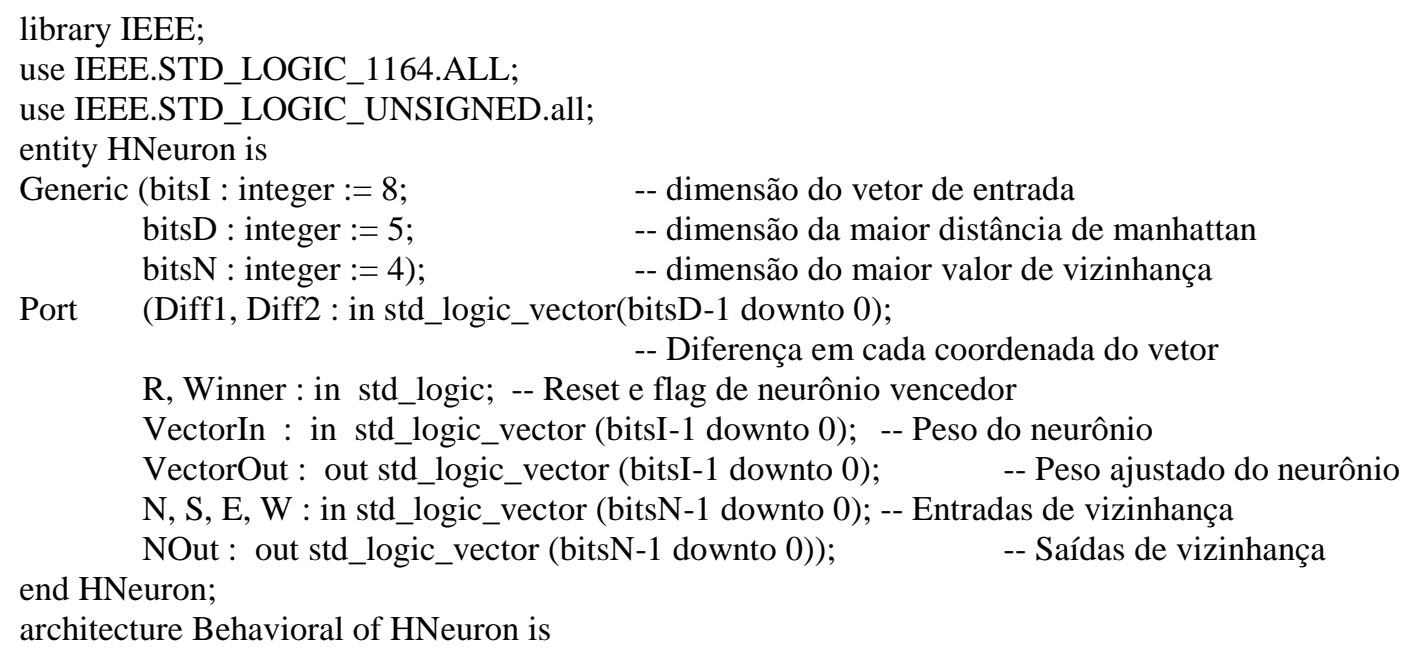


-- Bloco para cálculo da região de vizinhança

component MenorDe5 is

Port (N, S, E, W, Inner : in std_logic_vector (bitsN-1 downto 0);

$\mathrm{R}:$ in std_logic;

Minor : out std_logic_vector (bitsN-1 downto 0));

end component;

-- Mux de apoio ao cálculo da região de vizinhança, para fixação do vencedor component mux $2 \times B$ ITS is

Port(in_A, in_B : in std_logic_vector (bitsN-1 downto 0); sel : in std_logic;

mux : out std_logic_vector (bitsN-1 downto 0));

end component;

-- Bloco para ajuste dos pesos

component Adjust is

Port(R : in std_logic;

Neighbour : in std_logic_vector (bitsN-1 downto 0);

Dif1, Dif2 : in std_logic_vector (bitsD-1 downto 0);

InVector : in std_logic_vector (bitsI-1 downto 0);

OutVector : out std_logic_vector (bitsI-1 downto 0));

end component;

signal InNeigh, OutNeigh, IncNeigh : std_logic_vector (bitsN-1 downto 0);

begin

MuxViz:

mux2xBITS port map (in_A => OutNeigh, in_B $=>$ "0001", sel $\Rightarrow$ Winner, mux => InNeigh); Vizinh: MenorDe5 port map

$(\mathrm{N}=>\mathrm{N}, \mathrm{S} \Rightarrow \mathrm{S}, \mathrm{E}=>\mathrm{E}, \mathrm{W}=>\mathrm{W}$, Inner $\Rightarrow$ InNeigh, $\mathrm{R} \Rightarrow>\mathrm{R}$, Minor $=>$ OutNeigh);

IncNeigh <= OutNeigh +1 after 1 ps; -- incremento do índice de vizinhança dos neurônios próximos

NOut <= IncNeigh; $\quad$-- Difusão do valor de vizinhança

NewW: Adjust port map $(\mathrm{R}=>\mathrm{R}$, Neighbour $\Rightarrow$ InNeigh, Dif1 $\Rightarrow$ Diff1, Dif2 $\Rightarrow$ Diff2, InVector $=>$ VectorIn, OutVector $=>$ VectorOut);

end Behavioral;

Bloco MenorDe2_bit

library IEEE;

use IEEE.STD_LOGIC_1164.ALL;

entity MenorDe2_bit is

Port (a, b : in std_logic;

carrier_in : in std_logic_vector $(1$ downto 0$)$;

carrier_out : out std_logic_vector (1 downto 0$)$ );

end MenorDe2_bit;

architecture Behavioral of MenorDe2_bit is

begin

carrier_out $(1)<=($ carrier_in $(1)$ or $(($ not carrier_in $(0))$ and (not a) and b));

carrier_out $(0)<=($ carrier_in $(0)$ or $(($ not carrier_in $(1))$ and a and $($ not b) $))$;

end Behavioral;

-- MUX de 2 entradas e quantidade de bits genérico

library IEEE;

use IEEE.STD_LOGIC_1164.ALL;

entity mux $2 \times B$ ITSb is

Generic (bitsD : integer $:=5$;

bits $X$ : integer $:=5$ )

Port( in_A, in_B : in std_logic_vector (bitsD+bitsX-1 downto 0); sel : in std_logic;

end mux2xBITSb;

mux : out std_logic_vector (bitsD+bitsX-1 downto 0)); 
architecture componente of mux $2 \times \mathrm{BITSb}$ is

begin

process (sel, in_A, in_B)

begin

case sel is

when ' 0 ' $\Rightarrow$ mux $<=$ in_A;

when ' 1 ' $\Rightarrow$ mux $<=$ in_B;

when others $=>$ NULL;

end case;

end process;

end componente;

-- Bloco para ajuste simples de peso, incremento ou decremento de bits em cada

-- coordenada do peso de acordo com o valor do erro entre os vetores de entrada e do neurônio

-- calculado pelo bloco de distância de manhattan. O neurônio vencedor ajusta a quantidade

-- máxima de bits e há decaimento de 1 bit a cada degrau de distância de vizinhança.

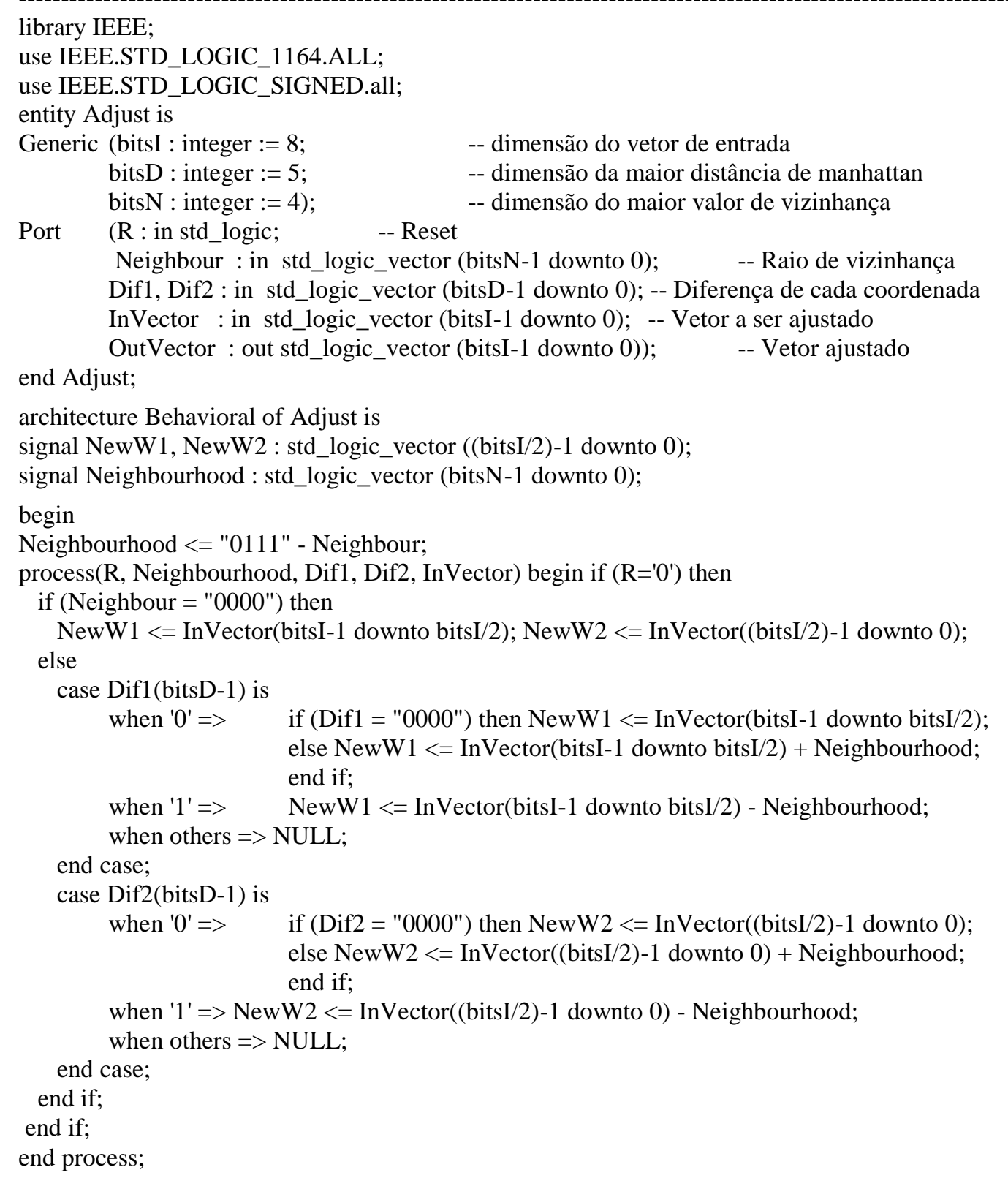

OutVector(bitsI-1 downto bitsI/2) <= NewW1 after 1 ps;

OutVector((bitsI/2)-1 downto 0$)<=$ NewW2 after 1 ps;

end Behavioral; 


\section{APÊNDICE D - AVALIAÇÃO DA RELEVÂNCIA DA ESTRUTURA DO SOM NO PROCESSO DE IDENTIFICAÇÃO DE SINAIS QAM}

Este conjunto de experimentos foi elaborado com o objetivo de se perceber se a estrutura de mapeamento que o SOM permite realizar sobre as amostras de entrada é relevante para o problema de identificação de símbolos 16-QAM. Com tal objetivo, admitiram-se os sinais produzidos segundo os mesmos critérios como entrada do sistema de execução do SOM em FPGA e se realizou o monitoramento de sua saída. Em seguida, submeteu-se o método de quantização chamada Quantização Vetorial VQ (mencionado na seção 3.3) às mesmas condições. Considera-se este experimento relevante porque se propõe uma abordagem ao problema que realiza a identificação da constelação distorcida por um processo de agrupamento dos símbolos QAM, portanto, propõe-se comparar o SOM com uma técnica clássica de quantização vetorial de menor complexidade computacional. Os resultados obtidos encontram-se na Figura 59, que apresenta a evolução da taxa de identificação correta de sinais QAM para o VQ e o SOM sob as mesmas condições, e na Figura 60, com a configuração final do posicionamento dos vetores do VQ e do SOM ao final do processo treinamento.

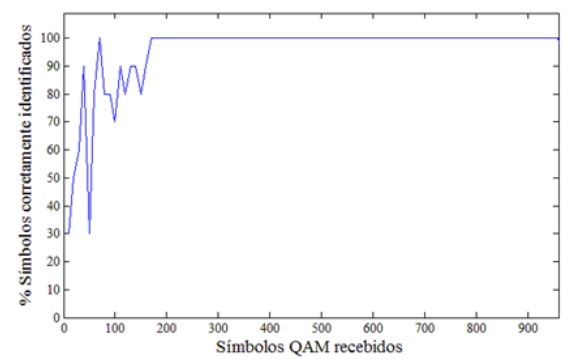

(a)

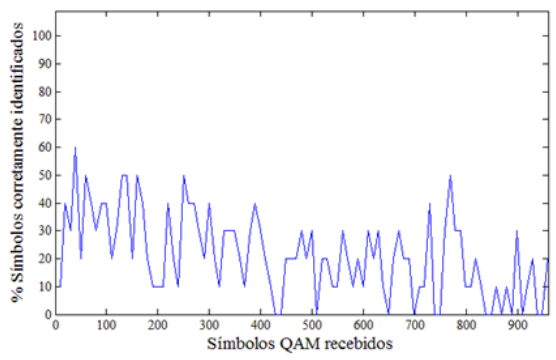

(b)

Figura 59 - Evolução da taxa de identificação correta de símbolos 16-QAM distorcidos pelo SOM executado em FPGA (a). Desempenho do algoritmo VQ (b) sob as mesmas condições de teste a que estava submetido o SOM.

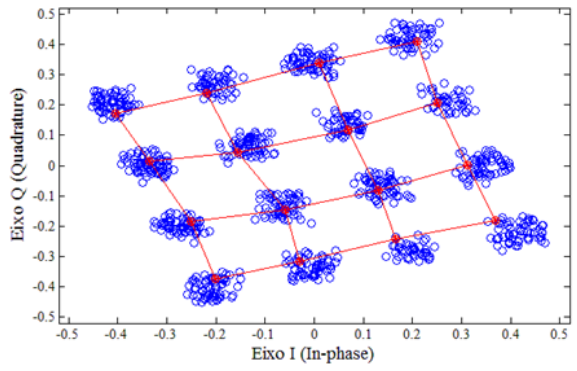

(a)

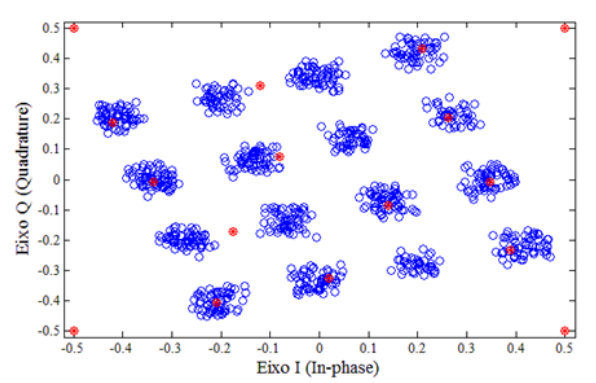

(b)

Figura 60 - Configuração final do posicionamento dos vetores peso do SOM (a), identificados por círculos vermelhos, em relação aos símbolos 16-QAM, identificados por círculos azuis. Configuração final dos vetores do algoritmo VQ (b), identificados por círculos vermelhos, em relação aos mesmos símbolos QAM. 
Pode-se perceber, pela Figura 59(a), que o SOM executado em FPGA passa por um período de aprendizagem, no qual há um oscilante crescimento de sua taxa de identificações corretas, de aproximadamente 200 iterações (200 símbolos 16-QAM recebidos). Após este período há uma estabilização satisfatória da taxa de reconhecimento. A Figura 60(a) apresenta a configuração final do posicionamento dos vetores peso do SOM em conjunto com os grupos de símbolos da constelação QAM distorcida. Nesta figura nota-se que cada neurônio está posicionado em um dos grupos de símbolos da constelação. Entretanto, não há esta mesma equiparação entre vetores e grupos de símbolos no processo executado pelo VQ, como ilustra a Figura 60(b). Desta forma, não ocorre uma estabilização satisfatória da taxa de reconhecimento da constelação QAM distorcida quando processada pelo VQ, conforme se pode observar na Figura 59(b). Embora tenham as mesmas condições de inicialização, o SOM é capaz de se adaptar acompanhando a rotação da constelação QAM. Para se obter um melhor posicionamento dos vetores do VQ, seria necessário utilizar informações a priori sobre as condições do canal de transmissão, o que não é necessário para o SOM. Nota-se que o posicionamento inicial de protótipos / neurônios é a mesma para o VQ e para o SOM: um posicionamento padrão sem rotação. Isso indica que a implementação do VQ não tem a capacidade de lidar com constelações distorcidas, enquanto o SOM sim. Para confirmação dessa indicação repetiu-se o experimento 35 vezes com diferentes séries aleatórias de símbolos. A Figura 61 mostra a curva média de aprendizado (linha vermelha) e o desvio padrão (barras azuis).
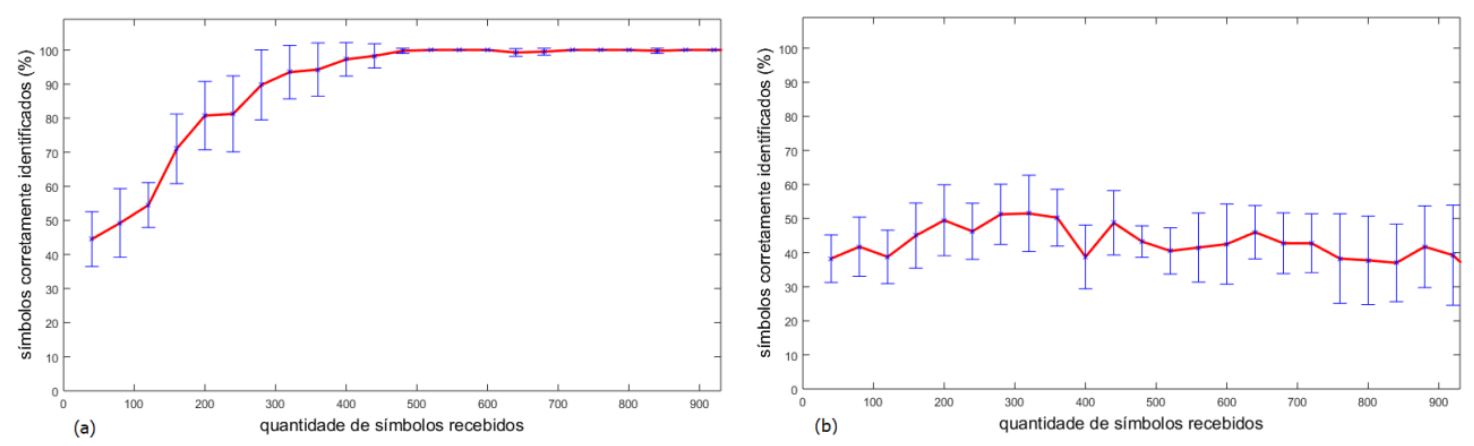

Figura 61 - Repetição de 35 vezes dos experimentos de comparação do SOM (a) com o VQ (b) para cálculo da média da taxa de acertos (linha vermelha) e do desvio padrão (barras azuis).

Novamente, nota-se que não há evolução na aprendizagem para a implementação do VQ e um bom comportamento de aprendizagem para a 
implementação SOM após uma fase inicial oscilante contendo cerca de 500 símbolos. Pode-se entender, portanto, que a maior complexidade exigida pelo procedimento computacional do SOM em relação ao procedimento computacional do VQ se justifica no problema de identificação do sinal QAM. Percebe-se, também, que o SOM é adequado para essa tarefa, não apenas por seus recursos de agrupamento, mas também por seu processo de manutenção topológica entre os conjuntos de entrada. Tal propriedade é importante porque os pontos iniciais na constelação QAM são afetados em conjunto pelos efeitos de distorção do canal, e não individualmente. A dinâmica do seu processo de auto-organização permite à estrutura do SOM capturar esse fenômeno. 


\section{APÊNDICE E - CONJUNTO DE EXPERIMENTOS PARA COMPARAÇÃO ENTRE AS IMPLEMENTAÇÕES DO SOM EM HARDWARE E EM SOFTWARE}

Apresenta-se aqui a repetição dos experimentos com o SOMprocessor para avaliar a resolução dos agrupamentos realizados pelo mapa, pelo erro de quantização (segundo a seção 7.1) e para avaliar a estrutura das relações entre os vetores mapeados, pelo erro topográfico (segundo a seção 7.3). As Figuras 62, 63 e 64 apresentam, primeiramente, o declínio do erro de quantização de acordo com a evolução do processo de treinamento do SOM implementado em software e em hardware. Da mesma forma que na seção 7.1, As curvas foram obtidas em 11 observações durante a fase de aprendizado da rede neural: a primeira no instante zero do processo de treinamento e as demais a cada 100 épocas de apresentação das amostras de entrada.

As repetições dos experimentos obedeceram às configurações detalhadas no capítulo 7, porém com pesos iniciais diferentes (definidos aleatoriamente). Destaca-se também que, em cada experimento, o conjunto de pesos iniciais é o mesmo para as implementações em hardware e em software. Pode-se perceber, pela sequência de figuras, que a tendência das curvas se repete em todos os experimentos.

Por fim, as Figuras 65, 66 e 67 mostram as curvas dos erros topográficos em função épocas de treinamento do SOM - também implementado em software e em hardware - para a repetição do experimento de avaliação do SOMprocessor. De forma semelhante à apresentada na seção 7.3, os dados foram obtidos em 11 observações do processo de aprendizagem: a primeira na época zero do treinamento e as demais a cada 100 épocas de ajuste de pesos da rede neural.

Destaca-se que, assim como para a obtenção das curvas de erro de quantização, estes experimentos seguiram as configurações do SOM discutidas no capítulo 7, e que, também da mesma fora, a tendência das curvas se repete em todos os resultados obtidos. Para cada repetição, há um conjunto de pesos iniciais diferentes, aleatoriamente definidos, e tal conjunto se manteve o mesmo para a execução da rede em software e pelo SOMprocessor. 


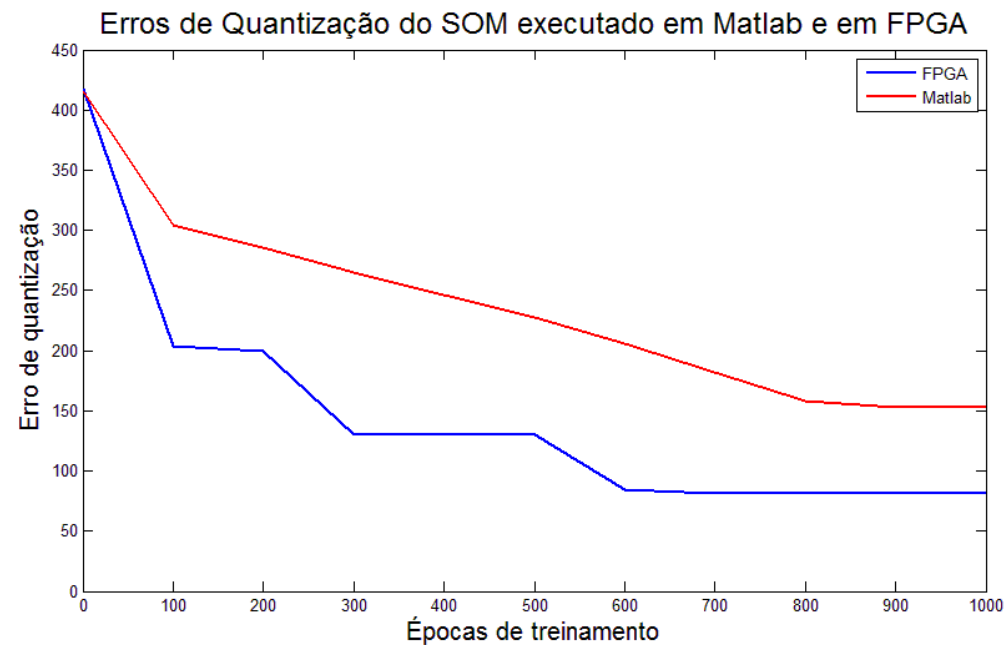

Figura 62 - Resultado da primeira repetição do experimento para comparação dos erros de quantização entre o SOMprocessor e a implementação em software da mesma rede.

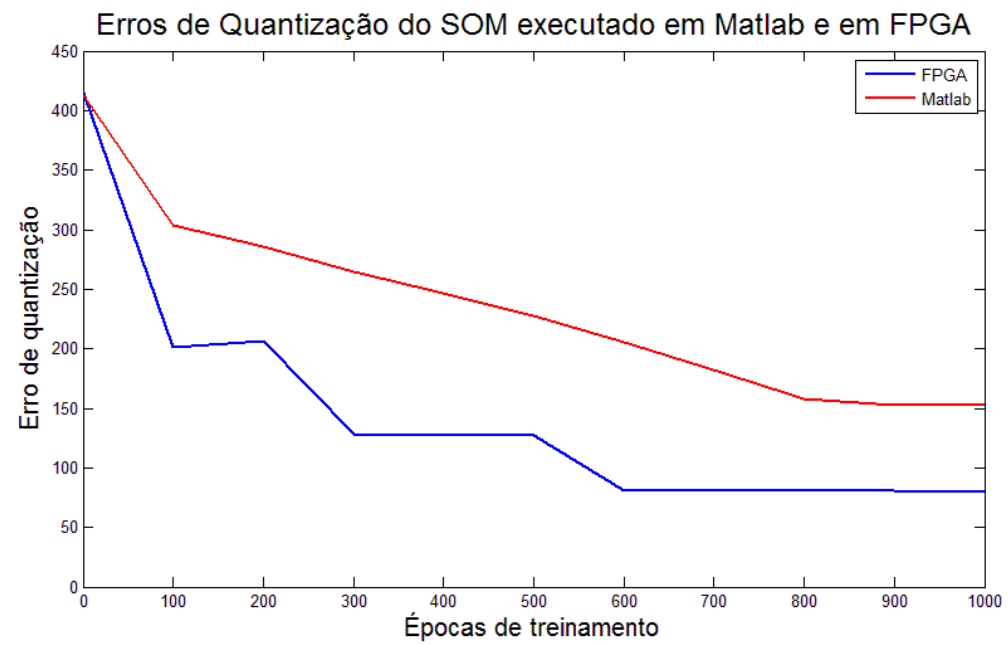

Figura 63 - Resultado da segunda repetição do experimento para comparação dos erros de quantização entre o SOMprocessor e a implementação em software da mesma rede.

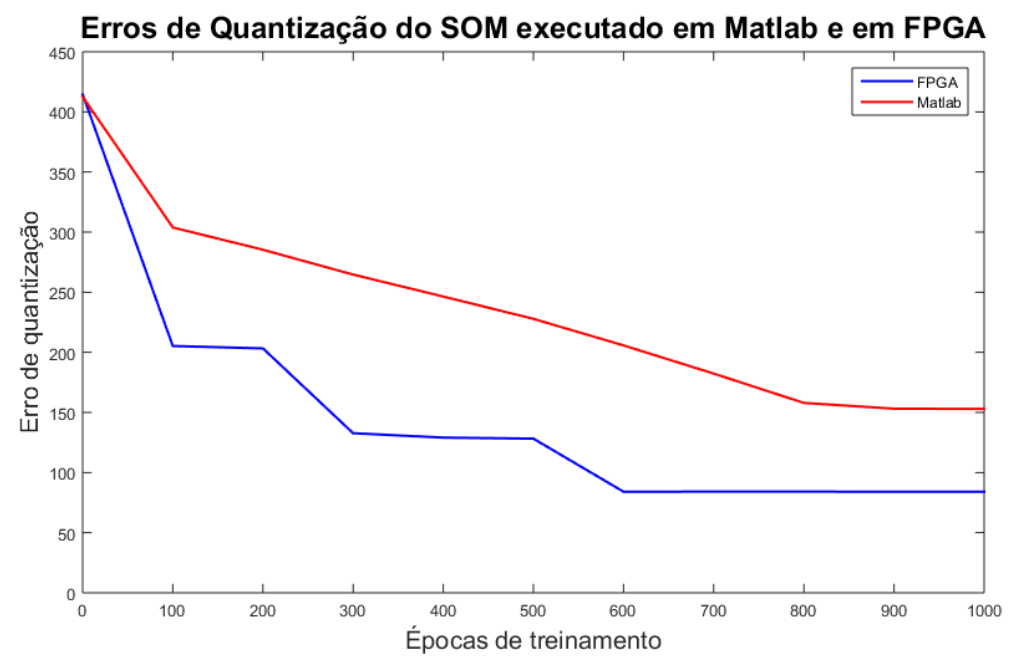

Figura 64 - Resultado da terceira repetição do experimento para comparação dos erros de quantização entre o SOMprocessor e a implementação em software da mesma rede. 


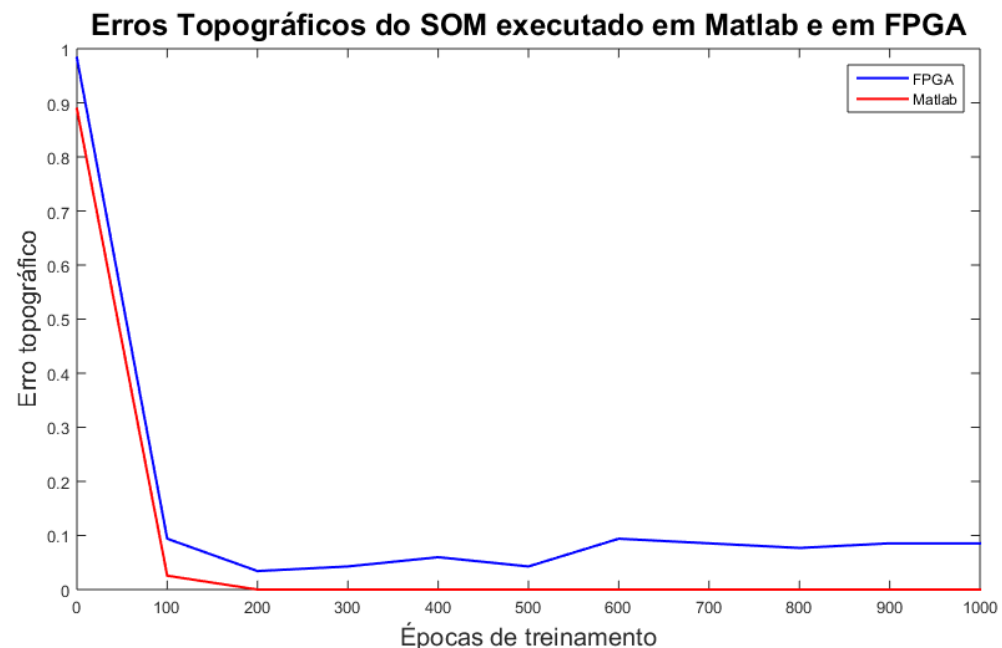

Figura 65 - Resultado da primeira repetição do experimento para comparação dos erros topográficos entre o SOMprocessor e a implementação em software da mesma rede.

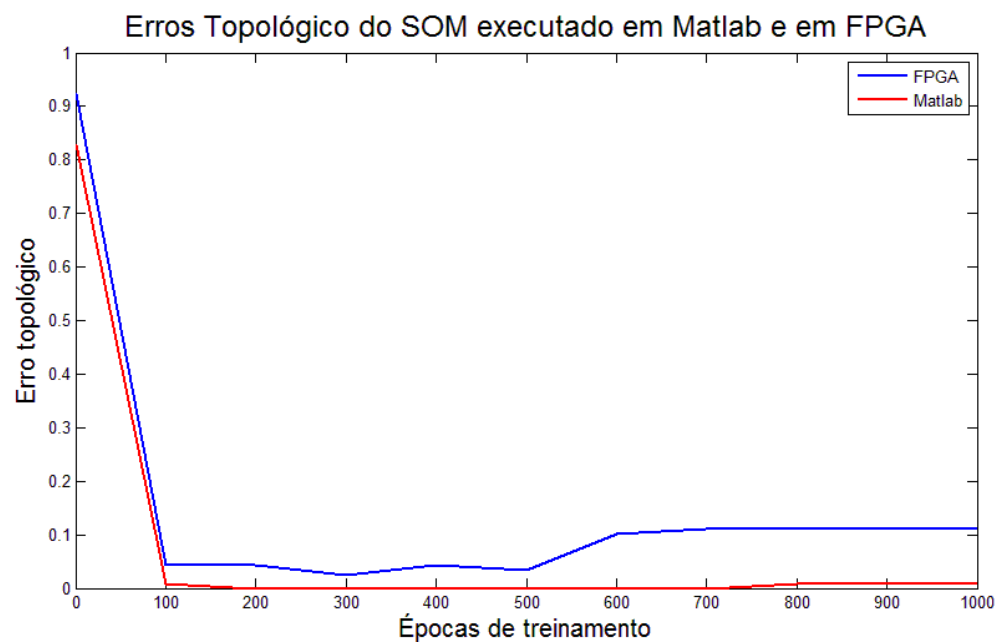

Figura 66 - Resultado da segunda repetição do experimento para comparação dos erros topográficos entre o SOMprocessor e a implementação em software da mesma rede.

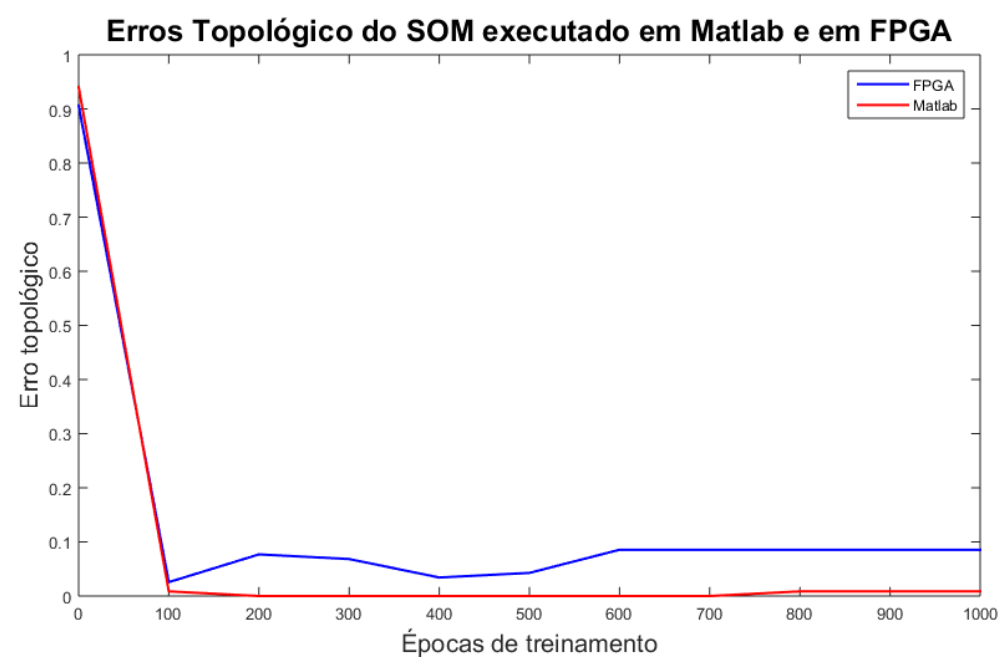

Figura 67 - Resultado da terceira repetição do experimento para comparação dos erros topográficos entre o SOMprocessor e a implementação em software da mesma rede. 


\section{APÊNDICE F - ABSTRACTS DOS ARTIGOS PUBLICADOS DURANTE A REALIZAÇÃO DESTA PESQUISA}

Neural Comput \& Applic

DOI $10.1007 / \mathrm{s} 00521-017-2957-0$

CrossMark

ORIGINAL ARTICLE

\section{OFDM symbol identification by an unsupervised learning system under dynamically changing channel effects}

Miguel Angelo de Abreu de Sousa ${ }^{1,2} \cdot$ Ricardo Pires $^{2} \cdot$ Emilio Del-Moral-Hernandez $^{1}$

Received: 29 August 2016/Accepted: 21 March 2017

(c) The Natural Computing Applications Forum 2017

\begin{abstract}
Orthogonal frequency-division multiplexing (OFDM) is one of the most successful digital communication techniques. Nevertheless, the decrease in intersymbol interference in quadrature amplitude modulation (QAM) over dispersive channels is still challenging. Different researches recently proposed the idea of using unsupervised learning as an alternative to the classic approaches to equalization of OFDM channels. In those purposes, the identification of a received QAM symbol is possible by the comparison of its position on the in-phase/ quadrature (IQ) plane relative to the positions of previously arrived symbols, generally processed by the Kohonen's Self-Organizing Map (SOM) algorithm. This work presents the SOM unsupervised learning method executed on an embedded system applied to QAM symbols identification. The system is implemented on an FPGA, a configurable digital circuit able to meet the low power and parallel process requirements of mobile applications. Also, in order to extend the classical set of experiments to evaluate our system, this paper proposes a theoretical model of the timevarying scheme representing the transition between different channel characteristics, obtained from real measurements available on a public repository. The model is
\end{abstract}

Miguel Angelo de Abreu de Sousa

miguel.angelo@usp.br

Ricardo Pires

ricardo_pires@ifsp.edu.br

Emilio Del-Moral-Hernandez

emilio@1si.usp.br

1 Polytechnic School, University of Sao Paulo, São Paulo, Brazil

2 Federal Institute of Education, Science and Technology of Sao Paulo, IFSP Campus Sao Paulo, São Paulo, Brazil employed to verify our purpose under dynamically both changing and realistic conditions. On the assumption that it is provided enough IQ symbols for the initial training process, the hardware implementation of SOM is able to track and identify the time-varying distorted QAM constellation. No knowledge of channel characteristics is necessary. The system spends only some microseconds at start-up to reach about $100 \%$ performance, and no dedicated training phase is needed afterward.

Keywords OFDM · FPGA · Self-Organizing Map · Embedded systems

\section{Introduction and related works}

Radio communications signals may suffer distortions, fading and be corrupted by noise during transmission, causing increase in error rates at the receiver. Recently, several researches have been reported on the use of computational intelligence to mitigate some of those problems, as, for example, the employment of Self-Organizing Maps (SOMs) to prevent from inter-symbol interference in OFDM (orthogonal frequency-division multiplexing) systems. Within this area, our study focuses on the quadrature amplitude modulation (QAM) symbol identification by an embedded system designed to execute the Kohonen's learning algorithm. Thus, three different research topics are involved in the development of the present work: SOM neural computing model, an alternative to the equalization of QAM signals by a clustering approach and the design of configurable digital systems. This section aims to bring context to the intersections of those topics and to introduce the proposed model employed to verify our unsupervised learning system under dynamically changing and realistic 


\title{
Research Article
}

\section{Architecture Analysis of an FPGA-Based Hopfield Neural Network}

\author{
Miguel Angelo de Abreu de Sousa, Edson Lemos Horta, \\ Sergio Takeo Kofuji, and Emilio Del-Moral-Hernandez \\ University of São Paulo, 05508-010 São Paulo, SP, Brazil \\ Correspondence should be addressed to Miguel Angelo de Abreu de Sousa; miguel.angelo@usp.br \\ Received 30 June 2014; Revised 11 November 2014; Accepted 12 November 2014; Published 9 December 2014 \\ Academic Editor: Ping Feng Pai
}

Copyright (C) 2014 Miguel Angelo de Abreu de Sousa et al. This is an open access article distributed under the Creative Commons Attribution License, which permits unrestricted use, distribution, and reproduction in any medium, provided the original work is properly cited.

Interconnections between electronic circuits and neural computation have been a strongly researched topic in the machine learning field in order to approach several practical requirements, including decreasing training and operation times in high performance applications and reducing cost, size, and energy consumption for autonomous or embedded developments. Field programmable gate array (FPGA) hardware shows some inherent features typically associated with neural networks, such as, parallel processing, modular executions, and dynamic adaptation, and works on different types of FPGA-based neural networks were presented in recent years. This paper aims to address different aspects of architectural characteristics analysis on a Hopfield Neural Network implemented in FPGA, such as maximum operating frequency and chip-area occupancy according to the network capacity. Also, the FPGA implementation methodology, which does not employ multipliers in the architecture developed for the Hopfield neural model, is presented, in detail.

\section{Introduction}

For nearly 50 years, artificial neural networks (ANNs) have been applied to a wide variety of problems in engineering and scientific fields, such as, function approximation, systems control, pattern recognition, and pattern retrieval $[1,2]$. Most of those applications were designed using software simulations of the networks, but, recently, some studies were developed in order to extend the computational simulations by directly implementing ANNs in hardware [3].

Although there were some works reporting network implementations in analog circuits [4] and in optical devices [5], most of the researches in ANNs hardware implementations were developed using digital technologies. Generalpurpose processors and application-specific integrated circuits (ASICs) are the two technologies usually employed in such developments. While general-purpose processors are often chosen due to economic motivations, ASIC implementations provide an adequate solution to execute parallel architectures of neural networks [6].
In the last decade, however, FPGA-based neurocomputers have become a topic of strong interest due to the larger capabilities and lower costs of reprogrammable logic devices [7]. Other relevant reasons to choose FPGA, reported in the literature, include high performance requirement which is obtained with parallel processing on hardware systems when compared to sequential processing in software implementations [8], reduction of power consumption in robotics or general embedded applications [9], and the maintenance of the flexibility of software simulations while prototyping. In this particular feature, FPGA presents advantages over ASIC neurocomputers because of the decreased hardware cost and circuit development period.

Among several studies on different network models implemented on electronic circuits, just recently were published in the literature works on the hardware implementations addressing specifically the Hopfield Neural Networks (HNNs). Those works usually aimed to approach the resolution of a target problem, such as, image pattern recognition [10], identification of DNA motifs [11], or video compression 


\title{
An FPGA Distributed Implementation Model for Embedded SOM with On-Line Learning
}

\author{
Miguel Angelo de Abreu de Sousa ${ }^{12}$, Emilio Del-Moral-Hernandez \\ ${ }^{1}$ Department of Electronic Systems Engineering, School of Engineering, University of Sao Paulo, Sao Paulo, Brazil \\ ${ }^{2}$ Electrical Department, Federal Institute of Education, Science and Technology - IFSP, Sao Paulo, Brazil \\ miguel.angelo@usp.br, emilio@lsi.usp.br
}

\begin{abstract}
Neuroengineering has contributed to the increasing capability of embedded hardware to efficiently execute neural computation models. These hardware structures, suitable for implementing only the recall phase or both phases learning and recall - of artificial neural networks (ANNs) are generally identified as neuromorphic systems. Some features of the FPGA technology resemble characteristics usually associated to ANNs, such as the parallel processing and the configurability of digital circuits. Embedded neural systems elaborated to execute Self-Organizing Maps (SOMs) can take advantage of the circuit parallelism to speed-up training process and also of the design flexibility by the hardware reconfiguration enabled by FPGA chips. Hardware-based SOMs capable of executing the training process on chip are relevant because they can be employed in a wide variety of stand-alone applications. IoT and mobile robotics are examples of some challenging research fields that use unsupervised learning to extract information from the surrounding environment and require the portability of embedded systems. This work presents a distributed architecture to implement SOM learning and recall algorithms into FPGAs. The distributed model does not employ any type of central control unit hence allowing a simple hardware redesign proces during the configuration of the neural system. The set of experiments used for verifying the proposed architecture is specified in a data stream format. The aim of choosing streaming specified in a data stream format. The aim of choosing streaming
condition is to simulate applications in which the FPGA-based SOM must process a continuous flow of information autonomously. All the steps of the SOM learning algorithm to process an input sample are performed in a single clock cycle and implementation results show a maximum clock speed of 2.38 MHz. Synthesis reports on FPGA implementation of the distributed architecture for the experiments carried out herein also indicate that the factor of increase in consumption of chip resources is lower than the increment in the total number of SOM connections.
\end{abstract}

Keywords - Embedded neural systems; Self-Organizing Maps; Neuromorphic hardware; On-line learning; FPGA.

\section{INTRODUCTION}

Neuroengineering is an active research field with some challenging tasks, such as the development of neuromorphic hardware systems [1]. Neuromorphic hardware can be described as electric circuits suitable to direct the implementation of artificial neural networks (ANN). A strong motivation for developing these systems is to allow for neural computing models to be employed in a wide range of applications with specific requirements [2]. Increasing the processing speed of ANNs is one example of such specificities. Some applications require shorter cycles of training and recall phases than CPU-based approaches to achieve the necessary data throughput, such as on-line video categorization [3] [4]. Other applications even require real-time responses from the ANN, for example, processing of sensor networks in IoT environments [5] [6]. Moreover, to decrease physical size and energy consumption in mobile applications, such as robotic platforms, is a different type of requirement also met by neuromorphic systems [7] [8].

Typically, neural computing models are developed by keeping the support hardware fixed and the software changeable. Besides the software, the FPGA technology allows the hardware to also be dynamic. Neuroengineering is exploring hardware reconfigurability of FPGA chips for enabling ANNs to operate immersed in the application environment. This way, neural configurations can change to adapt to modifications occurring during operation [9]. A literature survey indicates that several neural computational models have been implemented directly into FPGA, such as MLPs (Multilayer Perceptrons) [10] [11] and Recurrent Networks [12] [13]. Hardware implementation of Kohonen's Self-Organizing Maps (SOMs) has received great attention due to the possibility of supporting unsupervised learning in standalone applications [14] [15]. Furthermore, studies on FPGA implementation of SOMs also aim to speed-up learning processes by exploiting neuron parallelism during training phase [16].

Hardware architectures designed to directly compute SOM algorithms usually employ a central unit to control the parallel processing blocks of the system, e.g. [5] [14] [17]. In these centralized approaches, distance calculation to the input vector is often concurrently executed for all the neurons. However, other processes of the SOM algorithm, such as searching for the winning neuron, are usually performed by the central control unit, which must gather distance values from all the neurons to trigger the searching process. Recently, some studies point toward a distributed model for SOM implementation [18] [19]. The reason to indicate the development of distributed architectures to execute SOM is to avoid redesigning the control unit with changes in some network configurations, such as the output neuron lattice. This study presents a distributed model to implement SOM embedded systems using the FPGA chip that works without 


\title{
Comparison of Three FPGA Architectures for Embedded Multidimensional Categorization Through Kohonen's Self-Organizing Maps
}

\author{
Miguel Angelo de Abreu de Sousa ${ }^{12}$, Emilio Del-Moral-Hernandez ${ }^{1}$ \\ ${ }^{1}$ Department of Electronic Systems Engineering, Polytechnic School, University of Sao Paulo, Sao Paulo, Brazil \\ ${ }^{2}$ Electrical Department, Federal Institute of Education, Science and Technology - IFSP, Sao Paulo, Brazil \\ miguel.angelo@usp.br, emilio@1si.usp.br
}

\begin{abstract}
There is an increasing number of applications employing Self-Organizing Maps (SOM) for multidimensional categorization tasks. Those applications range from spoken- and written-word recognition and monitoring of industrial environments, to Internet of Things and image processing. SOM is a neural computing model with unsupervised learning, which is attractive for implementing embedded systems to operate autonomously in dynamic environments. Aiming to support comparisons among self-organizing computing methodologies, this work implements three different FPGA hardware architectures - distributed, centralized and hybrid - for executing SOM learning and recall phases. It also presents the contrasts between the characteristics of the elaborated circuits and the comparison of system design processes. Finally, comparisons with other published results of SOM neuromorphic systems are shown.
\end{abstract}

\section{Keywords-Neuromorphic System; SOM; FPGA;}

\section{INTRODUCTION, MOTIVATION AND RELATED WORK}

Neuromorphic Engineering (NE) has been a growing investigation field focused, among others, on designing nonvon Neumann architectures suitable to compute Artificial Neural Networks (ANN). Self-Organizing Maps (SOM) is a type of ANN mainly employed for multidimensional categorization [1], for example video recognition and robotics. Moreover, it is one of the most successful clustering methods with literature composed of thousands of published papers [2] As part of NE research, the execution of SOM learning and recall algorithms directly on-chip have also been studied [3] [4]. Different types of hardware have been employed to implement SOM embedded systems during the last decade. For example, [5] presented an ARM CortexM3 implementation for executions of small sizes winner-takes-all neural networks, to serve as a prototype for bigger SOM networks. Graphics Processing Units (GPUs) have also been used to compute SOM algorithms. A proposition with parallel implementation of the network, targeting applications in which hardware acceleration is required, is proposed in [6]. Targeting ultra-low power applications, there is work published addressing save power consumption in parts of the SOM computation algorithm for ASIC implementations [7]. Usually motivated by the speed and the low cost of parallel computation, numerous studies employ
FPGA technology as the hardware platform to implement SOM [3] [8]. Moreover, the flexibility provided by the hardware reconfiguration is also a frequently cited reason for choosing FPGA chips [9] [10]. This is particularly important to hardware implementations of SOM because its main configurations are application-sensitive.

Some reported works on FPGA-based SOM, e. g. [3] [9] [11], employ architectures with a central control unit. This unit is usually employed to collect the distance information from all neurons and to search for the one most similar to the samples entered into the network. The central unit is also used to control concurrent blocks of the SOM system, such as the circuits responsible for the adjustment of neuron weights. On the other hand, some recent studies argues for a distributed architecture for implementing SOM, with the aim of reducing the redesign of the control unit, and rework during changes in system size and weight dimension [4] [8]. A distributed architecture is proposed by [7] for an ASIC implementation of SOM. However, a survey of the literature on FPGA implementations of SOM indicates that the majority of published studies on hardware-based executions is related to some target application, which defines the configuration of the neural network (number of neurons, dimension etc) [8] [9] [11]. This may be a problem when comparing diverse architecture conceptions, such as centralized and distributed models. In order to support comparisons among different hardware structures, three FPGA implementation models of SOMs were designed, synthetized and contrasted herein. The possibility of controlling the size and configuration of the neural networks allows verifying the characteristics of hardware implementation and the features related to system design. The aim of this study is to describe and synthesize different FPGA circuits for implementing Kohonen's SOM, to compare the designs and to obtain results on the performance of the models. The first implemented architecture uses a central control unit to collect information from the neurons and to deliver management data. It is identified as centralized architecture and it is described in Section III-A. The second implemented architecture is a distributed model, with no central control unit, and in which neurons exchange data to compute the SOM algorithm. This distributed architecture is used for all processes and calculations of the SOM, such as, 


\title{
An FPGA-based SOM circuit architecture for online learning of 64-QAM data streams
}

\author{
Miguel Angelo de Abreu de Sousa ${ }^{12}$, Ricardo Pires ${ }^{1}$, Sara D. dos S. Perseghini ${ }^{1}$, Emilio Del-Moral-Hernandez ${ }^{2}$ \\ ${ }^{1}$ Electrical Department, Federal Institute of Education, Science and Technology - IFSP, Sao Paulo, Brazil \\ ${ }^{2}$ Department of Electronic Systems Engineering, School of Engineering, University of Sao Paulo, Sao Paulo, Brazil \\ angelo@ifsp.edu.br, ricardo_pires@ifsp.edu.br, sarad@ifsp.edu.br, emilio@1si.usp.br
}

\begin{abstract}
Responsible for fast transmission and large data volume, Quadrature Amplitude Modulation (QAM) has been applied in many communication systems, which explains the great interest in finding compatible techniques to improve its behavior. Kohonen Self-Organizing Maps (SOM) were implemented in a FPGA circuit to detect 64-OAM symbols. The use of SOM in the Quadrature/In-phase pair detection allowed the continuous adjustment to the QAM constellation with no supervision, as required in some adaptive communication systems. Bandwidth can thus be saved and training data retransmission was no longer necessary. The parallelism provided by FPGA processing showed to be compatible to the state-of-the-art works, presenting a performance of 8.05 GCUPs combined with a low percentage of hardware use $(\sim 7 \%)$. In addition, experiments with different physical channels data have been performed and the bit error rates (BER) are reported for several signal to noise ratios.
\end{abstract}

Keywords - Ouadrature Amplitude Modulation; embedded neural systems; Self-organizing Maps; online learning; FPGA.

\section{INTRODUCTION AND 64-QAM OVERVIEW}

With the advancement of communication systems, large amounts of data need to be transmitted more and more rapidly and with a low error rate. One of the methods widely applied and that satisfies these requirements is known as Quadrature Amplitude Modulation (QAM) [1]. Systems based on QAM vary from satellite communication, broadcast cable and terrestrial systems (DVB/DBA, ISDB-T), DSL and ADSL modems, CDMA, 3G (WCDMA/HSDPA), Wi-Fi (IEEE 802.11) to WiMAX broadband (IEEE 802.16) [2-5].

In the QAM technique, symbols with $\mathrm{N}$ bits are transmitted in two carriers, each having the same frequency but different in phase (90 degrees) [6]. The modulation therefore consists in the sum (S) of the two signals, one being the amplitude of the sinusoidal carrier $(\mathrm{Q})$ and the other the amplitude of the cosine carrier (I). Eq. 1 shows the carrier composition of a QAM signal:

$$
S(t)=Q \operatorname{sen}(\omega t)+I \cos (\omega t)
$$

where $\omega t$ represents the instantaneous phase. These carriers represent a Quadrature/In-phase set that can be graphically represented in the complex plane known as constellation [6].

Fig. 1 shows an example of 64-QAM constellation, where each symbol is represented by 6 bits. Note that in square constellations, it is possible to code the symbols based on the
Gray code, which guarantees the minimum variation (only 1 bit) between one symbol and the adjacent ones [7].

Greater constellations mean higher order of modulation and greater number of points in the constellation (from 16 to 4096-QAM). Increasing the order of modulation implies transmitting more bits per symbol. On the other hand, it is necessary to ensure a good signal to noise ratio (SNR) to minimize the intersymbol interference (ISI) and to not increase the bit error rate (BER) [8]

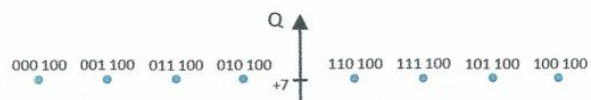

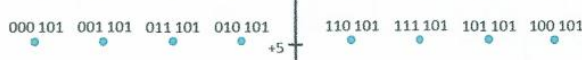

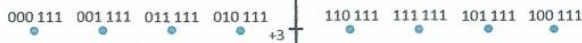

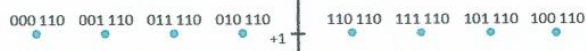

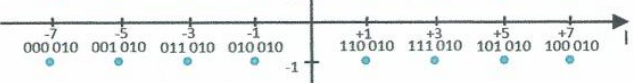

$$
\begin{aligned}
& \begin{array}{llllllll}
000011 & 001011 & 011011 & 010011 & 110011 & 111011 & 101011 & 100011
\end{array} \\
& \begin{array}{cc|ccc}
000001001001011001010001 & 110001 & 111001 & 101001 & 100001
\end{array} \\
& 000000001000011000010000{ }_{-7} \mid \begin{array}{cccc}
110000 & 111000 & 101000 & 100000
\end{array}
\end{aligned}
$$

Fig. 1. Example of 64-QAM constellation.

ISI occurs due to the multipath of the channel, which results in a sum of signal attenuation and delayed waveforms that reach the receiver. In addition, the channel parameters may vary due to transmitter and/or receiver movement as well as the climatic and atmospheric conditions. To minimize ISI problems, eventually an equalizer is coupled to the receiver [8], such as some adaptive equalization systems [9]. Among them there are supervised and self-adjusting ones [10]. In the first case, data training is sent to the receiver that adjusts its coefficients. This step needs to be regularly repeated implying in band loss due to periodic retransmission of the training sequence. Conversely, self-adjusting systems operate based on permanent learning. The receiver evaluates its coefficients through an algorithm that compares the received data and the stored values [8]. This kind of operation has only become feasible thanks to the advance in digital signal processing technology. 